\title{
International financial market dynamics : an empirical investigation of exchange rates, interest rates and stock returns
}

Citation for published version (APA):

Nissen, F. G. J. A. (1997). International financial market dynamics : an empirical investigation of exchange rates, interest rates and stock returns. [Doctoral Thesis, Maastricht University]. Universiteit Maastricht. https://doi.org/10.26481/dis.19970221fn

Document status and date:

Published: 01/01/1997

DOI:

10.26481/dis.19970221fn

Document Version:

Publisher's PDF, also known as Version of record

Please check the document version of this publication:

- A submitted manuscript is the version of the article upon submission and before peer-review. There can be important differences between the submitted version and the official published version of record.

People interested in the research are advised to contact the author for the final version of the publication, or visit the DOI to the publisher's website.

- The final author version and the galley proof are versions of the publication after peer review.

- The final published version features the final layout of the paper including the volume, issue and page numbers.

Link to publication

\footnotetext{
General rights rights.

- You may freely distribute the URL identifying the publication in the public portal. please follow below link for the End User Agreement:

www.umlib.nl/taverne-license

Take down policy

If you believe that this document breaches copyright please contact us at:

repository@maastrichtuniversity.nl

providing details and we will investigate your claim.
}

Copyright and moral rights for the publications made accessible in the public portal are retained by the authors and/or other copyright owners and it is a condition of accessing publications that users recognise and abide by the legal requirements associated with these

- Users may download and print one copy of any publication from the public portal for the purpose of private study or research.

- You may not further distribute the material or use it for any profit-making activity or commercial gain

If the publication is distributed under the terms of Article $25 \mathrm{fa}$ of the Dutch Copyright Act, indicated by the "Taverne" license above, 


\section{International Financial Market Dynamics}

An Empirical Investigation of Exchange Rates, Interest Rates and Stock Returns 


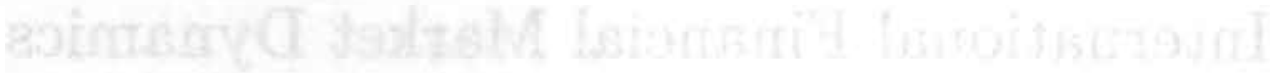

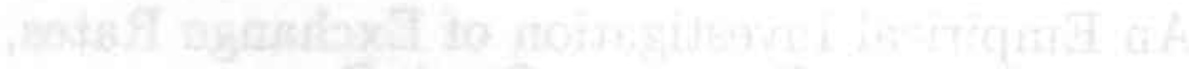

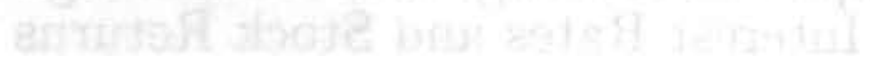




\section{International Financial Market Dynamics}

An Empirical Investigation of Exchange Rates, Interest Rates and Stock Returns

\section{PROEFSCHRIFT}

ter verkrijging van de graad van doctor aan de Universiteit Maastricht, op gezag van de Rector Magnificus, Prof. Mr. M.J. Cohen, volgens het besluit van het College van Decanen,

in het openbaar te verdedigen op vrijdag 21 februari 1997 om 16.00 uur

door

Franciscus Gertruda Josephus Anna Nissen 


\section{Promotores:}

Prof. dr. C.G. Koedijk

Prof. dr. C.J.M. Kool

Prof. dr. C.C.P. Wolff

Beoordelingscommissie:

Prof. dr. F.C. Palm (voorzitter)

Prof. dr. A.G.Z. Kemna

Prof. dr. P. Sercu (Katholieke Universiteit Leuven) 
One of the greatest pains to human nature is the pain of a new idea Walter Bagehot (1826-1877) 


\section{Preface}

In research the horizon recedes as we advance, and is no nearer at the completion of a doctoral thesis than it was at its beginning. As the power of endurance weakens as the moment of truth is ahead, the urgency of pursuit becomes more intense.

This thesis has grown out of four years of research on finance and international economics carried out at the Finance Department of Maastricht University (the Netherlands). The choice of this subject is not surprising, because already during my undergraduate studies I developed a particular interest in international economics. My interest was stirred by several developments, such as the debate about the consequences of the single market program aimed at removing all barriers to intra-Community trade, German reunification, the debate over the progress of EMU, the signing of the Maastricht. Treaty in December 1991, which set out a timetable for a single European currency, and the EMS currency crisis in September 1992.

Right from the beginning, my supervisors encouraged me to write separate papers on various subjects within the area of international finance and international economics. I had the opportunity to present these papers at conferences in Brussels, London, Hong Kong, Istanbul, San Francisco, Taipei, Uppsala and Washington.

While working on my thesis I realized that research gives only a random indication of the state of affairs and is therefore always incomplete. Yet, the thesis should not be considered as a completed whole, but rather as one of the materials of a new bridge between theory and practice.

I would like to thank my supervisors Kees Koedijk, Clemens Kool and Christian Wolff for their support and trust. I would like to thank Jelle Mensonides of the Algemeen Burgerlijk Pensioenfonds who gave me the opportunity to get an impression of practical investment issues. Several of my colleagues offered comments and advice on various parts of this 
viii

thesis. I would particularly like io thank Peter Schotman who gave relevant advice on the many econometric problems that I encountered. I would like to thank all the colleagues of the Finance Department who created a pleasant working environment. I especially enjoyed our fruitful discussions, sport contests and last but not least our drinks on Friday afternoon. Finally, I would like to thank Véronique for her continuing encouragement while I completed this thesis.

François G.J.A. Nissen

November 1996 


\section{Contents}

Preface vii

List of Tables $\quad$ xiv

$\begin{array}{lr}\text { List of Figures } & 16\end{array}$

1 Introduction 1

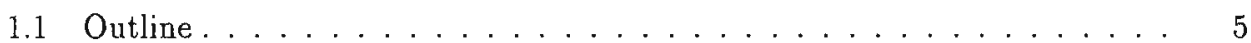

2 International Parity Conditions $\quad 9$

2.1 Purchasing Power Parity . . . . . . . . . . . . . . . . . . . . . 10

2.1 .1 PPP Theory . . . . . . . . . . . . . . . . 10

2.1 .2 Deviations from PPP . . . . . . . . . . . . . 12

2.2 Uncovered Interest Rate Parity . . . . . . . . . . . . . . . . . . 16

2.2 .1 Deviations from UIP . . . . . . . . . . . . . . . . . . . . . 18

2.3 Fisher Parity . . . . . . . . . . . . . . . . . . . 21

2.3.1 Deviations from Fisher Parity . . . . . . . . . . . . 22

2.4 The Interrelationship of the Parity Hypotheses . . . . . . . . . . . . . . . 24

$3 \quad$ PPP and Real Expenditure: A Multicountry Panel Investigation 27

3.1 Theoretical Models . . . . . . . . . . . . . . . . . . . . 28

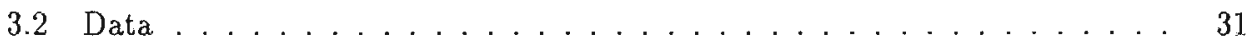

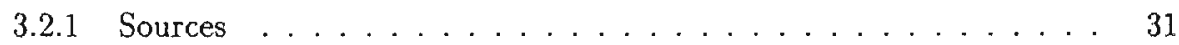

3.2 .2 Summary Statistics . . . . . . . . . . . . . . . . 31

3.3 Pooled Tests on Relative PPP ................... 33

3.3.1 Specification . . . . . . . . . . . . . . . . 33

3.3 .2 Empirical Results . . . . . . . . . . . . . . . . . 36

3.4 Pooled Tests on Absolute PPP . . . . . . . . . . . . . . . . . . . . 42

3.4 .1 Specification . . . . . . . . . . . . . . 42

3.4.2 Empirical Results . . . . . . . . . . . . . . . . . . 44 


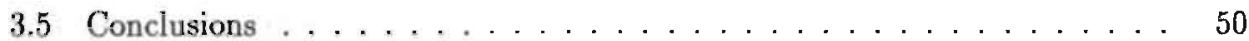

4 Common Factors and Tests for the Unbiasedness Hypothesis 51

4.1 Data .............................. 52

4.2 Time Series Tests . . . . . . . . . . . . . . . . . . . . . . . 54

4.3 Panel Approach . . . . . . . . . . . . . . . . . . . . 57

4.3.1 The Fixed Time Effects Model . . . . . . . . . . . . . . 57

4.3.2 The Random Effects Model ... . . . . . . . . . . . . 61

4.4 Outliers and EMS Realignments . . . . . . . . . . . . . . . . . 64

4.5 Conclusions . . . . . . . . . . . . . . . . . 70

5 Real Interest Rates and Shifts in Macroeconomic Volatility $\quad 71$

5.1 A Generalized Fisher Hypothesis . . . . . . . . . . . . . . . . 73

5.2 Data . . . . . . . . . . . . . . . . . . . . 75

5.3 Empirical Implementation . . . . . . . . . . . . . . . 76

5.3 .1 The Multi State Kalman Filter . . . . . . . . . . . . . 78

5.3.2 Conditional Second Moments ............... 80

5.4 Shifts in Macroeconomic Volatility . . . . . . . . . . . . . . 82

5.5 Conclusions ........................... 86

Appendix 5: The Multi State Kalman Filter . . . . . . . . . . . . . 8 T

6 An Empirical Investigation of the Domestic Pricing Error in an Inte$\begin{array}{ll}\text { grated World } & 91\end{array}$

6.1 International Asset Pricing . . . . . . . . . . . . . . . . . . 93

6.2 International versus Domestic Pricing . . . . . . . . . . . . . 96

6.2 .1 Methodology ... . . . . . . . . . . . . 96

6.2 .2 Test Approach . . . . . . . . . . . . . . . . 97

6.3 Data . . . . . . . . . . . . . . . . . . . . 99

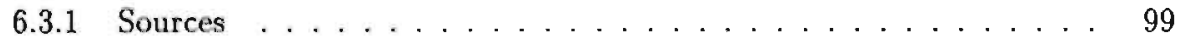

6.3 .2 Summary Statistics . . . . . . . . . . . . . . 100

6.4 Empirical Results . . . . . . . . . . . . . . . . 105

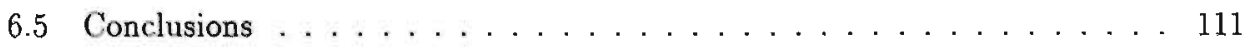

Appendix 6A: Numeraire Independence . . . . . . . . . . . . . . . . 112

Appendix 6B: Generalized Method of Moments . . . . . . . . . . . . . . 113

7 The Dynamics of Short-Term Interest Rate Volatility Reconsidered 117

7.1 GARCH and Level Effects . . . . . . . . . . . . . . . . . 118

7.2 Empirical Results . . . . . . . . . . . . . . . . . . 121 
$7.2 .1 \quad$ Data . . . . . . . . . . . . . . . . . . . . . 121

7.2 .2 Parameter Estimates . . . . . . . . . . . . . . . 121

7.2 .3 Diagnostic Tests . . . . . . . . . . . . . . 126

7.2 .4 Unconditional Distribution . . . . . . . . . . . . . . 128

7.2 .5 News Impact Curves $\ldots \ldots \ldots \ldots \ldots$

7.3 Bond Option Implications $\ldots \ldots \ldots \ldots \ldots \ldots \ldots$

7.3.1 The Price of Risk . . . . . . . . . . . . . . . . . 134

7.3 .2 The Term Structure . . . . . . . . . . . . . . 135

7.3 .3 Option Simulation $\ldots \ldots \ldots \ldots \ldots \ldots \ldots \ldots$

7.3 .4 Results . . . . . . . . . . . . . . . . 140

7.4 Conclusions . . . . . . . . . . . . . . . . . . . . . . . 142

Appendix 7A: The Unconditional Distribution of the Spot Rate . . . . . . 143

Appendix 7B: Computation of Standard Errors . . . . . . . . . . . . . . 144

8 Summary and Suggestions for Further Research $\quad 145$

8.1 Summary . . . . . . . . . . . . . . . . . . 145

8.2 Suggestions for Further Research . . . . . . . . . . . . . 149

$\begin{array}{ll}\text { Bibliography } & 151\end{array}$

$\begin{array}{lc}\text { Nederlandse Samenvatting } & 161\end{array}$

$\begin{array}{lr}\text { Index } & 166\end{array}$

$\begin{array}{lr}\text { Curriculum Vitae } & 169\end{array}$ 



\section{List of Tables}

1.1 Cross-Border Transactions in Bonds and Equities . . . . . . . . . . 2

1.2 Percentage of GDP Arising from Exports . . . . . . . . . . . 3

3.1 Augmented Dickey-Fuller Tests . . . . . . . . . . . . . . . 32

3.2 Summary Statistics . . . . . . . . . . . . . . . . 33

3.3 Parameter Estimates of PPP and Extensions . . . . . . . . . . 37

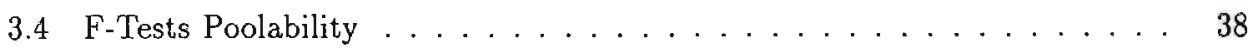

3.5 Panel Fixed Effects . . . . . . . . . . . . . . . . . . . . . . 39

3.6 Critical Values for Pooled Unit Root Test . . . . . . . . . . . . . . . . 43

3.7 Level Regression of PPP Model . . . . . . . . . . . . . . . . 45

3.8 Level Regression of Extended Model . . . . . . . . . . . . . . . 46

3.9 Error-Correction Model: PPP and Extension . . . . . . . . . . . 47

4.1 Summary Statistics . . . . . . . . . . . . . . . . . 53

4.2 Slope Bilateral Times Series Model . . . . . . . . . . . . . . 55

4.3 Country Specific Slope Coefficients . . . . . . . . . . . . . . . . 59

4.4 Panel Fixed Time Effects . . . . . . . . . . . . . . . . 60

$4.5 \quad$ F-Test Restrictions . . . . . . . . . . . . . . . . . 60

4.6 Panel Random Time Effects . . . . . . . . . . . . . . . . . . . 64

4.7 UIP and Outliers . . . . . . . . . . . . . . . . . . 67

4.8 Average UIP Differentials $\ldots \ldots \ldots \ldots$

5.1 Summary Statistics . . . . . . . . . . . . . . . . . . . 76

5.2 Multivariate Stochastic Volatility Model . . . . . . . . . . . 81

5.3 Principal Components Analysis . . . . . . . . . . . . . 83

5.4 Cointegration Test $\ldots \ldots \ldots \ldots \ldots \ldots \ldots$

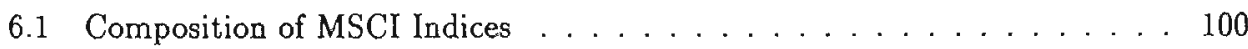

6.2 Total Number of Stocks . . . . . . . . . . . . . . . . . . . . . . 101

6.3 Summary Statistics . . . . . . . . . . . . . . . . . . . . . . . . . 102

6.4 Correlation Matrices . . . . . . . . . . . . . . . . . . 105 
6.5 Annualized Pricing Error . . . . . . . . . . . . . . . . . . . . . . 109

6.6 Significance of Global Pricing $\ldots \ldots \ldots \ldots \ldots$

7.1 Summary Statistics . . . . . . . . . . . . . . . . . . . . 122

7.2 Unrestricted Parameter Estimates . . . . . . . . . . . . . . . . . 124

7.3 Diagnostics . . . . . . . . . . . . . . . . . 127

7.4 Period $79-82$ excluded $\ldots \ldots \ldots \ldots \ldots \ldots$

7.5 Parameter Estimates of Restricted Models . . . . . . . . . . . . . 130

7.6 Percentage Option Value . . . . . . . . . . . . . . . . . 141 


\section{List of Figures}

2.1 Exchange Rate and PPP . . . . . . . . . . . . . . 13

2.2 Exchange Rate Changes and Forward Premiums . . . . . . . . . . . 19

2.3 Nominal Interest Rate and Inflation . . . . . . . . . . . . . . 23

3.1 Estimates of $\theta(k), \eta(k)$ and One-Standard-Error Bands . . . . . . . 39

3.2 Nominal Exchange Rate Changes versus Inflation Differentials . . . . . . 40

3.3 Real Exchange Rate Changes versus Output Growth Differentials . . . . 41

3.4 Fitted Exchange Rate Changes for Germany . . . . . . . . . . . . . 48

3.5 Fitted Exchange Rate Changes for Japan . . . . . . . . . . . . 49

4.1 Annualized Absolute Forward Premium . . . . . . . . . . . . . . 65

4.2 Cross-Sectional Standard Deviation . . . . . . . . . . . . . . . . 66

4.3 Parameter Estimates of UIP . . . . . . . . . . . . . . . . . . . 69

5.1 Conditional Variance of Money Growth . . . . . . . . . . . . . . . . 82

5.2 Interest Rate and Monetary Volatility . . . . . . . . . . . . . . . . 85

6.1 Distribution of Mean Return . . . . . . . . . . . . . . . . . 103

6.2 Distribution of Standard Deviations . . . . . . . . . . . . . . 104

6.3 Scatter of $\hat{d}_{i}$ versus $\hat{b}_{i} \hat{c}_{0} \ldots \ldots \ldots \ldots 10 \ldots \ldots$

6.4 Distribution of Domestic Pricing Errors . . . . . . . . . . . . . . . . . 108

6.5 Cumulative Density of $\chi^{2}$ Statistics . . . . . . . . . . . 110

7.1 One-month Treasury Bill . . . . . . . . . . . . . . . . . . . . . 122

7.2 Mean Reversion . . . . . . . . . . . . . . . . . . . . . . . . . . 125

7.3 Unconditional Distributions . . . . . . . . . . . . . . . . . . 129

7.4 News Impact Curves . . . . . . . . . . . . . . . . . . . . . . . . . 132

7.5 News Impact Surface $\ldots \ldots \ldots \ldots \ldots \ldots$

7.6 Naive Simulation . . . . . . . . . . . . . . . . . 136

7.7 Efficient Simulation . . . . . . . . . . . . . . . . . 137

7.8 Risk Neutral Unconditional Distribution . . . . . . . . . . . . 139 



\section{Chapter 1}

\section{Introduction}

International financial markets have grown rapidly over the last two decades. The deregulation of domestic financial markets, the liberalization of international capital flows, the arrival of powerful computers and rapid financial innovation delivered explosive growth and economic power to the international financial markets. This recent experience follows decades of severe government restrictions on external capital flows; in fact, it can be viewed as a return to a situation that already existed at the beginning of this century. The trend towards a massive global capital market beyond any single government's control is likely to continue in the future due to the liberalization of the markets of newly industrialized countries in Asia and Latin America.

Undoubtedly, it is especially during the last five years that trading volumes on foreign exchange and equity markets have increased dramatically. The statistics of the 1995 survey of the Bank of International Settlements (BIS) demonstrate the increasing importance of international financial flows. By way of illustration, in 1995 the daily average volume of foreign exchange transactions in the spot market was $\$ 1,190$ billion, up from $\$ 590$ billion in 1989. Goldstein et al. (1993) point out that the most significant development in the foreign exchange market, however, did not take place in the spot exchange market but in the trading in derivative securities like forwards, swaps, futures and options, a fact they illustrate with the following statistics. First, the outstanding notional principal of currency swaps increased more than fourfold to $\$ 800$ billion between end-1987 and end1991. Second, daily turnovers in currency futures and options traded in London grew from negligible amounts in 1986 to $\$ 8$ billion in 1992 , and from $\$ 3$ billion to $\$ 23$ billion in the United States. 
TABle 1.1: Cross-Border Transactions in Bonds and Equities

\begin{tabular}{lcccc}
\hline \hline & 1980 & 1985 & 1990 & 1995 \\
\hline Canada. & 9.6 & 26.7 & 64.4 & 192.0 \\
France & - & 21.4 & 53.6 & 178.2 \\
Germany & 7.5 & 33.4 & 57.3 & 168.3 \\
Italy & 1.1 & 4.0 & 26.6 & 250.9 \\
Japan & 7.7 & 63.0 & 120.0 & 65.7 \\
United States & 9.0 & 35.1 & 89.0 & 135.5 \\
\hline
\end{tabular}

Source: Bank of International Settlements, 66th Annual Report, 10th June 1995 , p. 98.

Note: Cross-border transactions are defined as gross purchases of securities between residents and non-residents as a percentage of gross domestic product.

Moreover, there has been an explosion of gross sales and purchases of bonds and equities between countries. Table 1.1 clearly illustrates this phenomenon in providing estimates of cross-border transactions in bonds and equities over the last fifteen years as a percentage of GDP. Cross-border transactions in bonds and equities between residents of the United States and other countries have risen from $9.0 \%$ of GDP in 1980 to $135.5 \%$ of GDP in 1995. For Italy, the rise is even more dramatic. However, from the capital account of these countries it can be concluded that net capital flows have not changed radically over the last decade. ${ }^{1}$

Alongside the growing importance of international financial markets, there has also been some growth in international trade. The growing importance of international trade is reflected in the international trade statistics of most industrialized countries. This is seen in table 1.2 which shows that exports as a percentage of gross domestic product (GDP) have risen in Canada, France, Germany, Italy and the United States. This increase is less dramatic compared to that of gross capital flows. The net effect of international trade is reflected in a country's current account which is approximately equal to the amount of net capital flows.

It is not uncommon for the huge increase in gross cross-border financial transactions between rich industrial countries to be interpreted as significant evidence that international capital is highly mobile. But at this stage some caution should be exercised. International finance literature points out that despite the rapid increase in the size of capital flows, domestic investors hold only a small fraction of their wealth in foreign assets to diversify away domestic idiosyncratic risk. Both research that directly investigates international

\footnotetext{
${ }^{1}$ See for instance Goldstein et al. (1993).
} 
TABLE 1.2: Percentage of GDP Arising from Exports

\begin{tabular}{lcccc}
\hline \hline & 1970 & 1980 & 1990 & 1994 \\
\hline Canada & 22.5 & 28.3 & 24.1 & 33.6 \\
France & 15.8 & 21.5 & 22.6 & 23.1 \\
Germany & 17.1 & 46.4 & 56.0 & 59.9 \\
Italy & 14.9 & 19.9 & 21.5 & 23.0 \\
Japan & 10.8 & 13.7 & 10.8 & 9.46 \\
United States & 5.6 & 10.3 & 10.1 & 10.7 \\
\hline
\end{tabular}

Source: International Financial Statistics Yearbook, 1995.

Note: Exports of goods and services are obtained from line 90 and gross domestic products are obtained from line 99.

equity holdings and research that looks at the implications for international consumption reach such a conclusion.

On the one hand, from international equity holdings it can be inferred that investors have a strong preference for the assets of their home country whereas portfolio theory suggests that they should hold the world market portfolio. This anomaly, which has been documented by many researchers, is referred to as the home bias puzzle. ${ }^{2}$ French and Poterba (1991) for example report that in 1989 domestic equity holdings ranged from $98 \%$ for Japan and $94 \%$ for the United States, to $82 \%$ for the United Kingdom.

On the other hand, consumption data exhibit low cross country correlations whereas capital mobility should lead to higher correlations as residents of a country, hit by country-specific shocks to income, can use international capital markets to smooth out the fluctuations in their consumption. ${ }^{3}$

Alternatively, researchers in international economics investigate the national account's balance of saving and investment as it reflects international trade in goods and services. They find that domestic investment and saving are highly correlated. This phenomenon, which was first reported by Feldstein and Horioka (1980) and subsequently confirmed by other empirical research, is interpreted as evidence that capital mobility is low. According to Feldstein and Horioka (1980), international capital mobility allows countries' domestic investment rates to deviate from their saving rates because funds would flow to the best

\footnotetext{
${ }^{2}$ See for instance Cooper and Kaplanis (1986), Eldor, Pines and Schwartz (1988), French and Poterba (1991), and Tesar and Werner (1992).

${ }^{3}$ See for instance Obstfeld (1994), Lewis (1996).

${ }^{4}$ See for instance Dooley, Frankel and Mathieson (1987), Obstfeld (1986), Bayoumi (1990) and Tesar (1991).
} 
investment opportunities, regardless of their location. Therefore, they consider the high correlations as evidence in favor of low capital mobility.

The above-mentioned studies all consider quantity variables like equity holdings, consumption, savings and investments. Another and more indirect approach is to investigate prices of commodities and financial assets across countries. The basic idea that underlies this approach is that in the absence of any barriers to trade, arbitrage ensures that identical traded goods and assets in different countries have identical prices when denominated in the same currency. For the goods market this hypothesis is often restated as purchasing power parity (PPP). According to this parity, the relative price level between two countries exactly equals the exchange rate. For the international bond market, the no-arbitrage condition is often referred to as covered interest rate parity (CIP), which states that the forward exchange rate between two countries is exactly equal to the two countries' interest rate differential. Another popular parity hypothesis that arises in the international bond market is the so-called uncovered interest rate parity (UIP) which states that, if investors are risk averse, the expected change of the spot exchange rate between countries is identical to the two countries' interest rate differential.

Marston (1995) uses these parity hypotheses to investigate the degree of capital mobility for the Group of Five industrial countries (G-5: France, Germany, Japan, the United Kingdom and the United States) and concludes the following. First, by the late 1980s deposit rates of all G-5 countries were tied closely to Eurocurrency rates in the same currency. Second, both deviations from CIP and UIP respectively, between the Eurodollar and the other G-5 Eurocurrencies have, on average, been quite small over the past twenty years. Finally, average real interest rate differentials are generally less than $2 \%$ per annum. Other studies, however, show that in the short-run there are substantial deviations from PPP and UIP. ${ }^{5}$ Marston (1995) claims that these deviations are not due to regulations and controls, but that exchange rate risk is separating markets.

Research on the price implication of financial integration is not restricted only to international bond markets, but also looks at international stock markets. To investigate stock returns in an integrated world, an international capital asset pricing model (ICAPM) is called for. Deviations from parity hypotheses play an important role in the ICAPM. Most of the international finance literature has been devoted to models that identify countries as a group of investors who use the same price index to determine their anticipated real returns. In a survey article Adler and Dumas (1983) describe the consequences of deviations from PPP for an international investor: "National groups of investors are delineated by

\footnotetext{
${ }^{5}$ See Froot and Rogoff (1995) and Engel (1996) for a survey of the empirical literature on PPP and UIP respectively.
} 
deviations from Purchasing Power Parity (PPP) which cause them to evaluate differently the returns from the same security." In other words, if PPP does not hold, investors' consumption opportunities differ according to their country of residence. Investors, therefore, hold different portfolios across countries in order to hedge for unanticipated price changes in their consumption basket.

A test for international integration based on stock returns now exploits the fact that the ICAPM predicts that in an integrated world the expected stock return contains a risk premium that is associated with the world market portfolio and a premium for the risk: that arises from PPP deviations. In contrast, in a segmented market the expected stock return only obtains a compensation for local market risk. Most empirical research that focuses on the cross-section of stock returns across countries finds evidence in favor of international integration.

The main conclusion that arises from this discussion is that international integration is usually investigated with quantity measures as well as price measures. The evidence that arises from the quantity measures suggest low international integration, whereas the evidence with regard to price measures is mixed. Firstly, average deviations from PPP, CIP and UIP are quite small. Secondly, there can be substantial short-run deviations from PPP and UIP. Finally, studies on international stock markets show some evidence in favor of international integration.

This thesis mainly focuses on financial prices as it investigates empirically the dynamics of exchange rates, interest rates and stock returns in international financial markets.

\subsection{Outline}

This thesis consists of five empirical studies that investigate the dynamics on financial markets, with an emphasize on interuational interdependence. The innovative character of the research resides not so much in the choice of the subjects but more in the use of alternative estimation techniques and data.

The investigation starts in chapter 2 with a survey of the literature on three fundamental parity hypotheses: purchasing power parity (PPP), uncovered interest rate parity (UIP) and the Fisher parity.

Whereas previous research concentrated on the modeling of financial markets in one in- 
dividual country, this thesis focuses on the empirical analysis of financial relations for a panel of countries. Chapters 3 and 4 investigate PPP and UIP for panels of fifteen and sixteen different countries respectively.

The comparison of different countries calls for alternative techniques because when comparing countries, the choice of the numeraire currency should not influence the results. The importance of this numeraire invariance principle has been pointed out by Adler and Dumas (1983):

No matter what economic setting is chosen, the decisions of rational economic units (investors, firms, etc.) should be invariant as one changes the unit of measurement or the currency of accounting, in which returns are expressed. This is a minimum criterion of rationality. (Adler and Dumas, 1983, p. 927.)

As the techniques used take away the numeraire effect, the estimation results in chapters 3,4 and 6 do not depend on the choice of the numeraire currency.

Chapter 3 details an empirical investigation of PPP. Theoretical extensions of the traditional PPP relation recently developed by Sercu, Uppal and Van Hulle (1995) and Sercu and Uppal (1995) show that exchange rate changes consist of the risk aversion weighted differential growth in real expenditures plus the marginal inflation differential. We consider a system of sixteen countries and impose restrictions that make parameter estimates invariant to the choice of the numeraire currency. We estimate their model at different horizons and use panel data as well as time series tests.

Risk premiums, peso-problems and market inefficiencies have been suggested as candidate explanations for the apparent rejection of the UIP relationship. If various explanations interact and show up in all exchange rates that are being considered, then these exchange rates share common factors, which are not being captured in standard time series tests. To account for these common factors, in chapter 4 the UIP hypothesis is tested using both fixed and random time effects for fifteen countries between 1979 and 1969. As in the previous chapter the results are numeraire independent.

A growing amount of research indicates that the relation between nominal interest rates and future inflation is country and period dependent. Chapter 5 investigates the relation between the short-term interest rate and inflation by means of an intertemporal consumption capital asset pricing model, resulting in a generalized Fisher equation in which the nominal interest rate is a function of inflation and the conditional variances of money growth and industrial production growth. The conditional variances are calculated using both the multi state Kalman filter (MSKF) model and the multivariate stochastic volatility 
model. These methods allow for occasional level shifts in our proxies for macroeconomic risk.

Deviations from the parity hypotheses referred to above play an important role in ICAPMs. Most of the international finance literature has been devoted to models that identify countries as a group of investors who use the same price index to determine their anticipated real returns. Investors from different countries evaluate differently the returns from the same security due to PPP deviations. Adler and Dumas (1983) developed an ICAPM that assumes that financial markets are integrated internationally and moreover explicitly takes into account deviations from PPP between investors of different countries.

Increasing capital market integration has important implications for the calculation of the cost of capital. In an integrated world the cost of capital should be determined using the ICAPM rather than the domestic CAPM. Chapter 6 investigates this issue with the model developed by Adler and Dumas (1983). The pricing error when using the domestic CAPM rather than an ICAPM is zero if diversifiable domestic risk is orthogonal to the global market portfolio return and foreign currency changes. In this chapter we implement an orthogonality test for ten different countries. Contrary to other studies, the comparison is not restricted to country stock market indices, but goes more into detail, using data on approximately 3000 individual stocks, thus meeting the objections from Stulz (1995a) who recently pointed out that:

One approach to obtain more powerful tests of international asset pricing models is to use more securities. Most existing empirical work uses indices; work that uses large numbers of securities for different countries seem to be primarily devoted to studying the relationship between asset returns in two countries rather than to testing international asset pricing models. (Stulz, 1995a, p. 220.)

The orthogonality test is used to investigate whether the global market portfolio and foreign currencies affect the cost of capital of an individual firm through the effect of the global market on the risk premium of the local market. It is also shown that this test statistic is invariant to the choice of the numeraire currency.

In chapter 7 we turn to a subject that is not totally in line with the previous chapters as it considers the time series dynamics of the short-term interest rate volatility. We present and estimate a model of short-term interest rate volatility that encompasses both the level effect of Chan, Karolyi, Longstaff and Sanders (1992) and the conditional heteroskedasticity effect of the GARCH class of models. This flexible specification allows different effects to dominate as the level of the interest rate varies. We also investigate implications for the 
pricing of bond options.

This thesis ends in Chapter 8 with a summary and suggestions for further research. 


\section{Chapter 2}

\section{International Parity Conditions}

This chapter investigates three fundamental international relations that have preoccupied researchers in international finance searching for links between markets.

The first of these fundamental relations is purchasing power parity (PPP) which occurs in the market of goods and services as a result of goods market arbitrage. PPP implies that the exchange rate between two countries is determined by the two countries' relative price levels. The two other relations occur in financial markets. The first financial relation, the so-called uncovered interest rate parity (UIP) hypothesis, tells us that as a result of uncovered arbitrage, the difference between interest rates on securities that are denominated in different currencies equals the expected change of the exchange rate between the two countries. The second financial relationship, which is referred to as Fisher parity, points out that the nominal interest rate is equal to the real interest rate plus the markets' expected rate of inflation. These parity hypotheses are important building blocks of models used to explain the functioning of international financial markets such as the international capital asset pricing model.

This chapter focuses on the theoretical foundations of the three parity hypotheses. In the next three chapters we will turn to empirical tests of these relations. Section 2.1 reviews the theory on PPP. In section 2.2 we consider some theoretical aspects of UIP. Sertion 2.3 deals with the Fisher parity. The three parities provide a very useful basis to investigate the relationship between exchange rates, inflation and interest rates. In section 2.4 we therefore investigate the relationship between the three parity hypotheses. 


\subsection{Purchasing Power Parity}

Purchasing power parity (PPP) has a long tradition in international economics, originating with classical writers including Ricardo in the early 19th century. It was Cassel, however, who first placed PPP within a systematic framework through a series of studies in the 1920s. Cassel's theory of PPP simply notices that the most important determinant of the exchange rate between two currencies is the two countries' price levels. Officer (1976) states that this theory of exchange rate determination:

... has remained a relatively unsophisticated theory, hardly advanced in complexity over three fourths of a century. Yet the PPP approach is resurrected from time to time, ushering in a period distinguished both by empirical applications and renewed criticism of the theory, whereupon again the approach falls into disuse. (Officer, 1976, p. 1.)

This statement is particularly illustrative for the changing popularity of PPP research over the last two decades.

Froot and Rogoff (1995) note that more than a decade ago hardly any research was conducted on PPP. After the introduction of floating exchange rates in the early seventies it was obvious to even the most stubborn defenders of purchasing power parity that PPP is a long-run relationship. In the seventies and early eighties, however, time spans of floating rate data were too short to identify these long-term relations. Furthermore, the empirical analysis was limited by the absence of econometric techniques to test for the interaction of long-term and short-term dynamics.

The last decade, however, has witnessed a resurgence of research on PPP, brought on by the development of co-integration techniques to test for long-term relations. Simultaneously, this development has resulted in a tremendous amount of empirical research. On the other hand, theoretical developments have been only limited.

\subsubsection{PPP Theory}

The theory of absolute PPP relates the exchange rate to weighted average price levels. Three sufficient conditions for PPP to bold exactly are the law of one price (LOP), homothetic preferences and identical tastes across countries. ${ }^{1}$

\footnotetext{
${ }^{1}$ Adler and Dumas (1983) note that these conditions are not necessary. PPP could emerge despite dif-
} ferences in tastes and the presence of nontradable goods, provided that there exists enough substitutability 
The tirst important building block underlying PPP is the LOP which states that in the absence of any trade barriers arbitrage ensures that the following condition holds for identical tradable goods in two countries:

$$
\frac{S(t) P_{2 i}(t)}{P_{1 i}(t)}=1, \quad i=(1, \ldots, N)
$$

where $t$ is a time index, $S(t)$ is the exchange rate, $P_{2 i}(t)$ is the country 2 domestic currency price of good $i$ and $P_{1 i}(t)$ is the country 1 domestic currency price of good $i$.

Samuelson and Swamy (1974) show that when preferences are homothetic, ther' "xists a price index with invariant weights that are equal to budget shares. This invariaut index reveals the consumption possibilities and preferences of the citizens of a country. ${ }^{2}$ Adler and Dumas (1983) state that only invariant consumption price indices can reasonably be compared across countries. The weighted average price level $P_{k}$ of country $k=(1,2)$ at time $t$, based on budget shares is:

$$
P_{k}(t)=\sum_{i=1}^{N} \frac{C_{k i}(t)}{C_{k}(t)} P_{k i}(t)=\sum_{i=1}^{N} w_{k i}(t) P_{k i}(t),
$$

where $C_{k i}(t)$ is the consumption of good $i$ and $C_{k}(t)$ is total consumption expenditures and $w_{k i}(t)=C_{k i}(t) / C_{k}(t)$ is the budget share of the $i$-th good.

The last condition that is required for PPP to hold exactly is identical tastes. Identical tastes across countries imply equal budget shares, $w_{\mathbf{1 i}}(t)=w_{2 \mathbf{i}}(t)$ for $i=(1, \ldots, N)$. From equations (2.1), and (2.2) it follows that:

$$
P_{1}(t)=\sum_{i=1}^{N} w_{1 i}(t) P_{1 i}(t)=S(t) \sum_{i=1}^{N} w_{2 i}(t) P_{2 i}(t)=S(t) P_{2}(t),
$$

or, equivalently, the real exchange rate $S(t) P_{2}(t) / P_{1}(t)$ is equal to unity.

A lot of empirical research weakens the theory of absolute PPP as it allows for a constant price differential between the two countries' absolute price levels: $\psi P_{1}(t)=S(t) P_{2}(t)$, where $\psi^{\prime}$ is a constant deviation from absolute PPP. Given this deviation from absclute PPP, a change in the relative price levels results in an equal change of the exchange rate.

$$
s(t+1)-s(t)=\pi_{1}(t+1)-\pi_{2}(t+1),
$$

where $s(t+1)$ denotes the logarithm of the exchange rate and $\pi_{k}(t+1)=\ln \left[P_{k}(t+1) / P_{k}(t)\right]$ for country $k=(1,2)$. This restatement of absolute PPP, in terms of changes in relative price levels and the exchange rates, is called relative PPP.

among goods in consumption and between tradable and nontradable goods in production.

${ }^{2}$ An invariant price index is a compression of the price vector into a single scalar leading to the same decisions and valid at all levels of the consumption budget. 


\subsubsection{Deviations from PPP}

Officer (1976) notes that only a few authors claim that absolute PPP is rejected if equation (2.3) does not hold exactly. Cassel, for example, already allowed for small and temporary divergences of the exchange rate from PPP. Figure 2.1 contains the actual exchange rate and price level relative to the United States for France, Germany, Japan and the United Kingdom respectively. ${ }^{3}$ The relative price ratio is indexed to begin at the same level as the actual exchange rate. For all countries the trend of relative prices and the exchange rate are in the same direction. In the short-run, however, there are substantial deviations from PPP. These results confirm the consensus of empirical research that PPP does not hold in the short-run, but there is a tendency for PPP to hold in the long-run (see Froot and Rogoff (1995), and Rogoff (1996) for a survey of the empirical literature). ${ }^{4}$

Deviations from PPP may occur if the LOP is violated, which implies that prices of some goods at home are different from the prices abroad. Dumas (1992), Uppal (1992) and Sercu, Uppal and Van Hulle (1995) investigate violations of LOP that are the result of transaction costs, such as shipping and insurance costs, tariffs and information costs. These models all assume that there are only two countries that are populated with identical consumers. The consumers have a constant relative risk aversion utility function, which implies homothetic preferences. Furthermore, there is only one consumption good, which implies that PPP reduces to the LOP.

Uppal (1992) assumes that there is one aggregate stock of capital. Furthermore preferences are state dependent with shipment costs being the state variable. From this model it follows that the deviation from LOP is directly related to the volume of capital flows, a result that is similar to Dumas (1992).

Dumas (1992) investigates an economy with two different countries, which are both endowed with one homogeneous stock of physical capital. The capital stock can be consumed, invested or shipped abroad at proportional transfer costs. Dumas shows that the deviation from the LOP remains between two boundary values that are determined by the shipment costs. When the real exchange rate reaches the boundary values, shipment is activated and the real exchange rate returns within the bounds. The deviation of the LOP within the bounds is a nonlinear function of the allocation of the stock of physical capital between

\footnotetext{
3 The sample frequency is quarterly. See chapter 3 for a description of the data.

4 Despite all the critical remarks that have been made with respect to the empirical validity of PPP, Officer (1976) notes that there are at least three cases where the theory is still applicable. First, PPP holds approximately under normal conditions. Second, PPP is useful when relative price movements dominate changes in relative prices. Third, when trade relations are interrupted between countries, PPP can provide an indication of the equilibrium exchange rate.
} 
France

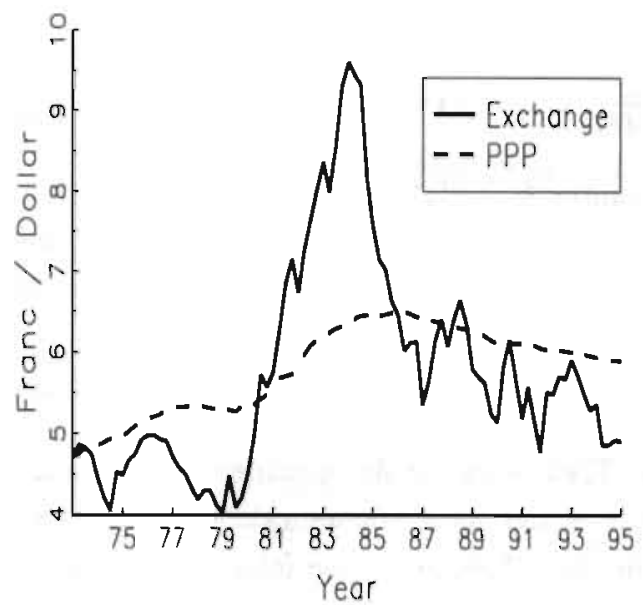

Japan

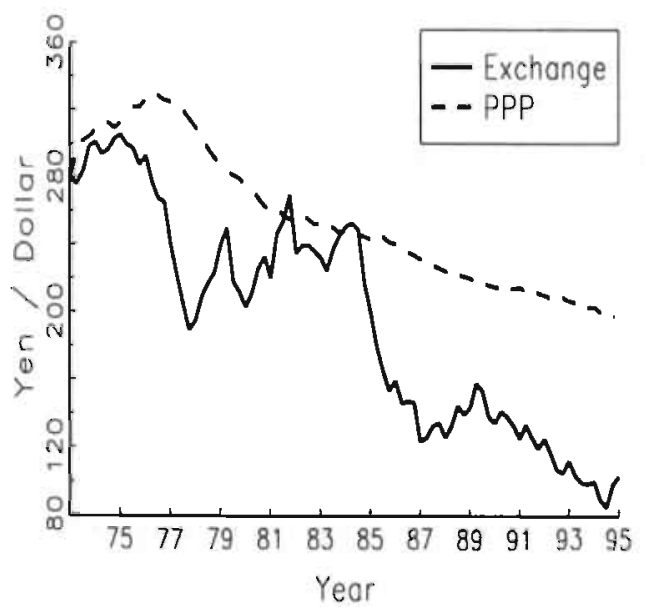

Germany

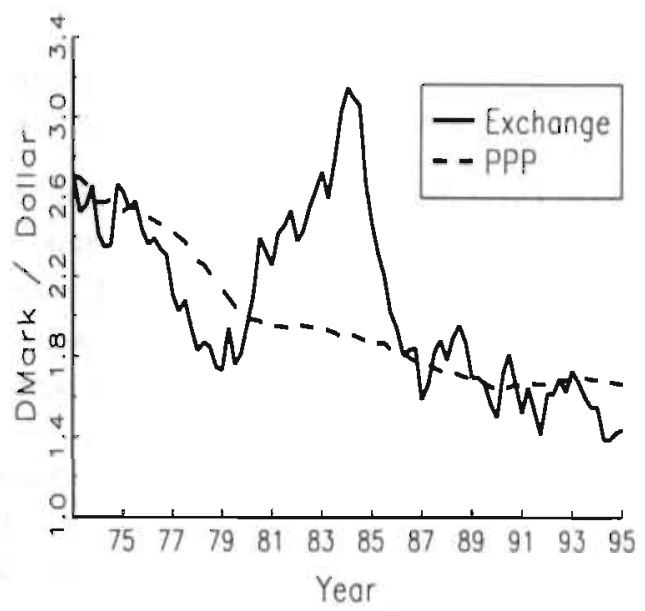

United Kingdom

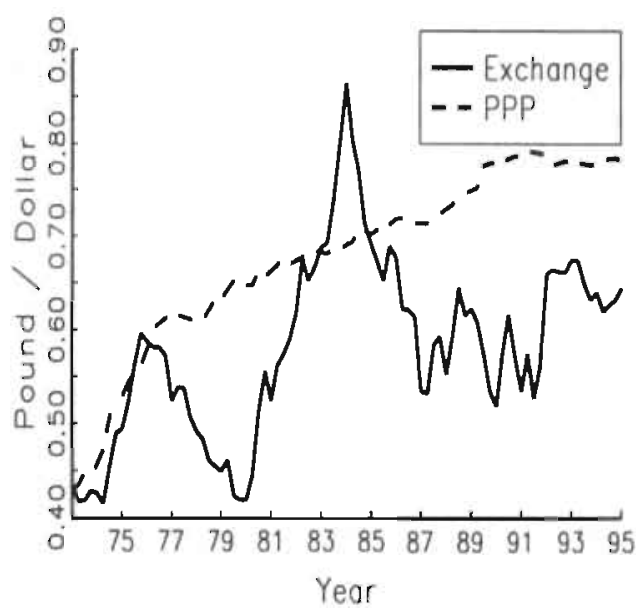

Figure 2.1: Exchange Rate and PPP 
the two countries and under perfect balance in the two countries' stock of capital, LOP prevails.

Sercu, Uppal and Van Hulle (1995) develop a model that is closely related to Dumas's (1992). ${ }^{5}$ They show that the real exchange rate depends on the marginal utilities of domestic and foreign real consumption:

$$
\frac{S(t) P_{2 i}(t)}{P_{1 i}(t)}=\frac{\partial U_{2 i}(t) / \partial C_{2 i}(t)}{\partial U_{1 i}(t) / \partial C_{1 i}(t)}, \quad i=(1, \ldots, N)
$$

where $U_{k}(t)$ denotes the utility function of country $k=(1,2)$. If, on the one hand, international trade is costless, the marginal utilities are be equalized across countries and PPP will hold. If, on the other hand, there are transaction costs to international trade, imbalances between marginal utilities are not equalized across countries. As a result, the real exchange rate depends on the two countries' real consumption.

Sercu and Uppal (1995) generalize this model. They allow for $M$ countries and $N$ goods. The consumers are not identical across countries and have nonhomothetic preferences. From the first-order approximation of equation (2.5) they derive the following expression for deviation from relative PPP $\Delta q(t)$ :

$$
\Delta q(t)=\eta_{1}(t)\left(\Delta c_{1}-\pi_{1}\right)(t)-\eta_{2}(t)\left(\Delta c_{2}-\pi_{2}\right)(t)+\left(\tilde{\pi}_{1}-\pi_{1}\right)(t)-\left(\tilde{\pi}_{2}-\pi_{2}\right)(t)
$$

where $\Delta c_{k}(t)$ is growth of nominal consumption expenditures, $\pi_{k}(t)$ is inflation weighted on the basis of total consumption, $\tilde{\pi}_{k}(t)$ is inflation weighted on the basis of marginal consumption and $\eta_{k}(t)$ is the coefficient of relative risk aversion. If preferences are homothetic, inflation weighted on the basis of total consumption is equal to inflation weighted on the basis of marginal consumption and the deviation from relative PPP now depends on the growth rates of real consumption expenditures. If indeed consumers are risk neutral, $\left(\eta_{1}=\eta_{2}=0\right)$, relative PPP prevails.

Sercu and Uppal (1995) state that for deviations from absolute PPP it is generally impossible to obtain closed form solutions when preferences are nonhomothetic. ${ }^{6}$ However, in the case of homothetic utility of the constant relative risk aversion form, the deviation from absolute PPP is:

$$
\frac{S(t) P_{2}(t)}{P_{1}(t)}=\theta_{2} \frac{\left(1-\eta_{2}\right)}{\left(1-\eta_{1}\right)} \frac{\left(C_{1}(t)-P_{1}(t)\right)^{\eta_{1}}}{\left(C_{2}(t)-P_{2}(t)\right)^{\eta_{2}}}
$$

where $\theta_{2}$ is a parameter that depends both on the wealth of country 2 relative to country 1 and the risk aversion parameters. The deviation from absolute PPP depends on domestic

\footnotetext{
${ }^{5}$ See also Benninga and Protopapadakis (1988) for a related approach.
}

${ }^{6}$ The reason is that the integrals of $\pi(t)$ and $\pi(t)$ do not always have closed form solutions. 
and foreign consumer expenditures. If investors in the countries are equally risk averse, $\left(\eta_{1}=\eta_{2}=0\right)$, and equally rich, $\left(\theta_{2}=1\right)$, then absolute PPP prevails.

A second explanation for deviations from LOP is the presence of nontradable gonds. Siuppose that the general price level of country $k=(1,2)$ is:

$$
P_{k}(t)=P_{k T}(t)^{i 11} P_{k N}(t)^{i j 2},
$$

where $P_{k T}(t)$ is the price level of tradable goods and $P_{k N}(t)$ is the price level of nontradable: goods. If PPP holds for tradable goods only, the deviation of absolute PPP depends on the relative price of tradable and nontradable goods:

$$
\frac{S(t) P_{2}(t)}{P_{1}(t)}=\frac{\left(P_{1 T}(t) / P_{1 N}(t)\right)^{\beta_{1}}}{\left(P_{2 T}(t) / P_{2 N}(t)\right)^{\beta_{2}}} .
$$

Balassa (1964) and Samuelson (1964) relate the relative price changes of tradable goods and nontradable goods to technological progress in the tradable goods sector. Technological progress has historically been faster in the tradable goods sector than in the nontradable goods sector. Furthermore, the tradable goods productivity bias is more pronounced in high income countries. The higher productivity in the tradable goods sector will raise wages in the whole economy. The higher wages in the whole economy bid up prices in the nontradable sector relative to the tradable sector. There is, therefore, a direct, link between the relative PPP deviations and economic growth. The empirical implications of the Balassa-Samuelson model are closely related to the model of Sercu and Uppal (1995).

The Balassa-Samuelson model has been criticized by Rogoff (1992), who argues that the assumption of perfect capital and labor mobility is too restrictive for the short-run. If capital and labor are immobile across sectors in the short-run, then demand variables such as government spending can produce a transitory deviation from PPP.

The Balassa-Samuelson model is developed in a static framework. Stulz (1987) investigated the effect of nontradable goods on PPP in an intertemporal model. The deviation from absolute PPP now depends solely on the ratio of the stock of domestic nontradable goods to the stock of foreign good changes. Sercu and Uppal (1995) argue how this result changes when shipment is costly. Combining equations (2.7) and (2.8) it turns out that the deviation from absolute PPP now directly depends on consumption expenditures and tradable and nontradable goods prices.

Other explanations for deviations from the LOP rely on imperfect competition in the tradable goods markets. Examples are sticky prices and the pricing to market theory which states that oligopolistic suppliers are able to charge different prices for the same goods in different countries (see also Froot and Rogoff (1995)). 
We now turn to deviations from PPP that do not rely on the violation of the LOP. A first candidate is nonhomothetic preferences. If the homotheticity assumption is violated, equation (2.5) shows that deviations from relative PPP depend on both inflation weighted on the basis of total consumption and inflation weighted on the basis of marginal consumption.

Secondly, differences in national consumption tastes (weighting schemes) will generally lead to deviations from PPP due to relative price variation. Samuelson (1964) argues that in the short-run real shocks lead to changes of relative prices and therefore relative PPP will not hold exactly. If price level changes are mainly dominated by monetary factors and if money is neutral, then PPP may be of some value. Roll and Solnik (1979) state that the existence of nontradable goods implies that relative price changes may be as important as nominal price changes even at moderate rates of inflation.

\subsection{Uncovered Interest Rate Parity}

Keynes (1923) was one of the first economists, who systematically investigated the topic of uncovered interest rate parity (UIP). His interest had been captured by the rapid expansion of organized trading in forward exchange following World War I. Since then, UIP has been widely used to investigate the link between interest rates and exchange rates. UIP states that with complete markets and risk neutral investors the expected returns on investments in deposits of two different countries are the same when measured in a single currency. The condition for equal expected profit is:

$$
\mathrm{E}_{t}\left[R_{1}(t)-\frac{R_{2}(t) S(t+1)}{S(t)}\right]=0
$$

where $R_{1}(t)$ and $R_{2}(t)$ are the nominal interest rates on domestic and foreign deposits. UIP is usually formulated in terms of the forward exchange rate $F(t)$ for delivery at time $t+1$. To prevent covered interest arbitrage, the return from investing in a foreign deposit and selling the foreign currency return in the forward market nust be identical to the return on a domestic deposit. The condition for covered interest rate parity (CIP) is:

$$
R_{1}(t)-\frac{R_{2}(t) F(t)}{S(t)}=0
$$

Using equations (2.10) and (2.11) the UIP hypothesis is often restated as:

$$
\mathrm{E}_{t}[S(t+1)-F(t)]=0,
$$

which is only identical to equation (2.10) if CIP holds. Equation (2.12) is often called speculative efficiency (Bilson (1981)), because it depends on the joint hypothesis of market 
efficiency and the speculative (expectations) theory of the forward rate. Marston (1995) argues that empirical tests based on equation (2.10) or (2.12) yield similar results.

Siegel (1972) points out that if the future spot exchange rate is uncertain, equation (2.12) is incompatible with equilibrium. From equation (2.12) it follows that $F(t)=\mathrm{E}_{t}[S(t+1)]$ and after changing the numeraire currency that $F(t)=1 / \mathrm{E}_{t}[1 / S(t+1)]$. These two expressions for the forward rate cannot hold simultaneously, because of Jensen's inequality which states that $\mathrm{E}_{t}[1 / S(t+1)]>1 / \mathrm{E}_{t}[S(t+1)]$. This observation is the so-called Siegel paradox.

Adler and Dumas (1983) argue that a solution for the Siegel paradox is to restate equation (2.12) in real terms:

$$
\mathrm{E}_{t}\left[\frac{S(t+1)-F(t)}{P_{1}(t+1)}\right]=0 .
$$

The equal profit condition for the foreign investor is:

$$
\mathrm{E}_{t}\left[\frac{S(t+1)-F(t)}{S(t+1) P_{2}(t+1)}\right]=0
$$

Equations (2.13) and (2.14) are equivalent only if $P_{1}(t+1)=S(t+1) P_{2}(t+1)$, that is if PPP holds. The model of Sercu and Uppal (1995) in equation (2.7) shows that PPP is compatible with risk neutrality, so there is no contradiction.

Frequently, the empirical literature assumes conditionally log-normally distributed returns. Under this condition equation (2.13) is of the form: ${ }^{7}$

$$
\mathrm{E}_{t}[s(t+1)]-s(t)=f(t)-s(t)-0.5 \operatorname{Var}_{t}[s(t+1)]+\operatorname{Cov}_{t}\left[s(t+1), p_{1}(t+1)\right]
$$

where the variables in small letters are the logs of the variables in capital letters. This equation shows that the $\log$ forward rate is a biased predictor of the log spot rate. Dumas (1994a) notes that the equality $\mathrm{E}_{t}[s(t+1)]-s(t)=f(t)-s(t)$ cannot be produced by any utility function either under risk aversion or risk neutrality. An appropriate equilibrium model includes the last two terms in equation (2.15). In empirical tests of UIP, however, these two terms can easily be ignored because they are small in size. ${ }^{8}$

${ }^{7}$ Equation (2.13) can be written as: $\mathrm{E}_{t}\left[\exp \left(s(t+1)-p_{1}(t+1)\right)\right]=\mathrm{E}_{t}\left[\exp \left(f(t)-p_{1}(t+1)\right)\right]$, where the variables in small letters are the logs of the variables in capital letters. Assuming log-normality this equation can be written as $\exp \left(\mathrm{E}_{t}\left[s(t+1)-p_{1}(t+1)\right]+0.5 \operatorname{Var}_{t}\left[s(t+1)-p_{1}(t+1)\right]\right)=\exp \left(E_{t}\left[f(t)-p_{1}(t+\right.\right.$ $\left.1)]+0.5 \operatorname{Var}_{t}\left[f(t)-p_{1}(t+1)\right]\right)$, which implies: $E_{t}\left[s(t+1)-p_{1}(t+1)\right]+0.5 \operatorname{Var}_{t}[s(t+1)]+0.5 \operatorname{Var}_{t}\left[p_{1}(t+\right.$ $1)]-\operatorname{Cov}_{t}\left[s(t+1), p_{1}(t+1)\right]=E_{t}\left[f(t)-p_{1}(t+1)\right]+0.5 \operatorname{Var}_{t}\left[p_{1}(t+1)\right]$, from which equation $(2.15)$ follows.

${ }^{8}$ See McCulloch (1975), Cumby (1988) and Bekaert and Hodrick (1992). 


\subsubsection{Deviations from UIP}

In a recent survey article Engel (1996) distinguishes two empirical puzzles with regard to UIP. First, empirical studies that regress the logarithmic exchange rate depreciation $s(t+1)-s(t)$ on a constant and the logarithmic forward premium $f(t+1)-s(t)$ find that the slope coefficient is significantly different from unity, which implies that the forward rate is a biased predictor of future spot changes. Second, the variability of the spot exchange rate change is relatively large compared to the variability of the forward premium. The poor predictive power of the forward premium and the high variability of the spot exchange rate change are confirmed in figure 2.2 , where the exchange rate change and the forward premium against the US dollar are plotted for France, Germany, the Netherlands and the United Kingdom respectively. ${ }^{9}$

Several theoretical models have been developed to solve these puzzling apparent anomalies. ${ }^{10}$ The most popular alternative to UIP is an asset pricing model with risk-averse investors. The starting point of these models is the no-arbitrage first-order condition:

$$
\mathrm{E}_{t}\left[Q(t+1) H_{j}(t+1)\right]=1
$$

where $Q(t+1)$ is referred to as a pricing kernel and $H_{j}(t+1)$ is the return on the $j$-th asset. In the intertemporal utility maximization model of Lucas (1982) the pricing kernel turns out to be the marginal rate of substitution:

$$
Q(t+1)=\left(M(t+1) \frac{P(t)}{P(t+1)}\right),
$$

where $M(t+1)=U_{c}(t+1) / U_{c}(t)$ is the marginal rate of substitution of consumption and $U_{c}$ is marginal utility. The return on a covered investment is $F(t) / S(t)$ and the return on an uncovered investment is $S(t+1) / S(t)$. The no-arbitrage condition for pricing the forward premium $f p(t+1)=\frac{F(t)-S(t+1)}{S(t)}$ now becomes:

$$
\mathrm{E}_{t}[Q(t+1) f p(t+1)]=0
$$

which can be rewritten as:

$$
\mathrm{E}_{t}[f p(t+1)]=\operatorname{Cov}_{t}[Q(t+1), f p(t+1)] / \mathrm{E}_{t}[Q(t+1)]=\operatorname{Cov}_{t}[Q(t+1), f p(t+1)] / R(t),
$$

where the last equality uses the fact that for the riskfree rate $R(t)$ the no-arbitrage condition implies:

$$
R(t)=1 / \mathrm{E}_{t}[Q(t+1)]
$$

9 The sample frequency is quarterly. See chapter 4 for a description of the data.

${ }^{10}$ Henderson and Sampson (1983) note that the validity of UIP has been a central issue in the policy debate over the effectiveness of official intervention in exchange markets. To the extent that UIP is valid, official intervention could not be viewed as providing the authorities with an effective policy instrument in addition to interest rates. 
France

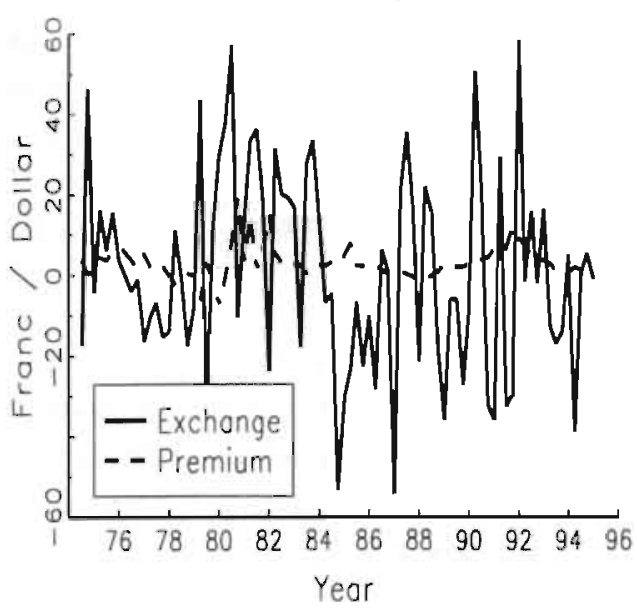

Netherlands

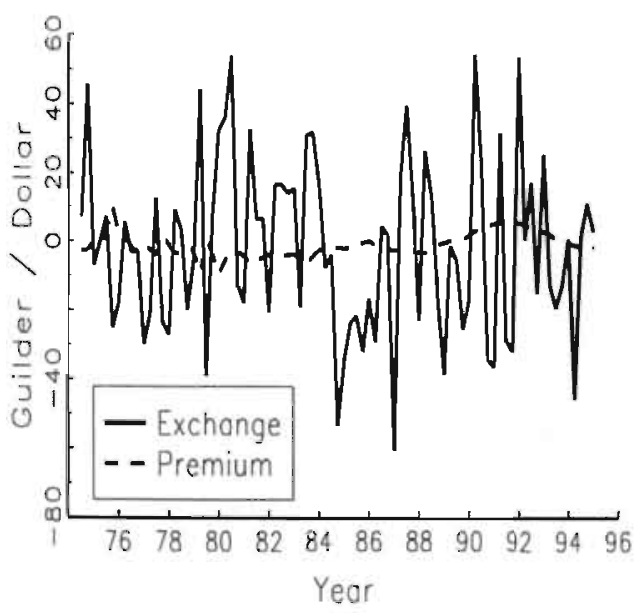

Germany

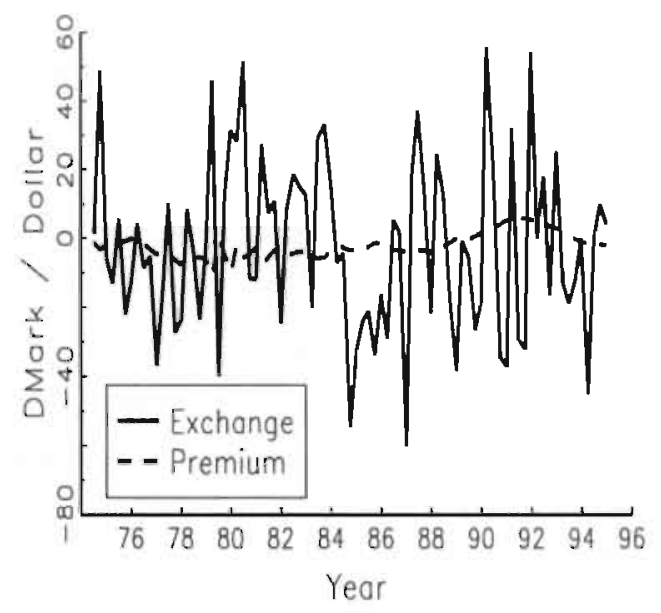

United Kingdom

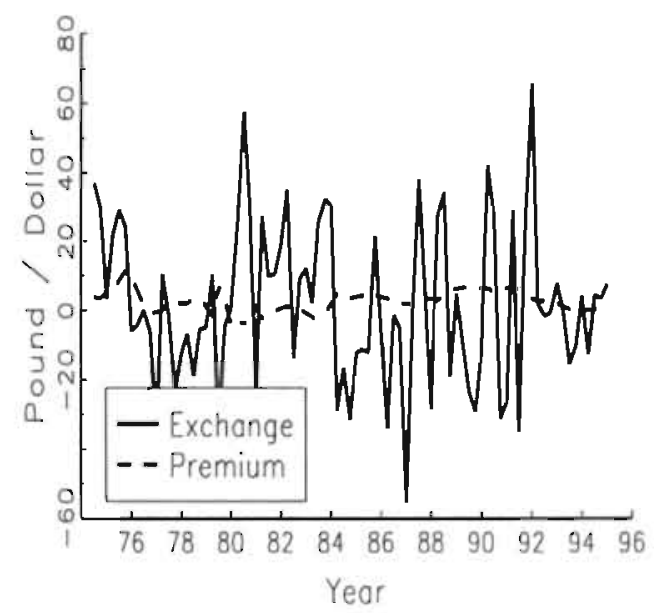

Figure 2.2: Exchange Rate Changes and Forward. Premiums 
Using equation (2.17) for an investor with constant relative risk aversion and assuming log-normally distributed returns, the first-order condition becomes: ${ }^{11}$

$$
\mathrm{E}_{t}[s(t+1)]-f(t)+0.5 \operatorname{Var}_{t}[s(t+1)]-\operatorname{Cov}_{t}[s(t+1), p(t+1)]=\eta \operatorname{Cov}_{t}[s(t+1), c(t+1)],
$$

where the variables in small letters are the logs of the variables in capital letters and where $\eta$ is the risk aversion parameter. This expression is different from the risk neutral case in that the risk premium $\eta \operatorname{Cov}_{t}[s(t+1), c(t+1)]$ now enters the equation. In practice, for plausible values of risk aversion the model is unable to generate the variability in deviations from UIP that is observed in the data (see Engel (1996)), because consumption is too smooth. This problem is closely related to the equity premium puzzle of Mehra and Prescott (1985) in stock returns.

Adler and Dumas (1983) derive a continuous time UIP relation under risk aversion, using the fact that total consumption for an investor of a country can be expressed in terms of the country's total wealth and its aggregate price level. The risk premium depends on the covariance of the exchange rate change with the return on the optimal portfolio held by the investor of this country. If, on the one hand, PPP holds, the deviation from UIP takes the following form:

$$
\mathrm{E}[s]-f=(1-\eta) \operatorname{Cov}\left[\Delta s, \pi_{1}\right]+\eta \operatorname{Cov}\left[\Delta s, R_{m}\right],
$$

where $R_{m}$ is the return on the optimal portfolio. If PPP does not hold, the model in equation (2.22) also contains the covariances between the exchange rate and the inflation rates of all foreign countries. In chapter 6 we will turn to this model.

Another explanation (see Lewis (1995)) for deviations from UIP is that systematic forecast errors can produce a negative correlation between the spot change and the forward premium. There are at least two reasons for systematic, but rational, forecast errors. The first reason is the so-called peso-problem that gets its name from the behavior of the Mexican peso prior to its devaluation in 1976. Peso-problems arise when discrete shifts in regimes are expected but not realized in a particular sample period. A second explanation for systematic forecast errors is that market participants may be learning about regime changes that have occurred.

Lewis (1995) clearly describes the interaction of deviations from UIP due to risk premiums and systematic forecast errors as:

Examining each of these explanations in isolation might lead to the conclusion that predictable excess returns remain a complete mystery. However, each of

${ }^{11}$ See for example Hansen and Hodrick (1983) for a closely related formulation. 
these explanations have ignored the other explanations. It seems likely that if there are shift in regimes, then anticipations of these shifts will affect the market's assessment of risk and therefore the foreign exchange risk premium. Heterogeneous views towards this risk may be compounded into an aggregate measure of the risk premium that exceeds the measures in conventional studies. Thus, a difficult but important direction for future research will be to integrate the various explanations for the behaviour of excess returns. (Lewis, 1995, p. 1950.)

Alternatively, explanations for the rejection of the unbiasedness hypothesis are market inefficiencies (Bilson (1981)), transaction costs (Baldwin (1990)) and government intervention (McCallum (1994)).

The models discussed so far are partial equilibrium models in that they take the stochastic process of exchange rates and prices as given. A full equilibrium model relates those processes explicitly to monetary and fiscal policy intervention, the behavior of firms and transaction costs. Dumas (1994a) and Engel (1996) review the literature on general equilibrium models. They conclude that none of the general equilibrium models can explain the large negative correlation between the spot change and the forward premium.

\subsection{Fisher Parity}

In a theory generally attributed to Fisher (1930) nominal interest rates should compensate an investor for his required real rate of return and changes in the purchasing power of money. Under uncertainty Fisher (1930) replaces the known change in the purchasing power of money with expected inflation. Under certainty the change of the purchasing power of money is equal to the rate of inflation, whereas under uncertainty we get $1 / \mathrm{E}[P(t) / P(t+1)]$ which is not equal to expected inflation $\mathrm{E}[P(t+1) / P(t)]$ because of Jensen's inequality. This observation is closely related to the Siegel paradox of UIP.

Under risk neutrality and lognormality, equations (2.17) and (2.20) can now be solved to obtain:

$$
r(t)=g+\mathrm{E}_{t}[\pi(t+1)]-0.5 \operatorname{Var}_{t}[\pi(t+1)]
$$

where $r(t)=\ln [R(t)], \pi(t+1)=\ln [P(t+1) / P(t)]$ and $g$ is a constant real rate. ${ }^{12}$ The nominal interest rate depends on the growth rate of the price level and its variability. ${ }^{13}$ However,

\footnotetext{
${ }^{12}$ Sercu and Uppal (1995) note that risk neutrality implies nonstochastic marginal utility. If expected marginal utility is constant the real rate also is constant.

${ }^{13}$ For small price changes the growth rate of the price level is approximately equal to the rate of inflation.
} 
Another explanation advocated by Lucas (1990) is that deviations from the Fisher parity are the result of systematic forecast errors:

I would attribute all the remaining difference in the nominal rates, and most of the year-to-year changes in these rates to changes in expected inflation rates. Throughout most of the 1970s, I think people in the OECD countries expected inflation rates to be reduced to earlier levels; throughout most of the 1980s, they expected high inflation to resume. After the fact these beliefs were proven wrong and for many years they were less accurate than extrapolations based on inflation rates in the recent past would have been. The alternative view within the Fisherian framework is that people repeatedly underestimated real returns on capital throughout the 1970s and then repeatedly overestimated real returns through the 1980s. (Lucas, 1990, p. 73.)

This view is related to the rational learning explanation for systematic forecast errors in exchange rate expectations. Alternatively, Evans and Lewis (1995b) give a peso-type explanation in that they argue that people incorporate anticipated shifts in the inflation process into their expectations.

\subsection{The Interrelationship of the Parity Hypotheses}

The traditional derivation of PPP is based on goods market arbitrage. Roll (1979) argued that alternatively an efficient markets version of PPP may be derived from asset market conditions. If we drop the second moments that arise from uncertain exchange rates and inflation, UIP and the Fisher Parity for country $k=(1,2)$ can be written respectively as:

$$
\mathrm{E}_{t}[s(t+1)]-s(t)=r_{1}(t)-r_{2}(t),
$$

and

$$
r_{k}(t)=g_{k}(t)+\mathrm{E}_{t}\left[\pi_{k}(t+1)\right] .
$$

If, on the one hand, the marginal intertemporal tastes for the goods of the two countries are identical, the real interest rates are equal across countries and we can combine equations (2.24) and (2.25) to obtain the expected form of relative PPP:

$$
\mathrm{E}_{t}[s(t+1)]-s(t)=\mathrm{E}_{t}\left[\pi_{1}(t+1)\right]-\mathrm{E}_{t}\left[\pi_{2}(t+1)\right],
$$

which implies under rational expectations that deviations from real PPP are random. Because each of the three hypotheses in equations (2.24) to (2.26) can be derived from the other two, any condition must be correct if the other two are correct. 
If, on the other hand, the marginal intertemporal tastes for the goods of the two countries are not identical and UIP holds, the deviation from real interest parity:

$$
\left.g_{\mathbf{1}}(t)-g_{2}(t)=\mathrm{E}_{t}[s(t+1)]-s(t)-\mathrm{E}_{t}\left[\pi_{\mathbf{1}}(t+1)\right]-\pi_{\mathbf{2}}(t+1)\right],
$$

is equal to the deviation from relative PPP. This is related to the Adler and Dumas (1983) model where deviations from PPP cause investors in different countries to evaluate the returns from the same security differently. Real interest parity only holds if both UIP and PPP hold simultaneously. ${ }^{16}$ Engle (1996) argues that there is no point in decomposing failures of UIP into failures of PPP and failures of real interest parity, because there is no independent interpretation of.failures of real interest parity.

In this chapter we considered the theoretical foundations of three fundamental parity hypotheses: PPP, UIP and Fisher Parity. These three parity hypotheses have generated an enormous amount of empirical research. The general conclusion that emerges from this research is that there are substantial short-run deviations from all three parities. The graphs in this chapter provide preliminary evidence for this conclusion. Explanations for deviations from the parities are risk premiums, systematic forecast errors and transaction costs. In the next three chapters we will take a closer look at the parity hypotheses and their deviations.

${ }^{16}$ Real interest parity is often referred to as the international Fisher relation. 
Chapter 2 


\section{Chapter 3}

\section{PPP and Real Expenditure: A Multicountry Panel Investigation}

The theory of purchasing power parity (PPP) is of central importance to many models in international economics. While PPP was refuted many times in the late seventies and early eighties, there is growing evidence which indicates that PPP may hold in the longrun. Important studies in this vein are Abuaf and Jorion (1990), who use a multivariate time series analysis, and Frankel and Rose (1995), who employ panel data techniques.

In a recent study Sercu, Uppal and Van Hulle (1995) (SUV) consider a one good economy that consists of two counties that are populated with identical consumers with hornothetic preferences. SUV show that traditional tests of PPP are affected by the presence of transaction costs to international and make clear that due to transaction costs the regression coefficients in regressions of the change in the exchange rate on the inflation differential will be less than unity. In a follow-up study, Sercu and Uppal (1995) (SU) have generalized this model to allow for many goods, many countries and nonidentical consumers across countries with nonhomothetic preferences. They show that the exchange rate change consists of a risk-aversion weighted differential growth in nominal spending deflated by the total-consumption weighted inflation rate plus the 'marginal' inflation differential.

In this chapter we empirically test the model put forward by SUV and SU which includes real expenditures, using quarterly observations between 1973 and 1993 for the following sixteen countries: Australia, Austria, Canada, Finland, France, Germany, Italy, Japan, the Netherlands, Norway, South Africa, Spain, Sweden, Switzerland, the United Kingdom and the United States. We perform pooled tests for both the absolute as well as 
the relative version of the $\mathrm{SU}$ model. In these two dimensions the implications take the form of extensions of the traditional PPP regressions that relate nominal exchange rate changes to the inflation differential. Additional variables in the regressions that proxy for real expenditures are growth rates of real consumption, real gross national product and real industrial production. Furthermore, we consider a measure of tradable good prices. The sixteen countries are considered as a system and we impose restrictions that make parameter estimates invariant to the choice of the numeraire currency.

The plan of this chapter is as follows. Section 3.1 contains a description of the theoretical models. Section 3.2 describes the data. Section 3.3 considers panel tests for relative PPP and section 3.4 focuses on the pooled time series tests. Section 3.5 contains some concluding remarks.

\subsection{Theoretical Models}

The theory of PPP is one of the oldest and most fundamental theories of exchange rate determination. The traditional building block underlying PPP is the law of one price (LOP), that is perfect commodity arbitrage of individual goods between two countries. In the absence of any barriers to trade commodity arbitrage ensures identical prices of commodities expressed in the same currency across countries. If the LOP holds for all individual good, then it will also hold for any identical baskets of traded goods, which is often referred to as the absolute version of PPP. ${ }^{1}$

The general framework for empirical tests of absolute PPP is not to compare identical baskets of traded goods, but consumer price indices. This absolute consumption-based PPP relates the logarithm of the exchange rate between currencies $i$ and $j$ to the logarithm of the consumer price indices in countries $i$ and $j$ :

$$
s_{i j}(t)=\theta_{i j}+\theta_{i} p_{i}(t)-\theta_{j} p_{j}(t)+u_{i j}(t),
$$

where $s_{i j}$ is the logarithm of the nominal exchange rate and $p_{i}$ denotes the logarithm of the consumer price index for country $i$. Absolute consumption-based PPP is said to hold in the long-run if the following three conditions are fulfilled (i) $\theta_{i}=\theta_{j}$ (symmetry) (ii) $\theta_{i}=\theta_{j}=1$ (proportionality) and (iii) the error term $u_{i j}(t)$ is stationary. Most empirical tests simply impose that the first two conditions hold. Under these restrictions the null hypothesis to be tested is that the real exchange rate: $q_{i j}(t)=s_{i j}(t)-p_{i}(t)+p_{j}(t)$, contains a unit root, against the alternative hypothesis that the real exchange rate is stationary. The first as

\footnotetext{
${ }^{1}$ See section 2.1 for an exposition on the theoretical foundations of PPP.
} 
well as the second condition are often rejected, particularly for US dollar (USD) bilateral exchange rates.

A number of researchers (Roll (1979) and Adler and Lehmann (1983)) tested the hypothesis that the real exchange rate contains a unit root and are unable to reject this hypothesis. If true, the random walk has the disturbing implication that there is no tendency for PPP to hold. In the past few years, however, a number of studies have appeared which all indicated that PPP still holds in the long-run (see Abuaf and Jorion (1990), Diebold and Nason (1990), Koedijk and Schotman (1990) and Schotman and Van Dijk (1991)).

The relative version of PPP requires that the percentage change in the bilateral exchange rate equals the inflation differential between the domestic and foreign country. Taking first differences of equation (3.1), relative consumption-based PPP becomes:

$$
\Delta s_{i j}(t)=\theta_{i} \pi_{i}(t)-\theta_{j} \pi_{j}(t)+\Delta u_{i j}(t)
$$

where $\Delta$ denotes the first-difference operator and where $\pi$ is the growth rate of the price level. Both the absolute as well as the relative version of consumption-based PPP have extensively been tested for many countries and different sample periods. Froot and Rogoff (1995) provide an excellent overview of the empirical literature.

Recently, the debate on PPP did get new empirical and theoretical stimuli. In their empirical studies Rose (1994) and Mark (1995) argue that real exchange rates depend on macroeconomic fundamentals. SUV, moreover, conveyed a theoretical impulse by investigating the exchange rate behavior in the presence of transaction costs for trading a single good in an economy that consists of two countries that are populated with identical consumers. The consumers have a constant relative risk aversion utility function, which implies that preferences are homothetic. SUV show that the nominal exchange rate moves within a band around the nominal PPP value in a two country one good economy. and that imbalances between marginal utilities are not equalized across countries. ${ }^{2}$ This implies that the real exchange rate depends on the ratio of the two countries' real consumption, which is equal to the ratio of their real money supply due to a cash-in-advance constraint. The transaction cost argument also explains why in typical exchange rate equations, like equation (3.2), the regression coefficients will be less than one. SUV note:

One implication of our analysis is that, if money supply effects are controlled for, the elasticity of the exchange rate with respect to the relative prices of tradable goods is below unity. (Sercu, Uppal and Van Hulle, 1995, p. 1318.)

${ }^{2}$ Other studies that examine the implications of transaction costs on deviations from PPP include Benninga and Protopapadakis (1988), Dumas (1992) and Uppal (1992). 
In a follow-up study SU generalize these results for an economy with $M$ countries and $N$ goods. Furthermore, they assume that, consumers are not identical across countries and have nonhomothetic preferences.

SU show that the exchange rate change consists of the risk aversion weighted differential growth in nominal expenditures deflated using the total-consumption weighted inflation rate, plus the 'marginal' inflation differential:

$$
\Delta s_{i j}(t)=\tilde{\pi}_{i}(t)-\tilde{\pi}_{j}(t)+\eta_{i}(t)\left(\Delta c_{i}-\pi_{i}\right)(t)-\eta_{j}(t)\left(\Delta c_{j}-\pi_{j}\right)(t)
$$

where $\Delta c_{i}, \pi_{i}$ and $\tilde{\pi}_{i}$ denote respectively the growth of nominal consumption expenditures, inflation weighted on the basis of total consumption and inflation weighted on the basis of marginal consumption for country $i$ and where $\eta_{i}(t)$ is a relative risk aversion parameter for country $i$.

$\mathrm{SU}$ argue that it is generally impossible to obtain closed-form solutions for the nominal exchange rate level if preferences are nonhomothetic. However, if the utility function exhibits constant relative risk aversion, preferences are homothetic and the nominal exchange rate becomes:

$$
s_{i j}(t)=\theta_{i j}+p_{i}(t)-\tilde{p}_{j}(t)+\eta_{i} y_{i}(t)-\eta_{j} y_{j}(t),
$$

where $y_{i}=c_{i}-p_{i}$ denotes the logarithm of real consumption expenditures and $\eta_{i}$ is the constant relative risk aversion parameter for country $i$. The constant $\theta_{i j}$ depends both on the relative wealth of the countries and the relative risk aversion parameter. Absolute PPP arises under risk neutrality when $\eta_{i}=\eta_{j}=0$. Another special interest is the case $\eta_{i}=\eta_{j}=1$, which is closely related to the model developed by Stulz (1987).

As a further extension it is possible to write the general price level as the weighted average of tradable and nontradable good prices as follows: $p_{k}(t)=\kappa p_{k}^{T}(t)+(1-\kappa) p_{k}^{N T}(t)$ for $k=(i, j)$, where the superscript ' $T$ 'refers to tradable and ' $N T^{\prime}$ ' to nontradable. If we substitute the price level by this expression, equation (3.4) becomes:

$$
s_{i j}(t)=\theta_{i j}+\kappa\left(p_{i}^{T}-p_{j}^{T}\right)(t)+(1-\kappa)\left(p_{i}^{N T}-p_{j}^{N T}\right)(t)+\eta_{i} y_{i}(t)-\eta_{j} y_{j}(t) .
$$

The cases of special interest considered by SU are: (i) exclude nontradable $(\kappa=1)$ and (ii) identical relative risk aversion $\left(\eta_{i}=\eta_{j}=\eta\right)$. 


\subsection{Data}

\subsubsection{Sources}

This study uses quarterly data which cover a period of twenty years (1973:1-1993:2). Nominal exchange rates, consumer prices and real expenditures have been collected for sixteen countries: Australia, Austria, Canada, Finland, France, Germany, Italy, Japan, the Netherlands, Norway, South Africa, Spain, Sweden, Switzerland, United Kingdom and the United States.

The nominal exchange rate, the consumer price index (CPI) and the wholesale price index (WPI) are available from the International Financial Statistics (IFS) tape (respectively line ae, line 64 and line 63). The WPI is not available for France and Switzerland.

Quarterly consumption data are not available for the Netherlands. Therefore, the panel tests are based on real income data. Real income data (constant prices) are obtained from the IFS tape except for the Netherlands. As the IFS tape does not contain Dutch income data prior to 1977. Therefore we use data from 'De Nederlandsche Bank'. Real income is measured by real gross national product (GNP) for Germany and Japan and by real gross domestic product (GDP) for the remaining countries (line 99). Real income data are seasonally adjusted except for Finland, Norway and Sweden. ${ }^{3}$

We also obtained nominal consumption data for all countries except the Netherlands from the IFS tape (line 96). We calculated real consumption (CNS) by adjusting these series for inflation measured by the consumer price index. Finally, we obtained nominal industrial production data from the IFS tape (line 66). Industrial production data are not available for South Africa and Switzerland. Again, we calculate real industrial production (IP) by adjusting these series for inflation measured by the consumer price index. Note, however, that industrial production is a noisy proxy for total expenditures.

\subsubsection{Summary Statistics}

All series are converted to logarithms. Real exchange rates against the dollar are constructed as $s_{i j}-p_{i}+p_{j}$, where $s_{i j}$ is the logarithm of the nominal exchange rate, $p_{i}$ denotes the logarithm of the consumer price index and $p_{j}$ denotes the logarithm of consumer price

${ }^{3}$ The Census-X11 method was applied in order to remove the seasonality in these series. 
TABlE 3.1: Augmented Dickey-Fuller Tests

\begin{tabular}{l|cccc|cccc}
\hline & \multicolumn{3}{|c|}{$\tau_{\mu}$} & \multicolumn{4}{c}{$\tau_{\tau}$} \\
\hline & $s$ & $p$ & $y$ & $q$ & $s$ & $p$ & $y$ & $q$ \\
\hline Australia & -1.06 & $-2.96^{\dagger}$ & -0.26 & -1.45 & -2.10 & 0.17 & -2.46 & -2.09 \\
Austria & -1.62 & -1.84 & -0.36 & -2.11 & -2.25 & -1.66 & -1.69 & -2.12 \\
Canada & -1.98 & -1.94 & -0.91 & -2.26 & -2.13 & -0.39 & -3.45 & -2.33 \\
Finland & -2.49 & -2.84 & -1.44 & -2.80 & -2.83 & -1.09 & -1.76 & -2.75 \\
France & -2.02 & -1.45 & -1.90 & -2.15 & -2.01 & -0.83 & -2.90 & -2.10 \\
Germany & -1.78 & -0.81 & -0.88 & -2.13 & -2.34 & -2.00 & -2.42 & -2.06 \\
Italy & -1.81 & -1.59 & -1.72 & -2.02 & -2.21 & -0.67 & -2.25 & -2.30 \\
Japan & -0.32 & $-3.32^{\dagger}$ & -1.51 & -1.12 & -2.14 & -3.36 & -1.80 & -1.99 \\
Netherlands & -1.85 & -1.98 & -0.24 & -2.07 & -2.20 & -1.82 & -2.10 & -2.08 \\
Norway & -1.80 & -2.40 & -2.05 & -2.25 & -2.17 & 0.74 & -2.58 & -2.21 \\
South Africa & -0.13 & 1.46 & -1.85 & -1.80 & -1.75 & -3.04 & -1.48 & -1.90 \\
Spain & -1.81 & $-4.37^{\dagger}$ & -0.73 & -2.31 & -2.18 & -1.09 & -3.18 & -2.30 \\
Sweden & -1.77 & -2.47 & -1.15 & -2.40 & -2.75 & -1.11 & -2.00 & -2.65 \\
Switzerland & -1.68 & 0.59 & -0.62 & -2.11 & -2.45 & -2.74 & -2.44 & -2.20 \\
United Kingdom & -2.62 & $-3.18^{\dagger}$ & -1.04 & -2.81 & -3.31 & -2.38 & -2.87 & -2.80 \\
United States & - & -1.45 & -0.83 & - & - & -1.27 & -2.99 & - \\
\hline
\end{tabular}

Notes: $s, p, y, q$ denote respectively the logarithm of the nominal exchange rate, the logarithm of the consumer price index, the logarithm of real gross domestic or national product and the logarithm of the real exchange rate. $\tau_{\mu}$ is the standard augmented Dickey-Fuller statistic and $\tau_{r}$ is the augmented Dickey-Fuller statistic with trend. ${ }^{\dagger}$ denotes rejection at the $5 \%$ level.

index for the United States. Table 3.1 gives augmented Dickey-Fuller statistics. We can see from the table that, as usual, the hypothesis of nonstationarity can never be rejected for real GDP or GNP, the nominal exchange rate and the real exchange rate. For the consumer price index the nonstationarity hypothesis cannot be rejected in almost all cases. Table 3.2 gives means and standard deviations for the first differences of the series that are available for all sixteen countries. Average annualized exchange rate changes range from $+7.66 \%$ (depreciation) for South Africa to $-4.50 \%$ (appreciation) for Japan. From the table we also see that average inflation rates are relatively high in counties with depreciating currencies. The cross-sectional dispersion for average real exchange rate changes, therefore, is much smaller than for nominal exchange rate changes. For Japan the appreciation of the real exchange rate is relatively large. Finally, the table shows that the average real growth rate of GDP or GNP ranges from $1.15 \%$ for Switzerland to $3.55 \%$ for Japan. 
TABL.E. 3.2: Summary Statistics

\begin{tabular}{l|cccc|cccc}
\hline \hline & \multicolumn{4}{|c|}{ Mean } & \multicolumn{4}{c}{ StDv } \\
\hline & $\Delta s$ & $\pi$ & $\Delta y$ & $\Delta q$ & $\Delta s$ & $\pi$ & $\Delta y$ & $\Delta q$ \\
\hline Australia & 3.68 & 8.26 & 2.82 & 1.41 & 18.88 & 4.70 & 5.06 & 18.84 \\
Austria & -2.72 & 4.44 & 2.43 & -1.19 & 26.12 & 3.37 & 5.60 & 25.99 \\
Canada & 1.23 & 6.53 & 2.10 & 0.67 & 8.42 & 3.42 & 4.57 & 8.51 \\
Finland & 1.88 & 7.99 & 1.57 & -0.13 & 20.82 & 4.77 & 9.47 & 20.45 \\
France & 1.11 & 7.20 & 2.04 & -0.11 & 25.50 & 4.15 & 2.88 & 24.87 \\
Germany & -2.57 & 3.54 & 1.95 & -0.13 & 26.90 & 2.52 & 4.27 & 26.81 \\
Italy & 4.81 & 11.01 & 2.64 & -0.22 & 24.67 & 6.08 & 3.81 & 24.00 \\
Japan & -4.50 & 4.78 & 3.56 & -3.30 & 23.75 & 6.02 & 3.23 & 24.59 \\
Netherlands & -2.18 & 4.17 & 1.99 & -0.37 & 26.29 & 3.55 & 6.77 & 26.72 \\
Norway & 0.94 & 7.15 & 3.21 & -0.22 & 21.98 & 3.85 & 10.98 & 22.00 \\
South Africa & 7.66 & 12.65 & 1.80 & 0.99 & 27.75 & 3.59 & 4.48 & 28.43 \\
Spain & 3.91 & 11.14 & 2.40 & -1.13 & 23.73 & 6.10 & 2.19 & 23.16 \\
Sweden & 2.66 & 7.91 & 1.41 & 0.74 & 24.95 & 4.38 & 9.38 & 24.31 \\
Switzerland & -3.77 & 3.80 & 1.15 & -1.58 & 29.49 & 3.25 & 5.24 & 29.31 \\
United Kingdom & 2.45 & 8.98 & 1.56 & -0.56 & 23.66 & 7.10 & 4.30 & 24.01 \\
United States & - & 5.98 & 2.22 & - & - & 3.44 & 3.89 & - \\
\hline Notes: $\Delta s, \pi, \Delta y$ and $\Delta q$ denote respectively first difference of the logarithm of the \\
nominal exchange rate, the first difference of the logarithm of the consumer price index, \\
the first difference of the logarithm of real gross domestic or national product and the \\
first difference of the logarithm of the real exchange rate. Units are percent per annum. \\
\hline \hline
\end{tabular}

\subsection{Pooled Tests on Relative PPP}

\subsubsection{Specification}

Our first empirical tests focus on the cross-sectional implications of relative PPP and the extended model proposed by SU. The advantage of cross-sectional tests is that the econometric inference is not affected by time series issues like unit roots and cointegration. Suppose we have a sample of $N+1$ currencies/countries numbered $i=0,1, \ldots, N$.

We now assume that the marginal-consumption weighted inflation rate in equation (3.3) is equal to the total-consumption weighted inflation rate. The empirical counterpart to the SU model becomes:

$$
\Delta s_{i j}(t)=\theta_{i}(t) \pi_{i}(t)-\theta_{j}(t) \pi_{j}(t)+\eta_{i}(t) \Delta y_{i}(t)-\eta_{j}(t) \Delta y_{j}(t)+\psi_{i j}(t),
$$

where $\Delta y_{i}$ is the growth rate of real expenditure in country $i$.

In a single period cross-section we cannot identify separate risk aversion coefficients for 
each country, so that we need to impose the restriction $\eta_{i}(t)=\eta_{j}(t)=\eta(t)$. For the same reason $\theta_{i}(t)=\theta_{j}(t)=\theta(t)$. However, in a cross-sectional regression the parameters can be different for every time period $t$, so that we do not need to assume that the utility function exhibits constant relative risk aversion. Alternatively, if we assume that the risk aversion parameters are constant over time, we can estimate country specific slope coefficients.

Now assume that we pool equation (3.6) over countries as well as over time, that is $\eta_{i}(t)=$ $\eta_{j}(t)=\eta$ and $\theta_{i}(t)=\theta_{j}(t)=\theta$. With these identifying restrictions equation (3.6) becomes:

$$
\Delta s_{i j}(t)=\theta\left(\pi_{i}-\pi_{j}\right)(t)+\eta\left(\Delta y_{i}-\Delta y_{j}\right)(t)+\psi_{i j}(t) .
$$

The testable implication of the SU model is that $\theta=1$ and $\eta>0$. For the actual estimation of equation (3.7) we only need data relative to one particular numeraire currency, say currency 0 . Simply subtracting the equations for currencies $\Delta s_{i 0}$ and $\Delta s_{j 0}$ yields the implied regression model for the cross exchange rate $\Delta s_{i j}$, which automatically has explanatory variables $\left(\Delta y_{i}-\Delta y_{j}\right)(t)$ and $\left(\pi_{i}-\pi_{j}\right)(t)$.

Since all data in the regression are expressed in the same numeraire currency 0 , the error trrms $\psi_{i 0}(t),(i=1, \ldots, N)$ are likely to be positively correlated due to the strong common numeraire effect. This implies that the cross-sectional ordinary least squares (OLS) estimator is consistent (as $N \rightarrow \infty$ ), but not efficient and that the standard errors are incorrect. Efficient estimates can be obtained by applying generalized least squares (GLS), which requires assumptions about the error terms $\psi_{i 0}(t)$. As a model for the cross-sectional dependence we assume the decomposition of Mahieu and Schotman (1994):

$$
\psi_{i j}(t)=\psi_{i}(t)-\psi_{j}(t)
$$

with

$$
\psi_{i}(t)=w(t)+e_{i}(t)
$$

The decomposition states that the error term in the exchange rate equation is the difference between an error term $\psi_{i}(i)$ for country $i$ and one for country $j$. The error term $\psi_{i}(t)$ is itself the sum of a worldwide systematic shock $u(t)$ and a country specific shock $e_{i}(t)$. In the panel literature this specification is referred to as the so-called random time effects model (see Baltagi (1995)). ${ }^{4}$ We assume that the country specific shocks are mutually uncorrelated and have a common variance $\frac{1}{2} \sigma^{2}$. The systematic component $w$ drops out in the relative shock $\psi_{i j}$. Under these assumptions the covariance matrix for the vector $\psi_{0}=\left(\psi_{10}, \ldots, \psi_{N 0}\right)^{\prime}$ takes the form:

$$
\Sigma=\frac{1}{2} \sigma^{2}\left(\boldsymbol{I}+\iota \iota^{\prime}\right),
$$

\footnotetext{
${ }^{4}$ In chapter 4 we consider a more general specification of the error term.
} 
with $I$ the $(N \times N)$ identity matrix and $\iota$ the $(N \times 1)$ vector of ones. This covariance structure imposes that all exchange rates have equal variance and that the correlation between exchange rate changes is $\frac{1}{2}$. Since $\Sigma$ is completely specified, the GLS estimator is directly applicable.

To see how the GLS estimator works in this model, note that the covariance structure (3.9) is equivalent to a simple transformation of the data involving the effective exchange rate. Let $\Delta S_{0}(t)=\left(\Delta s_{10}(t), \ldots, \Delta s_{N 0}(t)\right)^{\prime}$ be the $(N \times 1)$ vector of first differences of logarithms of all bilateral exchange rates $j=1, \ldots, N$ against the common numeraire currency 0 let $\Pi_{0}=\left(\left(\pi_{1}-\pi_{0}\right), \ldots,\left(\pi_{N}-\pi_{0}\right)\right)^{\prime}$ be the $(N \times 1)$ vector of the first differences of the logarithms of all relative price indices and let $\Delta Y_{0}=\left(\Delta\left(y_{1}-y_{0}\right), \ldots, \Delta\left(y_{N}-y_{0}\right)\right)^{\prime}$ be the $(N \times 1)$ vector of the first differences of the logarithms of all relative real expenditures. In vector notation and suppressing the time $(t)$ the regression model (3.7) reads:

$$
\Delta S_{0}=\theta \Pi_{0}+\eta \Delta Y_{0}+U_{0}
$$

Transforming the vector error term $U_{0}$ to a new error term $\tilde{U}_{0}$ with covariance matrix $\sigma^{2} \boldsymbol{I}$ entails premultiplying (3.10) by some matrix $Q$ such that $Q Q^{\prime}=\Sigma^{-1}$. One such $Q$ is given by:

$$
Q=I-\left(1-\frac{1}{\sqrt{N+1}}\right) \frac{1}{N} \iota \iota^{\prime}
$$

Applying the transformation yields:

$$
\Delta \tilde{S}_{0}=Q \Delta S_{0}=\Delta S_{0}-w \Delta \bar{S}_{0},
$$

where $\Delta \bar{S}_{0}$ is a $(N \times 1)$ vector with elements $\frac{1}{N} \sum_{j=1}^{N} \Delta s_{j 0}$ the average exchange rate change of currency 0 against all other currencies, i.e. an equally weighted index of the effective exchange rate and $w=1-\frac{1}{\sqrt{N+1}}$. The transformation to relative prices is similar. The transformation takes all variables in deviation of their cross-sectional mean times a factor $w$ which is equal to $\frac{3}{4}$ for our cross-sectional sample with $N=15$. The effect of GLS is to take out the common numeraire factor. The transformed model can be estimated by OLS and will yield the same parameter estimates as GLS.

The covariance structure in equation (3.9) does not only deal with the positive crosssectional correlations, but it also ensures that all results are completely invariant with respect to the choice of the numeraire currency. Whether we express all exchange rates against the USD, the Japanese yen (JPY), the Deutschmark (DEM) or any other currency, the point estimates and $t$-statistics of all the parameters will be identical. ${ }^{5}$

A further issue in the cross-sectional tests is the length of the differencing interval in equation (3.6). With quarterly data the shortest differences are quarterly, but the model

\footnotetext{
${ }^{5}$ See Koedijk and Schotman (1990) for a proof.
} 
could just as well be tested over longer horizons, as in Lothian (1985). SU argue that in the standard relative PPP regression:

$$
\Delta_{k} s_{i j}(t)=\theta(k)\left(\pi_{i}-\pi_{j}\right)_{k}(t)+u_{i j}(t)
$$

with $k$ the $k$-th period difference, the slope coefficient $\theta(k)$ is expected to be less than unity on high frequency data but converges to unity for long horizon differences. This hypothesis can be tested by applying the cross-sectional GLS estimator for successively longer differences.

\subsubsection{Empirical Results}

Table 3.3 contains parameter estimates of $\theta$ and $\eta$. The cross-sectional parameter estimates are restricted to be equal for every country and every period. The first column shows results for the pure relative PPP regression with only the inflation differential as an explanatory variable. Since data are overlapping for longer differencing intervals, $k>1$, the standard errors have been computed by applying the Newey-West procedure that corrects for serial correlation both within and across countries. ${ }^{6}$ For differencing intervals of four quarters or more the parameter estimate of $\theta$ is never significantly different from one, indicating that relative PPP works well in these cross-sectional regressions.

The next two columns show results when real GNP or GDP are included in the regression as a proxy for real expenditures. The estimate of $\eta$ is not significantly different from zero for any horizon up to twelve quarters. ${ }^{7}$ On the other hand, the estimate of $\theta$ again increases to unity with the length of the differencing interval as predicted by SUV. The coefficient on the inflation differential stabilizes at unity after about four quarters, implying that the PPP hypothesis seems to hold for longer horizons.

To check for robustness of the results we estimated equation (3.7) with different measures for real expenditure and find that the results are very similar. The parameter estimates for $\left(\Delta_{k} y_{i}-\Delta_{k} y_{j}\right)$ are not significant, no matter how we measure real expenditure. One reason for these negative results could be the small cross-sectional sample size. However, the cross-section seems sufficiently informative to find a significant role for relative prices. ${ }^{8}$ The coefficient on $\left(\pi_{i}-\pi_{j}\right)_{k}$ always converges to unity for the long horizon regressions.

\footnotetext{
${ }^{6}$ See Newey and West (1987).

${ }^{7}$ Since the sample contains only 88 time series observations the standard error over longer horizons than $k=12$ rapidly increases.

${ }^{8}$ Another possible explanation is measurement errors in our proxies for real expenditures.
} 
TABLE 3.3: Parameter Estimates of PPP and Extensions

$$
\Delta_{k} s_{i j}(t)=\theta(k)\left(\pi_{i}-\pi_{j}\right)_{k}(t)+\eta(k)\left(\Delta_{k} y_{i}-\Delta_{k} y_{j}\right)(t)+\psi_{i j}(t) .
$$

\begin{tabular}{c|c|cc|cc|cc|cc}
\hline \hline & CPI & CPI & GNP & CPI & CNS & CPI & IP & CPI & $\begin{array}{c}\text { WPI/ } \\
\text { CPI }\end{array}$ \\
\hline$k$ & $\theta(k)$ & $\theta(k)$ & $\eta(k)$ & $\theta(k)$ & $\eta(k)$ & $\theta(k)$ & $\eta(k)$ & $\theta(k)$ & $\eta(k)$ \\
\hline 1 & 0.72 & 0.73 & 0.07 & 0.52 & -0.11 & 0.77 & 0.03 & 0.81 & 0.68 \\
& $(0.09)$ & $(0.09)$ & $(0.06)$ & $(0.44)$ & $(0.04)$ & $(0.09)$ & $(0.03)$ & $(0.07)$ & $(0.11)$ \\
4 & 0.98 & 0.98 & 0.09 & 0.95 & 0.06 & 0.96 & -0.21 & 0.99 & 1.15 \\
& $(0.18)$ & $(0.19)$ & $(0.36)$ & $(0.25)$ & $(0.09)$ & $(0.21)$ & $(0.37)$ & $(0.12)$ & $(0.15)$ \\
8 & 1.00 & 1.00 & -0.07 & 1.02 & 0.11 & 0.99 & -0.37 & 0.99 & 1.38 \\
& $(0.25)$ & $(0.23)$ & $(0.63)$ & $(0.44)$ & $(0.26)$ & $(0.28)$ & $(0.68)$ & $(0.13)$ & $(0.50)$ \\
12 & 1.02 & 1.02 & -0.08 & 1.06 & 0.14 & 1.02 & -0.37 & 1.03 & 1.49 \\
& $(0.33)$ & $(0.03)$ & $(0.92)$ & $(0.49)$ & $(0.36)$ & $(0.35)$ & $(0.91)$ & $(0.17)$ & $(0.64)$ \\
\hline
\end{tabular}

Notes: $k$ denotes the length of the differencing interval in quarters. The parameter estimates are based on the numeraire invariant covariance matrix. In parentheses are the standard errors of the parameter estimates computed by the Newey-West procedure.

As a final check we also included relative wholesale prices next to consumer prices. If PPP only holds for tradable goods prices and if wholesale prices are a good proxy for tradable goods prices then the nominal exchange rate would be mainly determined by relative wholesale prices. Table 3.3 shows that consumer prices become unimportant when wholesale prices are included in the regression.

We also test the restrictions imposed by the pooled numeraire-invariant model. ${ }^{9}$ In the first column of table 3.4 we test for the individual country effects while the second and third column contain the test statistics at different nonoverlapping horizons for the extent to which we can pool across countries and across time respectively. As can be seen from table 3.4 individual effects are never significant. On the one hand, poolability across countries, $\left(\eta_{i}=\eta_{j}=\eta\right.$ and $\left.\theta_{i}=\theta_{j}=\theta\right)$, is never rejected. On the other, hand pooling, across time, $(\eta(t)=\eta)$ and $\theta(t)=\theta$ ), restrictions are rejected for horizons shorter than three year.

Figure 3.1 provides a graphical summary of the main results. The figure shows GLS cross-sectional estimates $\hat{\theta}(k)$ and $\hat{\eta}(k)$ for increasing differencing intervals $k$, and a onestandard-error band. Figure 3.2 shows the relation between real price changes and exchange rate changes for four nonoverlapping periods of five year. ${ }^{10}$ The straight line is based on full sample panel estimates. The figure shows that countries with relatively high inflation

${ }^{9}$ See Baltagi (1995) for a description of tests for poolability.

${ }^{10} \mathrm{Al}, \mathrm{As}, \mathrm{Cn}, \mathrm{Fr}, \mathrm{Fr}, \mathrm{Gr}, \mathrm{It}, \mathrm{Jp}, \mathrm{Nt}, \mathrm{Nr}, \mathrm{Sr}, \mathrm{Sp}, \mathrm{Sd}, \mathrm{Sw}$, Uk denote Australia, Austria, Canada, Finland, France, Germany, Italy, Japan, the Netherlands, Norway, South Africa, Spain, Sweden, Switzerland and the United Kingdom respectively. 
TABLE 3.4: F-'Tests Poolability

\begin{tabular}{cccc}
\hline \hline$k$ & Zero Intercept & Country Specific Slope & Time Specific Slope \\
\hline 1 & $F_{1}(15,1184)=1.17$ & $F_{2}(15,1184)=0.85$ & $F_{3}(79,1120)=2.99$ \\
& $p=0.34$ & $p=0.62$ & $p=0.00$ \\
4 & $F_{1}(15,284)=0.40$ & $F_{2}(15,284)=0.36$ & $F_{3}(19,280)=2.63$ \\
& $p=0.97$ & $p=0.98$ & $p=0.00$ \\
8 & $F_{1}(15,134)=0.46$ & $F_{2}(15,134)=0.50$ & $F_{3}(9,140)=2.40$ \\
& $p=0.95$ & $p=0.93$ & $p=0.02$ \\
12 & $F_{1}(15,89)=0.53$ & $F_{2}(15,89)=0.57$ & $F_{3}(6,98)=2.45$ \\
& $p=0.91$ & $p=0.88$ & $p=0.03$ \\
16 & $F_{1}(15,59)=0.91$ & $F_{2}(15,59)=0.97$ & $F_{3}(4,70)=1.55$ \\
& $p=0.55$ & $p=0.50$ & $p=0.20$ \\
\hline
\end{tabular}

Notes: $k$ denotes the length of the differencing interval in quarters. $F_{1}$ tests for a zero intercept across countries, $F_{2}$ tests for an equal slope across countries and $F_{3}$ tests for an equal slope over time. $p$ denotes the $p$-value of the $F$-statistic with a $F(m, T-l)$ distribution.

tend to experience a depreciation of their currency. It is interesting to note that there is strong cross-sectional mean reversion. Countries that lie below the straight line in the first subperiod, lie above the straight line in the second subperiod and return to it in the third subperiod. In the last subperiod cross-sectional differences between inflation differences are relatively small. Figure 3.3 shows that when we account for relative price changes there is no relation between real exchange rate changes and output growth differentials.

The GLS estimator is closely related to the panel estimator with fixed time effects. ${ }^{11}$ For the panel estimator with fixed time effects $w$ in equation (3.12) is equal to one. Thus, when the number of countries increases the GLS estimator converges to the panel estimator with fixed time effects. Table 3.5 contains estimates of panels with fixed time effects, fixed individual effects and both fixed time effects and fixed individual effects. Of course, the results for the panel fixed time effects are very close to the GLS estimates. The individual effects account for any country specific effects that are not included in the regression. The individual effects reduce the coefficient of the inflation differential. The parameter of the inflation differential increases in all cases as the differencing interval increases and in all cases is not significantly different from one at the three year horizon.

${ }^{11}$ See Baltagi (1995) for an exposition on the panel model with fixed time effects. 


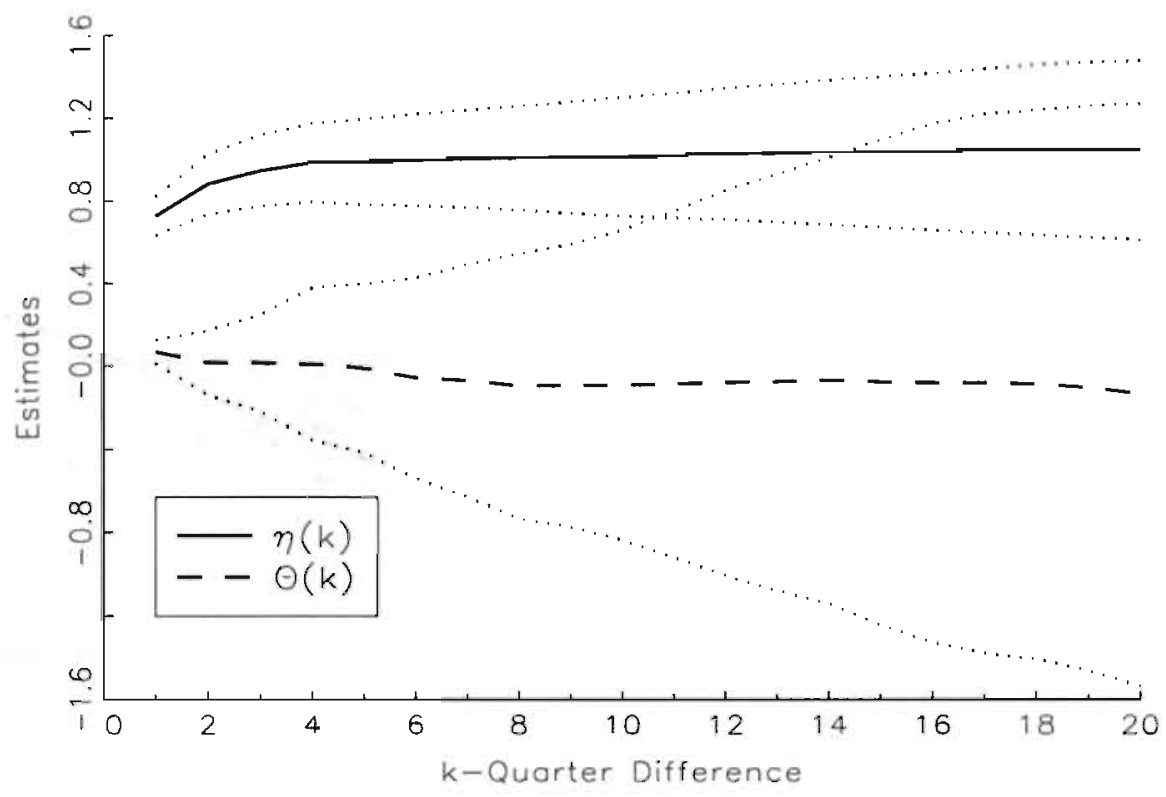

Figure 3.1: Estimates of $\theta(k), \eta(k)$ and One-Standard-Error Bands

TABle 3.5: Panel Fixed Effects

$\Delta_{k} s_{i j}(t)=\theta(k)\left(\pi_{i}-\pi_{j}\right)_{k}(t)+\eta(k)\left(\Delta_{k} y_{i}-\Delta_{k} y_{j}\right)(t)+\psi_{i j}(t)$.

\begin{tabular}{l|cc|cc|cc}
\hline \hline & \multicolumn{2}{|c|}{ Time Effects } & \multicolumn{2}{|c|}{ Indv Effects } & \multicolumn{2}{c}{ Both Effects } \\
\hline & CPI & GNP & CPI & GNP & CPI & GNP \\
\hline$k$ & $\theta(k)$ & $\eta(k)$ & $\hat{\theta}(k)$ & $\eta(k)$ & $\hat{\theta}(k)$ & $\eta(k)$ \\
\hline 1 & 0.73 & 0.10 & 0.56 & -0.21 & 0.50 & 0.09 \\
4 & 0.98 & 0.04 & 0.83 & -0.25 & 0.75 & 0.02 \\
8 & 1.05 & -0.09 & 1.00 & -0.10 & 0.76 & -0.12 \\
12 & 1.03 & -0.11 & 1.18 & 0.43 & 0.80 & -0.09 \\
\hline
\end{tabular}

Note: $k$ denotes the length of the differencing interval in quarters. 
First Subperiod

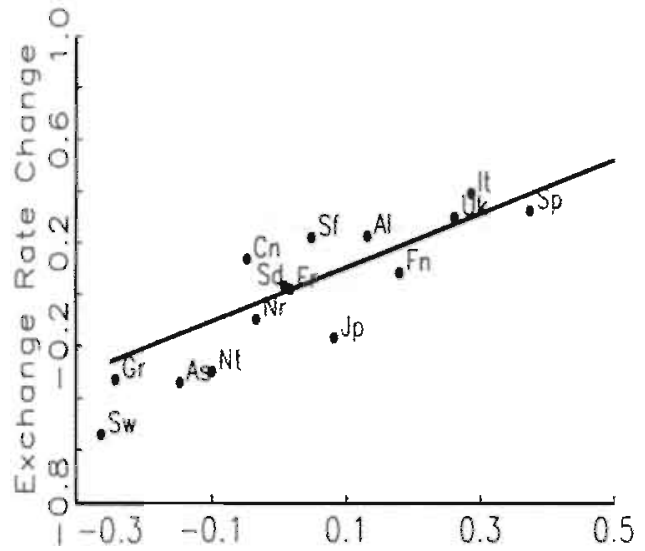

Relative Price Change

Third Subperiod

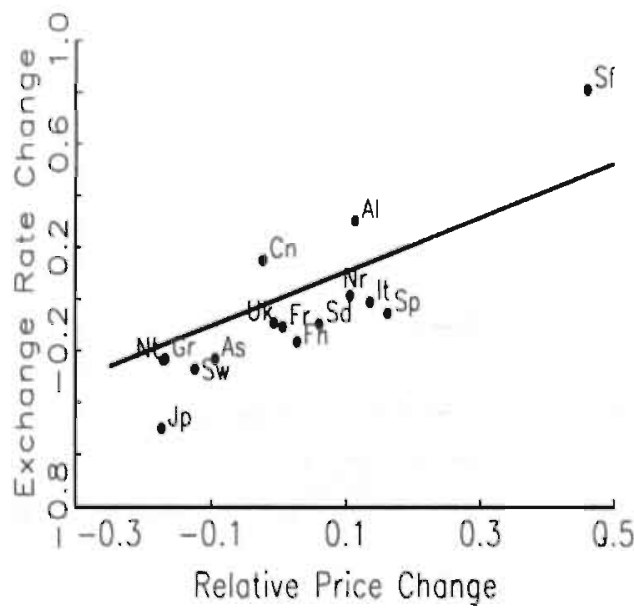

Second Subperiod

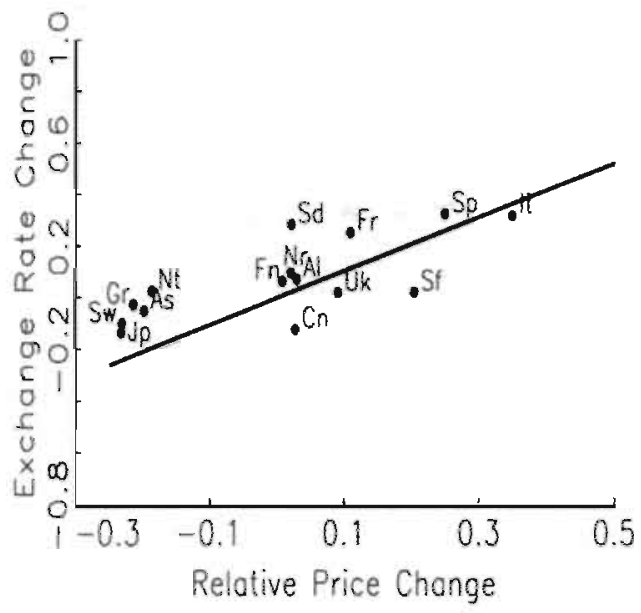

Fourth Subperiod

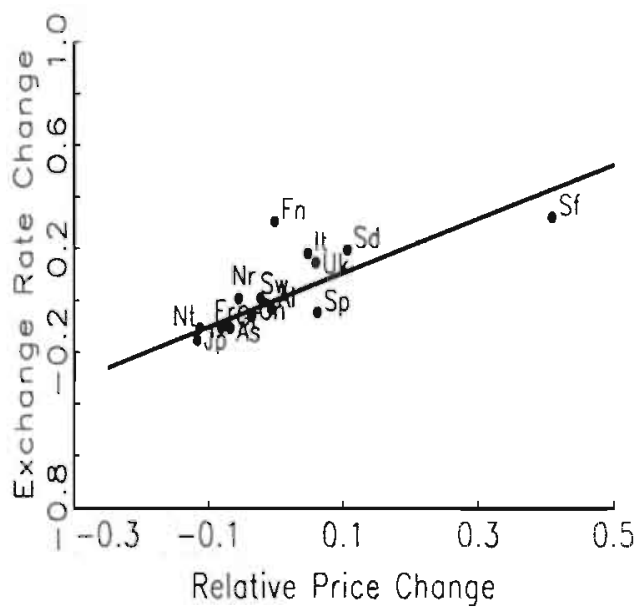

Frgure 3.2: Nominal Exchange Rate Changes versus Inflation Differentials 
First Subperiod

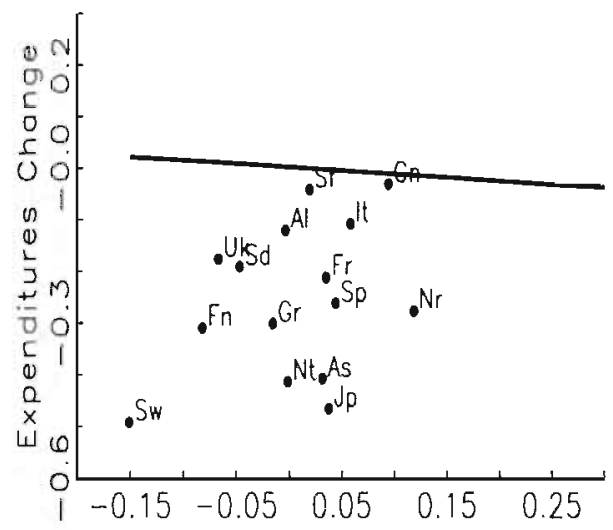

Real Exchange Rate Change

Third Subperiod

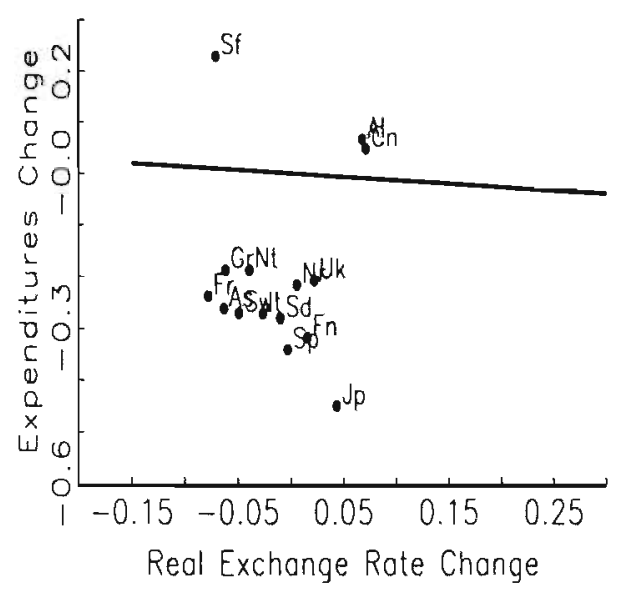

Second Subperiod

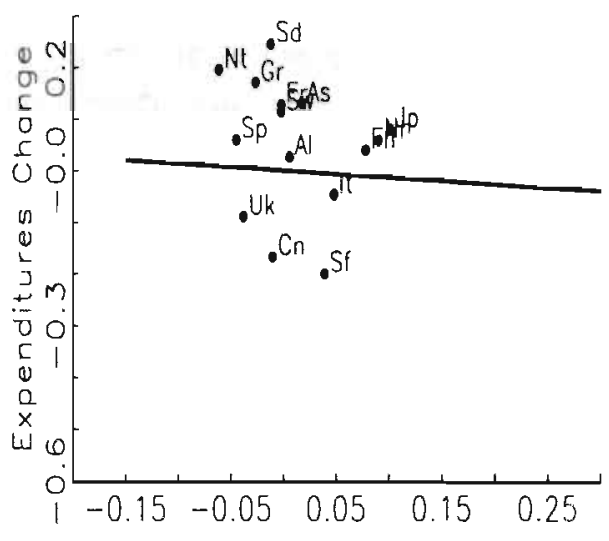

Real Exchange Rate Change

Fourth Subperiod

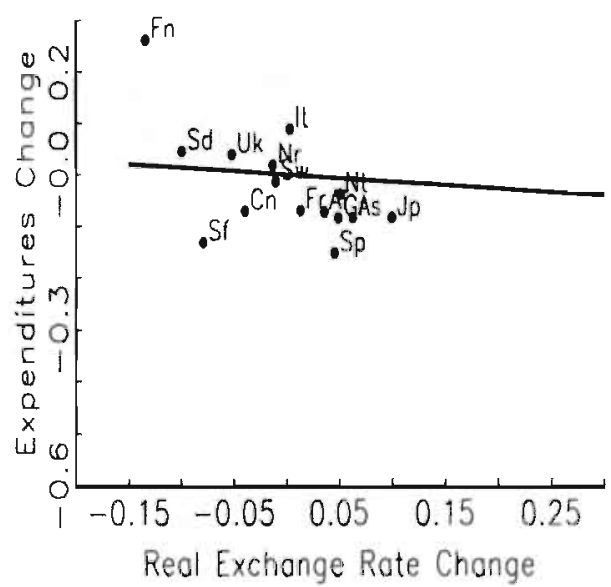

Figure 3.3: Real Exchange Rate Changes versus Output Growth Differentials 


\subsection{Pooled Tests on Absolute PPP}

\subsubsection{Specification}

Our second empirical tests focus on the time series implications of absolute PPP and the extended model proposed by SU. From a time series perspective equation (3.6) is likely to be misspecified because of overdifferencing, when there also exists an equilibrium relation for the level of the nominal exchange rate. In that case cointegration theory implies an error-correction term in either the exchange rate equation or in the model for prices and real expenditure. But since both $p$ and $y$ are treated as exogenous variables not affected by the exchange rate, the error-correction should enter directly in equation (3.6). We first discuss tests of long-run absolute PPP, then extend the analysis to other determinants of the real exchange rate and finally return to the time series extension of equation (3.6).

The general framework for tests of absolute PPP relates the logarithm of the exchange rate between currencies $i$ and $j$ to the logarithm of the price indices in countries $i$ and $j$. Recall from section 3.1:

$$
s_{i j}(t)=\theta_{i j}+\theta_{i} p_{i}(t)-\theta_{j} p_{j}(t)+u_{i j}(t),
$$

where $s$ is the logarithm of the nominal exchange rate and $p$ denotes the logarithm of the price index. Absolute PPP holds if (i) $\theta_{i}=\theta_{j}$ (symmetry) (ii) $\theta_{i}=\theta_{j}=1$ (proportionality) and (iii) the error term $u_{i j}(t)$ is stationary. First, we concentrate on condition (i) and estimate the price elasticities $\theta_{i}$ for a set of $N+1$ countries numbered $i=0, \ldots, N$. Condition (ii) of the PPP hypothesis implies that only relative prices matter in equation (3.14):

$$
s_{i j}(t)=\theta_{i j}+\theta\left(p_{i}-p_{j}\right)(t)+u_{i j}(t) .
$$

A formal test of this hypothesis is conducted jointly with the unit root hypothesis for absolute PPP by specifying the pooled regression model:

$$
\Delta s_{i j}(t)=c_{i j}+\gamma\left(s_{i j}-\theta\left(p_{i}-p_{j}\right)\right)(t-1)+\alpha\left(\pi_{i}-\pi_{j}\right)(t)+u_{i j}(t) .
$$

Equation (3.16) differs slightly from the usual Dickey-Fuller test based on the AR(1) model:

$$
\Delta q_{i j}(t)=c_{i j}+\gamma q_{i j}(t-1)+u_{i j}(t),
$$

where $q_{i j}=s_{i j}-p_{i}+p_{j}$ is the real exchange rate. This model imposes the restrictions $\theta=1$ and $\alpha=1$. Since the last restriction is almost certainly violated, equation (3.16) will provide a better fit without affecting the asymptotic distribution of test of $\gamma=0$. 
Table 3.6: Critical Values for Pooled Unit. Root. Test

\begin{tabular}{lccl|ccc}
\hline \hline & \multicolumn{3}{c|}{$t_{\mu}$} & \multicolumn{3}{c}{$t_{\tau}$} \\
\hline$N$ & $1 \%$ & $5 \%$ & $10 \%$ & $1 \%$ & $5 \%$ & $10 \%$ \\
\hline 1 & -3.25 & -2.55 & -2.16 & -3.60 & -2.85 & -2.43 \\
2 & -3.94 & -3.34 & -3.04 & -4.78 & -4.20 & -3.89 \\
5 & -4.93 & -4.35 & -4.03 & -6.38 & -5.76 & -5.46 \\
10 & -6.06 & -5.48 & -5.12 & -8.05 & -7.53 & -7.23 \\
15 & -6.95 & -6.34 & -6.01 & -9.47 & -8.91 & -8.61 \\
20 & -7.59 & -7.04 & -6.71 & -10.56 & -9.99 & -9.70 \\
\hline
\end{tabular}

Notes: Critical values are simulated percentage points of the regression $t$-statistic on $\gamma$ in the model:

$$
\Delta q_{i j}(t)=c_{i j}+\gamma q_{i j}(t-1)+g_{i j} t+u_{i j}(t)
$$

The statistic $\tau_{\mu}$ refers to the model without trend $\left(g_{i j}=0\right)$, while $\tau_{T}$ refers to the $t$-statistic of the model with trend and constant. Data are generated under the null hypothesis as $N$ random walks without drift $\left(\gamma=0, g_{i j}=0\right)$ with $T=90$ observations.

Following Abuaf and Jorion (1990) and Koedijk and Schotman (1990) we treat (3.14) as a system of $N$ equations that we estimate by seemingly unrelated regressions (SUR). Since our cross-section of sixteen countries is relatively large for a SUR system, the covariance matrix of the $u_{i j}(t)$ errors contains 120 parameters. With a sample size of only 88 quarters the covariance matrix is not always well estimated, which reduces the efficiency gain of employing SUR. We therefore restrict the contemporaneous covariance matrix of the errors in the same way as with the cross-sectional regressions. The covariance matrix $\Sigma$ defined in equation (3.9) has the same effect as in the cross-sectional tests: it takes out the numeraire common factor from the exchange rate system.

Since the regressions involve time series that are likely to be nonstationary, the regression $t$-statistics should be interpreted with caution. For the error-correction model Abuaf and Jorion (1990) provide Monte Carlo evidence that the $5 \%$ critical value of the $t$-8tatistic on $\gamma$ in the pooled SUR models equals -4.92 , which is much more negative than the ordinary Dickey-Fuller statistic. Flores, Preumont and Szafarz (1994) provide the asymptotic dis." tribution of the pooled SUR for a bivariate system. Reliable critical values for our fifturin equation system are not available, so that we also rely on Monte Carlo simulations.

Table 3.6 provides critical values for designs with and without a time trend. The null hypothesis is that all series are a random walk. The alternative hypothesis is that all series are stationary AR(1) with the same autoregressive coefficient. The larger the number of equations in the system, the more the critical values become negative. 
Returning to the full model with real expenditure the levels regression extending PPP becomes:

$$
s_{i j}=\theta_{i j}+\theta_{i} p_{i}(t)-\theta_{j} p_{j}(t)+\eta_{i} y_{i}(t)-\eta_{j} y_{j}(t)+u_{i j}(t)
$$

In the theoretical derivation of the levels relation $\eta_{i}$ again equals the relative risk aversion parameter. Analogous to the absolute PPP regressions the homogeneity restrictions lead to the fully pooled system:

$$
s_{i j}=\theta_{i j}+\theta\left(p_{i}-p_{j}\right)(t)+\eta\left(y_{i}-y_{j}\right)(t)+u_{i j}(t) .
$$

The same analogy provides the general error-correction model that nests all hypotheses of interest:

$\Delta s_{i j}(t)=c_{i j}+\gamma\left(s_{i j}-\theta\left(p_{i}-p_{j}\right)-\eta\left(y_{i}-y_{j}\right)\right)(t-1)+\alpha\left(\pi_{i}-\pi_{j}\right)(t)+\beta \Delta\left(y_{i}-y_{j}\right)(t)+u_{i j}(t)$,

where $\alpha$ and $\beta$ are the parameters of the short-term dynamics.

\subsubsection{Empirical Results}

We first describe the results of the levels regressions on absolute PPP deviations. Table 3.7 provides an overview. The first two columns contain univariate OLS regression results of equation (3.14) against the USD. The parameter estimates deviate from unity and differ substantially across equations. This result might be related to the numeraire effect in the OLS estimator. The third column contains GLS estimates that are numeraire invariant. These results are very similar to the cross-sectional tests discussed above. Table 3.7 shows that the long-run coefficient $\theta_{\mathrm{i}}$ is close to unity for all countries. ${ }^{12}$ The only country for which the time trend points at a possibly spurious regression is again the United States, not the least important country in the system. In the fully pooled model the coefficient on relative prices is close to unity. Finally, the results in the last column are based on a model that includes a time trend.

Table 3.8 contains estimates of equation (3.18). Again the coefficient on relative prices in the fully pooled model is close to unity, whereas the real expenditure coefficient has the wrong sign, just as in the long horizon cross-sectional tests. The results are robust with respect to the particular measure of real expenditure. The coefficients for the individual countries show considerable variation, but without any discernible pattern. The only regularity is a negative cross-sectional correlation between $\theta_{i}$ and $\eta_{i}$. For those countries

\footnotetext{
${ }^{12}$ The level regression does not capture the autocorrelation in the residuals. Therefore, standard errors will be misleading and are not reported here. The estimates of the error-correction model, however, provide the correct standard errors on the long-run parameters.
} 
TABLE 3.7: Level Regression of PPP Model

$$
s_{i j}(t)=\theta_{i j}+\theta_{i} p_{i}(t)-\theta_{j} p_{j}(t)+u_{i j}(t) .
$$

\begin{tabular}{|c|c|c|c|c|}
\hline & \multicolumn{2}{|c|}{$\overline{\text { OLS }}$} & GLS1 & GLS2 \\
\hline Country & $\overline{\theta_{i}}$ & $\theta_{j}$ & $\theta_{i}$ & $\theta_{i}$ \\
\hline Australia & 0.68 & 0.31 & 1.28 & 0.74 \\
\hline Austria & 0.00 & 0.32 & 1.14 & 1.23 \\
\hline Canada & 0.00 & -0.25 & 1.20 & 0.65 \\
\hline Finland & 0.15 & 0.00 & 1.04 & 0.77 \\
\hline France & 3.01 & 3.01 & 1.19 & 1.17 \\
\hline Germany & 4.10 & 2.50 & 1.54 & 1.73 \\
\hline Italy & 1.74 & 2.52 & 1.00 & 1.13 \\
\hline Japan & 1.06 & 1.40 & 0.68 & 0.88 \\
\hline Netherlands & 1.58 & 1.23 & 1.40 & 0.96 \\
\hline Norway & 0.28 & 0.10 & 1.13 & 0.88 \\
\hline South Africa & 0.99 & 0.70 & 1.21 & 1.85 \\
\hline Spain & 1.08 & 1.33 & 0.99 & 1.16 \\
\hline Sweden & -0.29 & -0.89 & 1.21 & 1.61 \\
\hline Switzerland & 0.29 & 0.70 & 1.06 & 1.14 \\
\hline United Kingdom & 0.50 & 0.51 & 1.00 & 0.60 \\
\hline United States & - & - & 1.13 & 0.04 \\
\hline Pooled & - & - & 1.06 & 1.03 \\
\hline \multicolumn{5}{|c|}{$\begin{array}{l}\text { Notes: The first two columns contain univariate OLS estimates. } \\
\text { The first column contains } \theta_{i} \text { and the second column contains } \bar{\theta}_{j} \text {, } \\
\text { where the numeraire country } j \text { is the United States. The next } \\
\text { column contains multivariate GLS estimates with } \theta_{j} \text { restricted for } \\
\text { all equations. The last column contains GLS estimates with a time } \\
\text { trend included. }\end{array}$} \\
\hline
\end{tabular}

where we find any positive effect for real expenditure, we mostly see that the coefficient on the price index becomes much smaller. This pattern is most clearly visible in the 'GNP' column.

As a check for robustness, the levels regressions were re-estimated with a time trend added as an explanatory variable. This does not affect the pooled estimator, which still finds a coefficient of unity for relative prices, even after taking out trends in nominal exchange rates and prices. The coefficient thus does pick up some dynamic relation between exchange rates and relative prices. Including the time trend there is still no evidence of any impact from the real expenditure measures. The time trend strongly disturbs most of the estimates of the individual $\eta_{i}$, though, with some major sign reversals. The only two countries for which the results are robust are Canada and the United States. For both countries we find a large positive coefficient both with and without the time trend in the regression. This suggests that the real expenditure model might well work for the bilateral relation between 
TABLE 3.8: Level Regression of Extended Model

$$
s_{i j}=c_{i j}+\theta_{i} p_{i}(t)-\theta_{j}(t) p_{j}+\eta_{i} y_{i}(t)-\eta_{j} y_{j}(t)+u_{i j}(t) .
$$

\begin{tabular}{|c|c|c|c|c|c|c|c|c|}
\hline & 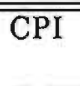 & $\overline{\text { GNP }}$ & $\overline{\text { CPI }}$ & $\overline{\mathrm{CNS}}$ & $\overline{\mathrm{CPI}}$ & $\overline{\text { IP }}$ & $\overline{\mathrm{CPI}}$ & $\begin{array}{c}\text { WPI } \\
\text { CPI }\end{array}$ \\
\hline A: No Trend & $\theta_{i}$ & $\eta_{i}$ & $\theta_{i}$ & $\eta_{i}$ & $\theta_{i}$ & $\eta_{i}$ & $\theta_{i}$ & $\eta_{i}$ \\
\hline Australia & 0.78 & 0.78 & 0.81 & 0.76 & 1.46 & 0.58 & 1.19 & 0.46 \\
\hline Austria & 1.02 & -0.64 & 0.85 & -0.22 & 0.58 & -0.17 & 1.51 & 1.58 \\
\hline Canada & 0.39 & 1.23 & 0.53 & 1.08 & 1.40 & 0.70 & 1.19 & 0.81 \\
\hline Finland & 0.99 & -0.59 & 0.97 & -0.52 & 0.69 & -0.13 & 1.12 & 0.92 \\
\hline France & 1.11 & -0.66 & 1.13 & -0.63 & 0.68 & -0.27 & - & - \\
\hline Germany & 1.35 & -0.64 & 1.47 & -0.75 & 0.72 & -0.29 & 1.53 & 3.09 \\
\hline Italy & 1.03 & -0.86 & 1.08 & -0.84 & 0.63 & -0.23 & 1.12 & 1.57 \\
\hline Japan & 0.74 & -0.58 & 0.80 & -0.73 & 0.07 & -0.42 & 1.24 & 1.40 \\
\hline Netherlands & 1.02 & -0.22 & - & - & 0.86 & -0.01 & 1.93 & 4.38 \\
\hline Norway & 0.78 & 0.23 & 0.89 & -0.01 & 0.97 & 0.31 & 1.22 & 1.51 \\
\hline South Africa & 1.18 & -0.81 & 1.40 & -1.59 & - & - & 1.14 & 0.90 \\
\hline Spain & 1.01 & -0.93 & 0.99 & -0.94 & -0.04 & -0.99 & 1.21 & 1.80 \\
\hline Sweden & 1.08 & -0.48 & 1.08 & -0.42 & 1.12 & 0.18 & 1.21 & 1.51 \\
\hline Switzerland & 0.28 & 0.48 & 0.47 & 0.15 & - & - & - & - \\
\hline United Kingdom & 0.67 & 0.52 & 0.72 & 0.33 & 1.31 & 0.63 & 0.95 & 1.06 \\
\hline United States & 0.25 & 1.44 & 0.44 & 1.01 & 1.37 & 1.00 & 1.05 & 0.25 \\
\hline Pooled & 1.05 & -0.45 & 1.09 & -0.29 & 0.71 & -0.22 & 1.01 & 1.27 \\
\hline \multicolumn{9}{|l|}{ B: Trend } \\
\hline Australia & 0.58 & 0.43 & 0.66 & -0.44 & 0.95 & 0.25 & 1.38 & 0.30 \\
\hline Austria & 0.94 & -0.49 & 1.10 & -0.12 & 1.09 & 0.08 & 0.62 & 2.72 \\
\hline Canada & 0.35 & 1.15 & 0.57 & 1.10 & 1.08 & 0.54 & 0.01 & 2.35 \\
\hline Finland & 0.72 & -0.75 & 0.69 & -0.88 & 0.48 & -0.22 & 0.92 & 1.34 \\
\hline France & 1.05 & -0.77 & 1.10 & -0.77 & 1.01 & -0.06 & - & - \\
\hline Germany & 1.30 & -0.51 & 1.39 & -0.79 & 1.30 & -0.07 & 1.43 & 3.32 \\
\hline Italy & 1.06 & -0.13 & 1.10 & -0.30 & 1.09 & 0.03 & 1.40 & 1.09 \\
\hline Japan & 0.87 & 1.55 & 0.80 & 0.05 & 0.91 & 0.13 & 1.11 & 1.73 \\
\hline Netherlands & 0.63 & -1.20 & - & - & 0.05 & -0.57 & 2.25 & 4.20 \\
\hline Norway & 0.67 & 0.11 & 0.80 & -0.02 & 0.93 & 0.22 & 1.51 & 1.33 \\
\hline South Africa & 1.84 & -0.51 & 1.58 & -1.53 & - & - & 2.20 & 1.55 \\
\hline Spain & 0.74 & -1.84 & 0.68 & -1.79 & 0.35 & -0.74 & 1.26 & 1.68 \\
\hline Sweden & 1.40 & -0.03 & 1.47 & -0.24 & 1.82 & 0.34 & 1.54 & 1.31 \\
\hline Switzerland & 2.08 & 1.64 & 2.44 & 2.76 & - & - & - & - \\
\hline United Kingdom & 0.54 & 0.21 & 0.48 & -0.23 & 0.86 & 0.30 & 0.74 & 1.80 \\
\hline United States & -0.06 & 0.60 & -0.04 & 0.04 & 0.27 & 0.37 & 0.37 & 2.71 \\
\hline Pooled & 1.01 & -0.11 & 0.99 & -0.21 & 1.01 & 0.12 & 1.16 & 1.25 \\
\hline
\end{tabular}

Note: Parameter are based on the numeraire invariant covariance matrix. 
TABle 3.9: Error-Correction Model: PPP and Extension

$$
\Delta s_{i j}(t)=c_{i j}+\gamma\left(s_{i j}-\theta\left(p_{i}-p_{j}\right)-\eta\left(y_{i}-y_{j}\right)\right)(t-1)+\alpha\left(\pi_{i}-\pi_{j}\right)(t)+\beta \Delta\left(y_{i}-y_{j}\right)(t)+u_{i j}(t) .
$$

\begin{tabular}{ccccc}
\hline \hline$\gamma$ & $\theta$ & $\eta$ & $\alpha$ & $\beta$ \\
\hline-0.063 & 0.96 & - & - & - \\
$(4.92)$ & $(10.49)$ & - & - & - \\
-0.063 & 1.00 & - & - & - \\
$(4.96)$ & - & - & - & - \\
\hline \multicolumn{5}{c}{$p=\mathrm{CPI}, y=\mathrm{GDP}$} \\
\hline-0.069 & 0.95 & -0.92 & 0.67 & 0.03 \\
$(5.28)$ & $(11.57)$ & $(2.47)$ & $(4.30)$ & $(0.33)$ \\
-0.070 & 1.00 & -0.89 & 0.68 & 0.03 \\
$(5.33)$ & - & $(2.42)$ & $(4.36)$ & $(0.41)$ \\
\hline \multicolumn{5}{c}{$p=\mathrm{CPI}, y=\mathrm{CPI} / \mathrm{WPI}$} \\
\hline-0.088 & 1.01 & 0.55 & 0.94 \\
$(5.12)$ & $(15.14)$ & $(1.78)$ & $(5.00)$ & $(5.84)$ \\
-0.091 & 1.00 & 1.00 & 0.89 & 0.83 \\
$(5.40)$ & - & - & $(4.83)$ & $(6.00)$ \\
\hline
\end{tabular}

Note: $t$-values are given in parentheses.

Canada and the United States. It also might explain why bilateral tests of long-run PPP tests have so much problems, since the USD is almost always the numeraire.

We estimated the system with both consumer prices and wholesale prices. The last column of table 3.9 contains the results. The pooled estimates are consistent with the crosssectional results: wholesale prices dominate the consumer prices in the PPP regressions.

Results for pooled dynamic models are presented in table 3.9. Despite a $t$-statistic of approximately five, the error-correction coefficient in the full model is not significant. Even if $\theta$ and $\eta$ would not have been estimated the $t$-statistic does not excod the critical value in table 3.6. Results improve when we include wholesale prices.

Finally, we graphically investigate the in-sample fit of the PPP deviations when we increase the difference interval. This analysis is related to Mark (1995). Figure 3.4 contains plots of the DEM/USD exchange rate change and the estimated exchange rate change for different lengths of the difference interval. The three year actual and estimated exchange rate changes move closely together. Figure 3.5 shows a similar plot for the JPY/DEM exchange rate. 
1 Quarter

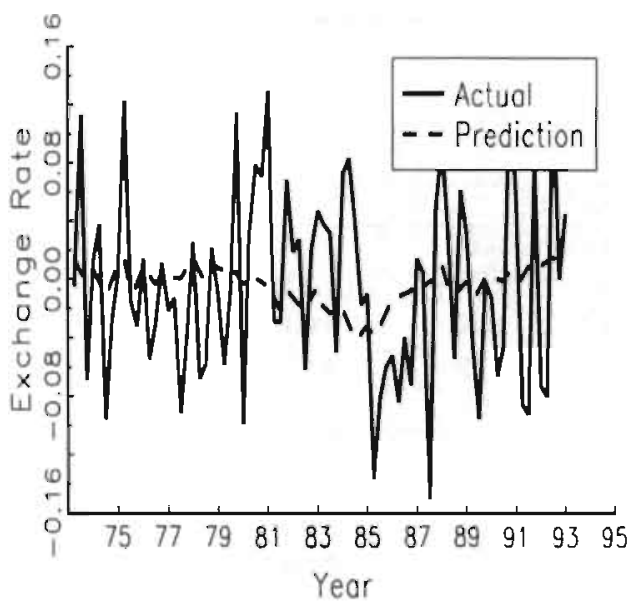

8 Quorters

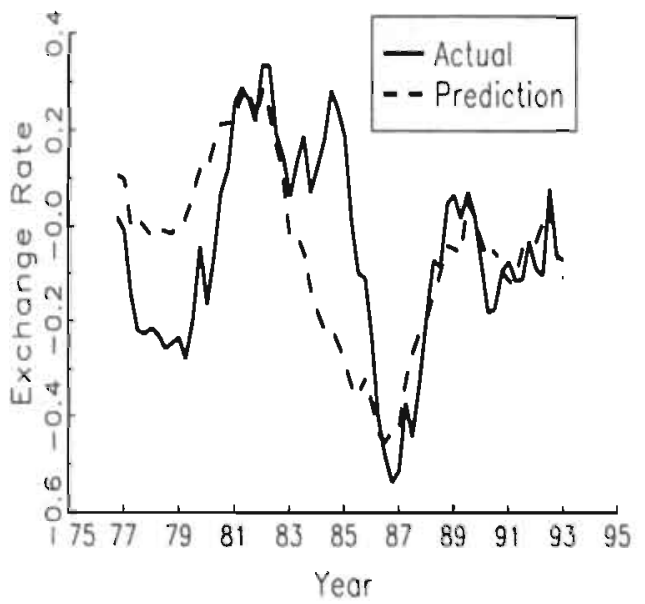

4 Quarters

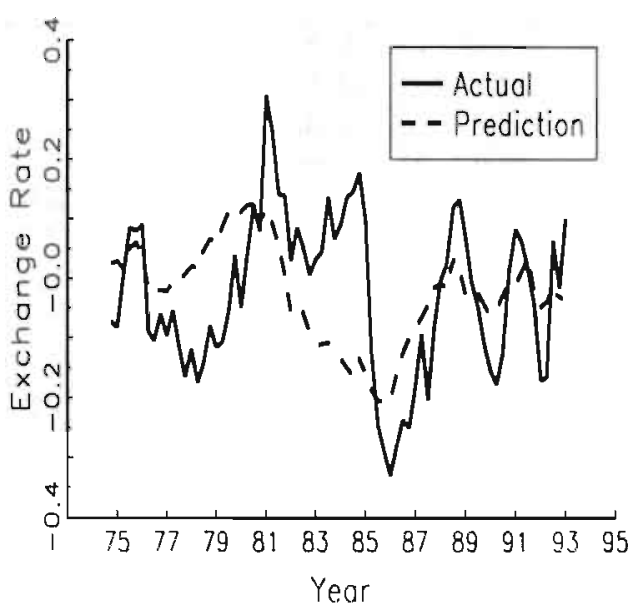

12 Quorters

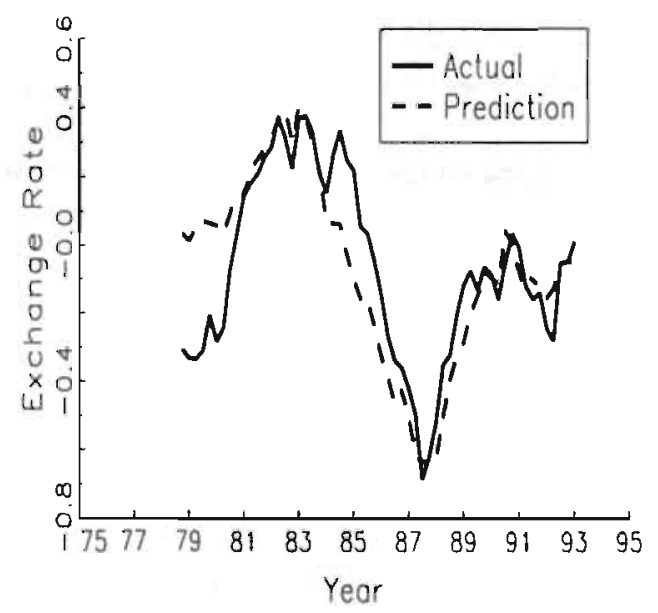

FIGURE 3.4: Fitted Exchange Rate Changes for Germany 
1 Quarter
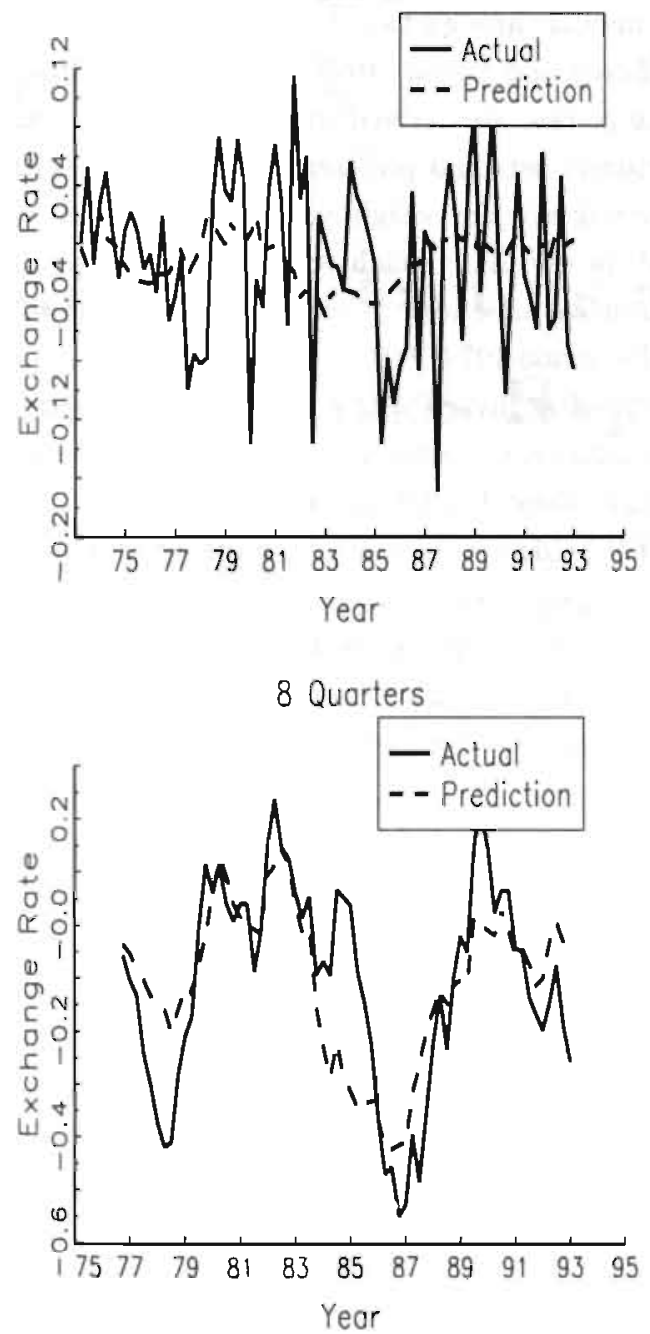

4 Quarters

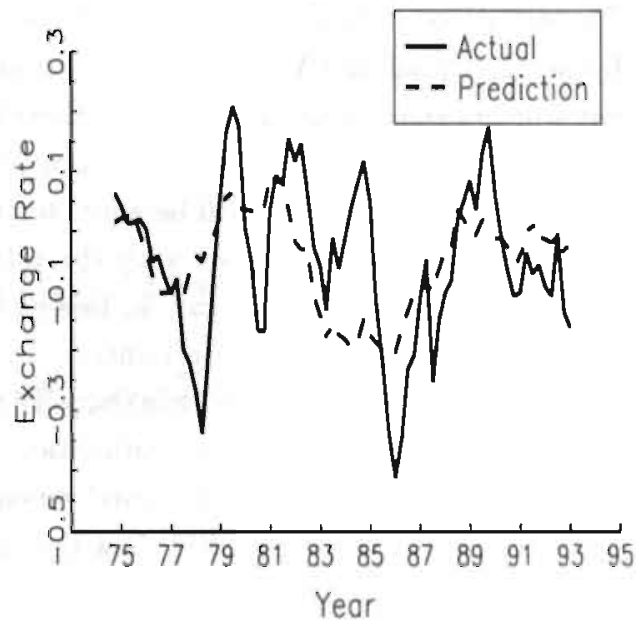

12 Quorters

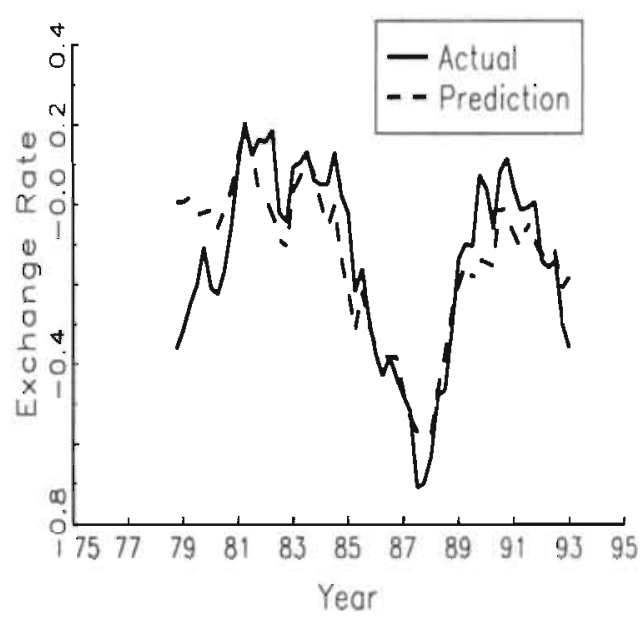

Figure 3.5: Fitted Exchange Rate Changes for Japan 


\subsection{Conclusions}

Purchasing power parity (PPP) is one of the central building blocks in international economics. The empirical evidence to date is not very supportive of this theory however. The debate on PPP recently received new impetus through two theoretical contributions by Sercu, Uppal and Van Hulle (1995) and Sercu and Uppal (1995). In the latter study, equilibrium conditions for the nominal exchange rate are derived when the exchange rate is jointly determined by consumption opportunity sets and preferences. It is shown that the exchange rate change will be equal to the risk-aversion weighted differential of growth in nominal spending deflated with the total-consumption weighted inflation rate plus a 'marginal' inflation differential. In this chapter we have tested Sercu and Uppal's (1995) model using data from sixteen countries for the period 1973-1993. In the empirical tests we imposed restrictions that make parameter estimates invariant to the choice of numeraire currency. This implies that the estimation results do not alter if we express all currencies in a different numeraire. Both pooled versions of absolute PPP as well as relative PPP are tested. Surprisingly, our results show that PPP holds very strongly at horizons of approximately three years. We fail to find any evidence, however, for the theoretical effect of real expenditure on nominal exchange rate changes. Our results show that rejections of PPP in the seventies and eighties were not so much related to shortcomings of the underlying theoretical model but much more to the empirical tests that were used. 


\section{Chapter 4}

\section{Common Factors and Tests for the}

\section{Unbiasedness Hypothesis}

The concept of uncovered interest rate parity (UIP) is of fundamental building blocks for the understanding of the behaviour of returns in international financial markets. Under the hypothesis of UIP the return on a domestic currency deposit equals the expected return from converting the domestic currency into the foreign currency, investing it in a foreign deposit and then converting the proceeds back into domestic currency at the future expected exchange rate, so that expected excess returns in the foreign exchange market should on average be equal to zero. In combination with covered interest parity the forward premium then is an unbiased predictor of the expected change in the exchange rate. This so-called unbiasedness hypothesis of the forward premium has been investigated for many different currencies and many different time-periods and has been rejected time and again. In a recent review article Lewis (1995) has evaluated various explanations for the rejection of the unbiasedness hypothesis, like risk premiums and systematic forecast errors and concludes that it is likely that these explanations interact.

We leave the source of deviations from UIP unspecified, but instead intend to provide supportive evidence that there is reason to believe that hidden below a mix of disturbing factors, UIP is a fact of life and not just a theoretical construct. Simultaneously, our approach offers suggestions for the most promising direction of future research into the causes of UIP violations. We account for UIP deviations by using information, pooled over fifteen countries at every point in time. ${ }^{1}$ We consider panel models with fixed time effects

\footnotetext{
${ }^{1}$ Chapter 3 considers sixteen countries, whereas this chapteir only investigates fifteen countries since forward rates for Japan are not available for our sample period.
} 
and with random time effects. The random effects model is invariant with respect to the choice of the numeraire and allows for cross-sectional correlation between exchange rate returns.

The plan of this chapter is as follows. Section 4.1 contains a description of the data for fifteen countries between 1979 and 1996. Section 4.2 contajns results from traditional time series tests of UIP. Section 4.3 describes the panel methodology and contains panel results. Section 4.4 shows how the distinction between large and small changes in the interest differentials affects estimates of the unbiasedness hypothesis and suggests an economic explanation for these results. Section 4.5 contains the conclusions.

\subsection{Data}

This study uses end-of-the-month spot and forward exchange rates which cover the period January 1979 until March 1996. ${ }^{2}$ The forward maturity is one month. All data are London closing mid prices against the pound sterling for fourteen countries: Austria, Belgium, Canada, Denmark, France, Germany, Ireland, Italy, the Netherlands, Norway, Spain, Sweden, Switzerland, the United Kingdom and the United States. ${ }^{3}$

The data are sampled following the procedure as described in Bekaert and Hodrick (1992) in order to use the exact delivery dates of the forward foreign exchange contracts. For a one month forward contract, the settlement on the spot market is two business days in the future. The delivery takes place on the calendar day in the next month that corresponds to the current settlement date in the spot market, under condition that the delivery date is a business day. If not, delivery takes place on the next business day given that it is in the same month. If the latter condition is not fulfilled, delivery takes place on the first previous business day.

Let $S_{\mathrm{o}}(t)$ be the price of the foreign currency $i$ in units of the numeraire currency 0 at time $t$ and $F_{\mathrm{i} 0}(t)$ be the forward price at $t$ of the exchange rate with a one month maturity $(i=1 . . N ; t=1 . . T)$. The continuously compounded rate of depreciation of the foreign currency relative to the numeraire currency in the period from $t$ until the forward delivery date $t+1$ is $s_{\mathrm{i0}}(t+1)-s_{\mathrm{i0}}(t)=\ln \left(S_{\mathrm{i} 0}(t+1) / S_{\mathrm{i} 0}(t)\right) \times 100$.

Table 4.1 presents unconditional estimates of UIP differentials defined as $s_{i 0}(t+1)-f_{i v}(t)$

\footnotetext{
${ }^{2}$ The data are obtained from Datastream.

3 We also conducted the analysis with bid and ask prices. As in Bekaert and Hodrick (1992) we find that the empirical results do not lead to different conclusions.
} 
TABLE 4.1: Summary Statistics

\begin{tabular}{l|ccc|ccc}
\hline \hline & $\mu$ & $\overline{\mathrm{SE}}(\mu)$ & $\sigma_{\Delta s} / \sigma_{f p}$ & $\mu$ & \multicolumn{3}{c|}{$\mathrm{SE}(\mu)$} & $\sigma_{\Delta s} / \sigma_{f p}$ \\
\hline & \multicolumn{3}{|c|}{$\mathrm{USD}$} & & & $\mathrm{DEM}$ \\
\hline Austria & -0.16 & $(2.96)$ & 12.44 & $-0.67^{\dagger}$ & $(0.32)$ & 4.64 \\
Belgium & -0.31 & $(2.97)$ & 13.22 & -0.82 & $(0.73)$ & 3.05 \\
Canada & 0.30 & $(1.12)$ & 8.91 & -0.82 & $(3.01)$ & 13.25 \\
Denmark & -1.15 & $(2.89)$ & 10.35 & $-1.66^{\dagger}$ & $(0.80)$ & 2.81 \\
France & -1.27 & $(2.88)$ & 10.12 & $-1.78^{\dagger}$ & $(0.75)$ & 2.68 \\
Germany & 0.51 & $(2.97)$ & 11.25 & - & - & - \\
Ireland & -1.68 & $(2.76)$ & 8.85 & $-2.19^{\dagger}$ & $(0.97)$ & 2.94 \\
Italy & -2.05 & $(2.88)$ & 10.71 & -2.57 & $(1.67)$ & 5.31 \\
Netherlands & 0.17 & $(2.95)$ & 12.15 & -0.33 & $(0.33)$ & 4.21 \\
Norway & -1.34 & $(2.54)$ & 9.02 & -1.85 & $(1.29)$ & 4.41 \\
Spain & -2.01 & $(2.76)$ & 8.39 & -2.52 & $(1.61)$ & 4.40 \\
Sweden & -0.31 & $(2.73)$ & 10.70 & -0.82 & $(1.96)$ & 9.71 \\
Switzerland & 1.74 & $(3.26)$ & 10.67 & 1.23 & $(1.21)$ & 10.77 \\
United Kingdom & -0.56 & $(2.91)$ & 13.89 & -1.08 & $(2.32)$ & 10.80 \\
United States & - & - & - & -0.51 & $(2.97)$ & 11.25 \\
\hline
\end{tabular}

Notes: $\mu, \operatorname{SE}(\mu)$ and $\sigma_{\Delta s} / \sigma_{f p}$ denote the mean UIP differential, the standard error of the UIP differential and the ratio of the spot variance and the forward variance respectively. The summary statistics cover the sample period from January 1979 until March 1996. Units are percents per annum. ${ }^{\prime}$ denotes rejection at the $5 \%$ level.

against the US dollar (USD) and the Deutschmark (DEM) expressed in percent per annum. For currencies relative to the USD, seven countries have average UIP differentials smaller than one percent and none of the average differentials is significantly different from zero. For currencies relative to the DEM, average differentials are slightly larger and significantly different from zero for Austria, Denmark, France and Ireland. Also, the variability of spot exchange rate changes importantly exceeds the variability of the forward premium, making the forward premium a very imprecise predictor of the future exchange rate change. For the DEM exchange rates of the European countries that participate in the European Monetary System (EMS), the variance of spot exchange rate changes is small relative to floating exchange rates, while the variance of the forward premium is comparable. 


\subsection{Time Series Tests}

In this section we replicate earlier attempts to discover UIP. Standard time series tests of UIP normally start from the following bilateral regression:

$$
s_{i 0}(t+1)-s_{i 0}(t)=\alpha_{i}+\beta_{i}\left(f_{i 0}-s_{i 0}\right)(t)+\psi_{i 0}(t+1),
$$

where $s_{i 0}$ and $f_{i 0}$ are the logarithms of the spot and forward exchange rates respectively and $\psi_{i 0}$ is an error term. The null hypothesis for the forward premium to be an unbiased estimator of the future change in spot rates is that the slope coefficient equals unity, that is $\beta_{i}=1$.

In table 4.2 we report estimates for the slope coefficients in the UIP regression equation (4.1) for the period 1979-1996 and the subperiods 1979-1996 and 1986-1996. Results are expressed relatively to the USD and DEM respectively. From table 4.2 , we observe that point estimates of the slope coefficient range from -5.09 (guilder/USD, 1979-1986) to +3.21 (lira/USD, 1987-1996) and are rarely close to unity. Since the precision with which the betas are estimated is generally quite low, rejection of the null hypothesis that beta equals one is not always - though still quite a few times - possible. Neither is rejected that beta is zero, however. A second observation is that beta estimates show strong instability across subperiods. A good example is Sweden which has a beta of -1.64 in the first subperiod and of +2.15 in the second period, both against the USD. Overall, we conclude that bilateral time series tests generally do not offer significant support for the UIP hypothesis. The choice of benchmark currency (USD or DEM) appears to be of little importance in this respect. The results in table 4.2 corroborate results reported in previous studies, as for example, Bilson (1981), Fama (1984), Bekaert and Hodrick (1992) and Lewis (1995). ${ }^{4}$

Many explanations have been suggested for the rejection of the unbiasedness hypothesis. ${ }^{5}$ The most commonly suggested explanation is that UIP differentials are due to risk premiums. If the average uncovered differentials in table 4.1 are interpreted as risk premiums then on average these risk premiums are quite small. However, this would not prevent the risk premium to vary over time and to alter between large positive and negative values. Fama (1984) decomposes the slope coefficient in the UIP test into a part depending on the time variability of risk premium and one depending on market's forecast errors. On the basis of his results, Fama (1984) concludes that the variance of the risk premium is significantly larger than the variance of the expected spot rate change, suggesting that it

\footnotetext{
4 We also considered (overlapping) data sampled at the daily and weekly frequency. Furthermore, we investigated various forward maturities. The results from these estimates are qualitatively similar to the results reported here.

5. See Lewis (1995) for a more detailed overview.
} 
TABle 4.2: Slope Bilateral Times Series Model

$$
s_{i 0}(t+1)-s_{i 0}(t)=\alpha_{i}+\beta_{i}\left(f_{i 0}-s_{i 0}\right)(t)+\psi_{i 0}(t+1) .
$$

\begin{tabular}{|c|c|c|c|c|c|c|}
\hline & (1) & (2) & (3) & (1) & (2) & (3) \\
\hline & & USD & & \multicolumn{3}{|c|}{ DEM } \\
\hline Austria & $\begin{array}{c}-0.61 \\
(0.89)\end{array}$ & $\begin{array}{c}-1.47 \\
(1.96)\end{array}$ & $\begin{array}{c}-0.51 \\
(1.34)\end{array}$ & $\begin{array}{c}-0.09 \\
(0.43)\end{array}$ & $\begin{array}{c}0.10 \\
(0.58)\end{array}$ & $\begin{array}{c}0.05 \\
(0.83)\end{array}$ \\
\hline Belgium & $\begin{array}{c}-0.46 \\
(0.80)\end{array}$ & $\begin{array}{c}-0.87 \\
(0.96)\end{array}$ & $\begin{array}{c}0.01 \\
(1.27)\end{array}$ & $\begin{array}{c}0.25 \\
(0.35)\end{array}$ & $\begin{array}{c}0.26 \\
(0.38)\end{array}$ & $\begin{array}{c}-1.49 \\
(0.83)\end{array}$ \\
\hline Canada & $\begin{array}{c}-1.63 \\
(0.64)\end{array}$ & $\begin{array}{c}-2.05 \\
(0.86)\end{array}$ & $\begin{array}{l}-1.02 \\
(1.11)\end{array}$ & $\begin{array}{l}-1.46 \\
(0.96)\end{array}$ & $\begin{array}{l}-2.05 \\
(2.33)\end{array}$ & $\begin{array}{c}-2.03 \\
(1.27)\end{array}$ \\
\hline Denmark & $\begin{array}{c}-0.53 \\
(0.68)\end{array}$ & $\begin{array}{c}-1.32 \\
(1.06)\end{array}$ & $\begin{array}{c}0.22 \\
(0.76)\end{array}$ & $\begin{array}{c}-0.26 \\
(0.48)\end{array}$ & $\begin{array}{c}-0.03 \\
(0.35)\end{array}$ & $\begin{array}{c}-1.45 \\
(0.76)\end{array}$ \\
\hline France & $\begin{array}{c}0.11 \\
(0.91)\end{array}$ & $\begin{array}{c}0.10 \\
(1.10)\end{array}$ & $\begin{array}{c}0.04 \\
(1.30)\end{array}$ & $\begin{array}{c}0.85 \\
(0.43)\end{array}$ & $\begin{array}{c}1.05 \\
(0.60)\end{array}$ & $\begin{array}{c}-0.92 \\
(0.53)\end{array}$ \\
\hline Germany & $\begin{array}{c}-0.83 \\
(0.84)\end{array}$ & $\begin{array}{c}-3.14 \\
(2.19)\end{array}$ & $\begin{array}{c}-0.24 \\
(1.18)\end{array}$ & - & - & - \\
\hline Ireland & $\begin{array}{c}0.58 \\
(0.96)\end{array}$ & $\begin{array}{c}-0.87 \\
(1.08)\end{array}$ & $\begin{array}{c}1.19 \\
(0.97)\end{array}$ & $\begin{array}{c}0.83 \\
(0.41)\end{array}$ & $\begin{array}{c}-0.11 \\
(0.60)\end{array}$ & $\begin{array}{c}1.08 \\
(0.60)\end{array}$ \\
\hline Italy & $\begin{array}{c}0.98 \\
(0.87)\end{array}$ & $\begin{array}{c}-0.05 \\
(0.91)\end{array}$ & $\begin{array}{c}3.21 \\
(2.06)\end{array}$ & $\begin{array}{c}-0.05 \\
(0.35)\end{array}$ & $\begin{array}{c}0.06 \\
(0.56)\end{array}$ & $\begin{array}{c}-1.59 \\
(1.22)\end{array}$ \\
\hline Netherlands & $\begin{array}{c}-1.71 \\
(0.84)\end{array}$ & $\begin{array}{c}-5.09 \\
(1.52)\end{array}$ & $\begin{array}{c}-0.69 \\
(1.30)\end{array}$ & $\begin{array}{c}0.08 \\
(0.47)\end{array}$ & $\begin{array}{c}0.00 \\
(0.61)\end{array}$ & $\begin{array}{c}-0.02 \\
(0.26)\end{array}$ \\
\hline Norway & $\begin{array}{c}-1.14 \\
(0.68)\end{array}$ & $\begin{array}{c}-0.95 \\
(0.81)\end{array}$ & $\begin{array}{c}-0.85 \\
(1.25)\end{array}$ & $\begin{array}{c}0.24 \\
(0.45)\end{array}$ & $\begin{array}{c}1.97 \\
(0.75)\end{array}$ & $\begin{array}{c}-0.78 \\
(0.46)\end{array}$ \\
\hline Spain & $\begin{array}{c}0.91 \\
(0.58)\end{array}$ & $\begin{array}{c}0.26 \\
(0.51)\end{array}$ & $\begin{array}{c}2.23 \\
(1.46)\end{array}$ & $\begin{array}{c}0.98 \\
(0.51)\end{array}$ & $\begin{array}{c}1.22 \\
(0.78)\end{array}$ & $\begin{array}{c}-0.19 \\
(0.66)\end{array}$ \\
\hline Sweden & $\begin{array}{c}0.43 \\
(0.84)\end{array}$ & $\begin{array}{c}-1.64 \\
(1.27)\end{array}$ & $\begin{array}{c}2.15 \\
(0.91)\end{array}$ & $\begin{array}{c}0.13 \\
(0.56)\end{array}$ & $\begin{array}{c}0.08 \\
(1.15)\end{array}$ & $\begin{array}{c}-0.14 \\
(0.52)\end{array}$ \\
\hline Switzerland & $\begin{array}{c}-1.57 \\
(0.78)\end{array}$ & $\begin{array}{c}-3.17 \\
(1.64)\end{array}$ & $\begin{array}{c}-1.69 \\
(1.42)\end{array}$ & $\begin{array}{c}-1.41 \\
(0.71)\end{array}$ & $\begin{array}{l}-1.50 \\
(0.84)\end{array}$ & $\begin{array}{c}-1.58 \\
(1.53)\end{array}$ \\
\hline United Kingdom & $\begin{array}{l}-2.57 \\
(1.05)\end{array}$ & $\begin{array}{c}-3.50 \\
(1.26)\end{array}$ & $\begin{array}{c}-1.03 \\
(1.91)\end{array}$ & $\begin{array}{c}-1.23 \\
(0.79)\end{array}$ & $\begin{array}{c}-4.13 \\
(1.50)\end{array}$ & $\begin{array}{c}-0.52 \\
(0.91)\end{array}$ \\
\hline
\end{tabular}

Notes: (1), (2), (3) contain results for the 1979-1986, 1979-1986 and 1987-1996 periods respectively. The coefficients are obtained from the univariate time series regression for exchange rates expressed against the USD and the DEM. Robust standard errors are given in parentheses. 
is dominantly a time-varying risk premium which causes the unbiasedness hypothesis to be rejected.

However, the existence and structure of foreign exchange risk premiums has been subject to intensive research over the past two decades. ${ }^{6}$ Well-known examples are Frankel (1982), Giovanni and Jorion (1987a,b), Hodrick (1987) and Cumby (1988). Despite the statistical evidence indicating the presence of a risk premium, it has proven to be very difficult to develop an economic model of the risk premium in the foreign exchange market which is empirically tractable.

Another explanation for the rejection of the unbiasedness hypothesis is the presence of systematic forecast errors. Using survey data on exchange rate expectations, Frankel and Froot (1987) decompose the components of predictable excess returns and find that the important components in the variability of predictable excess returns appear to be forecast. errors and not so much risk premiums. Systematic, but rational, forecast errors may arise when discrete changes in regimes are expected but not realized in a particular period. This phenomenon is called the peso-problem. Peso-problems may be found in fixed as well as floating exchange rates. If the average uncovered differentials in table 4.1 are interpreted as systematic forecast errors, these errors are on average relatively small. There could be periods, however. where peso-problems lead to substantial positive or negative forecast errors. Using a markov-regime-switching model for the exchange rate, Evans and Lewis (1995) find that peso-problems, as reflected by expected changes in exchange rate regimes, bias UIP tests. The reason is that expectations of shifts in the exchange rate process may induce a small sample serial-correlation between exchange rate forecast errors and the forward premium. Lewis (1995) notes that systematic forecast errors may also arise when market participants are learning about changes in regimes.

Alternative explanations for the rejection of the unbiasedness hypothesis are market inefficiencies (see Bilson (1981)), transaction costs (see Baldwin (1990)) and government intervention (see McCallum (1994)).

Most studies that investigate the unbiasedness hypothesis, so far concentrate on one explanation and seem to neglect the interaction between the various explanations. If risk premiums and forecast errors show up in UIP differentials for all countries, these differentials may share common factors. Adler and Dumas (1983), for example, derive an international asset pricing model. In their model, the forward rate is a biased predictor of the spot rate due to risk premiums. These risk premiums show up in all currencies and may be interpreted as common factors. Furthermore peso-problems, related to realignments,

\footnotetext{
${ }^{6}$ See chapter 2 for a theoretical exposition on risk premiums.
} 
might as well show up in multiple currencies. One way to deal with these common fartors is to use the cross-sectional information over different currencies. At each time period, we use cross-sectional information to remove the common factor from all currencies. We pool, therefore, the data and use a panel approach to which we now turn. This approach provides an efficient test of the unbiasedness hypothesis.

\subsection{Panel Approach}

It should be clear from the outset that our purpose here is not to discover the ultimate determinants of empirically observed deviations from UIP. We leave the source of such deviations unspecified, but instead intend to provide supportive evidence that there is reason to believe that hidden below a mix of disturbing factors, UIP is a fact of life and not just a theoretical construct. Simultaneously, our approach may offer suggestions for the most promising direction of future research into the causes of UIP violations.

The central theme of this chapter is the use of panel models to provide an alternative perspective on reality compared with time series models. To provide a link between the two, section 4.3 .1 contains the results of a simple fixed effects pooling model. This may be interpreted as a joint multivariate time series regression of equation 4.1 where all currencies are assumed to share a common time-dependent intercept but are allowed to have different betas. Subsequently, we impose the additional assumption of a common slope coefficient across countries and add country specific intercepts to the specification. Obviously, the results depend on the benchmark currency in this model. Section 4.3 .2 develops a benchmark invariant random effects model and test it under various assumptions on the covariance structure.

\subsubsection{The Fixed Time Effects Model}

In the fixed time effects model the error term $\psi_{i 0}(t)$ in equation $(4.1)$ is modelled as:

$$
\psi_{i 0}(t)=\mu(t)+\epsilon_{i 0}(t),
$$

where the common factor, $\mu(t)$, is assumed to be fixed parameters and the remainder disturbances $\epsilon_{i 0}(t)$ stochastic. In vector notation substitution of equation (4.2) into the times series model (4.1) yields:

$$
\Delta S_{0}(t+1)=B_{0} F_{0}(t)+\mu(t) \iota+\epsilon_{0}(t),
$$


where $\Delta S_{0}(t+1)=\left(\Delta s_{10}(t+1), \ldots, \Delta s_{N 0}(t+1)\right)^{\prime}, F_{0}(t)=\left(\left(s_{10}-f_{10}\right)(t), \ldots,\left(s_{N 0}-\right.\right.$ $\left.\left.f_{N 0}\right)(t)\right)^{\prime}, \epsilon_{0}(t)=\left(\epsilon_{10}(t), \ldots, \epsilon_{N 0}(t)\right)^{\prime}, \iota$ is a $(N \times 1)$ unit vector and $B_{0}$ is a $(N \times N)$ diagonal matrix with slope coefficients $\beta_{i 0}$ for each currency $i$ denoted in numeraire currency 0 on the diagonal.

We now define the transformation matrix: $\tilde{Q}=I-\frac{1}{N} \iota \iota^{\prime}$. Premultiplying any matrix $X$ by $\tilde{Q}$ transforms $X$ into a matrix wherein from each element at time $t$ the cross sectional mean is subtracted. Since $\mu$ is constant over all $i$ premultiplying equation (4.3) by $\dot{Q}$ wipes out the time fixed effect. Note that this definition causes $\mu$ to be numeraire dependent.

In table 4.3 the estimated slope coefficients for the simple fixed time effects model are presented for the total sample period 1979-1996 with respect to both the USD and DEM as numeraire currencies. Compared with the time series results in table 4.2 , the coefficients have in general moved towards unity. This holds for all USD exchange rates and most DEM exchange rates.

For the USD exchange rates, the null hypothesis that the slope coefficient is unity cannot be rejected for Canada, Ireland, Italy, Spain and Sweden at the $5 \%$ level, and for France and Norway not at the $10 \%$ level. For the DEM exchange rates no rejection at the $5 \%$ level is observed for Austria, Belgium, Ireland, Spain, and the United States, and at the $1 \%$ level for France and Sweden. However, note that in a considerable number of these cases, rejection of the hypothesis that the coefficient is equal to zero is impossible as well.

Now, we maintain the time-dependent intercepts and impose the additional restriction that the slope coefficients are equal across countries. The single slope coefficient reflects the average performance of the forward premium as an unbiased predictor of the future change in the spot rate across all currencies considered. Apart from the use of time-dependent intercepts, this model is comparable to Bilson (1981), Flood and Rose (1994), and Lothian and Simaan (1995). Following Flood and Rose (1994), we also estimate this model with country-specific intercepts. While the time-dependent intercepts may be interpreted as the common movement of the numeraire currency against all others that is unexplained by the forward premiums, the country-specific intercepts are thought to capture systematic biases between each country and the benchmark.

The results are presented in table 4.4, again for two numeraire currencies and for both the total sample period and the two subperiods. With only time-dependent intercepts, the common slope coefficient is estimated to be 0.46 and 0.41 with respect to the USD and DEM as benchmark respectively over the total sample. Similar magnitudes are found for the first subperiod, while a decline occurs to 0.25 and 0.28 in the second subperiod. The similarity 
TABlE 4.3: Country Specific Slope Coefficients

\begin{tabular}{l|cc|cc}
\hline \hline & \multicolumn{2}{|c|}{ USD } & \multicolumn{2}{c}{ DEM } \\
\hline Austria & 0.35 & $(0.36)$ & 1.55 & $(1.33)$ \\
Belgium & 0.08 & $(0.39)$ & 0.45 & $(0.31)$ \\
Canada & 0.77 & $(0.57)$ & -0.36 & $(0.30)$ \\
Denmark & -0.28 & $(0.29)$ & 0.21 & $(0.25)$ \\
France & 0.34 & $(0.29)$ & 0.47 & $(0.24)$ \\
Germany & 0.08 & $(0.32)$ & - & - \\
Ireland & 0.82 & $(0.25)$ & 0.63 & $(0.21)$ \\
Italy & 0.61 & $(0.20)$ & 0.36 & $(0.17)$ \\
Netherlands & -0.10 & $(0.36)$ & -0.26 & $(1.17)$ \\
Norway & 0.37 & $(0.28)$ & 0.25 & $(0.23)$ \\
Spain & 0.91 & $(0.17)$ & 0.71 & $(0.15)$ \\
Sweden & 0.75 & $(0.25)$ & 0.48 & $(0.25)$ \\
Switzerland & -0.02 & $(0.28)$ & -0.37 & $(0.63)$ \\
United Kingdom & 0.20 & $(0.25)$ & 0.03 & $(0.28)$ \\
United States & - & - & 0.35 & $(0.34)$ \\
\hline & Notes: Slope coefficients are based on a fixed time effects \\
model for exchange rates expressed against the USD and the \\
DEM for the sample period 1979-1996. Robust standard er- \\
rors are given in parentheses. \\
\hline \hline
\end{tabular}

of the coefficients across numeraire currencies suggests that this model is approximatcly benchmark-invariant. Although, the estimated coefficients differ significantly from unity, so that UIP has to be rejected, the average result is considerably more in accordance with UIP than the evidence from the bilateral regressions in table 4.2. Both over the total period and the first subperiod the coefficient is significantly different from zero as well. If we do not include fixed time effects the slope coefficient is much smaller.

The additional use of country-specific individual intercepts takes away most of the gain. The slope coefficients decline in magnitude, though they remain positive. No significant coefficients are found for the DEM. For the USD, only a significant coefficient of 0.28 for the whole period is observed. Apparently, the individual intercept and the forward premium to some extent compete in explaining individual country's exchange rate changes against the numeraire currency. Partly, this may be due to the sometimes extremely low time series variation of the forward premium (see table 4.1).

Table 4.5 contains test statistics for restrictions imposed on the various models. The restriction of equal slope coefficients across countries is rejected at the $5 \%$ level for the USD denominated test, however it is not rejected for the DEM denominated test. The exclusion of time effects is strongly rejected, illustrating the importance of using a time 
TABLE 4.4: Panel Fixed Time Effects

\begin{tabular}{l|ccc|ccc}
\hline \hline $\begin{array}{l}\text { Sample } \\
\text { Period }\end{array}$ & No & Time & $\begin{array}{c}\text { Time \& } \\
\text { Indv. }\end{array}$ & No & Time & $\begin{array}{c}\text { Time \& } \\
\text { Indv. }\end{array}$ \\
\hline & \multicolumn{3}{|c|}{ USD } & & \multicolumn{3}{c}{ DEM } \\
\hline $1979-1996$ & -0.025 & 0.46 & 0.27 & 0.30 & 0.41 & 0.20 \\
& $(0.16)$ & $(0.09)$ & $(0.12)$ & $(0.13)$ & $(0.10)$ & $(0.13)$ \\
$1979-1986$ & -0.16 & 0.53 & 0.28 & 0.40 & 0.46 & 0.13 \\
& $(0.21)$ & $(0.11)$ & $(0.18)$ & $(0.14)$ & $(0.12)$ & $(0.64)$ \\
$1987-1996$ & 0.30 & 0.25 & 0.06 & -0.17 & 0.28 & 0.18 \\
& $(0.26)$ & $(0.15)$ & $(0.20)$ & $(0.16)$ & $(0.17)$ & $(0.22)$ \\
\hline
\end{tabular}

Notes: The table contains slope coefficients of panel models. All exchange rates are expressed in DEM or in USD. Standard errors are given in parenthesis.

TABLE 4.5: F-Test Restrictions

\begin{tabular}{|c|c|c|c|}
\hline & Country Specific Slope & Time Effects & Individual Effects \\
\hline \multicolumn{4}{|l|}{ USD } \\
\hline & $\begin{array}{c}F_{1}(13,2677)=1.99 \\
p=0.03\end{array}$ & $\begin{array}{c}F_{2}(207,2690)=52.04 \\
p=0.00\end{array}$ & $\begin{array}{c}F_{3}(13,2677)=0.468 \\
p=0.94\end{array}$ \\
\hline & $\begin{array}{c}F_{1}(13,2677)=1.62 \\
p=0.07\end{array}$ & $\begin{array}{c}F_{2}(207,2690)=5.56 \\
p=0.00\end{array}$ & $\begin{array}{c}F_{3}(13,2677)=0.46 .8 \\
p=0.94\end{array}$ \\
\hline $\begin{array}{l}\text { Note } \\
\text { and } \\
F \text {-st: }\end{array}$ & $\begin{array}{l}\text { tests for slope coefficie } \\
\text { ts for equal individual } \\
\text { with } F(m, T-k) \text { degr }\end{array}$ & $\begin{array}{l}\text { cross countries, } \bar{F}_{2} \text { te } \\
\text { ients across countries } \\
\text { freedom. }\end{array}$ & $\begin{array}{l}\text { or significant time effect } \\
\text { lenotes the } p \text {-value of the }\end{array}$ \\
\hline
\end{tabular}

dependent common factor in exchange rates. Finally, the inclusion of individual effects is never rejected.

Overall, although our results still do not provide unambiguous support in favor of UIP, it is suggestive of the potential of the panel approach. Even this simple pooling model appears to be able to take account of part of the bias that is present in the time series approach. Pooling of the data, imposing a common time-invariant intercept -which may capture a common average factor behind the exchange rate behaviour against a specific benchmark- and restricting the slope coefficients to be equal across countries, result in a significant improvement over more traditional UIP tests. In the next subsection we extend our work in this direction. 


\subsubsection{The Random Effects Model}

We now generalize the previous fixed effects model in three directions. First, allowance is made for common factors (systematic shocks) that may affect all countries with differing intensities. Second, individual country-specific effects are included. Instead of modeling these as constant dummy variables (the fixed time effects in the previous section), they are now modeled as stochastic error terms (random effects) and taken account for in the covariance matrix of the disturbances. Third, the model is made benchmark-invariant. We follow Mahieu and Schotman (1994) to decompose the error term in the UIP relation. ${ }^{7}$ Suppose we have a sample of $N+1$ countries numbered $i=0,1, \ldots, N$ and all exchange rates are expressed relative to the same numeraire currency 0 . The error term in the UIP relation is decomposed as:

$$
\psi_{i 0}(t)=\psi_{i}(t)-\psi_{0}(t)
$$

The error term is the difference between an error term $\psi_{i}$ for currency $i$ and an error term for the numeraire 0 currency. The error term $\psi_{i}$ itself is the sum of $M$ factors common to all countries and one country specific factor:

$$
\psi_{i}(t)=\sum_{m=1}^{M} \gamma_{i m} w_{m}(t)+e_{i}(t),
$$

where $\gamma_{i m}$ is the sensitivity of country $i$ for the systematic shock, $w_{m}(t)$, and $e_{i}(t)$ is a country specific shock. The sensitivities may be interpreted as factor loadings to common risk factors. We assume that country specific shocks are mutually uncorrelated and have a variance $\lambda_{i}$. Moreover, the systematic shocks are also mutually uncorrelated with all variances normalized to unity. From equations (4.4) and (4.5) one can write the error term as:

$$
\psi_{i 0}(t)=\sum_{m=1}^{M}\left(\gamma_{i m}-\gamma_{0 m}\right) w_{m}(t)+e_{i}(t)-e_{0}(t) .
$$

All exchange rates expressed against a common numeraire currency contain the country specific random factor of the numeraire currency. In the panel literature this is called a random time effects model (see Baltagi (1995)) which can be efficiently estimated with generalized least squares (GLS). The systematic shocks enter the error term with sensitivities $\left(\gamma_{i m}-\gamma_{0 m}\right)$. The variance of the error term $\psi_{\mathrm{io}}(t)$ is:

$$
\operatorname{Var}\left(\psi_{i 0}\right)=\sum_{m=1}^{M}\left(\gamma_{i m}-\gamma_{0 m}\right)^{2}+\lambda_{i}+\lambda_{0},
$$

and the covariance of $\psi_{i 0}(t)$ and $\psi_{j 0}(t)$ is:

$$
\operatorname{Cov}\left(\psi_{i 0}, \psi_{j 0}\right)=\sum_{m=1}^{M}\left(\gamma_{i m}-\gamma_{0 k}\right)\left(\gamma_{j m}-\gamma_{0 m}\right)+\lambda_{0} .
$$

\footnotetext{
7 This specification generalizes the one used in chapter 3 .
} 
Let $\Sigma_{0}$ be the covariance matrix of the error term: $\psi_{0}=\left(\psi_{10}, \ldots, \psi_{N 0}\right)^{\prime}$. The covariance matrix contains $(N+1)(M+1)$ parameters. The factor structure of the error term imposes restrictions on the covariance matrix if $(N+1)(M+1)<\frac{1}{2}(N+1) N$ or equivalent if $M<\frac{1}{2} N-1$. The covariance matrix can be written as:

$$
\Sigma_{0}=\sum_{m=1}^{M} \tilde{\gamma}_{0 m} \tilde{\gamma}_{0 m}^{\prime}+\Lambda_{0}+\jmath_{0} \iota \iota^{\prime}
$$

where $\tilde{\gamma}_{0 m}=\left(\left(\gamma_{1 m}-\gamma_{0 m}\right), \ldots,\left(\gamma_{N m}-\gamma_{0 m}\right)\right)^{\prime}$ and $\boldsymbol{A}_{0}$ is a matrix with elements $\lambda_{1}, \ldots, \lambda_{N}$ on the principal diagonal and zeros elsewhere, and $\iota$ the $(N \times 1)$ vector of ones.

Let $\Delta S_{0}(t+1)=\left(\Delta s_{10}(t+1), \ldots, \Delta s_{N 0}(t+1)\right)^{\prime}$ be the $(N \times 1)$ vector of the logarithms of all bilateral exchange rates against the common numeraire currency 0 , let $F_{0}(t)=$ $\left(\left(s_{10}-f_{10}\right)(t), \ldots,\left(s_{N_{0}}-f_{N 0}\right)(t)\right)^{\prime}$ be the $(N \times 1)$ vector of forward premiums and let $U_{0}(t+1)=\left(\psi_{10}(t+1), \ldots, \psi_{N 0}(t+1)\right)^{\prime}$ the $(N \times 1)$ vector of error terms with covariance matrix $\Sigma_{0}$. In vector notation the pooled regression model reads:

$$
\Delta S_{0}(t+1)=\beta_{0} F_{0}(t)+U_{0}(t+1)
$$

and suppressing the time subscript, the maximum likelihood estimator of $\beta_{0}$ is:

$$
\beta_{0}=\sum_{t=1}^{T}\left(F_{0}^{\prime} \Sigma_{0}^{-1} F_{0}\right)^{-1}\left(F_{0}^{\prime} \Sigma_{0}^{-1} \Delta S_{0}\right)
$$

Oue ultraction of the maximum likelihood estimator is that it is invariant with respect to the choicr of the numeraire currency. Now introduce an $(N \times N)$ transformation matrix $\boldsymbol{P}_{k}$ with -1 s on the $k$-th row, 1 s along the principal diagonal except for the $k$-th row, and 0 s elsewhere. The transformation for $S_{0}$ If we go from numeraire 0 to numeraire $k$ the transformation for $S_{0}$ is:

$$
\Delta S_{k}=\boldsymbol{P}_{k} \Delta S_{0}
$$

Combining equations (4.11) and (4.12) we obtain:

$$
\beta_{0}=\sum_{t=1}^{T}\left(F_{k}^{\prime} \boldsymbol{P}_{k}^{\prime} \Sigma_{0}^{-1} \boldsymbol{P}_{k} F_{k}\right)^{-1}\left(F_{k}^{\prime} \boldsymbol{P}_{k}^{\prime} \boldsymbol{\Sigma}_{0}^{-1} \boldsymbol{P}_{k} \Delta S_{k}^{\prime}\right)
$$

From equation (4.13) and the fact that $\boldsymbol{P}_{k}^{-1}=\boldsymbol{P}_{k}$ it follows that if $\beta_{0}=\beta_{k}$ it must be true that $\boldsymbol{\Sigma}_{k}=\boldsymbol{P}_{k}^{\prime} \boldsymbol{\Sigma}_{0} \boldsymbol{P}_{k}$. The transformation of covariance matrix (4.9) is:

$$
\boldsymbol{P}_{k}^{\prime} \boldsymbol{\Sigma}_{0} \boldsymbol{P}_{k}=\sum_{m=1}^{M} \tilde{\gamma}_{k m} \tilde{\gamma}_{k m}^{\prime}+\boldsymbol{A}_{k}+\jmath_{k} \iota \iota^{\prime}=\boldsymbol{\Sigma}_{k}
$$

which implies that the paraneter estimate is invariant to the choice of the numeraire currency. 
Four different assumptions are implemented for the covariance structure. First, the covariance matrix is estimated without restrictions, allowing for an unknown but differential impact of the common factors. The unrestricted covariance matrix is an $N \times N$ matrix with $\frac{1}{2}(N+1) N$ free parameters. Second, the covariance matrix in equation $(4.9)$ is estimated with one common factor $(m=1)$, that influences currencies with different intensity. This assumption leads to the following specification of the covariance matrix:

$$
\Sigma_{0}=\tilde{\gamma}_{01} \tilde{\gamma}_{01}^{\prime}+\Lambda_{0}+\jmath_{0} \iota \iota^{\prime}
$$

Third, the covariance matrix is assumed to have the structure as in equation (4.16) with $N+1$ parameters. Here, exchange rate changes are assumed not to depend on any common factors so that only idiosyncratic noise influences the dependent variable. In this case $\gamma_{i m}$ equals $\gamma_{0 m}$ for $(i, m)=(1, \ldots, N ; 1, \ldots, M)$ and the exchange rate change in currency $i$ against the numeraire does not depend on the systematic shocks. The covariance matrix now becomes:

$$
\Sigma_{0}=\Lambda_{0}+\lambda_{0} \iota \iota^{\prime} .
$$

Fourth, we follow Koedijk and Schotman (1990) and impose the restriction on equation (4.16) that all country specific shocks have equal variance, that is: $\succ_{0}, \ldots, \lambda_{N}$ in equation (4.16) are equal to $\frac{1}{2} \sigma^{2}{ }^{8}$ Under this set of restrictions the covariance matrix takes the form:

$$
\Sigma_{0}=\frac{1}{2} \sigma^{2}\left(I+\imath \iota^{\prime}\right),
$$

with $\boldsymbol{I}$ the $(N \times N)$ identity matrix. For this covariance structure it holds that $\boldsymbol{\Sigma}_{k}=\boldsymbol{P}_{k}^{\prime} \boldsymbol{\Sigma}_{0} \boldsymbol{P}_{k}$ $=\Sigma_{0}=\Sigma$, which implies that for every choice of the numeraire currency the covariance matrix is exactly the same. Because the covariance matrix is completely specified up to a scalar the GLS estimator is directly applicable. In chapter 3 we note that the covariance structure in equation (4.17) is equivalent to a simple transformation of the data:

$$
\Delta \tilde{S}_{0}=Q \Delta S_{0}=\Delta S_{0}-\left(1-\frac{1}{\sqrt{N+1}}\right) \Delta \bar{S},
$$

where $\boldsymbol{Q}$ is $I-\left(1-\frac{1}{\sqrt{N+1}}\right) \frac{1}{N} u c^{\prime}$ which has the property that $Q Q^{\prime}=\boldsymbol{\Sigma}^{-1}$ and $\bar{S}$ is a vector with elements $\frac{1}{N} \sum_{j=1}^{N} \Delta s_{j 0}$, the effective exchange rate of currency 0 . The transformation for the forward premium is similar. We can now simply apply OLS on the transformed variables. Note that for large $N, \boldsymbol{Q}$ is approximately equal to $\tilde{\boldsymbol{Q}}$ in the fixed time effects model, which explains the approximate benchmark invariance of table 4.4 .

Table 4.6 contains maximum likelihood estimates for the slope coefficient of the random effects model. The slope estimates across these four specifications range from 0.43 to 0.55 and are, thus, quite close, despite the relatively large differences of the respective likelihood

\footnotetext{
8 This specification is alsa considered in chapter 3.
} 
TABLE 4.6: Panel Random Time Effects

\begin{tabular}{lcccc}
\hline & $(1)$ & $(2)$ & $(3)$ & $(4)$ \\
\hline$\hat{\beta}$ & 0.50 & 0.54 & 0.55 & 0.43 \\
se $(\beta)$ & $(0.06)$ & $(0.06)$ & $(0.06)$ & $(0.10)$ \\
Loglik & -1724 & -1940 & -2275 & -3198 \\
\hline Notes: Loglik denotes the log likelihood. Column (1) corresponds \\
to the unrestricted covariance matrix (4.9), column (2) corresponds \\
to (4.9) with $m=1$, column (3) corresponds to covariance ma- \\
trix (4.16) and column (4) corresponds to covariance matrix (4.17). \\
\hline \hline
\end{tabular}

values. ${ }^{9}$ The first common factor explains a large amount of the cross-sectional dependence but the imposed restrictions must be rejected. However, we conclude that in all cases the estimated slope is quite insensitive to these restrictions, so that we feel rather confident with respect to the robustness of the result. Note that the results are also similar to the full-sample fixed time effects in table 4.4, as could be expected. Again, though UIP has to be rejected, the results point in the right direction.

The results found here indicate that the deviations from UIP are not that far as was assumed previously. Our suggestion is that the time series approach is not suited to account for several factors that incorporate biases in the times series results that may exist simultaneously. The panel model setup as suggested accounts for these phenomena on average over all currencies being considered.

The results shown in the previous text, indicate a sharp improvement of the slope coefficient in the UIP test. Although, for some currencies the slope coefficient does not statistically differ from one, UIP is still rejected for a majority of currencies. In the following we concentrate us on explanations for these UIP deviations. In performing this analysis we altered the above analysis in such a way that we restricted the slope coefficient to be equal for all currencies.

\subsection{Outliers and EMS Realignments}

To investigate the remaining gap between the theoretical slope coefficient of one and the empirically estimated 0.5, we now follow Bilson (1981) and Flood and Rose (1994) and distinguish between large and small observations in our analysis.

\footnotetext{
${ }^{2}$ The models can easily be compared by means of a likelibood ratio test.
} 

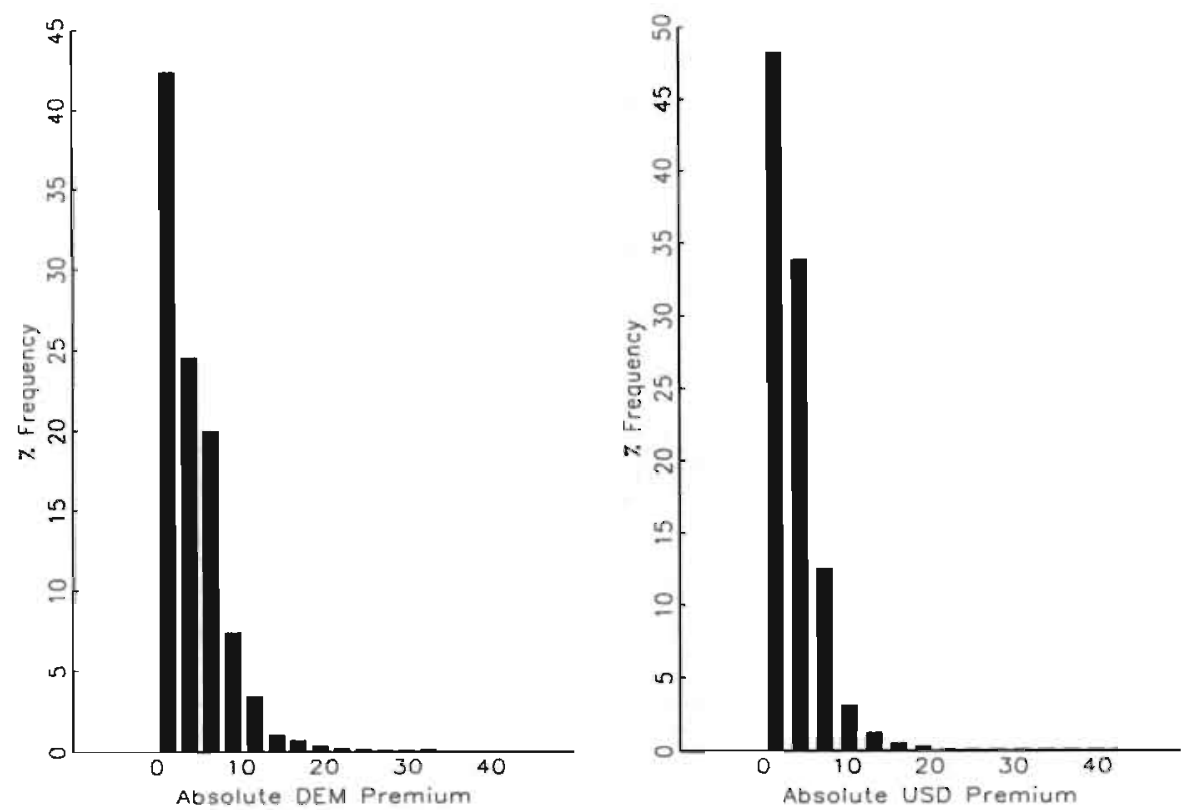

FIgURE 4.1: Annualized Absolute Forward Premium

Bilson (1981) investigates the effect of using forward premiums larger than $10 \%$ in absolute value compared to a forward premium smaller than $10 \%$. Bilson (1981) finds a significant difference between large and small forward premiums in tests of UIP. Figure 4.1 contains histograms of the annualized forward premium expressed against the USD and the DEM. The $5 \%$ right tail observations are approximately forward premiums in excess of $10 \%$. The $10 \%$ tight tail approximately contains premiums larger than $5 \%$.

We now estimate the random effects model with the restricted covariance matrix in equation (4.17), but this time we distinguish between large premiums and small premiums, by including for a separate slope coefficient for the largest observations of the forward premium. We do not consider the outliers of the absolute forward premiums for the individual currencies but the outliers of the cross-sectional standard deviation of the forward premium defined as $\sigma(t)=\left(F_{0}(t)^{\prime} \Sigma_{0}^{-1} F_{0}(t)\right)^{\frac{1}{2}}$. We now divide the observations in two separate samples. The first sample contains $5 \%$ of the months with the largest cross-sectional standard deviation. The second sample contains the remaining observations. The advantage of this procedure is that the cross-sectional standard deviation is numeraire invariant and. therefore the slope coefficients are the same for every choice of the numeraire currency. ${ }^{10}$

${ }^{10}$ Results are similar when we consider outliers of the absolute for ward premium for individual countries. 


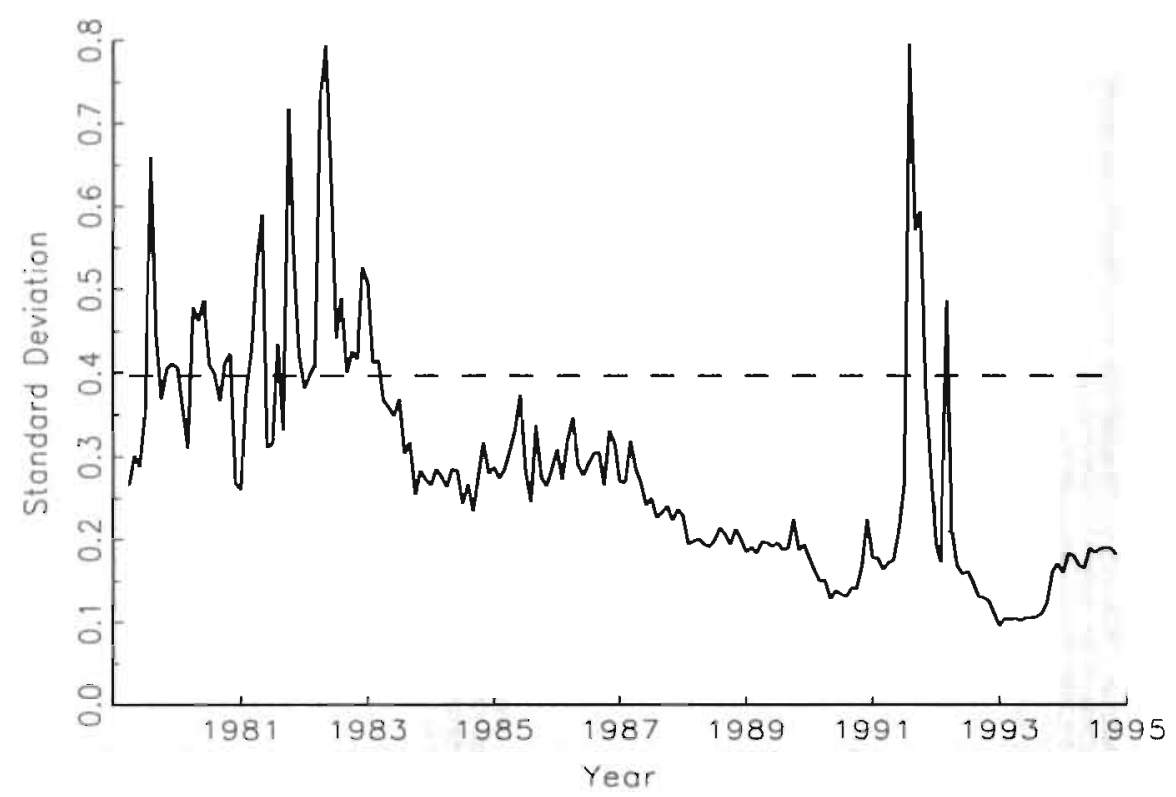

Figure 4.2: Cross-Sectional Standard Deviation

Note: The dashed line denotes $20 \%$ outliers.

Figure 4.2 displays a time series plot of the estimates of the cross-sectional standard deviation $\sigma(t)$. The figure clearly shows two periods of large cross-sectional standard deviations. First, the initial period of the EMS in the early eighties. Second, the period around the EMS crisis in 1992 and 1993.

The results in table 4.7 clearly show that the relation between the forward premium and the future spot rate differ between periods with normal observations and periods indicated as outliers $(5 \%)$. The value of the estimated slope coefficient comes very close to unity, especially when only the $5 \%$ largest observations are used. In the first panel of figure 4.3 we have graphed the slope coefficient versus the number of outliers in percentages. As can be seen, when only the largest observations are used the coefficient is close to unity and the theoretical relationship of UIP seems to hold. If more and more observations are included coefficient decreases and the deviations from uncovered interest rate parity increase. The slope coefficient on the remaining observations is small. Our results from table 4.7 and figure 4.3 clearly indicate that the relationship between the forward premium and the future change in the spot rate, as suggested by UIP, tends to be particular strong in periods with large forward premiums, i.e. periods with high volatility. 
TABLE 4.7: UIP and Outliers

\begin{tabular}{|c|c|}
\hline Normal Days & $\overline{\text { Outlier Days }}$ \\
\hline 0.24 & 1.04 \\
\hline$(0.11)$ & $(0.20)$ \\
\hline $\begin{array}{l}\text { Notes: Outliers are } \\
\text { servations in terms } \\
\text { of the forward pren }\end{array}$ & $\begin{array}{l}\text { s the } 5 \% \text { largest ob- } \\
\text { erage absolute value }\end{array}$ \\
\hline
\end{tabular}

A few conjectures could possibly explain the observed phenomenon. The first explanation for our results would be in line with work of Baldwin (1990). In his work Baldwin (1990) argues that even the presence of small transaction costs may lead to a large inactivity band within which no arbitrage takes place. Baldwin implements his theoretical model by making additional assumptions with respect to the plausible values of the model's parameters to arrive at the conclusion that interest differentials between one and four percent on an annual basis may persist without introducing arbitrage flows. ${ }^{11}$

Another explanation would be peso-problems. The recent experience with exchange rates within the EMS might be a situation where peso-problems, like for instance the risk of realignments, might frequently occur. Recently, Flood and Rose (1994) have investigated UIP within the EMS and show that the coefficient of the forward premium in pooled tests of UIP is 0.6 for these currencies. Moreover, they have investigated the effect of the realignments on tests of UIP and find that excluding the realignment observations from the sample leads to a sharp drop in the coefficient of the forward premium. Flood and Rose (1994) attribute this to the peso-problem that arise from expectations about future realignment possibilities. Flood and Rose (1994) estimate that the peso-problem for EMS exchange rates leads to a bias of 0.35 , which is equal to the difference between the slope coefficients in the UIP regressions when the latter is estimated with and without realignments.

To get an idea of the influence of realignments on the UIP differentials we first recalculate the average differentials in table 4.1 but this time we exclude the realignment days from the sample. The average UIP differentials in table 4.8 are generally larger in magnitude than the UIP deviations calculated for the complete sample.

Given the findings of Flood and Rose (1994), we now investigate whether the outlier results can be solely attributed to EMS realignments.

\footnotetext{
"Interestingly, in a recent survey Rogoff (1996) also mentions inactivity bands as a potential explanation for persistent deviations from PPP.
} 
TABLE 4.8: Average UIP Differentials

\begin{tabular}{|c|c|c|c|c|}
\hline & $\mu$ & $\mathrm{SE}(\mu)$ & $\mu$ & $\mathrm{SE}(\mu)$ \\
\hline & \multicolumn{2}{|c|}{ USD } & \multicolumn{2}{|c|}{ DEM } \\
\hline Austria & 1.18 & $(3.06)$ & $-0.68^{\dagger}$ & $(0.32)$ \\
\hline Belgium & 0.56 & $(3.01)$ & $-1.31^{\dagger}$ & $(0.66)$ \\
\hline Canada & -0.67 & (1.11) & -2.54 & (3.16) \\
\hline Denmark & -0.42 & (2.98) & $-2.29^{\dagger}$ & $(0.78)$ \\
\hline France & -0.93 & $(2.94)$ & $-2.80^{\dagger}$ & $(0.65)$ \\
\hline Germany & 1.87 & $(3.08)$ & - & - \\
\hline Ireland & -1.28 & $(2.82)$ & $-3.16^{\dagger}$ & $(0.83)$ \\
\hline Italy & -2.69 & $(2.88)$ & $-4.56^{\dagger}$ & $(1.51)$ \\
\hline Netherlands & 1.53 & (3.04) & -0.33 & $(0.31)$ \\
\hline Norway & -0.81 & $(2.65)$ & $-2.68^{\dagger}$ & $(1.35)$ \\
\hline Spain & -3.06 & $(2.80)$ & $-4.92^{\dagger}$ & (1.53) \\
\hline Sweden & -0.74 & $(2.71)$ & -2.61 & $(1.92)$ \\
\hline Switzerland & 3.74 & $(3.35)$ & 1.86 & $(1.25)$ \\
\hline United Kingdom & -0.51 & $(2.95)$ & -2.37 & $(2.32)$ \\
\hline United States & -. & - & -1.87 & $(3.08)$ \\
\hline
\end{tabular}

Notes: $\mu, \mathrm{SE}(\mu)$ denote the mean UIP differential and the standard error of the UIP differential respectively. The summary statistics cover sample period from January 1979 until March 1996. Units are percents per annum. ${ }^{\dagger}$ denotes rejection at the $5 \%$ level.

We now replicate table 4.7 but exclude all realignment days and find that realignments do no explain it all. When EMS realignments are excluded from the sample the slope coefficient on the outlier observations $(5 \%)$ is 0.58 and significantly different from zero. ${ }^{12}$ However, the coefficient on the normal observations is -0.06 and not significantly different from zero. In the second panel of figure 4.3 we graph the slope coefficients versus the number of outliers in percentages, when realignments are excluded. Again, the line that contains the coefficients of the outlier observations lies substantially above the line that contains the normal coefficients. These results indicate that large forward premiums predict exchange rate changes and these large premiums are not only related to realignments.

\footnotetext{
${ }^{12}$ We also considered a covariance matrix that explicitly allows for two exchange rate regimes. The first regime consists of EMS currencies, $j=1, \ldots, f$, that are targeted against currency 0 , the DEM. The second regime consists of currencies $k=f+1, \ldots, N$ that are floating against the DEM. The German error component is defined: $\psi_{0}(t)=\gamma_{01} w_{1}(t)+\gamma_{02} u_{2}(t)+e_{0}(t)$ where $w_{1}$ is the EMS factor and $w_{2}$ is the float factor. The error components of the EMS currencies consist of the EMS factor $w_{1}(t)$ with loading $\gamma_{j 1}$ and a country specific factor. The floating currencies consist of the float factor $u_{2}(t)$ with loading $\gamma_{k 2}$ and also a country specific factor. For this exchange rate system the covariance matrix becomes: $\boldsymbol{\Sigma}_{0}=W_{1}+W_{2}+\lambda_{0}+\lambda_{0} \iota \iota^{\prime}$, where $W_{1}$ is a block matrix with a block that contains covariances of EMS currencies and zeros elsewhere, and $W_{2}$ is a block matrix that contains covariances of floating currencies and zeros elsewhere. The covariance structure allows for a different covariance between EMS currencies and floating currencies. Slope coefficients are qualitatively similar to the fully restricted covariance matrix.
} 
All Observations

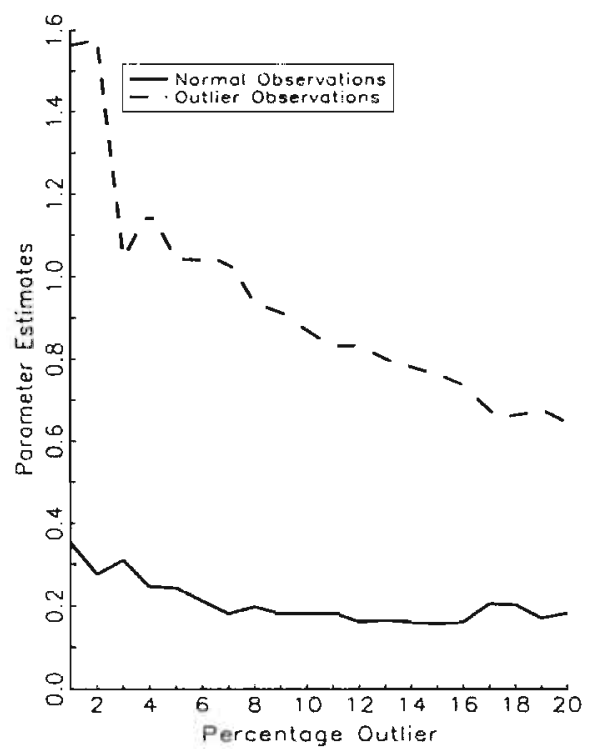

EMS Reclignments Excluded

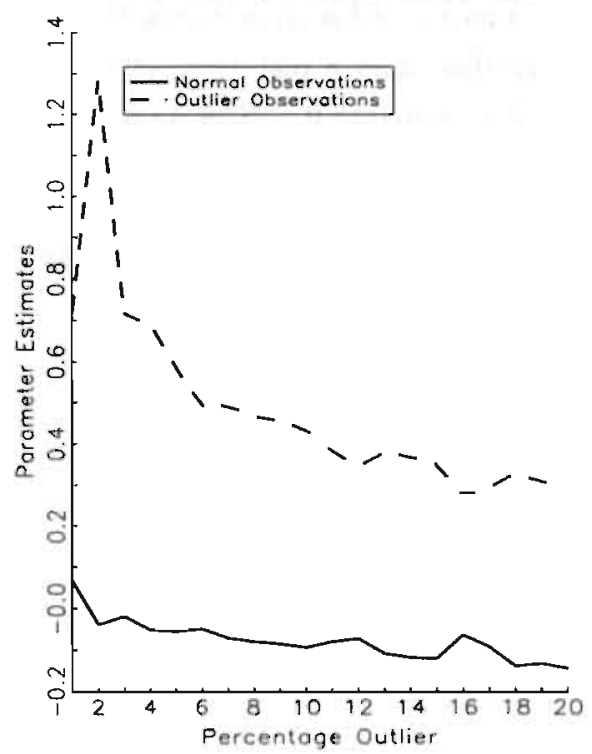

FIgure 4.3: Parameter Estimates of UIP 


\subsection{Conclusions}

There is a vast literature on the rejection of the unbiasedness of the forward premium. Many explanations like risk premiums, peso-problems and have market inefficiencies been advanced. So far, the literature has neglected the fact that the various factors explaining why the unbiasedness hypothesis may be rejected may be interrelated and in fact may share common factors. If this is the case, a panel approach is called for. In this chapter we have tested the unbiasedness hypothesis using several different panel models for fifteen countries between 1979 and 1996. We distinguish the fixed time effects model and the individual effects random time effects model. Our results indicate that the rejection of uncovered interest rate parity is not as severe as is commonly found: the panel estimates show that the slope coefficient in a regression of the forward premium on the future change in the exchange rate is equal to 0.5 . The results show that for tests of UIP it is important to pool the data and to allow for time effects. A possible explanation is that pooling increases the efficiency of the tests. Moreover, we show that the slope coefficient is very close to unity if only the largest five to ten percent of the observations are taken into account. These findings point to the potential importance of peso-problems and/or inactivity bands as explanation for the rejection of UIP. 


\section{Chapter 5}

\section{Real Interest Rates and Shifts in}

\section{Macroeconomic Volatility}

A growing amount of empirical research over the past five years provides evidence that the relation between current nominal interest rates and future inflation is strongly country and period dependent. ${ }^{1}$ More precisely, Evans and Lewis (1995b) for instance provide empirical evidence that real interest rates appear to be subject to persistent shocks, which cloud the relation between nominal interest rates and inflation. They blame the apparent. nonstationarity of real interest rates to expected changes in inflation regimes that cause peso-type problems in small samples. In a closely related study, Tzavalis and Wickens (1996) use an ad hoc dummy to capture the change in monetary regirne in the early eighties. When included, this dummy restores the traditional one-to-one effect of expected inflation to nominal interest rates in the United States.

Movements in real interest rates are at the heart of research in macroeconomics as well as in finance and have been the subject of extensive study. ${ }^{2}$ Macroeconomic explanations of real interest rate changes generally focus on the role of economic state variables like budget, deficits, expected economic growth, favourable changes in business taxation, the price of energy, monetary policy and inflation. In finance, asset pricing theory in a straightforward way leads to the role of risk, which is often captured by the (conditional) covariance of real returns and the market index or consumption. Here, we intend to blend these

\footnotetext{
${ }^{1}$ Similarly, attempts to predict future inflation changes using the slope of the term structure of nominal interest rates yield disappointing results. See Fama (1984, 1990), Mishkin (1990a, 1990b), Jorion and Mishkin (1991) and Koedijk and Kool (1995).

${ }^{2}$ See Bodie, Kane and MacDonald (1983), Wilcox (1983), Huizinga and Mishkin (1986), Barro and Sala-I-Martin (1990) and Lucas (1990).
} 
two approaches, in accordance with Cochrane (1994), who points out the importance of the relation between asset pricing and macroeconomic risk. Cochrane states: "Thus, the central task of finance is to understand and measure what are the sources of aggregate or macroeconomic risk that drive asset prices".

Empirically, modeling financial risk premiums requires the computation of some proxy for conditional variances. With respect to computing conditional second moments no unique and optimal choice exists. The last decade has witnessed a surge in the number of available econometric techniques for estimating time-varying conditional variances. An important element of this development is the discussion on the stationarity of the conditional variances and hence risk premiums. Recently, it has been suggested by Evans and Lewis (1994) that permanent shocks to risk premiums are important and that risk premiums in financial markets can be marginally nonstationary. For the empirical technique involved in estimating risk premiums this implies that it should explicitly allow for the possibility that conditional second moments have unit roots.

In this chapter we extend the existing literature along the following lines. First, we develop a simple intertemporal consumption capital asset pricing model (CCAPM) to analyze the dynamics between the short-term nominal interest rate, inflation and macroeconomic volatility measures that proxy for financial risk. To this end, we formulate a CCAPM with a nominal budget constraint and use shocks to money supply and economic activity as macroeconomic state variables that drive real consumption growth. We do not a priori constrain inflation to be incorporated one-for-one in nominal interest rates, but let the data determine the strength of the link.

Second, we allow for time-varying and nonstationary conditional second moments as proxies for risk premiums. For robustness, two independent statistical methods are used for the computation of these volatility measures. On the one hand, a recursive Bayesian forecasting method - the multi state Kalman filter (MSKF) method, see Kool (1989) - is used. On the other hand, we implement the multivariate stochastic volatility (MSV) model of Harvey, Ruiz and Shephard (1994). To our knowledge, neither method has been applied before in a CCAPM framework. Reassuringly, results obtained through these methods are qualitatively similar. We find real short-term interest rates to be significantly related to the conditional variance of money growth.

The chapter is organized as follows. In section 5.1 we formulate a simple consumption based asset pricing model and extend it to account for macroeconomic state variables. Section 5.2 contains a description of the data. In section 5.3 the MSKF method and the MSV model are discussed and implemented. Section 5.4 relates nominal short-term 
interest rates to conditional variances of industrial production growth and money growth. Section 5.5 contains the conclusions.

\subsection{A Generalized Fisher Hypothesis}

Consider a consumer maximizing expected utility over a period subject to a budget constraint:

$$
\mathrm{E}_{t}\left[\sum_{t=1}^{T} \theta^{t} U\left(C_{t}\right)\right]
$$

where $\theta$ is a discount factor, $C_{t}$ is consumption at time $t$ and expectations are conditional on information at time $t$. If the general price level of this economy is not fixed, the standard Euler condition for the current price $H_{t}$ of a one-period discount bond is:

$$
\mathrm{E}_{t}\left[M_{t, t+1} \frac{P_{t}}{P_{t+1}} H_{t}\right]=1,
$$

where $M_{t, t+1}=\theta U^{\prime}\left(C_{t+1}\right) / U^{\prime}\left(C_{t}\right)$ is the marginal rate of substitution from time $t$ to $t+1$ and $P_{t}$ is the price level. The utility function is assumed to be of the class of constant relative risk aversion (CRRA): ${ }^{3}$

$$
U\left(C_{t}\right)=\frac{C_{t}^{1-\gamma}}{(1-\gamma)}
$$

where $\gamma$ is the coefficient of relative risk aversion $(\gamma \geq 0)$.

From the definition of a one-period discount bond $H_{t}=e^{-r_{t}}$ and the equilibrium condition in equation (5.2) can now be rewritten as:

$$
r_{t}=-\ln E_{t}\left[\theta\left(\frac{C_{t+1}}{C_{t}}\right)^{-\gamma}\left(\frac{P_{t}}{P_{t+1}}\right)\right],
$$

where $r_{t}$ is the one-period interest rate. An expansion of (5.4) in the second-order Taylor series around the natural logarithms of consumption and prices then yields the following approximation for $r_{t}:^{4}$

$r_{t}=-\ln (\theta)+\gamma \mathrm{E}_{t}\left[\Delta c_{t+1}\right]+\mathrm{E}_{t}\left[\pi_{t+1}\right]-\frac{1}{2} \gamma^{2} \operatorname{Var}_{t}\left[\Delta c_{t+1}\right]-\frac{1}{2} \operatorname{Var}_{t}\left[\pi_{t+1}\right],-\gamma \operatorname{Cov}_{t}\left[\Delta c_{t+1}, \pi_{t+1}\right]$,

${ }^{3}$ Weil (1989) shows that the use of a more complicated utility function in which risk aversion and intertemporal substitution are identified separately does not solve either the riskfree rate puzzle or the equity premium puzzle.

${ }_{4}^{4}$ We neglect higher order terms in the approximation. Furthermore we use that $\mathrm{E}\left[x_{t+1}-x_{t}\right]^{2}$ is approximately equal to $\operatorname{Var}\left[x_{i+1}\right]+$ higher order terms. See Lee (1995) and Pagan, Hall, and Martin (1994) for related but slightly alternative approaches to this linearization. 
where $\pi_{t+1}$ the inflation rate and $\Delta c_{t+1}$, the consumption growth rate, are approximately equal to $\ln \left(P_{t+1} / P_{t}\right)$ and $\ln \left(C_{t+1} / C_{t}\right)$. When inflation is nonstochastic, the last two terms are zero and equation (5.5) reduces to the standard Fisher parity. Then, the real interest rate depends on expected consumption and the variance of consumption shocks.

However, previous studies, see for example Chen, Roll and Ross (1986) and Ferson (1990), have shown that it is empirically difficult to find supporting evidence of the hypothesized links between aggregate consumption and financial asset returns. Partly, this may be due to measurement errors in consumption. An alternative and promising route is the use of macroeconomic state variables as proxies for consumption, see also Chen (1991). Commonly used state variables are industrial production, the term structure of interest. rates, the Treasury bill rate, the default spread, the dividend yield, consumption growth, growth of the gross domestic product, money supply and inflation.

Recently, theoretical models have been developed to explicitly incorporate money in capital asset pricing models. Examples are Stulz (1986), Labadie (1989), Marshall (1992), Lee (1995) and Chan, Foresi, and Lang (1996). Most of these papers use some version of the cash-in-advance constraint. In addition, Lee (1995), for example, imposes the equilibrium conditions that consumption equals output and money growth equals inflation. Stulz (1986) includes a monetary policy rule. The various models are non-unanimous about the sign of the effect of monetary uncertainty on real interest rates. According to Lee (1995), high monetary variability leads to lower real interest rates. Stulz (1986), however, distinguishes a number of cases where the sign of the effect of monetary uncertainty on real rates depends among other things on the correlation between monetary shocks and output shocks. Mascaro and Meltzer (1983) study the relation from a macroeconomic perspective using an extended IS/LM framework. In their analysis, increased monetary uncertainty raises the precautionary demand for money and consequently increases the real interest rate. Their empirical evidence supports the hypothesized positive relation.

In this chapter, we incorporate the potential impact of economic state variables in an admittedly ad hoc and unrestricted way. We assume that both real consumption growth and inflation are linear functions of 2 independent macroeconomic state variables, money growth $\left(\Delta m_{t}\right)$ and production growth $\left(\Delta i p_{t}\right)$, plus a random noise term with. ${ }^{5}$ Formally:

$$
\begin{aligned}
\Delta c_{t} & =\lambda_{0}+\lambda_{1} \Delta m_{t}+\lambda_{2} \Delta i p_{t}+\epsilon_{c t}, \\
\pi_{t} & =\delta_{0}+\delta_{1} \Delta m_{t}+\delta_{2} \Delta i p_{t}+\epsilon_{\pi t},
\end{aligned}
$$

where $\epsilon_{c t}$ and $\epsilon_{\pi t}$ have constant variances $\sigma_{\epsilon_{c}}^{2}$ and $\sigma_{\epsilon_{\pi}}^{2}$ respectively. Substitution of equations

\footnotetext{
${ }^{5}$ The hypothesized independence is confirmed in section 5.3 where we show that the correlation between money shocks and output shocks is not significantly different from zero.
} 
(5.6) and (5.7) into equation (5.5) and assuming constant expected consumption growth yields the following expression for the nominal interest rate:

$$
r_{t}=\alpha_{0}+E_{t}\left[\pi_{t+1}\right]+\alpha_{1} \operatorname{Var}_{t}\left[\Delta m_{t+1}\right]+\alpha_{2} \operatorname{Var}_{t}\left[\Delta i p_{t+1}\right]
$$

where the $\alpha_{i}$ 's for $i=(1,2)$ depend on the parameters $\gamma, \lambda_{i}$ and $\delta_{i}$. The intercept $\alpha_{0}$ depends on $\theta, \sigma_{\epsilon_{c}}^{2}$ and $\sigma_{\epsilon_{x}}^{2}$ and on the unconditional expectation of consumption growth. According to equation (5.8), the nominal interest rate is a linear function of the expected rate of inflation plus the variances of money and output growth. Due to the assumed independence of real and monetary shocks, no covariance terms appear in this equation. This relation may be interpreted as a generalization of the traditional Fisher hypothesis.

\subsection{Data}

The empirical analysis is based on monthly data for the United States for the period January 1968 - July 1996 (343 observations). The data are all obtained from the Federal Reserve Board. The nominal interest rate is the one-month Treasury bill rate at the last Friday of the month. The macroeconomic variables that we consider are the consumer price index (CPI), money stock (M1) and total industrial production (IP). All macroeconomic series are seasonally adjusted.

Panel A of table 5.1 provides summary statistics for the levels of the nominal interest rate, the ex post real interest rate, the inflation rate, the growth rate of money and the growth rate of production. ${ }^{6}$ The average nominal interest, rate over the sample period was $6.56 \%$ and the average inflation over this period was $5.35 \%$. The growth rates of money and industrial productivity are characterized by relatively high volatility over this period. Furthermore, the unit root hypothesis cannot be rejected for the nominal interest rate, inflation and the real interest rate. Money and output growth appear to be stationary series.

Panel B of table 5.1 contains statistics for the first differences of all previous series. The distribution of all the variables is skewed and exhibits excess kurtosis. Finally, the hypothesis of homoskedasticity is rejected for all the variables.

${ }^{6}$ The growth rate, $z_{t}$, is defined as $z_{t}=\ln \left(Z_{t} / Z_{t-1}\right) \times 1200$. 
TABLE 5.1: Summary Statistics

\begin{tabular}{|c|c|c|c|c|c|}
\hline & $r$ & $r-\pi$ & $\pi$ & $\Delta m$ & $\Delta i p$ \\
\hline \multicolumn{6}{|l|}{ A: [-evels } \\
\hline Mean & 6.56 & 1.21 & 5.35 & 6.30 & 2.63 \\
\hline Standard Deviation & 2.62 & 3.28 & 3.70 & 6.28 & 9.71 \\
\hline Minimum & 2.59 & -12.71 & $-6.5 x$ & -17.39 & -51.73 \\
\hline Maximum & 16.21 & 12.92 & 21.52 & 30.02 & 29.63 \\
\hline Dickey-Fuller(12) & -2.27 & -2.71 & -2.20 & $-3.81^{\dagger}$ & $-4.87^{\dagger}$ \\
\hline \multicolumn{6}{|l|}{ B: First Differences } \\
\hline Mean & 0.00 & 0.00 & 0.00 & -0.04 & 0.00 \\
\hline Standard Deviation & 0.67 & 3.08 & 3.09 & 6.66 & 10.59 \\
\hline Minimum & -5.99 & -20.73 & -16.20 & -31.43 & -33.07 \\
\hline Maximum & 3.09 & 15.84 & 21.52 & 20.76 & 50.43 \\
\hline Skewness & -1.74 & -0.41 & 0.48 & -0.57 & 0.44 \\
\hline Excess Kurtosis & 21.64 & 7.56 & 8.50 & 2.18 & 1.79 \\
\hline Jarque Bera & $6847^{\star}$ & $825^{\star}$ & $1041^{\star}$ & $86^{\dagger}$ & $57^{\star}$ \\
\hline Ljung-Box(12) & $24.13^{\dagger}$ & $28.60^{\star}$ & $27.37^{\star}$ & $62.70^{\star}$ & $29.43^{\star}$ \\
\hline $\operatorname{LM}(\operatorname{ARCH}(12))$ & $42.40^{*}$ & $94.66^{\star}$ & $83.82^{\star}$ & $52.00^{\star}$ & $53.19^{\star}$ \\
\hline \multicolumn{6}{|c|}{$\begin{array}{l}\text { Notes: } r, r-\pi, \pi, \Delta m \text { and } \Delta i p \text { denote the nominal interest rate, the real } \\
\text { interest rate, inflation, money growth and production growth respectively. } \\
\text { Units are percent per annum. The Dickey-Fuller statistic corrects for serial } \\
\text { correlation of order } 12 \text {. Skewness is defined as } m_{3} / s^{3} \text {, with } m_{3} \text { the centred } \\
\text { third moment of the data and } s \text { the sample standard deviation. Kurtosis } \\
\text { is defined as }\left(m_{1} / s^{4}\right)-3 \text {, with } m_{4} \text { the centred fourth moment of the data. } \\
\text { The Ljung-Box statistic is adjusted for heteroskedasticity. LM(ARCH(12)) } \\
\text { denotes the LM test. statistics for ARCH(12) effects. }{ }^{\dagger}\left({ }^{*}\right) \text { denote rejection } \\
\text { at the } 5 \%(1 \%) \text { level. }\end{array}$} \\
\hline
\end{tabular}

\subsection{Empirical Implementation}

Our objective here is to empirically investigate the link between the nominal interest rate, (expected) inflation and the conditional second moments of shocks to the proposed state variables, money and output growth. This requires computation of the conditional second numents of the innovations in the proposed state variables, money and output growth. To this end, we primarily employ the MSKF method. To check for the robustness of the results, the MSV method is implemented for comparison.

The MSKF method is a recursive Bayesian forecasting method that simultaneously generates a one period ahead forecast of the variable under consideration and an associated forecast variance. ${ }^{7}$ Due to the recursive character of the method, only currently available information is used for future forecasts. The MSKF method allows for changes in

\footnotetext{
${ }^{7}$ See Kool (1989) for a detailed exposition of the method and for empirical applications.
} 
the stochastic process of the forecasted variable using a time-varying mixture of a number of prespecified parallel models. ${ }^{8}$ The overall MSKF forecast is a weighted average of the individual forecasts of the parallel models, where the weights depend on the relative success of each model in the recent past. A simple Bayesian learning procedure updates the weights on the individual models. The overall forecast variance is a function of the weighted average of the individual models' forecast variances and of the distance between the individual models' forecasts. The latter part is a measure of parameter (model) uncertainty. The overall forecast distribution, thus, is a mixture of the distribution of the underlying parallel models.

Of course, no unique optimal choice exists for computing proxies of conditional second moments. The last decade in particular has witnessed a surge in the number of available econometric time series techniques for estimating and using time-varying conditional second moments, due to their increased importance in empirical tests of modern asset pricing theories. ${ }^{9}$

Mascaro and Meltzer (1983), Pindyck (1984) and Huizinga and Mishkin (1986) use a simple specification where the conditional variance is equal to the weighted average of squared innovations. A related class of models for conditional second moments is the family of autoregressive conditional heteroskedasticity (ARCH) models, developed by Engle (1982) and generalized (GARCH) by Bollerslev (1986). ${ }^{10}$ Engle and Bollerslev (1986) introduce the integrated GARCH (IGARCH) process. The IGARCH process is strictly stationary but not covariance stationary. Furthermore, the IGARCH exhibits persistence of shocks, i.e. a shock to the volatility remains forever. Alternatively, Pagan and Ullah (1988) suggest nonparametric models. The use of these techniques in empirical applications so far has been limited. Most recently, stochastic volatility models have been introduced, allowing for permanent shifts in the volatility. ${ }^{11}$ To our knowledge this chapter is the first application of stochastic volatility methods in a CCAPM for the short-term interest rate. Uhlig (1995) introduces a combination of Bayesian vector autoregressions and ARCH models as a further extension.

To evaluate the sensitivity of our results to the use of the MSKF method in computing

\footnotetext{
${ }^{8}$ This is related to Shephard (1994).

${ }^{9}$ Pagan (1984) and Pagan and Ullah (1988) analyze the difficulties associated with these proxies as generated regressors in subsequent work.

${ }^{10}$ See Bollerslev, Chou and Kroner (1992) for a survey of empirical studies in this vein. Lee (1995), uses multivariate GARCH to estimate stationary conditional second moments of money and output growth in a model similar to ours.

11 See Jacquier, Polson, and Rossi (1994) (with comments) for a discussion of the relation between ARCH and stochastic volatility models and of the appropriate way to estimate stochastic volatility models. They point out that the quasi-maximum likelibood estimator has small sarnple problems.
} 
conditional second moments, we compute second moments for the money and output innovations using the MSV method proposed by Harvey, Ruiz and Shephard (1994) as an alternative. The forecast errors for money and output generated by the MSKF method are used as inputs in the MSV method.

Sertion 5.3.1 provides a brief introduction and discussion of the MSKF method, while sectiun 5.3.2 contains a short description of the MSV method. Also an empirical comparison of the second moments generated by the MSKF and MSV methods respectively is given.

\subsubsection{The Multi State Kalman Filter}

In the current application of the MSKF method we assume that money growth and industrial production growth respectively can each be univariately predicted using the following model: ${ }^{12}$

$$
y_{t}=\beta_{t}+v_{t} . \quad v_{t}=N\left(0, h / \lambda_{t}\right)
$$

Observation equation (5.9) relates the dependent variable $y_{t}$ to the time-varying state variable $\beta_{t}$ and a serially independent white noise term $v_{t}$ with time-dependent variance $h / \lambda_{t}$. The state variable $\beta_{t}$ is assumed to behave as random walk, so that its dynamics may be described by the following discounted relation between the posterior distribution for $\beta_{t} \mid \tilde{I}_{t}$ and the prior distribution $\beta_{t+1} \mid I_{t}$, where / denotes conditioning on the information set $I_{t}$. Let the (normal) posterior distribution at time $t$ be:

$$
\left(\beta_{t} \mid I_{t}\right) \sim N\left(b_{t}, H_{t} / \lambda_{t}\right)
$$

where $b_{t}$ is the best estimate of $\beta_{t}$ conditional on all information up to and including period $t$ and $H_{t} / \lambda_{t}$ the associated variance. Then, the prior distribution for period $t+1$ conditional on $I_{t}$ is:

$$
\left(\beta_{t+1} \mid I_{t}\right) \sim N\left(b_{t}, R_{t+1} / \lambda_{t+1}\right)
$$

with:

$$
\left(R_{t+1} \mid I_{t}\right)=A^{-\frac{1}{2}} H_{t} A^{-\frac{1}{2}},
$$

where $A$ is a discount factor between one and zero. The closer $A$ is to zero, the larger is the implied variance of $\beta .^{13}$

\footnotetext{
${ }^{12}$ In its more general form the MSKF method allows for the linear incorporation of a vector of explanatory variables $x_{t}$, see Kool (1989) and the appendix to this chapter. Due to the method's flexibility in changing the weights of the different parallel models, the simple univariate model of equation (5.9) is able to approximate the dynamics of a wide range of statistical processes.

${ }^{13}$ When the new observation $y_{t}$ arrives, the forecast is evaluated and the prior is updated in a Bayesian manner to arrive at a new posterior. See the appendix for details of the Kalman filter recursions.
} 
The precision parameter $\lambda_{t}$ is stochastic and is assumed to follow a Gamma-distribution, which is updated through Bayesian procedures, analogous to state variable $\beta$. The posterior distribution of $\lambda$, conditional on $I_{t}$ is:

$$
\left(\lambda_{t} \mid I_{t}\right) \sim \Gamma\left(S_{t} / 2, n_{t} / 2\right)
$$

while the corresponding prior for period $t+1$ may be written as:

$$
\left(\lambda_{t+1} \mid I_{t}\right) \sim \Gamma\left(\alpha_{v} S_{t} / 2, \alpha_{v} n_{t} / 2\right)
$$

In equations (5.13) and (5.14) $\alpha_{v}$ is an exogenously fixed discount fartor for the variance level, $S_{t}$ is the weighted sum of past squared forecast errors and $n_{t}$ is the discounted number of observations. ${ }^{14}$

To motivate the above model, note that it allows for both transitory and permanent shocks to the forecasted variable. A discount factor $A$ close to one in combination with a large variance $h$ in the noise term in the observation equation corresponds to the case of transitory noise that has no impact on $\beta$, but only on $y_{t}$. A low variance $h$ and a discount factor $A$ close to zero, on the other hand, account for permanent shocks, affecting the state variable $\beta$.

If the mix of transitory and permanent shocks to $y_{t}$ changes over time, optimal values of $h$ and $A$ change as well. The MSKF method uses a number $(i=1, \ldots, n)$ of parallel forecasting models to account for this and to increase the method's flexibility to adjust to changes in the stochastic process generating observations on $y_{i}$. The parallel models share the functional form of equations (5.9) to (5.12), but differ with respect to the prespecified values of the discount factor $A^{(i)}$ and the variance level $h^{(i)}$. Finally, the precision (variance) factor, $\lambda_{t}$ is assumed equal for all models.

The MSKF method's overall forecast for $y_{t+1}$ is a weighted average of the forecasts of the $n$ individual models. Similarly, the forecast variance, associated with this forecast, is a weighted average of each model's forecast variance plus a component that takes into account the differences in forecasts among the models. This latter part is a mieasure of model uncertainty. The weights vary over time and depend on the relative performance of each of the individual models in forecasting $y$. They may be thought of as the prior probabilities on each of the $n$ models and are updated over time using a Bayesian learning

\footnotetext{
${ }^{14}$ Note that $l^{3}$ and $\lambda$ have a joint conjugate Normal-Gamma distribution. Their priors and posteriors are simultaneously updated through Kalman filter recursions. Uhlig (1995) uses a related Bayesian approach and models the precision parameter with a Beta distribution.
} 
mechanism. It can be shown that the overall forecast for $y_{t+1}$ is:

$$
\hat{y}_{t+1}=\sum_{i=1}^{n} \sum_{j=1}^{n} p_{t}^{(i)} \pi_{t+1}^{(j)} \hat{y}_{t+1}^{(i)}=\sum_{i=1}^{n} p_{t}^{(i)} \hat{y}_{t+1}^{(i)}=\sum_{i=1}^{n} p_{t}^{(i)} b_{t}^{(i)}
$$

while the overall forecast variance is:

$$
\hat{Y}_{t+1}=\sum_{i=1}^{n} \sum_{j=1}^{n} p_{t}^{(i)} \pi_{t+1}^{(j)}\left[\frac{\alpha_{u} n_{t} \hat{\lambda}}{\alpha_{v} n_{t}-2} \hat{Y}_{t+1}^{(i, j)}+\left(\hat{y}_{t+1}^{(i)}-\hat{y}_{t+1}\right)^{2}\right],
$$

where $\hat{y}_{t+1}^{(i)}$ and $\hat{Y}_{t+1}^{(i, j)}$ are the individual forecasts and forecast variances, $p_{t}^{(i)}$ represents the posterior probability on model $i$ being valid in period $t$, and $\pi_{t+1}^{(j)}$ represents the prior probability that model $j$ will hold in period $t+1$. Together the $p_{t}^{(i)}$ and $\pi_{t+1}^{(j)}$ determine the weights in the forecast and variance equations. The unconditional forecast $\hat{y}_{t+1}$ follows a (mixture of) Student- $t$ distributions (see also equation (5.48) in the appendix).

It is the forecast variance from equation (5.16) that we will use in our analysis of the relation between nominal interest rates, inflation and risk. It should be borne in mind that nothing in the MSKF method prevents the variance from being nonstationary. In this sense, the resulting second moments may potentially account for the apparent nonstationarity of risk premiums and real interest rates, (see Evans and Lewis (1994)).

In the current application, four parallel models are used. The first model assumes shocks to be dominantly transitory (high $h$, high $A$ ), while the second model preconditions shocks to be mostly permanent (low $h$, low $A$ ). The remaining two models are outlier models, each corresponding to one of the first two models. The outlier models are used only when a tracking signal indicates significant deterioration of the forecast performance. ${ }^{15}$

\subsubsection{Conditional Second Moments}

An alternative multivariate volatility specification has recently been provided by Harvey, Ruiz and Shephard (1994). Let $\eta_{t}$ be a $2 \times 1$ vector of observable disturbances of money growth and output growth: ${ }^{16}$

$$
\eta_{i t}=\epsilon_{i t}\left[\exp \left(h_{i t}\right)\right]^{\frac{1}{2}}, \quad i=1,2 \quad t=1, \ldots, T
$$

\footnotetext{
${ }^{15}$ Initially, models 1 and 2 have equal prior probability. The discount factor $A$ for benchmark model 1 is 0.99 , while variance factor $h$ is 1 and 0.1 for models 1 and 2 respectively. The discount factor for the variance is 0.975 . Outlier models 3 and 4 are assumed to have a variance 16 times as large as models 1 and 2. We have performed a sensitivity analysis for different initializations of the filter. Overall the outcomes are robust for different initializations of the filter. These results are available on request.

${ }^{16}$ In this application these are the forecast errors of the MSKF.
} 
TABLE 5.2: Multivariate Stochastic Volatility Model

\begin{tabular}{cccc}
\hline \hline$\sigma_{m}$ & $\sigma_{y}$ & $\rho_{\nu}$ & $\rho_{c}$ \\
\hline 0.12 & 0.10 & 0.88 & 0.01 \\
$(2.63)$ & $(1.86)$ & $(5.81)$ & $(0.16)$ \\
\hline Note: The heteroskedasticity & consistent $t$-values of the coefficients \\
are given in parentheses. \\
\hline \hline
\end{tabular}

where $\epsilon_{i t}$ is multivariate normally distributed with mean zero and covariance matrix:

$$
\Sigma_{\varepsilon}=\left(\begin{array}{cc}
1 & \rho_{\epsilon} \\
\rho_{\epsilon} & 1
\end{array}\right),
$$

The variances, $h_{i t}$, are assumed to be generated by an AR(1) process:

$$
h_{i t}=\omega_{0 i}+\omega_{1 i} h_{i t-1}+\nu_{i t},
$$

where $\nu_{i t}$ is multivariate normally distributed with mean zero and covariance matrix:

$$
\Sigma_{\nu}=\left(\begin{array}{cc}
\sigma_{m}^{2} & \rho_{\nu} \sigma_{m} \sigma_{y} \\
\rho_{\nu} \sigma_{m} \sigma_{y} & \sigma_{y}^{2}
\end{array}\right),
$$

where $\sigma_{m}^{2}$ and $\sigma_{y}^{2}$ denote the variance of shocks to the volatility of money growth and output growth respectively. Squaring equation (5.17) and taking logarithms gives:

$$
\ln \left(\eta_{i t}^{2}\right)=h_{i t}+\ln \left(\epsilon_{i t}^{2}\right)=-1.27+h_{i t}+\psi_{i t},
$$

Harvey, Ruiz and Shephard (1994) show that $\mathrm{E}\left[\psi_{i t}^{2}\right]=\pi^{2} / 2$, and the disturbances $\psi_{i t}$ and $\nu_{i t}$ are uncorrelated. quasi-maximum likelihood (QML) estimates of the parameters $\sigma_{m}$, $\sigma_{y}, \rho_{\nu}, \rho_{\varepsilon}, \omega_{0 i}$ and $\omega_{1 i}$ can now be obtained by means of the Kalman filter, where (5.21) is the observation equation and (5.19) is the measurement equation. Unreported results show that we cannot reject the restrictions that $\omega_{01}=0$ and $\omega_{1 i}=1$ in equation (5.19). Therefore, we explicitly impose these restrictions. The estimation results of the restricted model of equations (5.17)-(5.21) are reported in table 5.2.

From the table we conclude that shocks to money and output are approximately uncorrelated, as reflected in the small and insignificant value of $\rho_{c}$. On the other hand, the tabie shows a significant and positive correlation coefficient $\rho_{\nu}$. This implies that news to the volatility of industrial production and money growth is strongly related, which may be due to an underlying common factor to their volatilities. For illustrative purposes, figure 5.1 contains the estimated conditional variance series for money growth based on the two different volatility models. The figure shows that the variance series which are obtained by 


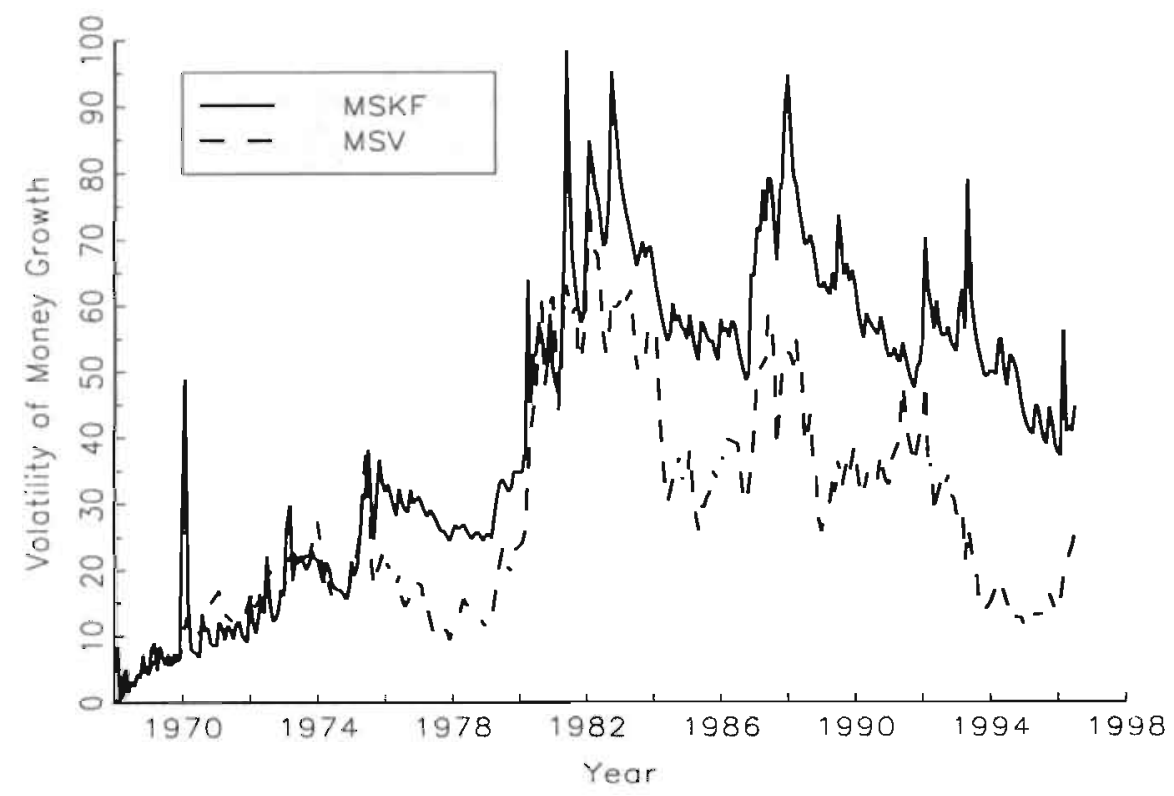

FIGURE 5.1: Conditional Variance of Money Growth

two different methods behave very similar over time. We conclude that results are quite insensitive to the choice of method. In the remainder we focus on the MSKF volatility estimates. ${ }^{17}$

\subsection{Shifts in Macroeconomic Volatility}

In this section we empirically analyze the generalized Fisher equation equation (5.8) from section 5.1:

$$
r_{t}=\alpha_{0}+\mathrm{E}_{t}\left[\pi_{t+1}\right]+\alpha_{1} \operatorname{Var}_{t}\left[\Delta m_{t+1}\right]+\alpha_{2} \operatorname{Var}_{t}\left[\Delta i p_{t+1}\right] .
$$

According to this equation the nominal interest rate is a linear function of the second moments of money and output growth. The Dickey-Fuller statistics for the variances of inflation, money growth and production growth, computed with the MSKF, are $-4,46$, 1.77 and -2.85 respectively and the null hypothesis of a unit root is only rejected for the

${ }^{17}$ Results using the conditional second moments generated with the stochastic volatility methodology are very similar and are available upon request. 
TABLE 5.3: Principal Components Analysis

\begin{tabular}{|c|c|c|c|c|}
\hline Principal Component & 1 & 2 & 3 & 4 \\
\hline \%Variance & 92 & 8 & 0 & 0 \\
\hline \multicolumn{5}{|c|}{$\begin{array}{l}\text { Notes: Principal Component denotes the } n \text {-th principal component } \\
\text { and \%variance is the percentage of the variance explained by the } \\
n \text {-th principal component. }\end{array}$} \\
\hline
\end{tabular}

variance of the inflation series. ${ }^{18}$

Since nonstationarity cannot be rejected for the other series, special care has to be taken to reduce the possibility of making errors in inference. To test for a relationship between the nominal interest rate, the expected inflation and the two conditional variances, we first determine the number of principal components. The results are reported in table 5.3. The first principal component is found to capture $92 \%$ of all movements. With respect to the conditional second moments, this implies the danger of multicollinearity when the two volatility term are jointly incorporated in a regression analysis.

As a second step, we formally test whether there is a cointegrating relationship between the nominal interest rate, inflation and the two conditional variances. We replace expected inflation with the lagged realized inflation and therefore consider the following regression model:

$$
r_{t}=\alpha_{0}+\alpha_{1} \operatorname{Var}_{t}\left[\Delta m_{t+1}\right]+\alpha_{2} \operatorname{Var}_{t}\left[\Delta i p_{t+1}\right]+\alpha_{3} \pi_{t}+u_{t},
$$

where $\operatorname{Var}_{t}\left[\Delta m_{t+1}\right]$ and $\operatorname{Var}_{t}\left[\Delta i p_{t+1}\right]$ are the conditional variances of money growth and real production growth respectively. In order to test for cointegration, we perform the Johansen test. Consider the following linear system:

$$
\Delta z_{t}=D_{0}+\sum_{i=1}^{k-1} D_{i} \Delta z_{t-i}+\delta z_{t-k}+e_{t}
$$

where $z$ is a vector of $I(1)$ time series and $k$ gives the number of lags. A test for the null hypothesis that there are $r$ cointegrating vectors can be based on the maximum likelihood approach of Johansen (1988). The Johansen cointegration test is a test for the hypothesis that $\delta$ has less than full rank. In order to determine whether this is the case, Johansen proposes two test-statistics, which are the trace statistic (TRACF) and the maximaleigenvalue statistic (MEV). We determine the order of the system by mearis: of the Wald statistic.

The results of the Johansen test for equation (5.23) indicate that it impossible to discriminate between one and two cointegrating vectors. A cointegration analysis of this equation

\footnotetext{
${ }^{18}$ We refer to Pagan (1996) for a discussion of the issue of co-persistence of variancess.
} 
TABLE 5.4: Cointegration Test

\begin{tabular}{lcccc}
\hline \hline & MEV & MEV(5\%) & TRACE & TRACE(5\%) \\
\hline$l=0$ & 59.57 & $(17.89)$ & 75.15 & $(24.31)$ \\
$l=1$ & 10.27 & $(11.44)$ & 12.58 & $(12.53)$ \\
$l=2$ & 5.20 & $(3.84)$ & 5.31 & $(3.84)$ \\
\hline
\end{tabular}

without the variance of money suggests that no cointegrating vector exists. On the other hand, exclusion of the variance of output instead of the variance of money results in exactly one cointegrating vector. ${ }^{19}$ The result is robust for different lag lengths. Table 5.4 contains the maximal-eigenvalue statistic and the trace statistics for the nominal interest rate, inflation and the variance of money growth.

The normalized cointegration model is: $-0.90 r_{t}=\pi_{t}+0.07 \operatorname{Var}_{t}[\Delta m]$. According to the value of the likelihood ratio test (LR), we are unable to reject the hypothesis that the cointegrating vector is $(-1,1,0.07) \cdot{ }^{20}$ Our results imply that the nominal interest rate varies one-for-one with monthly inflation once the effect of monetary uncertainty is taken into account. The real interest rate is positively related to the conditional variance of money growth. Our evidence is consistent with Mascaro and Meltzer (1983) who also find this positive relation and with Tzavalis and Wickens (1996). The ad hoc dummy in their approach has a roughly similar pattern as our conditional variance estimates and possibly captures the effects of monetary uncertainty.

In figure 5.2 we have graphed the nominal interest rate, the inflation rate and the combined effect of inflation plus monetary volatility. It follows from figure 5.2, that our model is able to adequately track the interest rate time path through the combined effect of inflation and monetary volatility. The model provides an alternative explanation for the relatively high nominal and real interest rates in the early eighties. We suggest that the persistent increase in monetary uncertainty in that period contributed to the high real rates even when inflation was decreasing rapidly. Note that Lucas (1990) attributes the high real rate in that period to misperceptions about expected inflation. Evans and Lewis (1995b) also point to the impact of expected regime changes in the inflationary process. To the extent that learning is part of their explanation, monetary uncertainty and the potential

19 The hypothesis that the variances of money growth and output growth are cointegrated is only marginally rejected in the general analysis. In a bilateral test, cointegration is not rejected. Again, the results suggest that these variables capture similar effects.

${ }^{20}$ The value of the LR statistic is 1.05 and the $p$-value is 0.60 . 


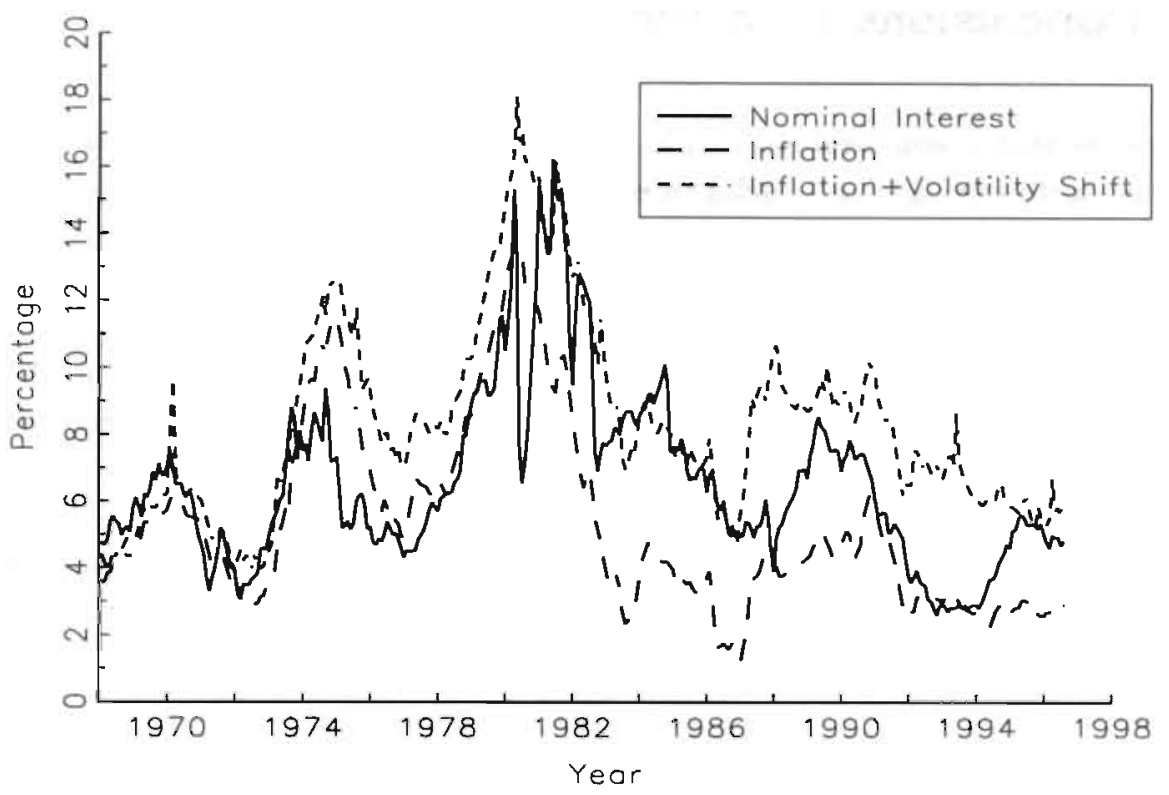

FIGURE 5.2: Interest Rate and Monetary Volatility

of inflationary regime changes may be seen as two sides of the same coin. Evans and Lewis (1994) emphasize the potential effects of nonstationary risk premiums, which is closer to our result.

The track record of our model only appears to break down temporarily in the beginning of the nineties. Between 1992 and 1994 the nominal interest rate drops below the total effect of inflation plus monetary uncertainty. Consequently, figure 5.2 suggests that the real question with respect to nominal interest rates is not so much why they were high in the eighties but why are they so low in the early nineties. After 1994, the good model performance is restored. 


\subsection{Conclusions}

A growing amount of empirical research indicates that the relation between current and nominal interest rates and future inflation is strongly country and period dependent. We argue in this chapter that it is important to incorporate a proper risk premium.

The starting point of our analysis of the short-term interest rate is an intertemporal consumption capital asset pricing model. We derive a generalized Fisher equation in which the nominal interest rate is a function of inflation and the conditional second moments of money and production growth. The conditional second moments have been computed along two independent routes to check for robustness, on the one hand, a recursive Bayesian forecasting method - the multi state Kalman filter (MSKF) - and on the other, the so-called multivariate stochastic volatility (MSV) model. Both methods allow for (marginally) nonstationary second moments. The MSKF method and the MSV models produce very similar results.

Since both dependent and independent variables are potentially nonstationary, we first used principal components and subsequently cointegration methodology in the analysis. In the principal components analysis we find that the first principal component captures $92 \%$ of all movements, which suggests a common trend. Using the Johansen (1988) test for cointegration we find that the nominal interest rate, the inflation and the conditional volatility of money growth are cointegrated. The results in this chapter suggest that the common rejection of the Fisher hypothesis in the literature could at least partly be due to a misspecification bias. Incorporating macroeconomic monetary uncertainty by means of the conditional variance of money growth into the Fisher equation is important. Moreover, it is relevant that the econometric techniques used to estimate the conditional second moments allow for the possibility of permanent shocks to the risk premium and hence for a potential unit root in second moments.

Whether our proxy of macroeconomic risk is equally successful in explaining movements in other asset prices than the nominal interest rate is left for future research. Evidence by Lee (1996) is suggestive of the potential role of macroeconomic uncertainty in asset pricing. He reports significant effect of both the variance of money and the variance of output growth on term structure spreads. 


\section{Appendix 5: The Multi State Kalman Filter}

The MSKF method is implemented with $n$ parallel normal discount Bayesian models $\left(M^{(i)}, i=1, \ldots, n\right)$. The parallel models for our application are described in footnote 15 . The differences between the models arise from the diagonal matrix with discount factor $A^{(i)}$ and variance of the measurement equation $V_{(i)}^{(t)}$. The variance $V_{t}^{(i)}$ is parameterized as $h_{t}^{(i)} / \lambda$. The information set $I_{t}$ contains all past observations of $y_{t}$.

Assume the following conditional distribution of $y_{t+1}$ :

$$
y_{t+1} \mid I_{t} \sim N\left(\beta_{t} x_{t}, h / \lambda_{t+1}\right),
$$

while $\left(\beta_{t}, \lambda_{t}\right)$ have a conjugate normal-Gamma distribution:

$$
\begin{aligned}
\left(\lambda_{t} \mid I_{t}, M_{t}^{(i)}\right) & \sim \Gamma\left(S_{t} / 2, n_{t} / 2\right), \\
\left(\beta_{t} \mid I_{t}, M_{t}^{(i)} \lambda_{t}\right) & \sim N\left(b_{t}^{(i)}, H_{t}^{(i)} / \lambda_{t}\right) .
\end{aligned}
$$

Conditional on model $i$ prevailing in period $t$ and model $j$ in period $t+1$, the corresponding prior distributions for $\lambda_{t+1 \mid t}$ and $\beta_{t+1 \mid t}$ are:

$$
\begin{gathered}
\left(\lambda_{t+1} \mid I_{t}, M_{t}^{(i)}, M_{t+1}^{(j)}\right) \sim \Gamma\left(\alpha_{v} S_{t} / 2, \alpha_{v} n_{t} / 2\right), \\
\left(\beta_{t+1} \mid I_{t}, M_{t}^{(i)}, M_{t+1}^{(j)}, \lambda_{t+1}\right) \sim N\left(G b_{t}^{(i)}, R_{t+1}^{(i, j)} / \lambda_{t}\right),
\end{gathered}
$$

where $\alpha_{y}$ is an exogenous, model independent discount parameter and:

$$
\left(R_{t+1}^{(i, j)} \mid I_{t}\right)=A^{-\frac{1}{2}} G H_{t} G^{\prime} A^{-\frac{1}{2}},
$$

with $G$ a transition matrix (here $G=1$ ). Using observation $y_{t+1}$, the combined posterior distribution of $y_{t+1}, \beta_{t+1}$ and $\lambda_{t+1}$ may be obtained for each combination $M_{t}^{(i)}$ and $M_{t+1}^{(j)}$ by the distributional products of equation (5.25), (5.28) and (5.29). The posterior distributions of $\beta_{t+1}$ and $\lambda_{t+1}$ are then:

$$
\begin{gathered}
\left(\lambda_{t+1} \mid I_{t+1}, M_{t}^{(i)}, M_{t+1}^{(j)}\right) \sim \Gamma\left(S_{t}^{(i, j)} / 2, n_{t+1} / 2\right), \\
\left(\beta_{t} \mid I_{t+1}, M_{t}^{(i)}, M_{t+1}^{(j)}, \lambda_{t+1}\right) \sim N\left(b_{t+1}^{i, j}, R_{t+1}^{(i, j)} / \lambda_{t}\right),
\end{gathered}
$$

with:

$$
\begin{gathered}
b_{t+1}^{(i, j)}=G b_{t}^{(i)}+K_{t+1}^{(i, j)} e_{t+1}^{(i)}, \\
R_{t+1}^{(i, j)}=R_{t+1 \mid t}^{i, j}+K_{t+1}^{(i, j)} x_{t+1}^{i} R_{t+1 \mid t}^{(i, j)} \\
K_{t+1}^{(i, j)}=R_{t+1 \mid t}^{(i, j)} x_{t+1} /\left(h^{(j)}+x_{t+1}^{i} R_{t+1 \mid t}^{(i, j)} x_{t+1}\right),
\end{gathered}
$$




$$
\begin{gathered}
S_{t+1}^{(i, j)}=\alpha_{v} S_{t}+\left(h^{(j)}+x_{t+1}^{\prime} R_{t+1 \mid t}^{(i, j)} x_{t+1}\right)^{-1}\left(e_{t+1}^{(i)}\right)^{2}, \\
n_{t+1}=\alpha_{v} n_{t}+1 \\
e_{t+1}^{(i)}=y_{t+1}+x_{t+1}^{\prime} G b_{t}^{(i)} .
\end{gathered}
$$

Equations (5.26)-(5.27) and (5.31)-(5.32) are posterior distributions of $(\beta, \lambda)$ at time $t$ and $t+1$ respectively. Equations (5.31)-(5.32) however depend on $M_{t}^{(i)}$ and $M_{t+1}^{(j)}$ instead of $M_{t+1}^{(j)}$ alone. To reduce equations $(5.31)-(5.32)$ to the form $(5.26)-(5.27)$, a condensation procedure is used. Note that the posterior probability, $P$, on $\left(M_{t}^{(i)}, M_{t+1}^{(j)}\right)$ for some $(i, j)$ equals:

$$
q_{t+1}^{(i, j)} \equiv P\left(M_{t}^{(i)}, M_{t+1}^{(j)} \mid I_{t+1}\right)=\frac{P\left(y_{t+1} \mid I_{t}, M_{t}^{(i)}, M_{t+1}^{(j)}\right) P\left(M_{t+1}^{(j)} \mid I_{t}, M_{t}^{(i)}\right) P\left(M_{t}^{(i)} \mid I_{t}\right)}{P\left(y_{t+1} \mid I_{t}\right)}
$$

which is the product of the likelibood function, the prior probability on model $j$ obtaining next period and the posterior probability on model $i$ being correct this period. The division by $P\left(y_{t+1} \mid I_{t}\right)$ only serves as a normalization constant to assure that the sum of all $q^{(i, j)}$ 's adds to unity. Then apply:

$$
\begin{gathered}
p_{t+1}^{(j)} \equiv \sum_{i=1}^{n} q_{t+1}^{(i, j)} \\
b_{t+1}^{(j)}=\sum_{i=1}^{n} \frac{q_{t+1}^{(i, j)}}{p_{t+1}^{(j)}} b_{t+1}^{(i, j)} \\
R_{t+1}^{(j)}=\sum_{i=1}^{n} \frac{q_{t+1}^{(i, j)}}{p_{i+1}^{(j)}}\left[R_{t+1}^{(i, j)}+\left(b_{i+1}^{(i, j)}-b_{t+1}^{(j)}\right)\left(b_{t+1}^{(i, j)}-b_{t+1}^{(j)}\right)^{\prime}\right] .
\end{gathered}
$$

A similar condensation procedure for $\lambda$ has been used in the following way:

$$
\left(S_{t+1}\right)^{-1}=\sum_{j=1}^{n} \sum_{i=1}^{n}\left(S_{t+1}^{(i, j)}\right)^{-1}
$$

From the previous presentation we see that the posterior distribution for $\left(\beta_{t+1}, \lambda_{t+1}\right)$ is obtained, allowing for an ongoing repetition of recursions.

The ultimate goals of implementing the MSKF method are to track the time path of the aggregate parameter vector as well as possible, to estimate the uncertainty surrounding the parameter estimates and to generate aggregate forecasts of future realizations of the dependent variable with corresponding forecast variance estimates. The unconditional distributions for both the parameter vector $\beta$ and the one step ahead forecast take the following form:

$$
\left(\beta_{t} \mid I_{t}\right) \sim \sum_{i=1}^{n} p_{t}^{(i)}\left(\beta_{t} \mid I_{t}, M_{t}^{(i)}\right)
$$


Again, a condensation procedure replaces the weighted sum on the right hand side of this equation by a single approximate Student- $t$ distribution with mean $b_{t}$ and covariance matrix $B_{t}$, where:

$$
\begin{gathered}
b_{t}=\sum_{i=1}^{n} p_{t}^{(i)} b_{t}^{(i)}, \\
B_{t}=\sum_{i=1}^{n} p_{t}^{(i)}\left[\frac{n_{t} \hat{\lambda}}{n_{t}-2} H_{t}^{(i)}+\left(b_{t+1}^{(i)}-b_{t+1}\right)\left(b_{t+1}^{(i)}-b_{t+1}\right)^{\prime}\right], \\
\hat{\lambda}=n_{t} / S_{t} .
\end{gathered}
$$

Similarly the unconditional one period ahead forecast of the dependent variable may be represented by the following weighted average (mixture) of (conditional) Student- $t$ distributions:

$$
\left(y_{t+1} \mid I_{t}\right) \sim \sum_{i=1}^{n} \sum_{j=1}^{n} p_{t}^{(i)} \pi_{t+1}^{(j)}\left(y_{t+1} \mid I_{i}, M_{i}^{(i)}, M_{t+1}^{(j)}\right)
$$

with unconditional mean $\hat{y}_{t+1}$ and variance $\hat{Y}_{t+1}$ equal to:

$$
\begin{gathered}
\hat{y}_{t+1}=\sum_{i=1}^{n} \sum_{j=1}^{n} p_{t}^{(i)} \pi_{t+1}^{(j)} \hat{y}_{t+1}^{(i)}=\sum_{i=1}^{n} p_{t}^{(i)} \hat{y}_{t+1}^{(i)}, \\
\hat{Y}_{i+1}=\sum_{i=1}^{n} \sum_{j=1}^{n} p_{t}^{(i)} \pi_{t+1}^{(j)}\left[\frac{\alpha_{v} n_{t} \hat{\lambda}}{\alpha_{v} n_{t}-2} \hat{Y}_{t+1}^{(i, j)}+\left(\hat{y}_{t+1}^{(i)}-\hat{y}_{t+1}\right)^{2}\right],
\end{gathered}
$$

where $\hat{y}_{t+1}^{(i)}$ and $\hat{Y}_{t+1}^{(i, j)}$ are the mean and the variance of the individual conditional distributions equal to:

$$
\begin{gathered}
\hat{y}_{t+1}^{(i)}=x_{i+1}^{i} G b_{t}^{(i)}, \\
\hat{Y}_{t+1}^{(i, j)}=h^{(j)}+x_{t+1}^{\prime} R_{t+1 \mid t}^{(i, j)} x_{t+1},
\end{gathered}
$$

and $\pi_{t+1}^{(j)}$ the prior probability of model $j$ prevailing at time $t$. Finally, the following equations capture the dynamics of the prior probabilities:

$$
\begin{gathered}
\pi_{t+1}^{(j)}=\frac{\psi \pi_{t}^{(j)}+\bar{p}_{t}^{(j)}}{\sum_{j=1}^{n} \psi \pi_{t}^{(j)}+\bar{p}_{t}^{(j)}}, \\
\bar{p}_{t}^{(j)}=\sum_{i=1}^{n} q_{t}^{(j, i)} .
\end{gathered}
$$

The parameter $\psi$ regulates the inertia in the updating procedure; $\psi \rightarrow \infty$ implies fixed priors, whereas $\psi=0$ implies that priors totaly reflect the most recent experience. This allows for a feedback from the data to the prior probabilities. In the current application, $\psi$ is chosen equal to one. This implies equal weight on the previous prior and the new information. 



\section{Chapter 6}

\section{An Empirical Investigation of the Domestic Pricing Error in an Integrated World}

The issue of domestic versus international asset pricing has important implications for. financial decisions. In a segmented world, the domestic capital asset pricing model (CAPM) may be appropriately used to estimate a firm's beta and corresponding cost of capital. In a financially integrated world, however, the international capital asset pricing model (ICAPM) that estimates a firm's beta relative to the global market portfolio should be used as a basis for pricing, which implies that investment projects of equal risk in different countries should have the same cost of capital when expressed in a common currency.

Since the mid-1970s capital markets have become increasingly integrated internationally. Most empirical research that focuses on the cross-section of security returns across countries finds evidence in favor of international integration and fails to reject the ICAPM. ${ }^{1}$ This suggests that the expected return on assets may now be determined primarily on world capital markets. Thus, the cost of capital for firms should be estimated using a regression suggested by the ICAPM rather than the CAPM. However, tests of the ICAPM based on portfolio composition data tend to reject the model and report a structural home-bias. That is, domestic residents invest a larger proportion of their wealth in domestic assets

\footnotetext{
${ }^{1}$ Examples are Cho, Eun and Senbet (1986), Wheatley (1988), Korajczyk and Viallet (1989), Gultekin, Gultekin and Penati (1989), Cumby (1990), Harvey (1991), Bekaert and Hodrick (1992), Campbell and Hamao (1992), Heston, Rouwenhorst and Wessels (1995) and Dumas and Solnik (1995). As an exceptioja, Jorion and Schwartz (1985) reject international integration.
} 
than predicted by the model, see Lewis (1995) for an overview of this literature.

We start from the hypothesis that international capital markets are easily accessible and assume that the ICAPM rather than the CAPM holds. This does not necessarily imply that the CAPM provides the wrong cost of capital, however. The two asset pricing models give the same cost of capital if the local stock market portfolio contains all the information that is relevant to price assets internationally. We explicitly investigate the magnitude and significance of the pricing error that results from the use of the CAPM rather than the ICAPM.

Our approach generalizes Stulz (1995b), who assumes that purchasing power parity (PPP) deviations are not important enough to influence expected returns. However, Dumas and Solnik (1995) show that currency risk affects expected stock returns. Since substantial deviations from PPP occur at a monthly horizon (Abuaf and Jorion (1990), Frankel and Rose (1995) and chapter 3), we explicitly allow for PPP deviations and formally test the hypothesis that the local market portfolio contains all the information that is relevant to price domestic assets. We show that a test for the significance of the pricing error made when using the wrong pricing model can be interpreted as a test of orthogonality between diversifiable domestic risk and a set of global instruments. These global instruments are the return on the global market portfolio and foreign currency changes. An important advantage of our approach is that the test results are invariant to the choice of the numeraire currency.

In contrast with most other studies that test the CAPM versus the ICAPM, we use data on almost 3,000 individual stocks from ten different countries. ${ }^{2}$ Results are obtained through Hansen's (1982) generalized method of moments (GMM). We are unable to reject the hypothesis that the local market contains all pricing information. A firm's cost of capital as measured by the local CAPM is generally insignificantly different from its cost of capital as measured by the ICAPM.

The chapter is organized as follows. In section 6.1 we develop an international CAPM, starting from the. Adler and Dumas (1983) model. In section 6.2 we focus on the difference between domestic and international asset pricing and derive testable expressions. In section 6.3 the data are described, while the empirical results are presented and discussed in section 6.4. Conclusions are in section 6.5.

${ }^{3}$ Harvey (1991), Ferson and Harvey (1993) and Dumas and Solnik (1995). 


\subsection{International Asset Pricing}

The issue whether PPP holds is an important ingredient of the ICAPM. Only if PPP exactly holds the CAPM can easily be extended to an international framework. Adler and Dumas (1983) (AD) develop a general model, which takes into account the impact of PPP deviations. In this model, the expected return on asset $i$ depends both on its risk relative to the global market portfolio and on its real exchange rate risk. ${ }^{3}$

AD assume a world with $N+1$ countries, where the following equilibrium condition holds:*

$$
\mathrm{E}\left[R_{i 0}\right]=r_{0}+\theta \operatorname{Cov}\left[R_{i 0}, R_{G 0}\right]+\sum_{i=0}^{N} \eta_{l} \operatorname{Cov}\left[R_{i 0}, \pi_{i 0}\right] .
$$

The nominal return of asset $i$ expressed in numeraire currency 0 is denoted $R_{i 0}$. The nominal return on the riskfree asset in country $l$ in local currency $(l=0, \ldots, N)$ is denoted $r_{l}$. The nominal return on the global market portfolio is defined as $R_{G 0}=\sum_{l=0}^{N} w_{l} \sum_{i=1}^{M} x_{i l} R_{i 0}$, where $N$ is the number of countries, $w_{l}$ is the weight of country $l$ in the world portfolio, $M$ is the number of stocks and $x_{i l}$ is the weight of stock $i$ in the portfolio hold by residents of country $l$. Finally, the inflation rate in country $l$ expressed in the numeraire currency 0 is $\pi_{l 0}=S_{l 0}+\pi_{l}$, where $S_{l 0}$ is the exchange rate change in currency $l$ in terms of currency 0 and $\pi_{l}$ is the inflation rate in country $l$ in local currency. The AD model contains $N+2$ risk premiums. The first risk premium is associated with the global market portfolio and equals the wealth-weighted harmonic mean of the risk aversion parameters of the investors, $\theta_{l}$, in the different countries, that is $\theta=\left(\sum_{l=0}^{N} w_{l}\right) /\left(\sum_{i=0}^{N} w_{l} / \theta_{l}\right)$. The remaining $N+1$ premiums are defined $\eta_{l}=\theta\left(1 / \theta_{l}-1\right)\left(w_{l} / \sum_{l=0}^{N} w_{l}\right)$ and are related to the inflation risk in each country.

To derive the beta-pricing version of the model, equation (6.1) is applied to a set of basic assets that serve as instruments. All other assets are then priced relative to the basic assets. The resulting equilibrium relations do not contain unobservable variables like risk aversion parameters. The first instrument is the global market portfolio. Application of equation (6.1) to the return $R_{G 0}$ yields:

$$
\mathrm{E}\left[R_{G 0}\right]=r_{0}+\theta \operatorname{Var}\left[R_{G 0}\right]+\sum_{l=0}^{N} \eta_{l} \operatorname{Cov}\left[R_{G 0}, \pi_{l 0}\right] .
$$

Next we apply equation (6.1) to the expected returns (expressed in currency 0 ) on the $N$ foreign assets that are riskfree in their local currency. This gives a set of $N$ exchange rate

\footnotetext{
${ }^{3}$ Differences between the international models of Solnik $(1974,1983)$, Grauer, Litzenberger and Stehle (1976), Sercu (1980), Stulz (1981) and Adler and Dumas mainly arise from different assumptions with respect to nominal exchange rates and inflation differentials.

${ }^{4}$ See also Dumas (1994) and Stulz (1995a) for an overview of the literature on international asset pricing. Our notation also follows Dumas' (1994) exposition.
} 
risk premiums:

$$
\mathrm{E}\left[r_{k}+S_{k 0}\right]=r_{k}+\mathrm{E}\left[S_{k 0}\right]=r_{0}+\theta \operatorname{Cov}\left[S_{k 0}, R_{G 0}\right]+\sum_{l=0}^{N} \eta_{l} \operatorname{Cov}\left[S_{l 0}, \pi_{l 0}\right] .
$$

The final asset that is required to derive the beta-pricing model could be an instrument for the numeraire country inflation risk $\pi_{0}$. However, we use the assumption that only inflation differentials, $\pi_{l}-\pi_{0}$, are stochastic and that one of the inflation rates (or the level of world inflation) is nonstochastic. This reduces the number of covariance terms with inflation by one. Choosing the domestic inflation rate as the nonstochastic element one obtains: ${ }^{5}$

$$
\sum_{l=0}^{N} \eta_{l} \operatorname{Cov}\left[R_{G 0}, \pi_{l 0}\right]=\sum_{l=0}^{N} \eta_{l} \operatorname{Cov}\left[R_{G 0}, \pi_{l}-\pi_{0}+S_{l 0}+\pi_{0}\right]=\sum_{l=1}^{N} \eta_{l} \operatorname{Cov}\left[R_{G 0}, Q_{l 0}\right],
$$

where $Q_{l 0}=S_{l 0}+\pi_{l}-\pi_{0}$ is the real exchange rate return of $l$ against numeraire currency 0 , and where we have used the property that $\operatorname{Cov}\left(R_{G^{\circ} 0}, Q_{00}\right) \ldots \operatorname{Cov}\left[R_{G 0}, 1\right]=0$ and the assumption that $\operatorname{Cov}\left[R_{G 0}, \pi_{0}\right]=0$. Similar relations hold for all other assets. Since $\pi_{0}$ is nonstochastic, the preference parameter $\eta_{0}$ drops out. In order to solve for the preference parameters, $\theta$ and $\eta_{l}$ for $l=1, \ldots, N$ we introduce matrix notation. Let:

$$
\begin{array}{lll}
\tilde{\mu}_{G} & =\mathrm{E}\left[R_{G 0}-r_{0}\right], \\
\sigma_{G}^{2} & =\operatorname{Var}\left[R_{G}\right], \\
\dot{\nu} & :(N \times 1) \text { vector with elements } \mathrm{E}\left[S_{l 0}+r_{l}-r_{0}\right] & l=1, \ldots, N, \\
\omega_{S G}:(N \times 1) \text { vector with elements } \operatorname{Cov}\left[S_{l 0}, R_{G 0}\right] & l=1, \ldots, N, \\
\omega_{Q G}:(N \times 1) \text { vector with elements } \operatorname{Cov}\left[Q_{l 0}, R_{G 0}\right] & l=1, \ldots, N, \\
\Omega_{S Q}:(n \times n) \text { matrix with elements } \operatorname{Cov}\left[S_{k 0}, Q_{l 0}\right] & l, k=1, \ldots, N .
\end{array}
$$

where $\hat{\nu}$ is a vector that contains the expected deviations from uncovered interest parity (UIP). Equations (6.2) and (6.3) can now be rewritten in matrix notation as:

$$
\begin{aligned}
& \check{\mu}_{G}=\theta \sigma_{G}^{2}+\omega_{Q G}^{\prime} \eta, \\
& \tilde{\nu}=\theta \omega_{S G}+\Omega_{S Q} \eta
\end{aligned}
$$

where $\eta=\left(\eta_{1}, \ldots, \eta_{N}\right)^{\prime}$. Solving for $\theta$ and $\eta$ gives:

$$
\left(\begin{array}{c}
\theta \\
\eta
\end{array}\right)=\left(\begin{array}{cc}
\sigma_{G}^{2} & \omega_{Q G} \\
\omega_{S G}^{\prime} & \Omega_{S Q}
\end{array}\right)^{-1}\left(\begin{array}{c}
\tilde{\mu_{G}} \\
\tilde{\nu}
\end{array}\right) .
$$

Substituting equation (6.6) in the equilibrium in equation (6.1) we obtain:

$$
\tilde{\mu}_{i}=\left(\begin{array}{ll}
\omega_{i G} & \omega_{i Q}^{\prime}
\end{array}\right)\left(\begin{array}{cc}
\sigma_{G}^{2} & \omega_{Q G} \\
\omega_{S G}^{\prime} & \Omega_{S Q}
\end{array}\right)^{-1}\left(\begin{array}{c}
\tilde{\mu_{G}} \\
\tilde{\nu}
\end{array}\right),
$$

\footnotetext{
${ }^{5}$ As can be easily verified, the nonstochastic inflation rate bas no impart on the final model.
} 
where $\tilde{\mu}_{i}=\mathrm{E}\left[R_{i 0}-r_{0}\right], \omega_{i G}=\operatorname{Cov}\left(R_{i 0}, R_{G 0}\right)$ and $\omega_{i Q}=\operatorname{Cov}\left(R_{i 0}, Q_{10}\right)$ for $(l=1, \ldots, N)$. The pricing equation can be written equivalently as:

$$
\mathrm{E}\left[R_{i 0}\right]=r_{0}+\beta_{i 0} \mathrm{E}\left[R_{G 0}-r_{0}\right]+\sum_{l=1}^{N} \delta_{i 0} \mathrm{E}\left[S_{l 0}+r_{l}-r_{0}\right] .
$$

According to equation (6.8), each asset is priced with respect to the global market return and bilateral UIP deviations. The coefficients $\beta_{i 0}$ and $\delta_{i 0}$ depend on covariances with the real exchange rate changes and can be found from equation (6.10):

$$
\left(\begin{array}{c}
\beta_{i} \\
\delta_{i}
\end{array}\right)=\left(\begin{array}{ll}
\omega_{i G} & \omega_{i Q}^{\prime}
\end{array}\right)\left(\begin{array}{cc}
\sigma_{G}^{2} & \omega_{Q G} \\
\omega_{S G}^{\prime} & \Omega_{S Q}
\end{array}\right)^{-1} .
$$

These coeflicients can, therefore, be obtained from an instrumental variables regression, where the instruments are a constant, the excess return on the global market portfolio, $R_{G 0}-r_{0}$, and the real exchange rate returns $Q_{10}$ for $(l=1, \ldots, N)$.

Following Solnik (1974) and Sercu (1980), we assume that nominal exchange rate returns are uncorrelated with inflation differentials. ${ }^{6}$ Then, the instruments are the global market portfolio and the vector of $N$ nominal exchange rate changes:

$$
R_{i 0}=\alpha_{i}+\beta_{i 0} R_{G 0}+\sum_{i=1}^{N} \delta_{i 0} S_{l 0}+\epsilon_{i 0}
$$

Note that the global market beta $\beta_{i 0}$, that results from this multivariate regression, is invariant to the choice of the numeraire currency (see Appendix A). Sercu (1980) uses an alternative but equivalent approach to obtain a similar model. ${ }^{7}$ First, he estimates the following hedge regressions:

$$
\begin{aligned}
& R_{i 0}=\sum_{l=1}^{N} \delta_{i 0} S_{l 0}+\hat{R}_{i 0}, \\
& R_{G 0}=\sum_{l=1}^{N} \delta_{G 0} S_{l 0}+\hat{R}_{G 0},
\end{aligned}
$$

and then uses the residuals of both regressions to compute $\beta_{i 0}$ according to the following equation:

$$
\hat{\beta}_{i 0}=\frac{\operatorname{Cov}\left[\hat{R}_{i 0}, \hat{R}_{G 0}\right]}{\operatorname{Var}\left[\hat{R}_{G 0}\right]} .
$$

An often-used simplification in empirical applications of ICAPMs is that UIP holds on unconditionally. ${ }^{8}$ Then, $\mathrm{E}\left[S_{10}+r_{l}-r_{0}\right]$ equals zero and equation (6.8) reduces to:

$$
\mathrm{E}\left[R_{i 0}\right]=r_{0}+\beta_{i 0} \mathrm{E}\left[R_{G 0}-r_{0}\right] .
$$

\footnotetext{
${ }^{6}$ Mussa (1986) reports this phenomenon as a stylized fact for all floating exchange rates. We do not take into account a long run relation between exchange rates and inflation differentials.

7 This equivalence of the two approaches follows from the partial regression identity. Exchange rates drop out entirely if they are uncorrelated with the return on the global market portfolio.

${ }^{8}$ See for instance Wheatley (1988), Harvey (1991) and Stulz (1995b).
} 
Nevertheless, a correct estimate of $\beta_{i 0}$ still requires use of equation (6.10) with the nominal exchange rates as additional instruments. Only if PPP is assumed to hold as well, these instruments may be discarded, see the Grauer, Litzenberger and Stehle (1976) model.

\subsection{International versus Domestic Pricing}

\subsubsection{Methodology}

Stulz (1995b) investigates the issue of the pricing error between the domestic CAPM and the ICAPM under relative PPP. Here, we generalize his analysis in the absence of PPP. The firm's cost of capital then depends both on a firm's market risk and its currency risk. In the previous section, we assumed that international capital markets are integrated internationally and computed the global market beta. Under segmentation, on the other hand, a standard local market beta can be obtained through estimation of the following equilibrium condition:

$$
\tilde{\mathrm{E}}\left[R_{i 0}\right]=r_{0}+\tilde{\beta}_{i 0} \mathrm{E}\left[R_{L 0}-r_{0}\right],
$$

where $\tilde{\beta}_{i 0}$ measures beta risk with respect to the local market return $R_{L 0}$. To compare the domestic CAPM and the ICAPM we replace the expected return on the domestic market by its equilibrium return under the ICAPM in equation (6.8):

$$
\mathrm{E}\left[R_{L 0}\right]=r_{0}+\beta_{L 0} \mathrm{E}\left[R_{G 0}-r_{0}\right]+\delta_{L 0} \tilde{\nu}
$$

where $\delta_{L 0}$ and $\tilde{\nu}$ are defined in equations (6.9) and (6.5). Substituting this required return in equation (6.14) gives:

$$
\tilde{\mathrm{E}}\left[R_{i 0}\right]=r_{0}+\bar{\beta}_{i 0}\left(\beta_{L 0} \mathrm{E}\left[R_{G 0}-r_{0}\right]+\delta_{L 0} \tilde{\nu}\right)
$$

We now define the pricing error of the CAPM as $\mathrm{E}\left[R_{\mathrm{io}}\right]-\tilde{\mathrm{E}}\left[R_{\mathrm{i} 0}\right]$. From expressions (6.8) and $(6.16)$ it follows that the pricing error is zero if:

$$
\begin{aligned}
& \beta_{i 0}=\tilde{\beta}_{i 0} \beta_{L 0}, \\
& \delta_{i 0}=\tilde{\beta}_{i 0} \delta_{L 0} .
\end{aligned}
$$

Under these conditions the expected return according to the domestic model is equal to the expected return according to the international model. 


\subsubsection{Test Approach}

In this chapter we empirically investigate for a wide range of stocks the pricing error made when using the CAPM rather than the ICAPM by testing the set of restrictions in equations (6.17) and (6.18). Consider the following framework.

Let $R_{i 0}$ be the $(T \times 1)$ vector of time series observations on the return of some asset $i$ expressed in currency 0 . Let $R_{L 0}$ be the $(T \times 1)$ vector of time series observations on the return of the domestic portfolio of country 0 . Let $R_{G 0}$ be the $(T \times 1)$ vector containing observations on the global market return and let $\boldsymbol{S}_{0}$ be the $(T \times N)$ matrix containing the observations on the nominal exchange rate returns with elements $S_{l 0}$ for $l=1, \ldots N$, aiso expressed in currency $0 .^{9}$ The ICAPM now includes nominal exchange rate changes. Let $G_{0}=\left[R_{G 0}, S_{0}\right]$ be the $(T \times(N+1))$ matrix containing the observations on the global market return and the $N$ nominal exchange rate returns all expressed in currency 0 . All observations are in deviations of their sample mean. Consider the following regressions:

$$
\begin{aligned}
& R_{i 0}=R_{L 0} b_{i}+e_{i}, \\
& R_{L 0}=G_{0} c_{0}+u_{0}, \\
& R_{i 0}=G_{0} d_{i}+v_{i} .
\end{aligned}
$$

Under the maintained hypothesis that the formulated ICAPM holds, $G_{0}$ will be orthogonal to both $u_{0}$ and $v_{i}$. Equations (6.20) and (6.21) are just-identified and $c_{0}$ and $d_{i}$ can be estimated by OLS. An advantage of the multicurrency approach is that the global market betas are independent from the choice of the numeraire currency. ${ }^{10}$

To test the hypothesis that the pricing error is zero, we need to consider the expression $\hat{d}_{i}-\hat{c}_{0} \hat{b}_{i}$, which may be written as:

$$
\hat{d}_{i}-\hat{c}_{0} \hat{b}_{i}=\left(G_{0}^{\prime} G_{0}\right)^{-1} G_{0}^{\prime} R_{i 0}-\left(G_{0}^{\prime} G\right)^{-1} G^{\prime} R_{0}\left(R_{L 0}^{\prime} R_{L 0}\right)^{-1} R_{L 0}^{\prime} R_{i 0}=\left(G_{0}^{\prime} G_{0}\right)^{-1} G_{0}^{\prime} M R_{i 0}
$$

where $M=\left(I-R_{L 0}\left(R_{L 0}^{\prime} R_{L 0}\right)^{-1} R_{0}^{\prime}\right)$. Because $\left(G_{0}^{\prime} G_{0}\right)^{-1}$ is positive definite, the difference between the direct and the indirect parameter estimates is zero if and only if $G_{0}^{\prime} M R_{i 0}=$ $G_{0}^{\prime} \hat{e}_{i}=0$.

\footnotetext{
${ }^{9}$ We do not take into account the long run relation between exchange rates and inflation differentials.In our empirical application we assume that for the monthly horizon, inflation differentials are uncorrelated with nominal returns.

${ }^{10}$ It can be shown that the value-weighted sum of the ICAPM betas equals inity. Some studies that use global beta estimates find that global betas for individual stocks are systematically lower than local betas. Examples are Stulz (1995b) and Reilly and Athkar (1995). These results are related to the choice of the numeraire currency when no additional currencies are included in the analysis.
} 
Thus, a test for the pricing error to be zero is equivalent to a test of orthogonality between $G_{0}$ and $\hat{e}_{i}$. If this restriction holds, the risk that is diversifiable domestically is orthogonal to the global instruments. Consequently, the domestic market portfolio contains al] the information that is relevant to price assets. If not, diversifiable domestic risk is not diversifiable internationally. While the CAPM ignores diversifiable domestic risk for an individual asset that is not diversifiable internationally, because these risks are orthogonal to the domestic market portfolio, the ICAPM will require a risk premium. In that case, the CAPM leads to a different cost of capital than the ICAPM. ${ }^{11}$

To formally test for the orthogonality between diversifiable domestic risk and the global instruments, we use Hansen's (1982) GMM method. ${ }^{12}$ We estimate the local market beta $b_{i}$ in equation (6.19) and impose orthogonality of $G_{0}$ and $e_{i}$. This model is overidentified, in that the number of orthogonality conditions (moment conditions) exceeds the number of parameters to be estimated. The parameter estimates are chosen to make the orthogonality conditions as close to zero as possible by minimizing an objective function of the form $g^{\prime} \boldsymbol{W} g$, where $g$ is a vector that contains the orthogonality conditions, $\boldsymbol{G}_{0}^{\prime} \hat{e}_{i}$, and $\boldsymbol{W}$ is a weighting matrix.

Under the null hypothesis that the local market contains all relevant pricing information Hansen's (1982) test statistic, which is the minimized value of the objective function, is distributed $\chi^{2}$ with degrees of freedom equal to the number of overidentifying restrictions. In this application with ten countries, we have ten degrees of freedom, reflecting the number of international instruments: the global market portfolio and nine currencies.

The test statistic depends on the choice of the weighting matrix. Hansen (1982) proposes to use the inverse of the asymptotic variance matrix of the moment conditions. We use an alternative specification of this variance matrix proposed by Andrews (1991) that allows for heteroskedastic and serially dependent regression residuals of unknown form. ${ }^{13}$

Appendix B contains an analytic expression for the GMM estimator and a more detailed

${ }^{11}$ It must be noted that the local market as a whole is priced correctly by the ICAPM and that the local market risk premium reflects the internationally undiversifiable risks of that portfolio. By construction the market weighted average pricing error is equal to zero. This means that for an individual firm the CAPM and the ICAPM might give different cost of capital but on average domestic pricing provides the correct cost of capital.

${ }^{12}$ Alternatively, this test can be interpreted as a test of a firm's exposure to international risk. This interpretation is related to Jorion (1990) who measures currency exposure as the coefficient of the exchange rate change that is obtained from a regression of a firm's return on the rate of change on a trade-weighted exchange rate and the local market index.

${ }^{13}$ Engle and Mustafa (1992) report highly significant test statistics for conditional heteroskedasticity for individual stock returns. Lo and MacKinlay (1990) provide evidence of serial dependence in individual stock returns. 
description of the weighting matrix. It also shows that the test statistic is invariant to the choice of the numeraire currency. Before we present the test results, we will first turn to the data.

\subsection{Data}

\subsubsection{Sources}

This study uses monthly data for ten countries: Australia, Canada, France, Germany, Italy, Japan, the Netherlands, Switzerland, United Kingdom and the United States. Nominal exchange rates for all countries are taken from the International Financial Statistics (IFS) tape (line ae). Short-term interest rates are Eurocurrency rates except for Austria where we use the Treasury bill rate. In the empirical application we focus on the period 1980:01-1995:06. Stulz (1995b) argues that for this sample period markets are fairly well integrated. ${ }^{14}$ The market weighted local equity indices and the market-weighted world market index are from Morgan Stanley Capital International (MSCI). Table 6.1 shows that the ten countries together account for approximately $92 \%$ of the MSCl market-weighted world index in July 1994. Furthermore, Australia, Canada, France, Germany, Italy, the Netherlands and Switzerland each are less than $4 \%$ of the MSCI market-weighted world index. The United States takes approximately $35.6 \%$ of the index.

The data on individual stocks in this study are obtained from Datastream. We have downloaded stock prices, dividend yields and dividends of firms that are included in the Datastream equity lists. These lists contain firms that are currently listed as well as firms that were delisted during the period due to mergers or bankruptcies. If monthly dividends are unavailable we use annual dividend yields to calculate total returns. The annual dividend is uniformly distributed across the months. If neither dividend data nor dividend yields are available, the stock is excluded from the sample. ${ }^{15}$

We also exclude stocks that are denominated in a currency different from the local currency of the country where they are listed. Furthermore, the data are filtered for data errors;

\footnotetext{
14 Unreported results for two subperiods, that exclude the October 1987 crash 1980:01-1987:9 and 1987:11-1995:06 that exclude the October $1987 \mathrm{crash}$, are available: from the authors. The subperiod results only lead to marginally different conclusions. Because of more limited capital mobility, we do not take observations prior to 1980 into consideration.

15 These: are stocks with average annual returns larger than $200 \%$, and stocks that only have a limited amount of price changes.
} 
TABLE 6.1: Composition of MSCI Indices

\begin{tabular}{lc}
\hline \hline Country & $\begin{array}{c}\text { Weight in MSCI } \\
\text { World Index }\end{array}$ \\
\hline Australia & 2.3 \\
Canada & 2.2 \\
France & 3.7 \\
Germany & 3.8 \\
Italy & 1.4 \\
Japan & 28.7 \\
Netherlands & 2.1 \\
Switzerland & 2.7 \\
United Kingdom & 9.4 \\
United States & 35.6 \\
Total & 92.1 \\
\hline Source: Morgan Stanley Capital International \\
Perspective Third Quarter 1994. \\
Note: Composition of the MSCI index on July 29, \\
1994. \\
\hline \hline
\end{tabular}

stocks with outlier observations are excluded from the sample. ${ }^{16}$ For the US and UK the number of firms included in the equity lists is very large. For these two countries we have randomly drawn a sample from the equity lists.

Table 6.2 shows for every country the number of stocks included after the above-mentioned selection procedures. From the table we see that for the 1980:01-1995:06 period the sample consists of 2815 stocks with complete returns. We have constructed national market portfolios from the individual stocks in our sample. A country-by-country comparison of the constructed index with the MSCI market weighted index shows high correlation coefficients, generally exceeding 0.9 .

\subsubsection{Summary Statistics}

Table 6.3 contains summary statistics for stock market (MSCI) returns, currency returns and interest rates, where returns are defined as monthly logarithmic differences multiplied by 100 . The average market return in local currency ranges from 0.69 for Japan to 1.47 for Italy. Corresponding standard deviations vary between 7.47 for Italy and 4.33 for the United States. On average, countries with low domestic market returns have had

${ }^{16}$ These are stocks with average annual returns larger than $200 \%$ and infrequently traded stocks. 
TABLE 6.2: Total Number of Stocks

\begin{tabular}{lc}
\hline Country & $\begin{array}{c}\text { Total Number } \\
\text { of Stocks }\end{array}$ \\
\hline Australia & 89 \\
Canada & 206 \\
France & 119 \\
Germany & 183 \\
Italy & 68 \\
Japan & 841 \\
Netherlands & 103 \\
Switzerland & 105 \\
United Kingdom & 562 \\
United States & 539 \\
Total & 2815 \\
\hline Note: The table shows the total number of stocks \\
that have observations for the sample period \\
1980:01-1995:06.
\end{tabular}

appreciating currencies against the US dollar (USD). The fifth column shows that the cross-sectional variation of average local market returns calculated in USD is lower than the variation of average returns calculated in local currencies. Columns seven and eight contain summary statistics of the MSCI world market portfolio expressed in local currency. Here, Japan is an outlier with an exceptionally low average return. The world portfolio has a lower standard deviation than any individual country. The last two columns show the mean and standard deviation of the short-term interest rate.

Figure 6.1 contains histograms of average stock returns for individual stock returns over the total sample period 1980:01-1995:06. For almost all countries, except Japan, the histograms are skewed to the left. The skewness may be partially attributed to the October 1987 crash. Figure 6.2 contains histograms of standard deviations of individual stocks. For most countries the shape of the histograms is skewed to the right. Canada and the United States have a relatively high percentage of stocks that exhibit high average volatility.

Correlations between local currency stock market returns are provided in panel A of table 6.4. Local stock markets generally move together, though far from perfectly. Correlations range from 0.25 (Italy versus the US) to 0.73 (Canada versus the US, and the Netherlands versus the UK). The Japanese stock market appears to have relatively low correlations with the rest of the world. The information on the correlations between dollar exchange rate changes in panel $\mathrm{B}$ of table 6.4 , suggests a wider range than stock market returns. While the European currencies appear to move together almost perfectly against 
Table 6.3: Summary Statistics

\begin{tabular}{|c|c|c|c|c|c|c|c|c|c|c|}
\hline \multirow[b]{2}{*}{ Country } & \multicolumn{2}{|c|}{$\begin{array}{l}\text { MSCI } \\
\text { Local }\end{array}$} & \multicolumn{2}{|c|}{$\begin{array}{c}\text { Currency } \\
\text { Dollar }\end{array}$} & \multicolumn{2}{|c|}{$\begin{array}{l}\text { MSCI } \\
\text { Dollar }\end{array}$} & \multicolumn{2}{|c|}{$\begin{array}{l}\text { World } \\
\text { Local }\end{array}$} & \multicolumn{2}{|c|}{$\begin{array}{c}\text { Interest } \\
\text { Local }\end{array}$} \\
\hline & Mean & StDv & Mean & StDv & Mean & StDv & Mean & StDv & Mean & St.Dev \\
\hline Australia & 1.16 & 6.83 & -0.24 & 2.96 & 0.92 & 8.15 & 1.38 & 4.84 & 0.96 & 0.32 \\
\hline Canada & 0.73 & 5.02 & -0.09 & 1.30 & 0.65 & 5.62 & 1.23 & 4.05 & 0.83 & 0.30 \\
\hline France & 1.18 & 6.06 & -0.11 & 3.47 & 1.07 & 6.79 & 1.25 & 4.73 & 0.92 & 0.40 \\
\hline Germany & 0.89 & 5.72 & 0.12 & 3.50 & 1.01 & 6.37 & 1.02 & 4.71 & 0.57 & 0.19 \\
\hline Italy & 1.47 & 7.47 & -0.38 & 3.41 & 1.09 & 7.85 & 1.52 & 4.68 & 1.20 & 0.46 \\
\hline Japan & 0.69 & 5.79 & 0.57 & 3.32 & 1.26 & 7.09 & 0.57 & 4.41 & 0.48 & 0.19 \\
\hline Netherlands & 1.36 & 4.99 & 0.11 & 3.51 & 1.47 & 5.17 & 1.03 & 4.69 & 0.60 & 0.18 \\
\hline Switzerland & 0.93 & 4.82 & 0.17 & 3.81 & 1.10 & 5.50 & 0.96 & 4.95 & 0.45 & 0.17 \\
\hline United Kingdom & 1.41 & 5.33 & -0.17 & 3.56 & 1.23 & 6.18 & 1.32 & 4.59 & 0.92 & 0.27 \\
\hline United States & 1.18 & 4.33 & - & - & 1.18 & 4.33 & 1.14 & 4.24 & 0.70 & 0.32 \\
\hline
\end{tabular}

Notes: Summary statistics of MSCl indices and exchange rates are calculated for the period 1980:01-1995:05. The first two columns contain the mean and the standard deviation of the MSCI country indices expressed in local currency respectively. The third and the fourth column contain respectively the mean and the standard deviation of exchange rate changes against the USD. The fifth and the sixth column contain the mean and the standard deviation of the MSCl country indices expressed in USD. The next two columns contain the mean and the standard deviation of the MSCI index expressed in local currency and the last two columns contain the mean and the standard deviation of the short-term interest rate. 
Australio

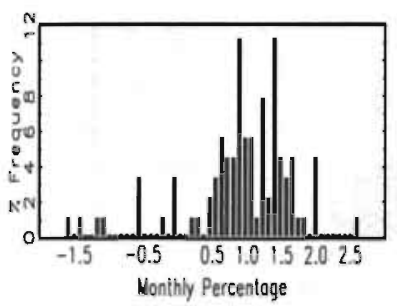

Germany

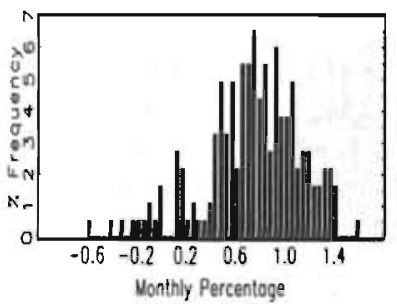

Netherlands

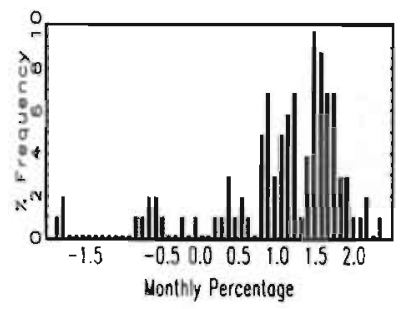

United States

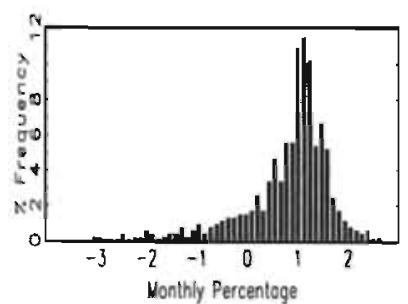

Canado

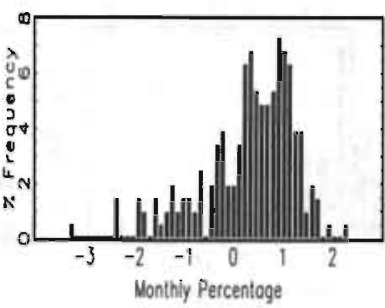

Italy

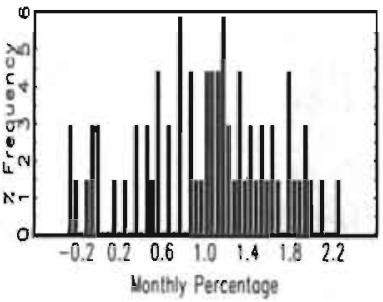

Switzerland

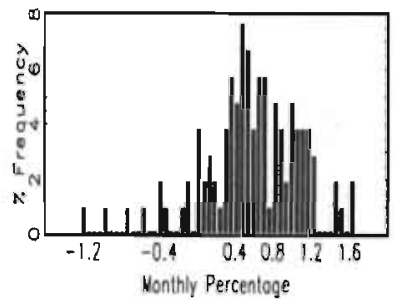

France

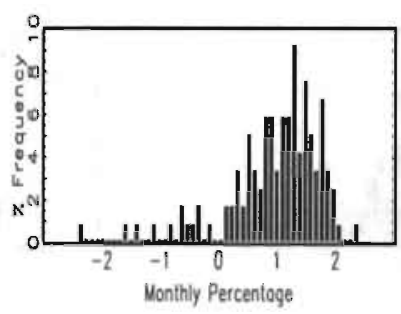

Japan

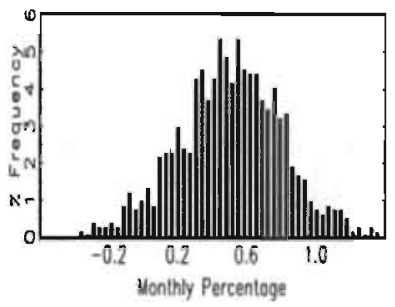

United Kingdom

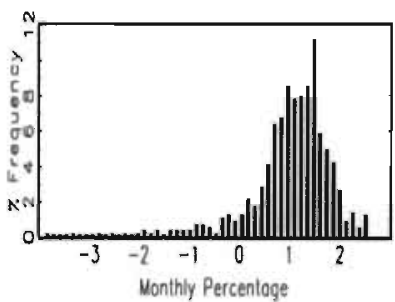

Figure 6.1: Distribution of Mean Return

Note: Average individual stock returns for: 1980:01-1995:06. 
Austrolia

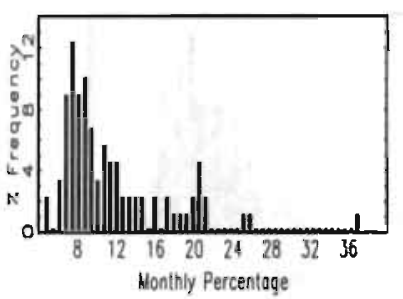

Germany

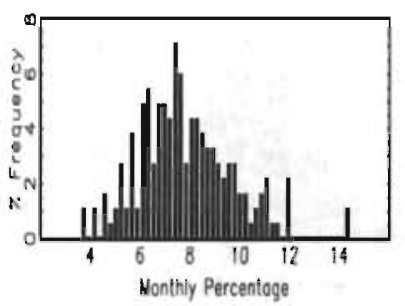

Netherlands

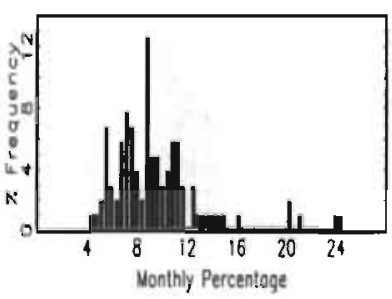

United States

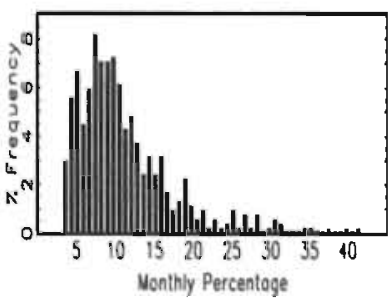

Canodo

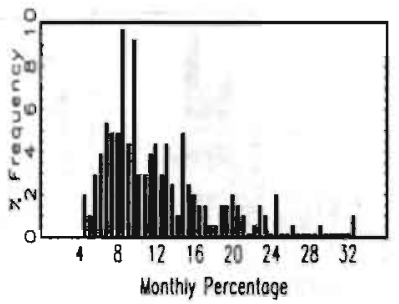

itoly

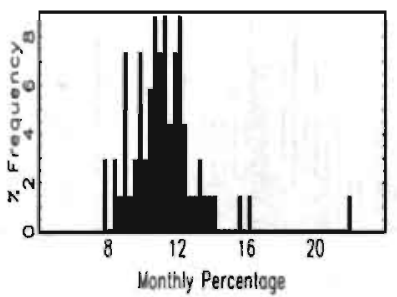

Switzerlond

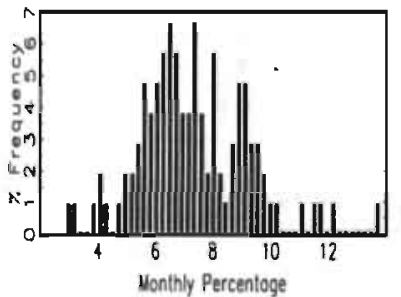

France

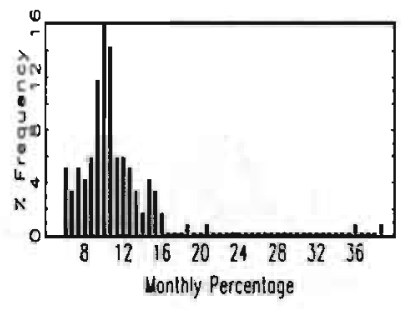

Japan

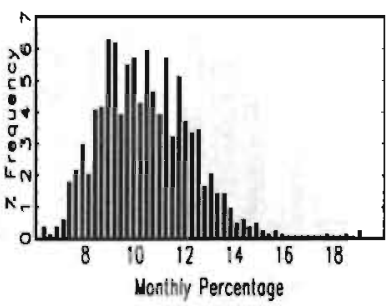

United Kingdom

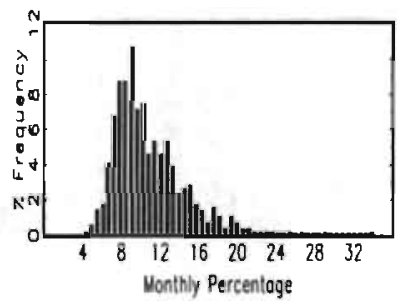

FIGURE 6.2: Distribution of Standard Deviations

Note: Standard deviation of individual stock returns for 1980:01-1995:06. 
TABLE 6.4: Correlation Matrices

\begin{tabular}{|c|c|c|c|c|c|c|c|c|c|}
\hline Country & Can & Fra & Ger & $\overline{\text { Ita }}$ & Jap & Net & Swi & Ukd & Usa \\
\hline \multicolumn{10}{|c|}{ Panel A: Stock Market Returns in Local Currency } \\
\hline Australia & 0.65 & 0.42 & 0.41 & 0.27 & 0.30 & 0.52 & 0.51 & 0.57 & 0.55 \\
\hline Canada & & 0.43 & 0.39 & 0.31 & 0.32 & 0.59 & 0.56 & 0.62 & 0.73 \\
\hline France & & & 0.59 & 0.43 & 0.35 & 0.56 & 0.57 & 0.56 & 0.52 \\
\hline Germany & & & & 0.39 & 0.29 & 0.62 & 0.71 & 0.51 & 0.45 \\
\hline Italy & & & & & 0.35 & 0.42 & 0.37 & 0.38 & 0.25 \\
\hline Japan & & & & & & 0.36 & 0.35 & 0.37 & 0.32 \\
\hline Netherlands & & & & & & & 0.67 & 0.73 & 0.64 \\
\hline Switzerland & & & & & & & & 0.64 & 0.64 \\
\hline United Kingdom & & & & & & & & & 0.68 \\
\hline \multicolumn{10}{|c|}{ Panel B: Exchange Rate Changes against US Dollar } \\
\hline Australia & 0.28 & 0.19 & 0.12 & 0.11 & 0.19 & 0.13 & 0.13 & 0.24 & - \\
\hline Canada & & 0.20 & 0.208 & 0.25 & 0.16 & 0.20 & 0.17 & 0.28 & - \\
\hline France & & & 0.96 & 0.86 & 0.61 & 0.95 & 0.89 & 0.72 & - \\
\hline Germany & & & & 0.87 & 0.62 & 0.99 & 0.92 & 0.72 & - \\
\hline Italy & & & & & 0.53 & 0.86 & 0.79 & 0.71 & - \\
\hline Japan & & & & & & 0.61 & 0.65 & 0.53 & - \\
\hline Netherlands & & & & & & & 0.92 & 0.74 & - \\
\hline Switzerland & & & & & & & & 0.70 & - \\
\hline
\end{tabular}

the USD, other correlations, for instance between Italy and Australia, are virtually zero.

\subsection{Empirical Results}

In the empirical analysis, we assume that countries are internationally integrated and that the MSCI world index is a good proxy for the global market portfolio of the ICAPM. Similarly, the local MSCI index is assumed to proxy the domestic market portfolio. Equations (6.20) to (6.21) are used to obtain estimates $\hat{d}_{i}$ and $\hat{b}_{i} \hat{c}_{0}$ of $\beta_{i 0}$ and $\tilde{\beta}_{i 0} \beta_{L 0}$ respectively. If the pricing error that results from using the CAPM instead of the ICAPM is zero, that is, if the local market portfolio contains all the information that is relevant to price assets in an integrated world, these two terms must be equal.

Figure 6.3 plots $\hat{d}_{i}$ against $\hat{b}_{i} \hat{c}_{0}$ for the sample period 1980:01-1995:06 (note that scaling is country-dependent). For each country, the dots are centred around the line with a slope 
of unity. ${ }^{17}$ For firms on this line, the estimated cost of capital is invariant to the use of the CAPM or ICAPM. However, it is clear, that for each country some firms plot off the straight line. Firms that plot below the line have a higher cost of capital using the (correct) ICAPM than using the (incorrect) CAPM. IF $\left(\delta_{i 0}-\tilde{\beta}_{i 0} \delta_{L 0}\right)$ is close to zero, the difference reflects a premium for risks that are diversifiable locally but not internationally. On the other hand, firms that plot above the line have a lower cost of capital with use of the ICAPM than with the CAPM, suggesting the presence of nondiverisifiable local risk that can be diversified internationally.

Next, we investigate the magnitude of the pricing error. In combination, equations (6.15) and (6.16) show that the pricing error consists of two parts:

$$
E\left[R_{i 0}\right]-\tilde{E}\left[R_{i 0}\right]=\left(\beta_{i 0}-\tilde{\beta}_{i 0} \beta_{L 0}\right) E\left[R_{G 0}-r_{0}\right]+\left(\delta_{i 0}-\dot{\beta}_{i 0} \delta_{L 0}\right) \tilde{\nu} .
$$

The first term on the right hand side of equation (6.23) is related to the global market premium and the second part is related to exchange risk premiums. In the computation of the pricing errors, we assume the global market premium to equal the local currency excess return of the global market portfolio, while expected exchange risk premiums are assumed to be zero. ${ }^{18}$

Table 6.5 and figure 6.4 contain the results for the whole sample period. The equal-weighted annualized pricing error is positive but close to zero for all countries. The range of pricing errors for individual stocks is quite large. Pricing errors range from $-9.33 \%$ for the United Kingdom to $+8.05 \%$ for the United States. However, for all countries the mean absolute pricing error is below $1 \%{ }^{19}$ The cross-sectional standard deviation for Japan is relatively low compared to the other countries. This is related to the small excess return on the global market index expressed in Yen.

Since the previous two figures do not allow a formal evaluation of the statistical significance of the pricing errors for individual firms, we use Hansen's GMM estimators to explicitly test whether firms significantly plot off the straight line in figure 6.3. This is the orthogonality test, described in section 6.2 and appendix $B$, between the diversifiable domestic risk and the set of global instruments, which provides a set of overidentifying restrictions. The test statistic is heteroskedasticity and autocorrelation consistent and is distributed $\chi^{2}$ with ten degrees of freedom. The $5 \%$ critical value is equal to 18.31 . Figure 6.5 contains cumulative

\footnotetext{
${ }^{17}$ Note that the value-weighted average domestic pricing error is zero by construction.

18 This latter assumption may be motivated by the lack of success in finding empirical evidence in support of systematic risk premiums, see for instance Dumas and Solnik who cannot reject a conditional version of equation 6.13. Another possibility for the exchange risk premiums is to use the forward premium on the exchange.

${ }^{19}$ Note that Stulz (1995b) finds a pricing error of $0.6 \%$ for Nestlé, which is close to the mean absolute pricing error for Switzerland.
} 
Austrolio

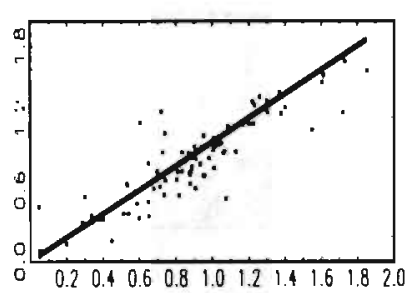

Germany

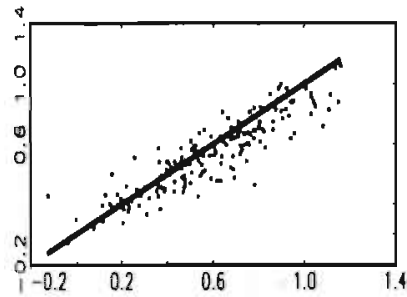

Netherlands
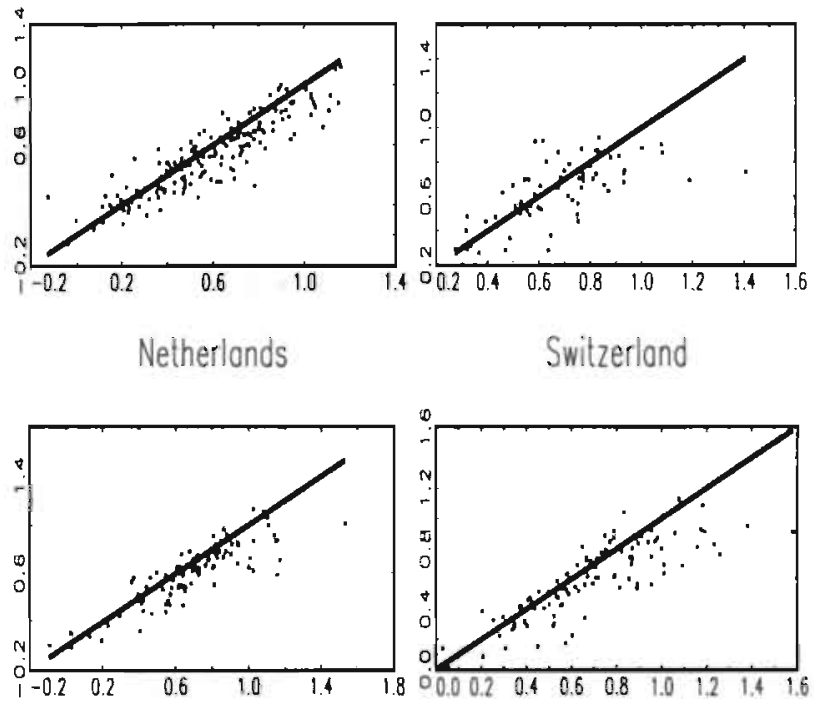

Switzerland

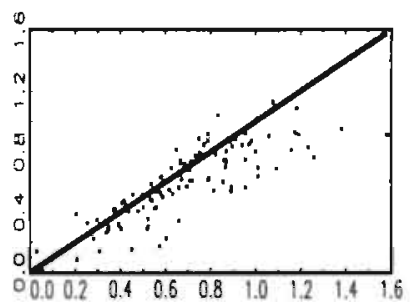

\section{France}

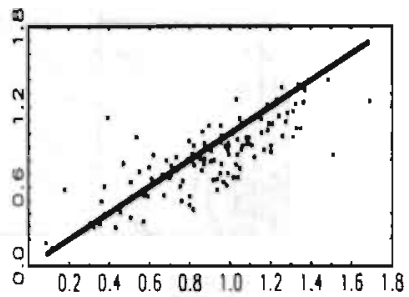

Japan

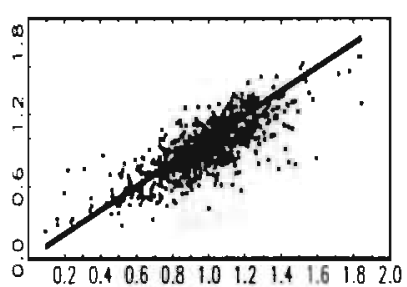

United Kingdom

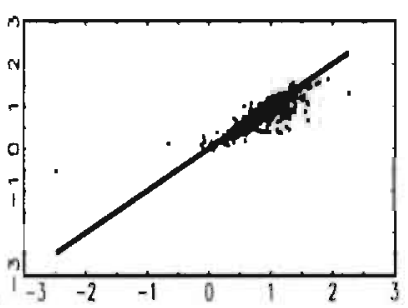

United States

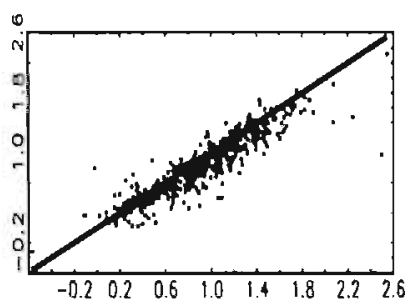

Figure 6.3 : Scatter of $\hat{d}_{i}$ versus $\hat{b}_{i} \hat{c}_{0}$ 
Austrolio

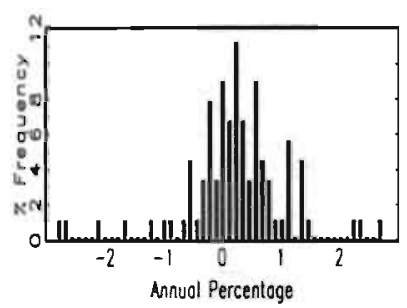

Germany

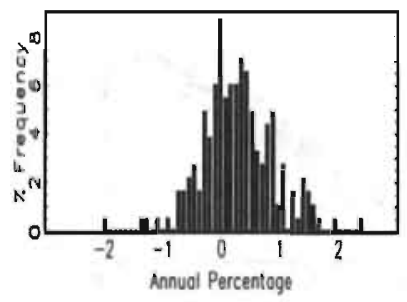

Netherlands

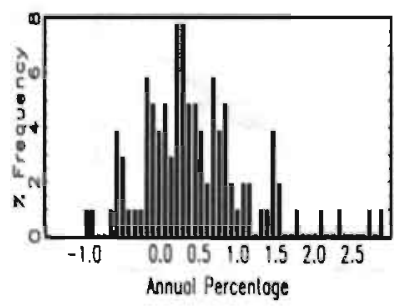

United Stotes

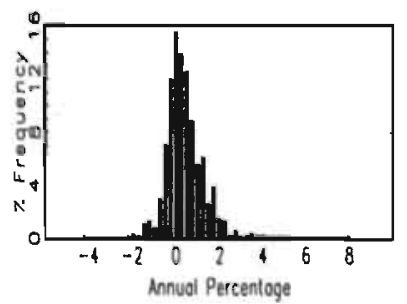

Canado

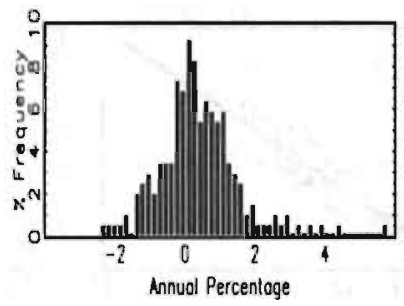

Itoly

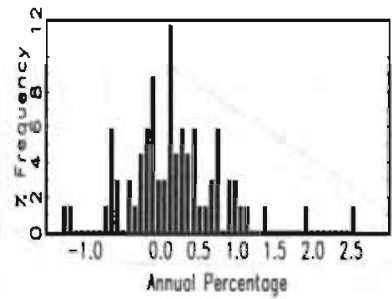

Switzerlond

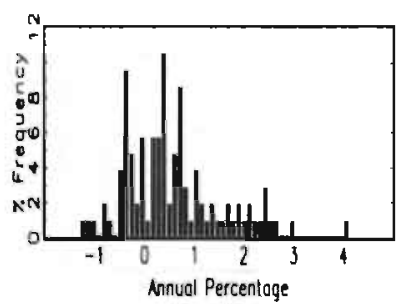

Fronce

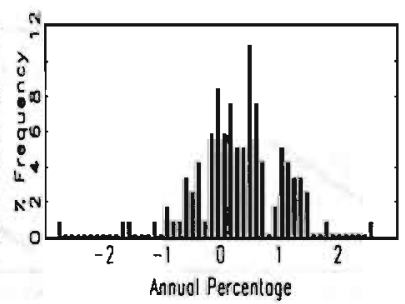

Japon

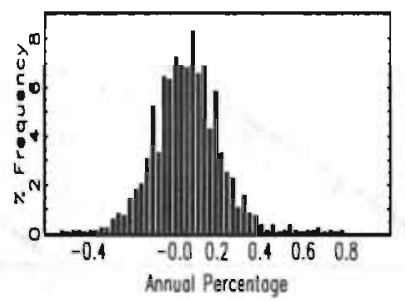

United Kingdom

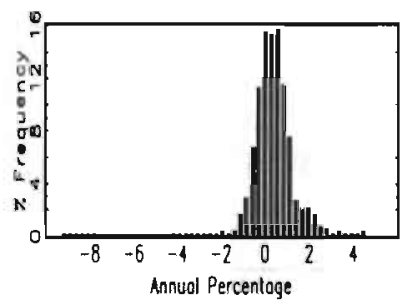

Figure 6.4: Distribution of Domestic Pricing Errors 
Table 6.5: Annualized Pricing Error

\begin{tabular}{lccccc}
\hline \hline Country & Mean & Abs & $\overline{\text { StDv }}$ & Min & Max \\
\hline Australia & 0.22 & 0.64 & 0.88 & 2.75 & -2.83 \\
Canada & 0.38 & 0.86 & 1.13 & 5.80 & -2.43 \\
France & 0.30 & 0.61 & 0.74 & 2.62 & -2.82 \\
Germany & 0.26 & 0.51 & 0.62 & 2.42 & -2.03 \\
Italy & 0.17 & 0.49 & 0.64 & 2.56 & -1.31 \\
Japan & 0.06 & 0.13 & 0.15 & 0.79 & -0.53 \\
Netherlands & 0.43 & 0.61 & 0.71 & 2.91 & -1.00 \\
Switzerland & 0.57 & 0.83 & 0.97 & 4.11 & -1.28 \\
United Kingdom & 0.39 & 0.69 & 0.95 & 4.59 & -9.33 \\
United States & 0.39 & 0.69 & 0.91 & 8.05 & -4.31 \\
\hline
\end{tabular}

Notes: Abs, StDv, Min and Max denote the mean absolute value, the standard deviation the minimum and the maximum respectively. The sample period is 1980:01-1995:06.

TABle 6.6: Significance of Global Pricing

\begin{tabular}{|c|c|c|c|}
\hline Country & $20 \%$ & $10 \%$ & $5 \%$ \\
\hline Australia & 0.18 & 0.10 & 0.04 \\
\hline Canada & 0.20 & 0.08 & 0.01 \\
\hline France & 0.16 & 0.07 & 0.03 \\
\hline Germany & 0.24 & 0.12 & 0.08 \\
\hline Italy & 0.13 & 0.00 & 0.00 \\
\hline Japan & 0.11 & 0.04 & 0.01 \\
\hline Netherlands & 0.18 & 0.11 & 0.03 \\
\hline Switzerland & 0.24 & 0.09 & 0.02 \\
\hline United Kingdom & 0.15 & 0.07 & 0.03 \\
\hline United States & 0.18 & 0.08 & 0.01 \\
\hline
\end{tabular}

density functions of the test statistic for firms within every country. Table 6.6 contains the percentages of firms with significant pricing errors at the $20 \%$, the $10 \%$ and the $5 \%$ level respectively. The table shows that only for a relatively small number of stocks the null hypothesis is rejected at the $5 \%$ level. $^{20}$

${ }^{20}$ Even for the longer period 1973:01-1995:06 the hypothesis that the local market portfolio contains all information relevant to price domestic assets cannot be rejected, although in the seventies capital markets were less integrated. Our findings are in line with Jorion (1990) who shows that only a small amount of US multinational firms exhibit significant currency exposure. 
Austrolio

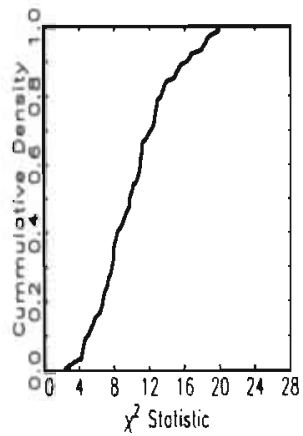

Itoly

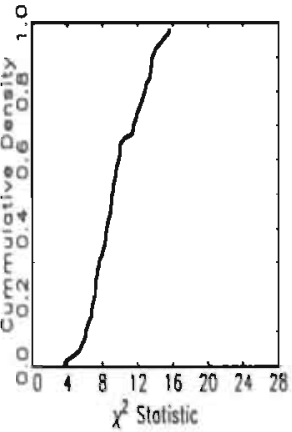

United Kingdom

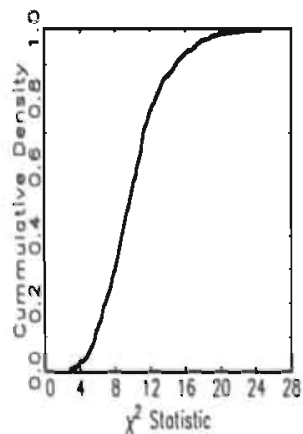

Conado

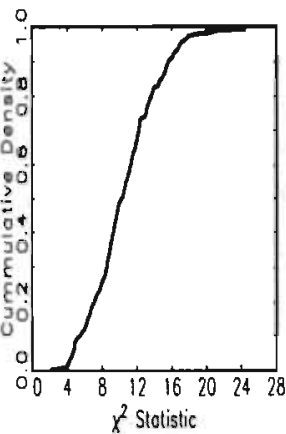

Japan

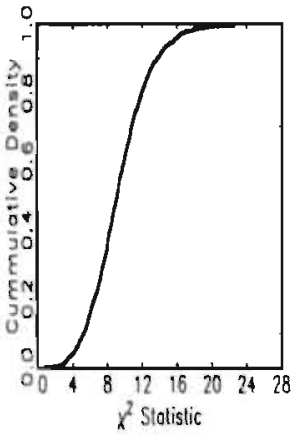

United States

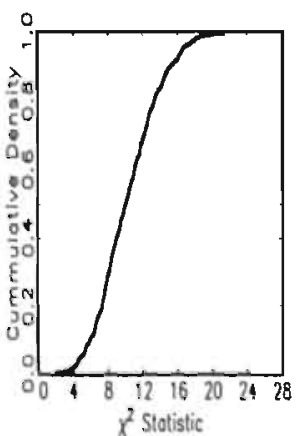

France

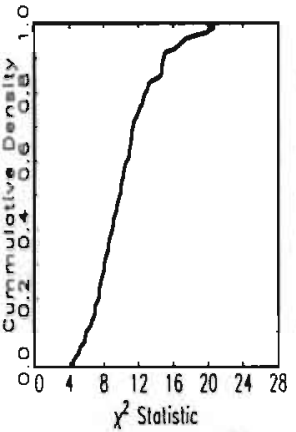

Netherlands
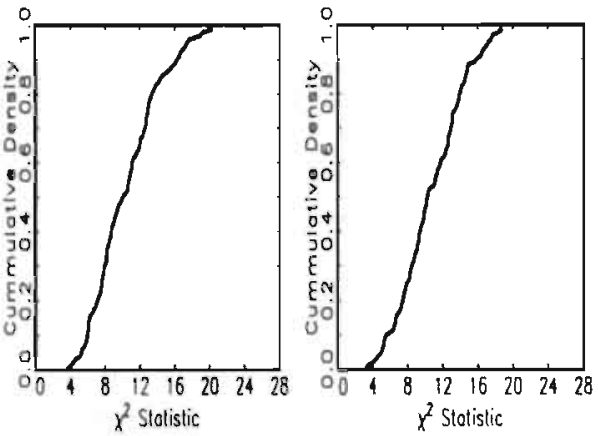

Figure 6.5: Cumulative Density of $\chi^{2}$ Statistics Note: The cumulative distribution Hansens's $\chi^{2}$ statistics that test for significant domestic pricing errors of individual stock returns. 


\subsection{Conclusions}

Increasing capital market integration has important implications for the calculation of the cost of capital. In an integrated world the cost of capital should be determined using the international capital asset pricing model (ICAPM) rather than the domestic capital asset pricing model (CAPM). In this chapter we investigate the domestic pricing error using an international asset pricing model that explicitly allows for deviations from purchasing power parity. The pricing error when using the CAPM rather than an ICAPM is zero if diversifiable domestic risk is orthogonal to the global market portfolio return and foreign currency changes. We use Hansen's (1982) generalized method of moments to test for orthogonality and implement this test for almost three thousand individual stocks from ten different countries. We cannot reject the hypothesis that the local market portfolio contains all the information relevant to price domestic assets. We find that the global market portfolio and the foreign currencies affect the cost of capital of an individual firm only through the effect of the global market on the risk premium of the local market and not through the global beta of the firm. 


\section{Appendix 6A: Numeraire Independence}

Let now $R_{i 0}$ be the $(T \times 1)$ vector of time series observations on the return of some asset $i$ expressed in currency 0 . Let $R_{G 0}$ be the $(T \times 1)$ vector containing observations on the global market return and let $\boldsymbol{S}_{0}$ be the $\left.(T \times N)\right)$ matrix containing the observations on the nominal exchange rate returns with elements $S_{l 0}$ for $l=1, \ldots N$, also expressed in currency 0 . All observations are in deviations of their sample mean. Now define $G_{0}=\left[R_{G 0}, S_{0}\right]$. The transformation for $G_{0}$ if we go from numeraire 0 to numeraire $k$ is:

$$
\boldsymbol{G}_{k}=\boldsymbol{G}_{0} \boldsymbol{P}_{k}
$$

where $\boldsymbol{P}_{k}$ is a $((N+1) \times(N+1))$ matrix with -1 s on the $k$-th row, 1s along the principal diagonal except for the $k$-th row, and zeros everywhere else. Furthermore the inverse matrix $\boldsymbol{P}_{k}^{-1}$ equals $\boldsymbol{P}_{k}$ The transformation for $R_{i 0}$ if we go to currency $k$ is $R_{i k}=R_{i 0}-S_{k 0}$. Consider the following regression:

$$
R_{i 0}=b_{i} G_{0}+e_{i}
$$

The least squares estimator $\hat{b}_{1}$ is:

$$
\hat{b}_{i}=\left(G_{0}^{\prime} G_{0}\right)^{-1} G_{0}^{\prime} R_{i 0}
$$

We can also express the regression in currency $k$. The least squares estimator $\tilde{b}_{i}$ is:

$$
\tilde{b}_{i}=\left(G_{k}^{\prime} G_{k}\right)^{-1} G_{k}^{\prime} R_{i k} .
$$

This equation can be written as:

$$
\tilde{b}_{i}=\boldsymbol{P}_{k}^{-1}\left(G_{0}^{\prime} G_{0}\right)^{-1} G_{0}^{\prime} R_{i 0}+P_{k}^{-1}\left(G_{0}^{\prime} G_{0}\right)^{-1} G_{0}^{\prime} S_{i 0}=P_{k}\left(\hat{b}_{i}+\iota_{k}\right),
$$

where $\iota_{k}$ is a $((N+1) \times 1)$ vector with the $k$-th element equal to 1 and zeros elsewhere. This equation shows that $\tilde{b}_{i}$ and $\hat{b}_{i}$ are equivalent except for the $k$-th element. 


\section{Appendix 6B: Generalized Method of Moments}

In this appendix we derive a GMM estimator for the domestic beta under the hypothesis that the ICAPM holds and that the domestic market contains all relevant information to price assets. In this case domestic diversifiable risk is not diversifiable internationally. This implies that domestic diversifiable risk is orthogonal to a set of global instruments. Consider the domestic market model for an asset in country 0 :

$$
R_{i 0}=\boldsymbol{R} b_{i}+e_{i}
$$

where $\boldsymbol{R}=\left[\iota, R_{L 0}\right]$ contains $r=2$ elements, a unit vector and the domestic market portfolio. Now impose orthogonality of diversifiable domestic risk, $e_{i}$ and a set of global factors, $G_{0}$, that consists of the return on the global market portfolio and $n$ exchange rate changes. We have the vector of sample moments $g\left(b_{i}\right)$ :

$$
g\left(b_{i}\right)=(1 / T)\left(\boldsymbol{Z}^{\prime} e_{i}\right),
$$

where $\boldsymbol{Z}$ includes the $p=n+3$ instruments: $\left[\boldsymbol{R}, \boldsymbol{G}_{0}\right]$. The parameter vector $b_{i}$ is chosen to make the orthogonality conditions as close to zero as possible by minimizing the objective function:

$$
g\left(b_{i}\right)^{\prime} \hat{\boldsymbol{W}}^{-1} g\left(b_{i}\right),
$$

where $\hat{\boldsymbol{W}}^{-1}$ is the inverse of an estimate of the variance of the sample moments. The GMM estimate $\hat{b}_{i}$ is the solution to the following system of equations:

$$
\left(\left.\frac{\partial g\left(b_{i}\right)}{\partial b_{i}^{\prime}}\right|_{b=\hat{b}_{i}}\right)^{\prime} \hat{\boldsymbol{W}}^{-1} g\left(\hat{b}_{i}\right)=\boldsymbol{R}^{\prime} \boldsymbol{Z} \hat{\boldsymbol{W}}^{-1} \boldsymbol{Z}^{\prime}\left(\boldsymbol{R}_{i}-\boldsymbol{R} \hat{b}_{i}\right)=0,
$$

which gives the GMM estimator:

$$
\hat{b}_{\mathrm{i}}=\left(\boldsymbol{R}^{\prime} Z \hat{\boldsymbol{W}}^{-1} \boldsymbol{Z}^{\prime} \boldsymbol{R}\right)^{-1}\left(\boldsymbol{R}^{\prime} Z \hat{\boldsymbol{W}}^{-1} Z^{\prime} R_{i}\right) .
$$

In our application $\hat{\boldsymbol{W}}$ is an estimate of: ${ }^{21}$

$$
\boldsymbol{W}=\lim _{T \rightarrow \infty} \sum_{t=1}^{T} \sum_{v=-\infty}^{\infty}\left(e_{i t} e_{i t-u}, z_{t} z_{t-v}^{\prime}\right),
$$

where $z_{t}$ is $((N+3) \times 1)$ vector that contains the elemerats of the $t$-th row of $Z$. The estimate of $\boldsymbol{W}$ depends on the distribution of the regression residuals. Suppose that $e_{i}$ is regarded conditionally homoskedastic and serially uncorrelated. In this case the variance in equation (6.34) can be consistently estimated by:

$$
\hat{\boldsymbol{W}}=(1 / T) \hat{\sigma}^{2} Z^{\prime} Z,
$$

${ }^{21}$ See Hamilton (1994). 
where $\hat{\sigma}^{2}$ is the variance of the $\epsilon_{i}$. If we substitute this expression in equation (6.33) we obtain the OLS estimator.

On the other hand suppose that the regression residuals are serially correlated and heteroskedastic. Andrews (1991) proposes the following estimator:

$$
\hat{W}=(T /(T-r))\left(\hat{\boldsymbol{\Gamma}}_{0}+\sum_{v=1}^{T-1} k\left(v / S_{T}\right)\left(\hat{\boldsymbol{\Gamma}}_{v}+\hat{\boldsymbol{\Gamma}}_{v}^{\prime}\right)\right)
$$

where $\hat{\Gamma}_{z^{\prime}}=(1 / T) \sum_{t=v+1}^{r}\left(z_{t} \hat{e}_{i t} \hat{e}_{i t-1} z_{t}^{\prime}\right)$, where $k(\cdot)$ is a quadratic spectral kernel (QSK), where $S_{T}$ is a bandwidth parameter and where $\hat{e}_{i}$ are OLS residuals. ${ }^{22}$ White's (1980) heleroscedasticity-consistent variance estimator is a special case when $k(\cdot)=0$. Andrews (1991) introduces an automatic bandwidth method where the bandwidth parameter $S_{T}$ is a function of the data. Andrews (1991) defines the automatic bandwidth parameter as follows: First specify $p$ univariate approximating parametric models for $z_{t} e_{i t}$. Second, estirnite the parameters of the approximating parametric models by standard methods. Third, substitute these estimates in a formula that expresses the bandwidth parameter as a function of the estimates of the parametric models. In our application we follow Andrews' (1991) suggestion to use AR(1) approximating parametric models. ${ }^{23}$

To estimate $b_{i}$ we use a two-step method. First we estimate the model under the assumption of homoskedastic and serially uncorrelated regression residuals. This estimate of $b_{i}$ is used to produce an initial estimate $\hat{\boldsymbol{W}}$. Next equation (6.33) is used to arrive at the final estimate of $b_{i}$. Hansen (1982) provides the conditions that guarantee that the estimates are consistent and asymptotically normal.

The model is overidentified, in that the number of orthogonality conditions $p$ exceeds the number of parameters to be estimated $r$. Hansen (1982) proposed a test of whether all orthogonality conditions simultaneously hold. The test statistic is given by the minimized value of the objective function:

$$
\left(\sqrt{T} g\left(\hat{h}_{i}\right)\right)^{\prime} \hat{\boldsymbol{W}}^{-1}\left(\sqrt{T} g\left(\hat{b}_{i}\right)\right)=T\left(\tilde{\epsilon}_{i}^{\prime} \boldsymbol{Z} \hat{\boldsymbol{W}}^{-1} \boldsymbol{Z}^{\prime} \hat{\epsilon}_{i}\right) \rightarrow \chi^{2}(p-r),
$$

where $\tilde{e}_{i}$ are the GMM residuals. The test statistic converges to a $\chi^{2}$ distribution with $p-r$ degrees of freedom. A high $\chi^{2}$ statistic means that the regression residuals are correlated with the global instrumental variables and that the CAPM and the ICAPM do not give the same cost of capital.

\footnotetext{
${ }^{22}$ Andrews (1991) shows with Monte Carlo simulations that the Bartlett kernel, used by Newey and West (1987), is inferior to the QSK.

${ }^{23}$ The weights for the univariate models are one except for the weight that corresponds to the intrcept. parameter in $z_{t}$ which is set to zero.
} 
Finally we show for the most general variance estimator that Hansen's test statistic is invariant to the choice of the numeraire currency of the global instruments. This result also holds for the restricted variance estimators. The transformation of $Z$ if we go from numeraire 0 to numeraire $k$ is $\left[\boldsymbol{R}, \boldsymbol{G}_{0} \boldsymbol{P}_{k}\right]=\boldsymbol{Z} \tilde{\boldsymbol{P}}_{k}$, where $\tilde{\boldsymbol{P}}_{\boldsymbol{k}}$ is a $((N+3) \times(N+3))$ matrix with $-1 \mathrm{~s}$ on the $k$-th row, 1 s along the principal diagonal except for the $k$ th row, and zeros everywhere else. The estimator of $\hat{\boldsymbol{\Gamma}}_{v}$, expressed in currency $k$ becomes $(1 / T) \sum_{t=v+1}^{T}\left(\tilde{\boldsymbol{P}}_{k}^{\prime} z_{t} \hat{e}_{i t} \hat{e}_{i t-v} z_{t}^{\prime} \tilde{\boldsymbol{P}}_{k}\right){ }^{24}$ According to equation (6.36) the currency $k$ estimator of $\hat{\boldsymbol{W}}$ now becomes $\tilde{\boldsymbol{P}}_{k}^{\prime} \hat{\boldsymbol{W}} \tilde{\boldsymbol{P}}_{k}$. This gives the equality:

$$
\boldsymbol{Z} \tilde{\boldsymbol{P}}_{k}\left(\tilde{\boldsymbol{P}}_{k}^{\prime} \hat{\boldsymbol{W}} \tilde{\boldsymbol{P}}_{k}\right)^{-1} \tilde{\boldsymbol{P}}_{k}^{\prime} \boldsymbol{Z}^{\prime}=\boldsymbol{Z}\left(\tilde{\boldsymbol{P}}_{k} \tilde{\boldsymbol{P}}_{k}^{-1}\right) \hat{\boldsymbol{W}}^{-1}\left(\tilde{\boldsymbol{P}}_{k}^{\prime-1} \tilde{\boldsymbol{P}}_{k}^{\prime}\right) \boldsymbol{Z}^{\prime}=\boldsymbol{Z} \hat{\boldsymbol{W}}^{-1} \boldsymbol{Z}^{\prime}
$$

The equality implies that the GMM estimator, $\hat{b}_{i}$ in equation (6.33) and the corresponding regression residuals $\tilde{e}_{i}$ are numeraire invariant. Therefore all ingredients for Hansen's (1982) test statistic in equation (6.37) are numeraire invariant.

${ }^{24}$ Note that the OLS residuals of the dornestic market model $\hat{e}_{i}$ are defined in local currency terms. 



\section{Chapter 7}

\section{The Dynamics of Short-Term}

\section{Interest Rate Volatility}

\section{Reconsidered}

Chan, Karolyi, Longstaff and Sanders (1992) (CKLS) compare a number of widely used continuous-time models of the short-term interest rate. They estimate various models and compare the models in terms of their ability to capture the actual behavior of the shortterm riskless rate. The issue of how these models compare is important because the models differ in their implications for valuing contingent claims and hedging interest rate risk. ${ }^{1}$ The testing approach of CKLS exploits the fact that many term structure models imply dynamics for the short-term riskless rate that can be nested in one stochastic differential equation. With respect to the most successful models they conclude:

The results for the tests of the one-month Treasury Bill indicate that it is critical to model volatility correctly. The models that best describe the dynamics of the interest rates over time are those that allow the conditional volatility of interest rate changes to be highly dependent on the level of the interest rate. (CKLS, 1992, p. 1209.)

${ }^{1}$ The research of CKLS has generated a lot of discussion in the finance literature. Recent contributions to the debate on the interest rate volatility dynamics include Aït-Sahalia (1996a,b), Andersen and Lund (1996a,b), Brenner, Harjes and Kroner (1995), Conley, Hansen, Luttmer and Scheinkman (1995), Tauchen (1996) and Torous and Ball (1995). 
With regard to the parameter that measures the sensitivity of interest rate volatility to the level of the interest rate itself $(\gamma)$ they report an unconstrained estimate of about 1.5. ${ }^{2}$

A different class of models to capture volatility dynamics in interest rates is the family of autoregressive conditional heteroskedasticity (ARCH) models, introduced by Engle (1982) and generalized (GARCH) by Bollerslev (1986). Key ingredients in these models are volatility clustering and volatility persistence. These effects are usually reliably present in estimated GARCH models of interest rate time series. ${ }^{3}$

In the current chapter we present and estimate a model of short-term interest rate volatility, developed in Koedijk, Nissen, Schotman and Wolff (1994) (KNSW), which encompasses both the level effect of CKLS and the conditional heteroskedasticity effect of the GARCH class of models. When compared with other existing models, our model exhibits a superior empirical fit. This feature results from a relatively flexible specification which allows different effects to dominate as the level of the interest rate varies.

It has long been recognized in the finance literature that the specification of volatility is one of the most important features for derivative security pricing. We investigate implications for the pricing of bond options. Specifically, we investigate the implications from different models of the short-term interest rate for the pricing of discount bond options. Our findings indicate that the inclusion of a volatility effect in the model specification, in addition to a level effect, is particularly relevant for the pricing of shorter-term options on long term bonds. The magnitude of the implied price differences is strongly dependent on the level of the interest rate.

The plan of the chapter is as follows. In section 7.1 we briefly review previous studies that model short-term interest rates, and introduce our new specification which nests both the level effect of CKLS and the volatility effect of the GARCH class of models. Section 7.2 describes our data and contains the empirical results. Section 7.3 considers the implications for the pricing of contingent claims. Finally, section 7.4 offers some concluding remarks.

\subsection{GARCH and Level Effects}

Most of the theoretical models of the short-term interest rate which are used in finance have been developed in a continuous time setting. CKLS review a number of widely used

\footnotetext{
${ }^{2}$ Sensitivity is defined as $\frac{\partial \ln h}{\partial \ln r}$, where ir is the interest rate level and $h$ is the standard deviation.

${ }^{3}$ Bollerslev, Chou and Kroner (1992) provide a survey of empirical studies in this vein.
} 
stochastic processes that are nested within the following stochastic differential equation:

$$
d r_{t}=\kappa\left(\mu-r_{t}\right) d t+\sigma r_{t}^{\gamma} d W_{t}
$$

where $r_{t}$ represents the short-term interest rate and $W_{t}$ is a standard Brownian motion. The interest rate process is mean reverting for $\kappa>0$. The parameter $\gamma$ determines the sensitivity of the variance with respect to the level of the spot rate; we will refer to $\gamma$ as the interest rate elasticity. This parameter turns out to be crucial in applications to option valuation. CKLS approximate this stochastic differential equation by the following discrete approximation:

$$
r_{t}-r_{t-1}=\alpha_{0}+\alpha_{1} r_{t-1}+\sigma r_{t-1}^{\gamma} \epsilon_{t}, \quad \epsilon_{t} \sim D(0,1)
$$

which they estimate for the one-month US Treasury bill rate. The bill yield was obtained from the Fama files within the CRSP database. The data are monthly quotations for the period 1964.06-1989.12. They used the Generalized Method of Moments to estimate the model, and report that $\gamma$ is 1.5 and highly significant, which means that the conditional variance of the short-term interest rate is highly sensitive to changes in the level of the interest rate. For comparison, the Cox, Ingersoll and Ross (1985) (CIR) square root term structure model implies $\gamma=\frac{1}{2}$. In fact, the estimated elasticity is so large that stationarity of the interest rate process is not guaranteed (see Broze, Scaillet and Zakoian (1995)).

Alternatively, Longstaff and Schwartz (1993) (LS) present a two factor model for the term structure. The first factor is the short-term interest rate. The second factor is the conditional variance of changes of the short-term interest rate, which is assumed to be generated by a GARCH-class process. ${ }^{4}$ In their application LS estimate the following: model:

$$
\begin{gathered}
r_{t}-r_{t-1}=\alpha_{0}+\alpha_{1} r_{t-1}+\alpha_{2} h_{t-1}^{2}+e_{t}, \\
h_{t}^{2}=\beta_{1}+\beta_{2} e_{t-1}^{2}+\beta_{3} h_{t-1}^{2}+\beta_{4} r_{t-1},
\end{gathered}
$$

where $e_{t}=h_{t} \epsilon_{t}$ is the prediction error of the interest rate and $h_{t}^{2}$ is the conditional variance. The error term $\epsilon_{t}$ is normalized to have unit variance. This specification differs from the standard GARCH-M model by the inclusion of the lagged spot rate in the volatility equation. ${ }^{5}$ Note that, if $\beta_{2}=0$ and $\beta_{3}=0$, the specification corresponds to a model with $\gamma=\frac{1}{2} \cdot{ }^{6}$ The level effect in the volatility proves significant, but the restriction that the interest sensitivity is equal to $\gamma=\frac{1}{2}$ might well be overly restrictive given the unrestricted

\footnotetext{
${ }^{4}$ Balduzzi, Das and Foresi (1995) identify the second factor with the central tendency of the short-term interest rate.

${ }^{5}$ Bomhoft and Schotman (1988) estimate the same model for monthly data for Germany, Japan and the United States and find that the level effect improves the specification of the volatility equation. The GARCH-M effect turns out to be insignificant.

${ }^{6}$ The constant term $\beta_{1}$ also enters the conditional variance equation under exact aggregation of the continuous time process of CKLS. See also section 7.3 below.
} 
estimate of $\gamma$ reported in CKLS. We therefore would like to generalize the Longstaff and Schwartz specification such that it can accommodate different interest rate sensitivities in the volatility. Stated differently, we search for a specification that combines the high interest rate sensitivity of CKLS with GARCH-type volatility clustering. This motivates the specification presented below. We assume conditional volatility of the form:

$$
h_{t}=\sigma_{t} r_{t-1}^{\gamma}
$$

which differs from CKLS by the time varying nature of $\sigma_{t}$, which is assumed to be generated by the $\operatorname{GAR}(\mathrm{H}(1,1)$ process:

$$
\sigma_{t}^{2}=\beta_{1}+\beta_{2}\left(\sigma_{t-1} \epsilon_{t-1}\right)^{2}+\beta_{3} \sigma_{t-1}^{2} .
$$

Substituting equation (7.6) in equation (7.5) and solving for $\sigma_{t}^{2}$, the proposed volatility process can be rewritten as:

$$
h_{t}^{2}=\beta_{1} r_{t-1}^{2 \gamma}+\left(\frac{r_{t-1}}{r_{t-2}}\right)^{2 \gamma}\left(\beta_{2} e_{t-1}^{2}+\beta_{3} h_{t-1}^{2}\right) .
$$

We will refer to this specification as the KNSW model. ${ }^{7}$ The CKLS model is a special case of this model; for $\beta_{2}=\beta_{3}=0$. Another special case is the GARCH model, which obtains if $\gamma=0$. A restricted version of LS obtains, i.e. with $\alpha_{2}=0$, if $\gamma=\frac{1}{2}$. An interesting feature of the above specification is the time varying persistence of shocks which depends on the interest rate level.

The unconditional distribution of the spot rate is not avajlable in closed form. It can however be easily computed numerically by simulation for different values of the parameters. In the discrete time process negative interest rates are possible, but this is simply an artefact of the discrete time approximation of a continuous time process. The probability that the short-term interest rate will ever attain negative values is extremely small when the unconditional mean and the drift are sufficiently large relative to $h_{\imath}^{2}$.

The interest rate process of CIR is stationary. Broze, Scaillet and Zakoian (1995) show that the Euler discretization of equation (7.1) is only (second-order) stationary if $\gamma<1$. If on the other hand, $\gamma>1$ the volatility at high interest rates makes it possible for interest rates to increase even further. To allow for higher variance elasticities it is necessary to introduce nonlinearities in the drift (see Ait-Sahalia (1996a,b) and Conley, Hansen, Luttmer and Scheinkman (1995)). We consider, therefore, the following parametrization of the conditional mean:

$$
r_{t}-r_{t-1}=\alpha_{0}+\alpha_{1} r_{t-1}+\alpha_{2} r_{t-1}^{2}+e_{t} .
$$

${ }^{7}$ Brenner, Harjes and Kroner (1995) propose a different approach. In equation (7.6) they use the unscaled prediction error $e_{t}$ instead of the scaled prediction error $\sigma_{t} \epsilon_{t}$. The stationarity conditions of their specification are hard to establish. 
For $\alpha_{2}<0$ the stronger mean-reverting drift is now able to pull back the interest rate to the unconditional mean from a high interest rate level in the presence of a larger variance.

An exact continuous time limit of the discrete time process in equation (7.7) is not available. One could consider the process as a simple approximation to the following process, which is closely related to the LS model:

$$
\begin{aligned}
& d r_{t}=\kappa\left(\mu-r_{t}\right) d t+\sigma r_{t}^{\gamma} d W_{1 t}, \\
& d \sigma_{t}^{2}=\theta\left(w-\sigma_{t}^{2}\right) d t+\psi \sigma_{t} d W_{2 t} .
\end{aligned}
$$

The scale parameter $\sigma_{t}$ is not a constant as in the models considered by CKLS but follows a diffusion process as in Nelson (1990). A major difference, however, is that $\gamma$ is not restricted to $\gamma=\frac{1}{2}$ in equation (7.9).

\subsection{Empirical Results}

\subsubsection{Data}

The one-month Treasury bill rate is chosen as the short-term interest rate. Monthly and weekly yields were obtained from the Federal Reserve Bank for the period January 1968 - July 1996. The monthly data are last Friday of the month observations and the weekly data are recorded at the last trading-day of the week.

The yield is expressed in annualized form. Figure 7.1 plots the level and the change of the one-month Treasury bill rate. The interest rate is more variable in the period subsequent to the 1979 change in Federal Reserve Bank operating procedures. Table 7.1 provides summary statistics for the two data series. The distribution of $\Delta r_{t}$ is skewed to the left and exhibits excess kurtosis.

\subsubsection{Parameter Estimates}

In this section we provide estimation and test results for the four different models for the behavior of short-term interest rate volatility: the GARCH(1,1), CKLS, LS and KNSW. We consider the the specification for the conditional mean in equation ( $7 . x)$ and the following 


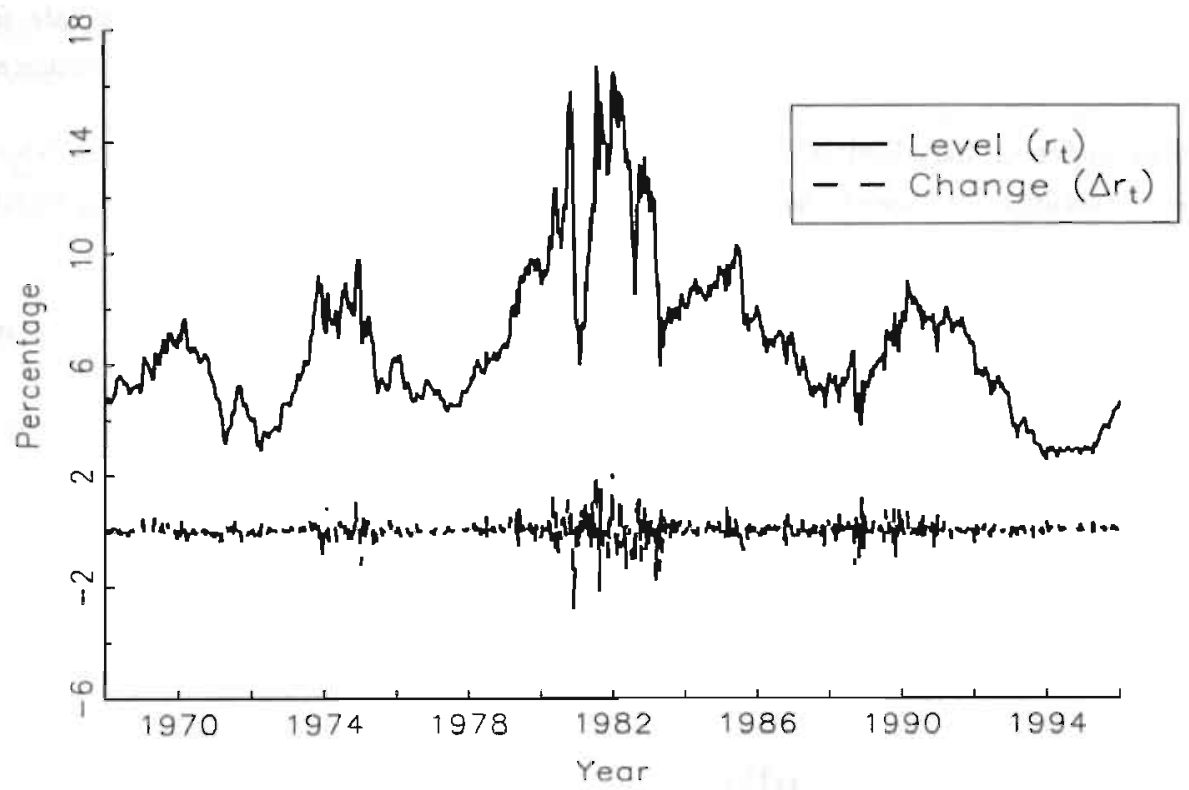

Figure 7.1: One-month Treasury Bill

TABLE 7.1: Summary Statistics

\begin{tabular}{|c|c|c|c|c|}
\hline & \multicolumn{2}{|c|}{ Levels } & \multicolumn{2}{|c|}{ First Differences } \\
\hline & Monthly & Weekly & Monthly & Weekly \\
\hline Number of Observations & 343 & 1440 & 342 & 1439 \\
\hline Mean & 6.56 & 6.56 & 0.00 & 0.00 \\
\hline Standard Deviation & 2.62 & 2.62 & 0.68 & 0.33 \\
\hline Minimum & 2.61 & 2.48 & -6.10 & -2.86 \\
\hline Maximum & 15.85 & 16.69 & 3.40 & 2.31 \\
\hline Skewness & 1.24 & 1.26 & -1.73 & -0.63 \\
\hline Excess Kurtosis & 1.82 & 2.00 & 22.77 & 14.04 \\
\hline \multicolumn{5}{|c|}{$\begin{array}{l}\text { Notes: Skewness is defined as } m_{3} / s^{3} \text {, with } m_{3} \text { the centred third moment } \\
\text { of the data and } s \text { the sample standard deviation. Kurtosis is defined as } \\
\left(m_{4} / s^{4}\right)-3 \text {, with } m_{4} \text { the centred fourth moment of the data. Units are } \\
\text { percent per annum. }\end{array}$} \\
\hline
\end{tabular}

volatility specification that nests the models of interest:

$$
h_{i}^{2}=\beta_{0}+\beta_{1} r_{i-1}^{2 \gamma}+\left(\frac{r_{t}}{r_{t-1}}\right)^{2 \gamma}\left(\beta_{2} e_{t-1}^{2}+\beta_{3} h_{t-1}^{2}\right)+\beta_{4} r_{t-1} .
$$

The models are estimated by the method of quasi-maximum likelihood (QML). The QML estimator is consistent and asymptotically normal for any distribution of $e_{t}$ providing some 
regularity conditions are satisfied (see Wooldridge (1994)). The asymptotic distribution for the QML estimator $\hat{\theta}$ is then:

$$
\sqrt{T}\left(\theta_{0}-\hat{\theta}\right) \rightarrow N\left(0, \mathbf{A}^{-1} \mathbf{B} \mathbf{A}^{-1}\right)
$$

where $\mathbf{A}$ denotes the information matrix, and $\mathbf{B}$ denotes the outer product of the gradient vector evaluated at the optimal parameter vector. The standard errors are estimated using the robust covariance matrix $\mathbf{A}^{-1} \mathbf{B} \mathbf{A}^{-1}$.

Because of severe multicollinearity problems we are unable to estimate the general specification nesting all the specific models. It turns out that the extra constant term $\left(\beta_{0}\right)$ of the LS model cannot be estimated if $\gamma$ is a free paraineter.

Panel A of table 7.2 reports empirical results for the four models using monthly observations. The first column contains the estimates of the standard $\operatorname{GARCH}(1,1)$ model, ${ }^{8}$ The GARCH parameters are highly significant even on the relatively low monthly frequency, and indicate strong persistence of variance shocks. The second and third columns report our estimates of the CKLS model in which the interest rate elasticity $\gamma$ is included. The estimates of $\gamma$ move from 1.40 to 2.51 when a constant term is added. ${ }^{9,10}$ The LS model in the fourth column adds the lagged level of $r_{t}$ to the GARCH specification, which appears an important improvement in terms of the likelihood function. ${ }^{11}$ The inclusion of $r_{t-1}$ also lowers the persistence of the variance shocks. The proposed KNSW specification is reported in the last column of table 7.2. It attains the highest value for the log-likelihood function. The GARCH and CKLS models are both nested within this specification, and can both be rejected at the $5 \%$ level. As in the LS model, the inclusion of the lagged interest rate lowers the persistence of the volatility shocks. Similar to the CKLS model we also find a large value for $\gamma$.

It has been illustrated by Drost and Nijman (1993) that GARCH effects are particulary dominant at high frequency data. We replicate, therefore, the estimates of Panel A using weekly observations. The parameter estimates for the weekly data are reported in Panel B. The higher frequency of the observation shows up in the parameters of the $\operatorname{GARCH}(1,1)$ model, where the point estimates $\beta_{2}$ and $\beta_{3}$ even add up to 1.03 , although we can never

\footnotetext{
8 The initial condition for $h_{0}$ is the unconditional variance.

${ }^{9}$ For example, in the CIR model $\left(\gamma=\frac{1}{2}\right)$ the exactly aggregated conditional volatility takes the form $h_{t}^{2}=\beta_{0}+\beta_{4} r_{t-1}$, with $\beta_{0}>0$ and $\beta_{4} \neq 1$ (see DeMunnik and Schotman (1994)). Pagan, Hall and Martin (1994) focus on temporal aggregation problems of the CKLS model.

${ }^{10}$ The estimate of $\gamma$ is lower than in CKLS. We have not been able to exactly replicate their results due to some differences between their data and ours. For the overlapping sample period we have some different data points in 1987 .

${ }^{11}$ In order to ensure that estimates are comparable across models we set the GARCH-M parameter in LS to zero. If this parameter is included it is not significantly different from zero. When $\beta_{1}$ is a free parameter it attains a negative value. Therefore we also impose $\beta_{1}=0$.
} 
TABle 7.2: Unrestricted Parameter Estimates

\begin{tabular}{|c|c|c|c|c|c|}
\hline & GARCH & CKLS1 & CKLS2 & $\overline{\mathrm{LS}}$ & KNSW \\
\hline \multicolumn{6}{|c|}{ A: Monthly } \\
\hline$\alpha_{0} \times 10$ & $\begin{array}{l}-0.25 \\
(0.15)\end{array}$ & $\begin{array}{c}0.01 \\
(0.07)\end{array}$ & $\begin{array}{c}0.45 \\
(0.73)\end{array}$ & $\begin{array}{c}-0.26 \\
(0.09)\end{array}$ & $\begin{array}{l}-0.30 \\
(0.30)\end{array}$ \\
\hline$\alpha_{1} \times 10$ & $\begin{array}{c}0.37 \\
(0.53)\end{array}$ & $\begin{array}{c}0.20 \\
(0.71)\end{array}$ & $\begin{array}{c}0.00 \\
(0.01)\end{array}$ & $\begin{array}{c}0.34 \\
(0.25)\end{array}$ & $\begin{array}{c}0.36 \\
(0.81)\end{array}$ \\
\hline$\alpha_{2} \times 10^{2}$ & $\begin{array}{l}-0.58 \\
(0.78)\end{array}$ & $\begin{array}{c}-0.26 \\
(0.88)\end{array}$ & $\begin{array}{l}-0.10 \\
(0.20)\end{array}$ & $\begin{array}{l}-0.42 \\
(0.34)\end{array}$ & $\begin{array}{l}-0.44 \\
(0.94)\end{array}$ \\
\hline$\beta_{0} \times 10$ & - & $\begin{array}{l}- \\
-\end{array}$ & $\begin{array}{c}0.70 \\
(3.49)\end{array}$ & - & - \\
\hline$\beta_{1} \times 10^{2}$ & $\begin{array}{c}0.77 \\
(0.96)\end{array}$ & $\begin{array}{c}0.13 \\
(2.18)\end{array}$ & $\begin{array}{l}0.001 \\
(0.53)\end{array}$ & - & $\begin{array}{c}0.02 \\
(1.15)\end{array}$ \\
\hline$\beta_{2}$ & $\begin{array}{c}0.26 \\
(3.89)\end{array}$ & $\begin{array}{l}- \\
-\end{array}$ & $\begin{array}{l}- \\
-\end{array}$ & $\begin{array}{c}0.25 \\
(2.31)\end{array}$ & $\begin{array}{c}0.18 \\
(3.08)\end{array}$ \\
\hline$\beta_{3}$ & $\begin{array}{c}0.75 \\
(12.03)\end{array}$ & - & - & $\begin{array}{c}0.70 \\
(5.11)\end{array}$ & $\begin{array}{c}0.74 \\
(8.90)\end{array}$ \\
\hline$\beta_{4} \times 10^{2}$ & $\begin{array}{l}- \\
-\end{array}$ & - & $\begin{array}{l}- \\
-\end{array}$ & $\begin{array}{c}0.31 \\
(1.70)\end{array}$ & - \\
\hline$\gamma$ & - & $\begin{array}{c}1.40 \\
(10.13)\end{array}$ & $\begin{array}{c}2.51 \\
(5.25)\end{array}$ & $\begin{array}{l}- \\
-\end{array}$ & $\begin{array}{c}1.24 \\
(4.90)\end{array}$ \\
\hline$\frac{\text { Loglik }}{\text { B: Weekly }}$ & \multicolumn{4}{|c|}{ B: Weekly } & -198 \\
\hline$\alpha_{0} \times 10$ & $\begin{array}{c}0.12 \\
(0.26)\end{array}$ & $\begin{array}{c}0.10 \\
(0.26)\end{array}$ & $\begin{array}{c}0.11 \\
(0.26)\end{array}$ & $\begin{array}{c}0.07 \\
(0.12)\end{array}$ & $\begin{array}{c}0.11 \\
(0.32)\end{array}$ \\
\hline$\alpha_{1} \times 10$ & $\begin{array}{c}0.01 \\
(0.04)\end{array}$ & $\begin{array}{c}0.01 \\
(0.28)\end{array}$ & $\begin{array}{c}0.01 \\
(0.18)\end{array}$ & $\begin{array}{c}0.03 \\
(0.13)\end{array}$ & $\begin{array}{c}0.01 \\
(0.09)\end{array}$ \\
\hline$\alpha_{2} \times 10^{2}$ & $\begin{array}{l}-0.01 \\
(0.26)\end{array}$ & $\begin{array}{l}-0.01 \\
(0.62)\end{array}$ & $\begin{array}{c}-0.01 \\
(0.48)\end{array}$ & $\begin{array}{l}-0.07 \\
(0.30)\end{array}$ & $\begin{array}{l}-0.03 \\
(0.25)\end{array}$ \\
\hline$\beta_{0} \times 10$ & - & - & $\begin{array}{c}0.10 \\
(1.83)\end{array}$ & $\begin{array}{l}- \\
-\end{array}$ & - \\
\hline$\beta_{1} \times 10^{2}$ & $\begin{array}{c}0.01 \\
(1.62)\end{array}$ & $\begin{array}{c}0.08 \\
(2.82)\end{array}$ & $\begin{array}{c}0.01 \\
(0.78)\end{array}$ & - & $\begin{array}{c}0.01 \\
(1.81)\end{array}$ \\
\hline$\beta_{2}$ & $\begin{array}{c}0.22 \\
(2.96)\end{array}$ & - & - & $\begin{array}{c}0.23 \\
(3.70)\end{array}$ & $\begin{array}{c}0.31 \\
(3.40)\end{array}$ \\
\hline$\beta_{3}$ & $\begin{array}{c}0.81 \\
(14.05)\end{array}$ & - & - & $\begin{array}{c}0.77 \\
(13.79)\end{array}$ & $\begin{array}{c}0.60 \\
(3.81)\end{array}$ \\
\hline$\beta_{4} \times 10^{2}$ & - & - & - & $\begin{array}{c}0.04 \\
(2.29)\end{array}$ & - \\
\hline$\gamma$ & - & $\begin{array}{c}1.21 \\
(13.59)\end{array}$ & $\begin{array}{c}1.67 \\
(6.03)\end{array}$ & - & $\begin{array}{c}1.31 \\
(6.33)\end{array}$ \\
\hline Loglik & 83 & -76 & -71 & 94 & 101 \\
\hline $\begin{array}{l}\text { Notes: Log } \\
\text { given in pa } \\
\text { Longstaft } \\
\text { Koedijk, N }\end{array}$ & $\begin{array}{l}\text { denotes } t \\
\text { beses. } \\
\text { Sanders } \\
n \text {, Schotn }\end{array}$ & $\begin{array}{l}\text { log-likel } \\
\text { LS, LS an } \\
\text { 992), Lor } \\
\text { an and W }\end{array}$ & $\begin{array}{l}\text { ond valu } \\
\text { KNSW } \\
\text { staff anc } \\
\text { Iff respec }\end{array}$ & $\begin{array}{l}\text { e. Robust } \\
\text { denote } \mathrm{Ct} \\
\text { I Schwart } \\
\text { tively. }\end{array}$ & $\begin{array}{l}\text { values ar } \\
\text { a, Karoly } \\
\text { 1992) an }\end{array}$ \\
\hline
\end{tabular}




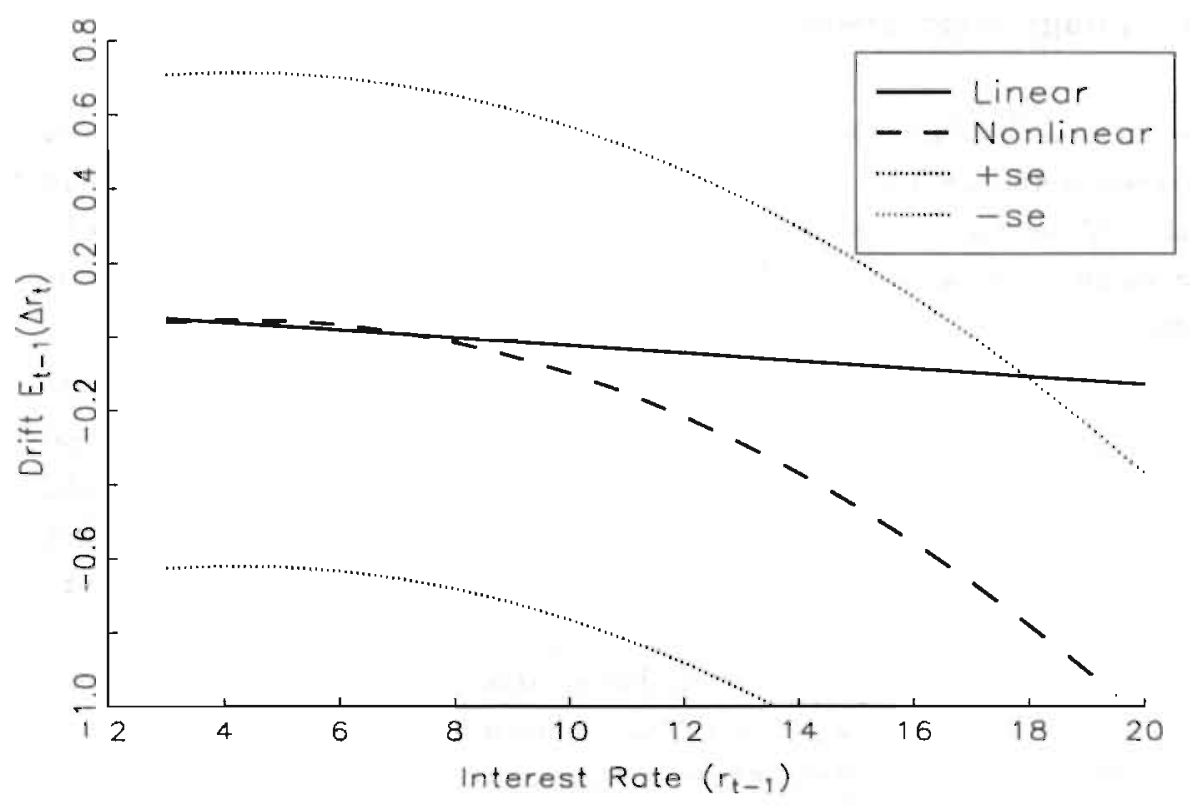

Figure 7.2 : Mean Reversion

Note: The figure contains the drift of the unrestricted (nonlinear) KNSW model and the (restricted) linear KNSW model. Se denotes the one-standard-error band for the nonlinear model.

reject the hypothesis that they add up to a number smaller than one. The interest rate sensitivity $\gamma$ of the CKLS model is identical to the estimate from monthly data. Inclusion of the nonlinearity term $\alpha_{2}$ has no influence on the estimated values of the parameters in the volatility specification. But the negative point estimates ensure stationarity even if $\gamma>1$.

Figure 7.2 plots the lagged interest rate level against the drift, $E_{t-1}\left[\Delta r_{t}\right]$, for the nonlinear KNSW model as well as for the linear KNSW model with $\alpha_{2}=0 .{ }^{12}$ For moderate interest rate levels there is very slight mean reversion, however at interest rates higher than $15 \%$ the drift sharply decreases. Note however that the standard error of the drift term is quite large. Ait-Sahalia (1996a,b), Andersen and Lund (1996b), Conley, Hansen, Luttmer and Scheinkman (1995), Pfann, Schotman and Tschernig (1996) and Stanton (1995) report similar nonlinearities in the dynamics of the short-term interest rate.

${ }^{12}$ Table 7.5 contains parameter estimates for the conditional mean of the linear KNSW model. 


\subsubsection{Diagnostic Tests}

In order to investigate the adequacy of the conditional variance model we employ a series of Lagrange multiplier (LM) tests as suggested by Bollerslev, Engle and Nelson (1994). With the LM tests we search for directions in which the model could be improved. Let $z_{t}$ be a vector of explanatory variables that we like to test for inclusion in the volatility equation:

$$
h_{t}^{2}=f\left(x_{t}, \theta\right)+\delta z_{t},
$$

where $f\left(x_{t}, \theta\right)$ is the volatility specification under the null hypothesis. Given the fattailedness of the data the conventional LM tests, described in Engle (1984) are no longer applicable. However, from Wooldridge (1994) and Bollerslev and Wooldridge (1992) a robust LM test may be computed from a simple set of auxiliary regressions. First, run the regression from $\frac{\partial \ln h_{t}^{2}}{\partial \theta}$ on $\frac{\partial \ln h_{t}^{2}}{\partial \delta}=z_{t} / \hat{h}_{t}^{2}$ both evaluated at the QML estimates under the null hypothesis. Next, calculate the score that is orthogonal to the scores under the null hypothesis as $s_{\delta t}=\left(\hat{e}_{t}^{2} / \hat{h}_{t}^{2}-1\right) \hat{\nu}_{\delta t}$ where $\hat{e}_{t}$, the prediction errors, and $\hat{h}_{t}^{2}$ are evaluated at the QML estimates under the null hypothesis and $\hat{\nu}_{5 t}$ are the residuals of the first regression. An asymptotically valid LM statistic is then calculated as the $T R^{2}$ from a regression of a vector of ones on $s_{s t}$ with $T$ the number of observations and $R^{2}$ the uncentered multiple correlation coefficient. The test statistic is asymptotically distributed as $\chi^{2}(k)$, with $k$ the number of elements in $z_{i}$. The directions of misspecification that we consider are:

1. Additional level effects: $z_{t}=r_{t-1}$.

2. Outliers between $79: 10$ and 81:12: $z_{t}=D_{1 t}$, a dummy variable that takes the value one in the period 79:10 - 81:12 and is zero elsewhere.

3. A permanent variance shift after 79:10: $z_{t}=D_{2 t}$, a dummy variable that takes the value one after 79:10. and zero elsewhere. This test can be interpreted as a test for the stability of the model over subperiods.

4. Sign bias (see Engle and $\mathrm{Ng}(1993)$ ): $z_{t}=S_{t}^{+}$, a dummy variable that takes the value one if $e_{t-1}>0$ and zero elsewhere.

5. Size bias (see Engle and $\mathrm{Ng}(1993)): z_{1 t}=S_{t}^{+} e_{t-1}, z_{2 t}=S_{t}^{+} e_{t-1}^{2}, z_{3 t}=S_{t}^{-} e_{t-1}$ and $z_{4 t}=S_{t}^{-} e_{t-1}^{2}$ where $S_{t}^{-}=1-S_{t}^{+}$.

All these tests indicate directions in which to search for improved specifications. Some of the tests have been proposed with specific alternatives in mind. The last two tests were suggested by Engle and $\mathrm{Ng}$ (1993) as powerful diagnostics for possible asymmetries in the 
TABLE 7.3: Diagnostics

\begin{tabular}{|c|c|c|c|c|}
\hline & GARCH & CKIS2 & IS & KNSW \\
\hline \multicolumn{5}{|l|}{ A: Monthly } \\
\hline Skewness & 0.10 & -0.03 & 0.01 & -0.08 \\
\hline Excess Kurtosis & $2.13^{\star}$ & $0.89^{\star}$ & $2.05^{*}$ & $1.08^{*}$ \\
\hline Jarque-Bera & $65.27^{\star}$ & $11.54^{\star}$ & $60.05^{\star}$ & $17.15^{\star}$ \\
\hline L.M(level) & $11.21^{*}$ & 0.78 & 0.01 & 0.10 \\
\hline I.M(level ${ }^{2}$ ) & $13.94^{*}$ & 0.44 & $6.85^{\star}$ & 0.85 \\
\hline $\operatorname{IM}(\operatorname{ARCH}(4))$ & 0.56 & $42.20^{*}$ & 2.00 & 1.54 \\
\hline L:M(79:10) & $4.23^{\dagger}$ & $3.11^{\dagger}$ & $4.99^{\dagger}$ & 1.19 \\
\hline $\operatorname{L} \cdot M(79: 10-81: 12)$ & $7.97^{\star}$ & $9.69^{\star}$ & $17.23^{\star}$ & $5.36^{\dagger}$ \\
\hline LM(sign) & 0.06 & $7.22^{\star}$ & $2.78^{ \pm}$ & 2.19 \\
\hline LM(size) & 0.83 & $30.74^{\star}$ & 2.89 & $7.90^{\ddagger}$ \\
\hline \multicolumn{5}{|l|}{ B: Weekly } \\
\hline Skewness & $-0.10^{\ddagger}$ & 0.25 & $-0.13^{\top}$ & $-0.14^{\dagger}$ \\
\hline Excess Kurtosis & $4.79^{\star}$ & $7.13^{\star}$ & $4.92^{\star}$ & $4.40^{\star}$ \\
\hline Jarque-Bera & $1379.73^{\star}$ & $3062^{\star}$ & $1456.03^{\star}$ & $1168.17^{*}$ \\
\hline LM(level) & $11.27^{\star}$ & 1.41 & 1.99 & 0.22 \\
\hline LM(level ${ }^{2}$ ) & $14.09^{\star}$ & 0.24 & $8.85^{\star}$ & 2.12 \\
\hline L.M(ARCH(16)) & 6.75 & $176.97^{\star}$ & 5.58 & 6.54 \\
\hline $\operatorname{LM}(79: 10)$ & 0.01 & $10.69^{*}$ & 0.17 & 0.67 \\
\hline $\operatorname{LM}(79: 10-81: 12)$ & $4.85^{t}$ & $54.79^{*}$ & $9.87^{*}$ & $5.77^{t}$ \\
\hline IM $($ sign $)$ & 0.01 & 0.01 & 0.79 & 0.22 \\
\hline IM(size) & $9.71^{\dagger}$ & $143.74^{\star}$ & 4.45 & $9.13^{*}$ \\
\hline
\end{tabular}

Notes: Skewness is defined as $m_{3} / s^{3}$, with $m_{3}$ the centred third moment of the data and $s$ the sample standard deviation. Kurtosis is defined as $m_{4} / s^{4}-3$, with $m_{4}$ the centred fourth moment of the data. Both are computed on the scaled residuals $\hat{e}_{\mathrm{t}} / \hat{h}_{\mathrm{p}}$. LM(level), LM(ARCH $(p))$, LM(79:10), LM(79:10-81:12), LM(sign), denote LM test statistics for the squared interest rate level, ARCH effects with $p$ lags, a shift dummy after october 1979, a shift dummy for 79:10-81:12, a sign effect, and a combined size effect respectively. The size effect combines: a pasitive size effect, a negative size effect, a positive size square effect and a negative size square effect. " ( $\left.{ }^{1}\right)$ [* ] denote rejection at the $10 \%(5 \%)[1 \%]$ level.

conditional variance. The negative size bias for example would suggest the leverage effect of Nelson's (1989) Exponential-GARCH model. Tests 2 and 3 would point at instability of the parameter estimates.

Table 7.3 shows the diagnostics for the different volatility specifications. The diagnostics for the monthly and weekly data show that the pure GARCH model fails on the level test and the 79-82 dummy. The CKLS model has severe problems on the ARCH test. The KNSW and LS models both capture the level effect as well as the GARCH effects. The difference between the LS model and the KNSW specification is in the interest rate 
TABLE 7.4: Period 79-82 excluded

$$
\begin{gathered}
r_{t}-r_{t-1}=\alpha_{0}+\alpha_{1} r_{t-1}+\alpha_{2} r_{t-1}^{2}+e_{t}, \\
h_{t}^{2}=\beta_{1} r_{t-1}^{2 \gamma}+\left(\frac{r_{t}}{r_{t-1}}\right)^{2 \gamma}\left(\beta_{2} e_{t-1}^{2}+\beta_{3} h_{t-1}^{2}\right) .
\end{gathered}
$$

\begin{tabular}{cccccccc}
\hline \hline & $\alpha_{0} \times 10$ & $\alpha_{1} \times 10$ & $\alpha_{2} \times 10^{2}$ & $\beta_{1} \times 10^{2}$ & $\beta_{2}$ & $\beta_{3}$ & $\gamma$ \\
\hline Monthly & 0.20 & 0.13 & -0.21 & 0.18 & 0.16 & 0.56 & 0.88 \\
& $(0.20)$ & $(0.32)$ & $(0.50)$ & $(0.14)$ & $(0.47)$ & $(0.30)$ & $(2.06)$ \\
\hline
\end{tabular}

Notes: Loglik denotes the log-likelihood value. Robust $t$-values, are given in parentheses.

elasticity of volatility. This elasticity is restricted to $\gamma=\frac{1}{2}$ in the LS model, while it is estimated as 1.24 in the monthly KNSW model.

The diagnostics indicate that none of the models can cope with the 79-82 high volatility episode. To see the impact of this period on the parameter estimates of the volatility equation, we re-estimate the KNSW model where we exclude the high volatility period. The estimate of $\gamma$ now drops to 0.88 for the monthly frequency. This result shows that the high sensitivity of volatility with respect to the level can partially be explained by this period. ${ }^{13}$

Normality is strongly rejected for all models. While this implies that we must be cautious in interpreting distributional implications of the models, it does not invalidate the parameter estimates, since QML is robust to departures from normality. Following Bollerslev (1987) we also cunsidered the standardized $t$-distribution, but do not include the tables in this chapter. The degrees of freedom parameter ranges from three to five, thereby reflecting substantial fat-tailedness. However, the adjustment for fat-tailedness has no significant impact on the other parameters.

\subsubsection{Unconditional Distribution}

The parameter estimates have implications for the unconditional moments of the interest rate. The unconditional moments also provide a test of the specification of the model, when the implied moments are compared to the sample moments of the interest rate level. For the unconditional distributions we would also have to take into account possible

${ }^{13}$ These results also hold for the CKLS model. Ait-Sahalia $(1996 \mathrm{a}, \mathrm{b})$ shows that the value of the $\gamma$ parameter is a nonlinear function of the interest rate level. The value of $\gamma$ decreases for high interest rate levels. 


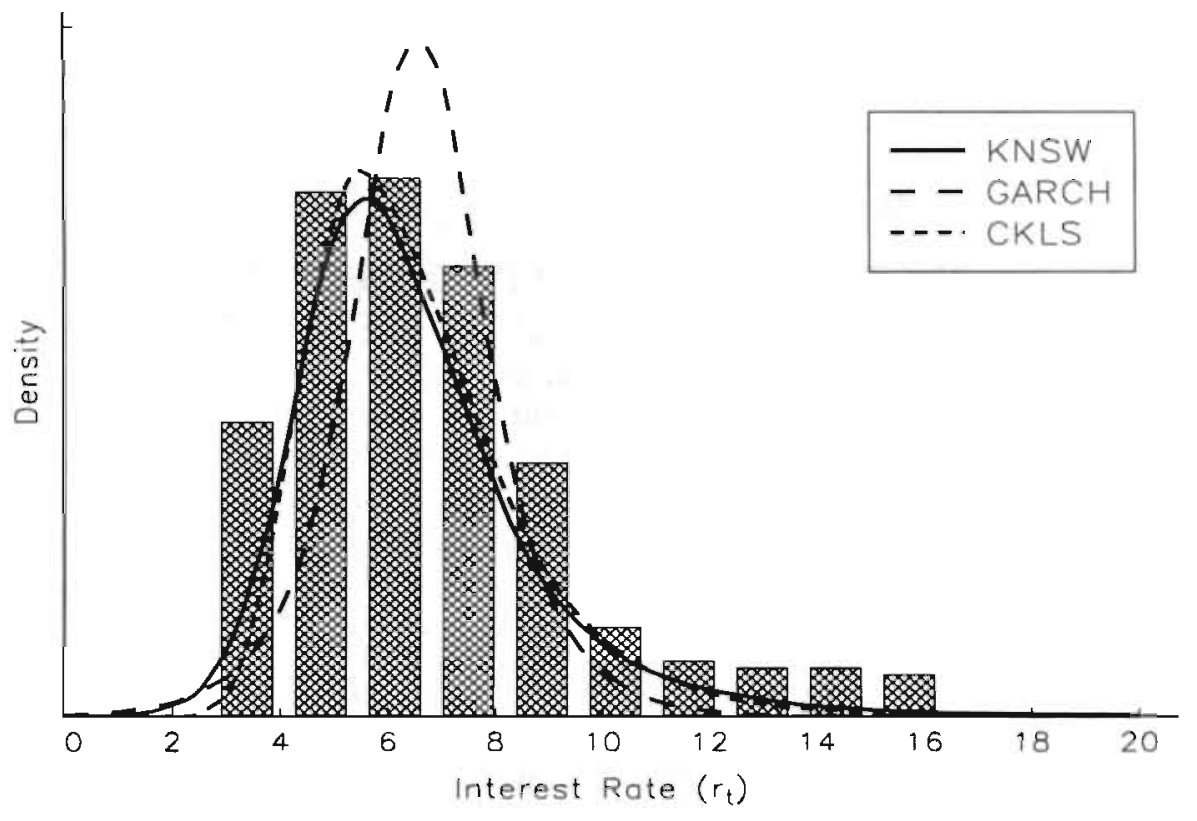

FIgure 7.3: Unconditional Distributions

Note: The shaded area is the sample histogram at the weekly frequency.

nonlinearities in the conditional mean (see section 7.1). In this chapter, however, we compare the implications of interest models that have a linear conditional minn.

In section 7.2 we discussed that this linear specification is nonstationary if $\gamma>1$. For the KNSW and the CKLS model we, therefore, impose the restriction $\gamma=1$ to obtain stationary distributions. Furthermore we consider the KNSW model with $\gamma=\frac{1}{2}$. Finally we investigate the GARCH model. For the GARCH specification it follows from panel $\mathrm{B}$ of table 7.2 that the sum of the parameter estimates $\beta_{2}$ and $\beta_{3}$ is larger than unity: This restriction implies that the interest rate is not a covariance-stationary process. We, therefore, impose the restriction $\beta_{2}+\beta_{3}<1$. Table 7.5 contains weekly parameter estimates of the restricted models.

Then we use the algorithm in appendix A to compute the implied unconditional distributions for the GARCH model, the CKLS model and the KNSW model for the parameter estimates of the restricted models in appendix A. Figure 7.3 shows the unconditional distribution of the monthly data together with a histogram of the actual distribution of the one-month spot rate. The implied distribution of the KNSW model captures much of the skewness of the actual data. The skewness of the CKLS model is small and the GARCH 
TABLE 7.5: Parameter Estimates of Restricted Models

\begin{tabular}{lcccc}
\multicolumn{5}{c}{$r_{t}-r_{t-1}=\alpha_{0}+\alpha_{1} r_{t-1}+e_{t}}$, \\
\multicolumn{5}{c}{$h_{t}^{2}=\beta_{1} r_{t-1}^{2 \gamma}+\left(\frac{r_{t}}{r_{t-1}}\right)^{2 \gamma}\left(\beta_{2} e_{t-1}^{2}+\beta_{3} h_{t-1}^{2}\right)}$. \\
\hline \hline & GARCH & CKLS & KNSW1 & KNSW2 \\
\hline$\alpha_{0}$ & 0.03 & 0.03 & 0.02 & 0.02 \\
& $(1.62)$ & $(1.77)$ & $(1.55)$ & $(1.63)$ \\
$\alpha_{1}$ & -0.01 & -0.01 & -0.01 & -0.01 \\
& $(1.27)$ & $(1.31)$ & $(0.95)$ & $(1.12)$ \\
$\beta_{1} \times 10^{2}$ & 0.01 & 0.17 & 0.01 & 0.03 \\
$\beta_{2}$ & $(2.05)$ & $(2.05)$ & $(2.59)$ & $(2.14)$ \\
& 0.17 & - & 0.26 & 0.23 \\
$\beta_{3}$ & $(3.43)$ & - & $(4.62)$ & $(3.36)$ \\
& 0.82 & - & 0.68 & 0.76 \\
$\gamma$ & $(15.97)$ & - & $(9.37)$ & $(11.99)$ \\
Loglik & 0 & 1 & 1 & 0.5 \\
Notes: Loglik denotes the log-likelihood value. & Robust $t$-values, \\
conditional on $\gamma$ are given in parentheses. \\
\hline \hline
\end{tabular}

model is symmetric. Note that we obtain this reasonable good fit despite the nonnormality of the errors. It appears that the rejection of the normality test is mainly due to a few large outliers in the 79-82 period, which have little impact on the unconditional distribution.

\subsubsection{News Impact Curves}

An insightful way to graphically illustrate the differences between the various volatility specifications is the news impact curve introduced in Engle and $\mathrm{Ng}$ (1993). The news impact curve shows the effect of the last shock, $e_{t}$, on the conditional volatility $h_{t}^{2}$. Writing $r_{t}$ explicitly as a function of $e_{t}$ and $r_{t-1}$, the general volatility specification (7.7) becomes a function of $e_{t}$ given values of the other state variables $\left(r_{t-1}, h_{t-1}^{2}\right)$ :

$$
h_{t}^{2}=\tilde{f}\left(e_{t} \mid r_{t-1}=r, h_{t-1}^{2}=h^{2}\right) .
$$

Since the mean reversion is negligible over a one period horizon, we approximate $r_{t} \approx$ $r_{t-1}+e_{t}$ and thus obtain $h_{t}^{2}$ as a function of $e_{t}$ and the other state variables. We write the function as:

$$
\tilde{f}\left(e \mid r, h^{2}\right)=\beta_{1}(r+e)^{2 \gamma}+\left(1+\frac{e}{r}\right)^{2 \gamma}\left(\beta_{2} e^{2}+\beta_{2} h^{2}\right) .
$$


Equation (7.15) is quadratic for the GARCH specification $(\gamma=0)$, but can be very asymmetric for the KNSW specification. For example, in the special case $\gamma=\frac{1}{2}$ the news impact curve is a cubic polynomial in $e$. The shape is also very different for different levels of the interest rate. A negative shock has two effects on the volatility. The first, the GARCH type volatility clustering, increases the volatility; the second effect is the decrease of the level and decreases the volatility. Eventually, for very large negative shocks, the level effect dominates.

The news impact curve of the KNSW model depends on the interest rate level, the last period's innovation and the last period's conditional variance. The news impact curve of the GARCH model depends on both last period's innovation and last period's conditional variance. The news impact curve of the CKLS model only depends on last period's interest rate level.

We will construct the news impact curves at different levels: the low level ( $r=4 \%$ ), the moderate level $(r=8 \%)$, and the high level $(r=12 \%) .{ }^{14}$ Figure 7.4 contains the news impact curves at three interest rate levels based on the parameter estimates in table 7.5. In the first panel a negative shock does not have large impact on volatility for the KNSW model, while it increases volatility for the GARCH model. The curve for the low level clearly displays the asymmetry of the KNSW model. At the intermediate level the GARCH and KNSW models are very close with respect to upward shocks. Again, for a negative shock the level effect and the GARCH effect almost cancel in the KNSW model so that volatility is not affected by downward shocks in the interest rate, while the CKLS model remains very asymmetric with a negative shock lowering volatility. The figures show the flexibility of the KNSW model: GARCH effects dominate at 'normal' levels while the asymmetry implied by the level effect is very strong at low levels. The KNSW model thus combines the features of the CKLS and GARCH models, shifting smoothly from one to the other as the level of interest rate varies. At high levels the three models diverge most in their volatility estimates. The CKLS model, which has the highest interest rate elasticity implies the highest conditional variance. The GARCH model which has no level dependence in the volatility does not show any big increase after a positive or negative shock. The figure is the same as the previous panels. The KNSW model is less asymmetric at high levels. Figure 7.5 combines the news impact curves of the previous figures. The surface gives the news impact curves of the KNSW model.

${ }^{14}$ The conditional variance is specified as $h^{2}=\left(\frac{1}{T} \sum_{t=1}^{T} e_{t}^{2} / r_{t-1}^{2 \gamma}\right) r^{2 \gamma}$. 

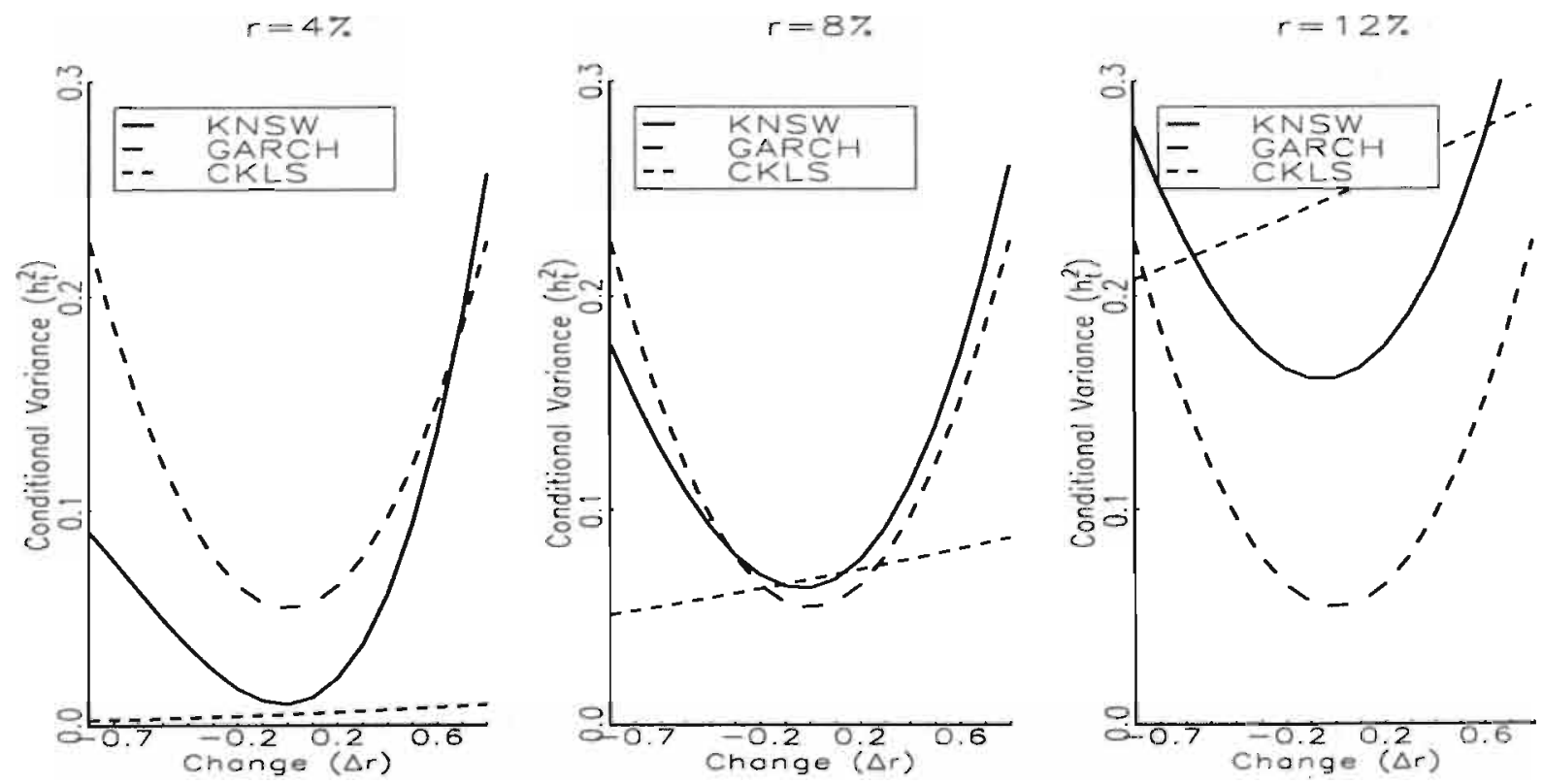

Figure 7.4: News Impact Curves 


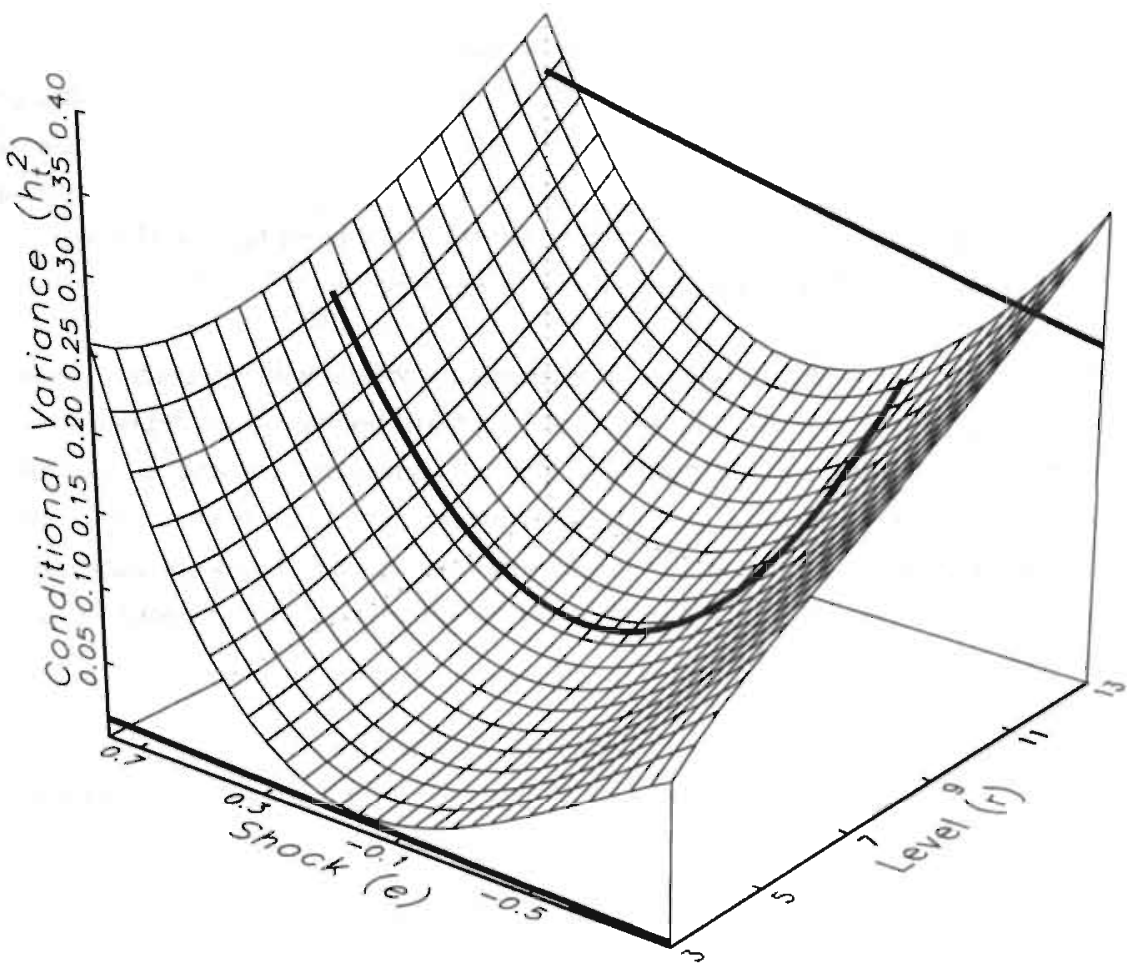

Figure 7.5: News Impact Surface

Notes: The surface are the news impact curves of the KNSW model. The parabola is the news impact curve of the GARCH model. The other two curves are the news impact curves of the CKLS model at the low level (4\%) and at the high level $(12 \%)$. 


\subsection{Bond Option Implications}

The economic differences between the various volatility specifications can best be illustrated by considering the valuation of bond options under each of the models of the conditional heteroskedasticity. The models will have different option implications, because they imply different conditional densities for future spot rates. Figure 7.3 already highlighted the different unconditional densities of the short-term interest rate. These densities have similar unconditional first and second moments: but very different higher order moments. The higher the value of $\gamma$, the more right-tail skewness is introduced. The stronger the ARCH effects, the higher the fourth moments of the conditional densities. These distributional properties carry over to option prices. Options that pay off if interest rates are high, will be more valuable, ceteris paribus, the fatter the right hand tail. In this section we consider the differences in short horizon predictive densities.

We consider option implications, because option values will be much more sensitive to the distributional assumption than prices of long term bonds, which depend predominantly on conditional first and second moments. We will concentrate on options on long term bonds, but with a short expiration period. Over longer expiration horizons the option value will depend on both the volatility dynamics as well as the degree of mean reversion of the short-term interest rate. It will then be impossible to identify the sources of the differences between the various models.

Since the volatility specifications have been developed in discrete time, we will also develop the option implications in discrete time. Let $P_{t}^{(n)}$ be the price of an $n$-period discount bond at the time $t$. A European call option on this bond with strike price $K$ and expiration date $t+m$ is defined as the risk neutral expected present value of the payoff at the expiration date:

$$
C_{t}(m, n, K)=\mathrm{E}_{t}\left[X_{t+m}\left[P_{t+m}^{(n-m)}-K\right]^{+}\right]
$$

where $X_{t+m}=\exp \left(-\sum_{i=0}^{m-1} r_{t+i}\right)$ is the discount factor, and the operator $[Z]^{+}$is defined as $\max (Z, 0)$.

\subsubsection{The Price of Risk}

The expectation in equation (7.16) has to be taken with respect to the risk neutral probability measure associated with the interest rate process. We therefore need an assumption about the price of risk. We assume that the risk adjustment takes the form of a change of 
the conditional mean of the interest rate process to:

$$
\mathrm{E}_{t}\left[r_{t+1}\right]=\mu+\rho\left(r_{t}-\mu\right)+\lambda h_{t+1},
$$

where $\lambda$ is a constant parameter, representing the price of risk. If $\gamma=1$ the volatility specification is $h_{t+1}=\sigma r_{t}$ and equation (7.17) can now be written as:

$$
\mathrm{E}_{t}\left[r_{t+1}\right]=\tilde{\mu}_{t}+\tilde{\rho}_{t}\left(r_{t}-\tilde{\mu}_{t}\right)
$$

This equation (7.17) defines the risk neutral conditional mean parameters: $\tilde{\rho}_{t}=\rho+\lambda \sigma_{t+1}$, and $\tilde{\mu}_{t}=\frac{1-\rho}{1-\bar{\rho}_{t}} \mu$. Since $\lambda>0$, the adjustment has the effect of increasing the mean of the interest rate $\left(\tilde{\mu}_{t}>\mu\right)$, and reducing the amount of mean reversion $\left(\tilde{\rho}_{t}>\rho\right)$ thereby increasing the unconditional variance.

The CKLS model belongs to the class of one factor models, with the spot rate as the only state variable. The KNSW model is a two factor model with volatility as a second factor. For comparability across models we assume that the price of volatility risk is equal to zero, so that we use a single risk price $\lambda$.

\subsubsection{The Term Structure}

The main obstacle in computing the option values is that the payoff at the expiration date $t+m$ depends on the value of a discount bond with maturity $(n-m)$, which is itself a function of all state variables, and not available in closed form. The value of a bond with some maturity $k$ is a function of all state variables. In the KNSW model there are three state variables: the level of the short-term rate $r$, the volatility $h^{2}$, and the latest shock $e$ :

$$
P^{(k)}=p\left(r, h^{2}, e\right) .
$$

In simulating the payoff of the option we must be able to compute the bond any value that the state variables can attain at time $t+m$. Since the function $p(\cdot)$ is not known analytically it must be computed numerically. Using a naive Monte Carlo method this would require a simulation for each particular combination of state variables. This naive simulation procedure is illustrated in figure 7.6. To obtain the distribution of the state variables, $\left(r_{m}, e_{m}, h_{m}\right)$, for the starting values, $\left(r_{0}, t_{0}, h_{0}\right)$, we have to sample $l_{m}$ paths of length $m$. Next, we have to sample $l_{n}$ paths of length $(n-m)$ to compute the bond price $P_{t+m}^{(n-m)}$ at any value $\left(r_{m}, e_{m}, h_{m}\right)$.

In practice, one could define a three dimensional grid for the state variables, compute the bond price only at the grid points and use interpolation for points in between. This is 


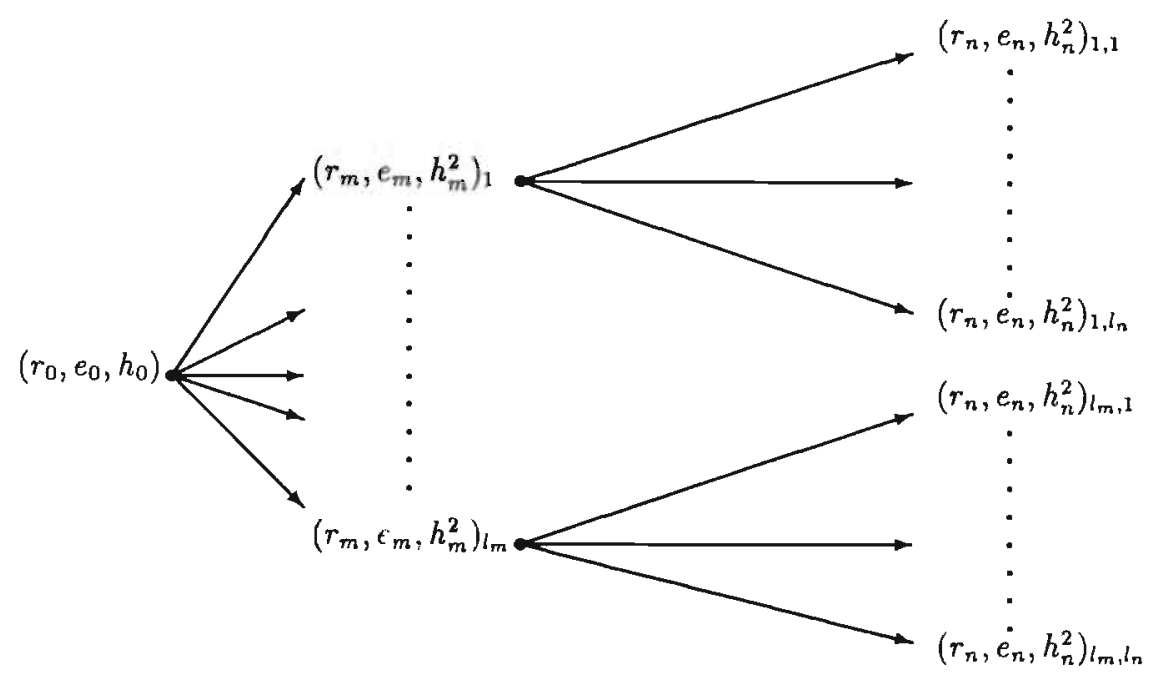

Figire 7.6: Naive Simulation

Notes: $m, n, l_{m}, l_{n}$ denote the maturity of the option, the maturity of the bond, the number of combinations $\left(r_{m}, e_{m}, h_{m}^{2}\right)$ and the number of combinations $\left(r_{n}, e_{n}, h_{n}^{2}\right)$ respectively.

still computationally very costly. We therefore opted for a different approach based on the same sampling idea as for the computation of the unconditional density described in appendix A. Figure 7.7 shows how this simulation reduces the number of sample paths. Again we first have to obtain the distribution of the state variables, $\left(r_{m}, e_{m}, h_{m}^{2}\right)$, at the expiration date of the option.

Let $r_{t},(t=1, \ldots, N)$ be a single long realization from the risk neutral interest rate process. At each $t$ we store the state variables $r_{t}, h_{t}^{2}$ and $e_{t}$, and also the quantities:

$$
I_{t}^{(k)}=\exp \left(-\sum_{i=0}^{k-1} r_{t+i}\right)
$$

for different values of $k$. We approximate the bond price function by a polynomial correction to the expectations hypothesis:

$$
P^{(k)}=\beta \exp \left(-k \tilde{\mu}-\frac{1-\tilde{\rho}^{k}}{1-\tilde{\rho}}(r-\tilde{\mu})\right)
$$




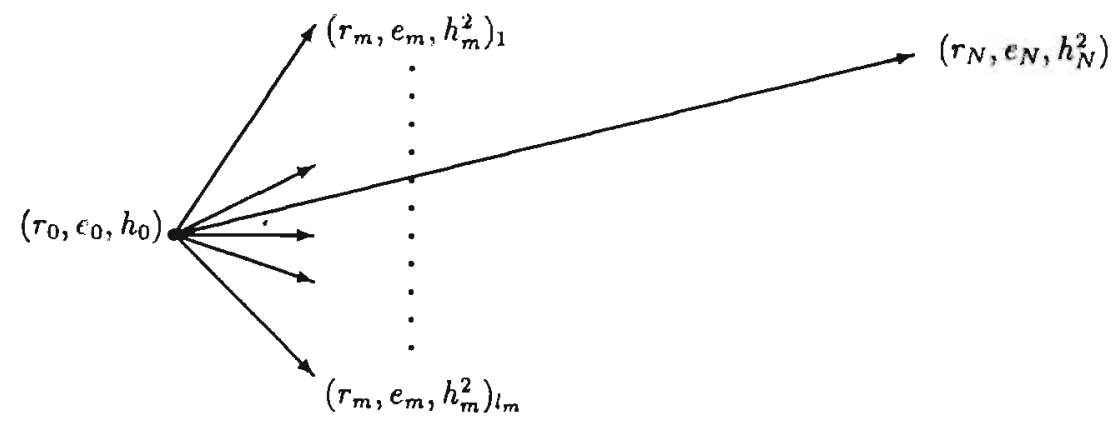

Figure 7.7: Efficient Simulation

Notes: $m, n, l_{m}, N$ denote the maturity of the option, the maturity of the bond, the number of combinations $\left(r_{m}, e_{m}, h_{m}^{2}\right)$ and the length of a single long realization.

$$
+a_{0}+\sum_{i=1}^{3} a_{i} x_{i}+\sum_{i=1}^{3} \sum_{j=1}^{i} a_{i j} x_{i} x_{j}+\sum_{i=1}^{3} \sum_{j=1}^{i} \sum_{\ell=1}^{j} a_{i j \ell} x_{i} x_{j} x_{\ell}
$$

where $x_{i},(i=1, \ldots, 3)$, are the state variables $\left(r_{m}, \epsilon_{m}\right.$ and $\left.h_{m}^{2}\right)$, and $\beta, a_{i}, a_{i j}$ and $a_{i j \ell}$ are parameters. The leading term in equation (7.21) is an approximation to the bond price according to the linearized expectations hypothesis under the risk neutral conditional mean in equation (7.17), which would set the price at time $t$ equal to $\exp \left(-E_{t}\left[\sum_{i=0}^{k-1} r_{i+i}\right]\right)$. The constant parameters $\tilde{\rho}$ and $\tilde{\mu}$ are fixed at the time series average of $\tilde{\rho}_{t}$ and $\tilde{\mu}_{t}$ from the simulation. The other parameters are estimated by OLS from the linear regression:

$$
\begin{aligned}
I_{t}^{(k)}= & \beta \exp \left(-k \tilde{\mu}-\frac{1-\hat{\rho}^{k}}{1-\tilde{\rho}}\left(r_{t}-\tilde{\mu}\right)\right) \\
& +a_{0}+\sum_{i=1}^{3} a_{i} x_{i t}+\sum_{i=1}^{3} \sum_{j=1}^{i} a_{i j} x_{i t} x_{j t}+\sum_{i=1}^{3} \sum_{j=1}^{i} \sum_{\ell=1}^{j} a_{i j \ell} x_{i t} x_{j t} x_{\ell t}+u_{i} .
\end{aligned}
$$

If the simulated sample size $N \rightarrow \infty$ the regression function converges to an approximation of the true bond price function. ${ }^{15}$ We now use the regression function to calculate the bond

\footnotetext{
${ }^{15}$ A consistent estimator of the true implied bond price can be obtained through a nonparametric kernel
} 
price for each combination of $\left(r_{m}, e_{m}, h_{m}^{2}\right)$.

In the discrete time process negative interest rates can occur during the simulations. We handle negative interest rates by introducing a reflecting barrier at $r_{t}=0$. This means that negative draws of $r_{t}$ are rejected (see Black (1995) for a motivation introducing such a reflecting barrier).

For the different specifications the risk price $\lambda$ was calibrated such that the estimated ten year discount bond price implies an average yield equal to the average ten year yield observed in the data. Using CRSP data for the period 1970-199.5 the ten year discount yield is $8.5 \%$. For example, for the model with $\gamma=1$ this gives $\lambda=0.05$. The average autocorrelation parameter of the risk neutral process then comes out at $\tilde{\rho}=\rho+\lambda \bar{\sigma}=$ $0.990+0.05 \times 0.052=0.993 .^{16}$ Figure 7.8 shows the unconditional density of the short rate and the risk neutral density of the short rate. The mean of the risk neutral density is about $8.5 \%$ and the standard deviation is larger than that of its empirical counterpart. We checked whether the approximation in equation (7.21) gives admissible bond prices $0<P^{(n)}\left(r, e, h^{2}\right)<1$. This appears true at all points realized in the simulation.

\subsubsection{Option Simulation}

Although all three specifications are univariate time series models, the conditional distribulion of next period's spot rate for the KNSW model depends on three state variables: the spot rate, the innovation to the spot rate and the conditional variance. For a full comparison of the different models. we must compare the implications at different levels of all the state variables. In order to keep things manageable we present our results in a two-way table, distinguishing three different levels of the spot rate $\left(r_{0}=4 \%, 8 \%\right.$, and $12 \%)$, and three different shocks.

The size of the typical shock at these different interest rates is calculated from the data as:

$$
\left|e_{0}\right|=\frac{\sum_{t=1}^{T} w_{t}\left|e_{t}\right|}{\sum_{t=1}^{T} w_{t}}
$$

method using the output of the simulation. But it would be computationally expensive to run the kernel estimator for every iteration in the subsequent Monte Carlo simulation of the option price.

${ }^{16}$ The parameter estimates $\rho$ and $\bar{\sigma}$ are based on the results in table 7.5. The autocorrelation parameter is calculated as: $\rho=1-\alpha_{1}=1-0.010=0.990$ and the average uncertainty is calculated as $\bar{\sigma}=$ $\left(\frac{f_{1}}{1-\epsilon_{2}-\digamma_{3}}\right)^{\frac{1}{2}}=\left(\frac{0.14 \times 10^{-2}}{1-0.23-0.76}\right)^{\frac{1}{2}}=0.052$. 


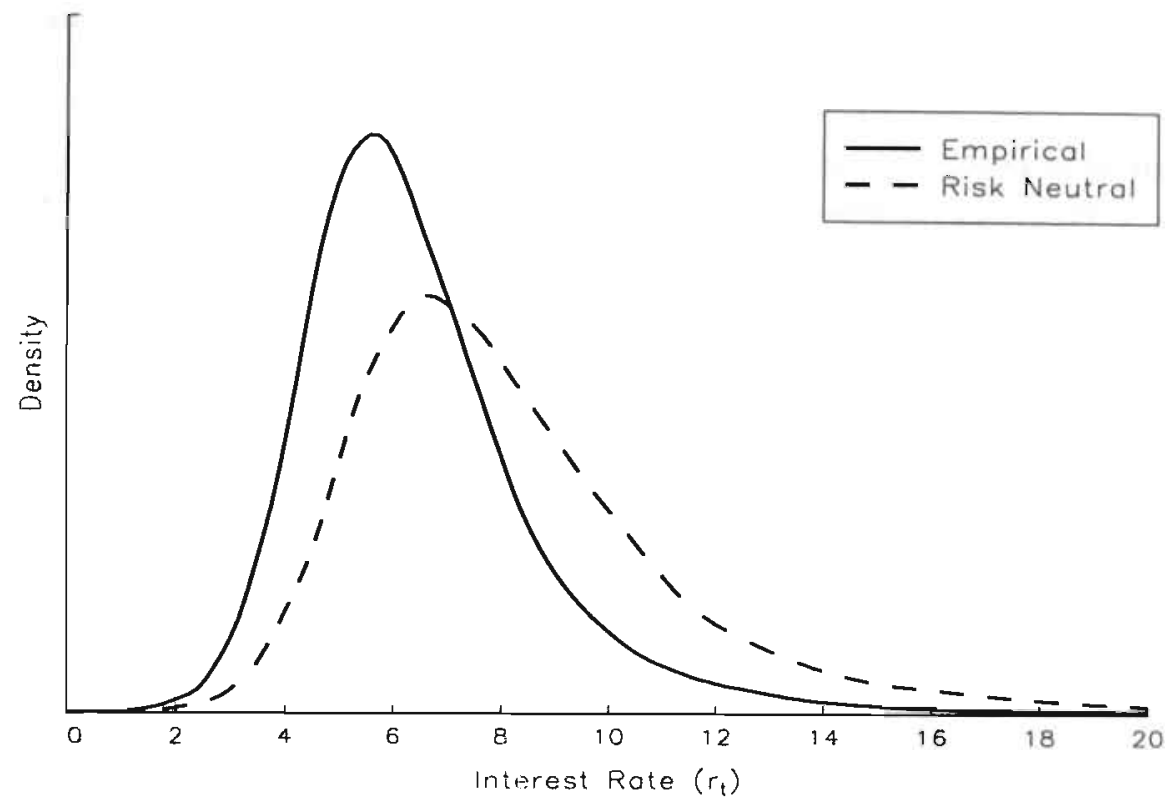

FIGURE 7.8: Risk Neutral Unconditional Distribution

Note: The risk neutral density assumes that the price of risk $\lambda=0.05$.

with $w_{t}$ a weight function based on a simple normal kernel:

$$
w_{t}=\exp \left(-\frac{1}{2 s \sigma_{r}^{2}}\left(r_{t}-r_{0}\right)^{2}\right),
$$

where $s$ is a bandwidth parameter and $\sigma_{r}^{2}$ is the sample variance of the interest rate. ${ }^{17} \mathrm{At}$ each of these initial conditions we set the initial conditions of the third state variable $h^{2}$ at its conditional expectation given the other state variables:

$$
h_{0}^{2}=E\left[h^{2} \mid r_{0}=r, e_{0}=e\right] \text {. }
$$

The conditional expectation is computed from the same simulation as used for the construction of the yield curve:

$$
\hat{h}_{0}^{2}=\frac{\sum_{t=1}^{N} w_{t} h_{t}^{2}}{\sum_{t=1}^{N} w_{t}},
$$

where $w_{t}$ is obtained from the multivariate kernel:

$$
w_{t}=\exp \left(-\frac{1}{2 s}\left(x_{t}-x_{0}\right)^{\prime} \Omega^{-1}\left(x_{t}-x_{0}\right)\right)
$$

\footnotetext{
17 The bandwidth parameter $s$ is chosen as $s=1.06 \sigma T^{-0.2}$ (see Silverman (1986)).
} 
where $x_{t}$ is the subvector of state variables $\left(r_{t}, c_{t}\right)$ and $\Omega$ is the sample covariance matrix of $x_{t}$ from the simulation of size $N$.

The future bond price $P_{t+m}^{(n-m)}$ in equation (7.16) is replaced by its approximate functional form $p\left(r_{t+m}, h_{t+m}^{2}, e_{t+m}\right)$ in equation (7.21). With this approximation we use a conventional Monte Carlo simulation to estimate the option value for various initial conditions $\left(r_{0}, \hat{h}_{0}^{2}, e_{0}\right)$ and strike prices $K$. The option prices in table 7.6 are computed for at-the-money options. The strike price for an at-the-money option is defined as the initial forward price:

$$
K=P_{0}^{(n)} / P_{0}^{(m)},
$$

where the bond prices are consistent with the implied term structure, i.e.:

$$
P_{0}^{(k)}=\frac{\sum_{t=1}^{N} w_{t} I_{t}^{(k)}}{\sum_{t=1}^{N} w_{t}}
$$

for $k=m, n$ and where $w_{t}$ is obtained from the kernel in equation (7.27) with $x_{t}$ the subvector $\left(r_{t}, e_{t}\right)$. Each sample path for the spot rate depends on $m$ drawings for the random variables $\epsilon_{t},(t=1, \ldots, m)$. Using the sequence $\epsilon_{t}$ a sample path for $r_{t}(t=$ $0, \ldots, m)$ is constructed based on the parameter estimates. The option value $C(m, n, K)$ is estimated by averaging over $N$ simulated paths.

\subsubsection{Results}

In table 7.6 we report option values as a percentage of the underlying long-term discount bond, i.e. $C_{t}(m, n, K) / P_{t}^{(n)}$. The table consists of seven rows and three columns. The columns refer to the three different levels of the spot rate; the rows represent the three different values for last period's shock to the spot rate. The upper panel and the middle panel report option values according to the KNSW model, with different restrictions on the parameters. The CKLS option values in the lower panel, only depend on the level of the spot rate. Appendix $\mathrm{B}$ describes how standard errors are computed.

From the table we draw several conclusions. The standard errors of the option values of the KNSW model are small, meaning that small differences with other models will lead to statistically significant differences in option valuation. Parameter uncertainty is not a big issue here.

Both dimensions, level and shock, are important for valuing options in the KNSW model. The effect of a shock is to increase volatility which will lead to higher option values. At low and moderate interest rates the effect of a positive shock on the option value is larger 
TABLE 7.6: Percentage Option Value

\begin{tabular}{|c|c|c|c|}
\hline & $4 \%$ & $8 \%$ & $12 \%$ \\
\hline KNSW1 & \multicolumn{3}{|c|}{$\alpha_{2}=0, \gamma=1$} \\
\hline zero shock & $\begin{array}{c}0.42 \\
(0.01)\end{array}$ & $\begin{array}{c}0.47 \\
(0.01)\end{array}$ & $\begin{array}{c}0.60 \\
(0.02)\end{array}$ \\
\hline positive shock & $\begin{array}{c}0.59 \\
(0.01)\end{array}$ & $\begin{array}{c}0.63 \\
(0.02)\end{array}$ & $\begin{array}{c}0.79 \\
(0.03)\end{array}$ \\
\hline negative shock & $\begin{array}{c}0.56 \\
(0.01)\end{array}$ & $\begin{array}{c}0.61 \\
(0.02)\end{array}$ & $\begin{array}{c}1.03 \\
(0.04)\end{array}$ \\
\hline KNSW2 & \multicolumn{3}{|c|}{$\alpha_{2}=0, \gamma=\frac{1}{2}$} \\
\hline zero shock & $\begin{array}{c}0.40 \\
(0.01)\end{array}$ & $\begin{array}{c}0.40 \\
(0.01)\end{array}$ & $\begin{array}{c}0.42 \\
(0.01)\end{array}$ \\
\hline positive shock & $\begin{array}{c}0.53 \\
(0.01)\end{array}$ & $\begin{array}{c}0.49 \\
(0.01)\end{array}$ & $\begin{array}{c}0.55 \\
(0.01)\end{array}$ \\
\hline negative shock & $\begin{array}{c}0.52 \\
(0.01) \\
\end{array}$ & $\begin{array}{c}0.50 \\
(0.01) \\
\end{array}$ & $\begin{array}{c}0.76 \\
(0.02) \\
\end{array}$ \\
\hline CKLS & \multicolumn{3}{|c|}{$\alpha_{2}=0, \beta_{2}=\beta_{3}=0$} \\
\hline & $\begin{array}{c}0.42 \\
(0.01)\end{array}$ & $\begin{array}{c}0.55 \\
(0.01)\end{array}$ & $\begin{array}{c}0.70 \\
(0.02)\end{array}$ \\
\hline $\begin{array}{l}\text { Notes: Option pr } \\
\text { standard errors a } \\
\text { and } 12 \% \text { interest } \\
(-0.6 \%, 0 \%, 0.6 \%)\end{array}$ & $\begin{array}{l}\text { based } \\
\text { renthes } \\
\text { el are } \\
\text { tively. }\end{array}$ & $\begin{array}{c}\text { weekly pe } \\
\text { size of } \mathrm{t} \\
0 \%, 0.2 \%\end{array}$ & $\begin{array}{l}\text { stimates. } \\
\text { at the } 4 \% \\
0 \%, 0.3 \%\end{array}$ \\
\hline
\end{tabular}

than the effect of a negative shock. At high interest rates, however, the effect of a negative shock is higher.

For all specifications differences along a column in the table depend on the value of $\gamma$. At low and moderate values of $r$ the option values when $\gamma=1$ are close to the option values when $\gamma=\frac{1}{2}$. At the high level the implied option value is positively related to the interest rate elasticity of the model. 


\subsection{Conclusions}

In this chapter we presented and estimated a model for the short-term interest, rate volatility, that encompasses both the level effect in the CKLS model and the conditional heteroskedasticity effect of the GARCH class of models. The flexible specification of the conditional variance equation allows different effects to dominate as the level of the interest rate varies. The different models were estimated for monthly as well as for weekly data. We find that both GARCH effects and level effect are important determinants of interest volatility.

The parameter that measures the sensitivity of interest rate volatility with respect to the interest rate level, $\gamma$, is higbly significant. The important empirical difference of the KNSW model and the CKLS type specifications is the smaller estimate of $\gamma$. For the estimation of the interest rate sensitivity in the variance specification one cannot ignore the strong GARo :H effects in monthly and weekly data. Ignoring GARCH creates an omitted variables problem for the estimate of the level effect in the volatility.

The most precise estimates of the volatility specification are obtained at the weekly frequency. The estimated value of $\gamma$ ranges from 1.40 for the CKLS model for the monthly frequency to 1.21 for the CKLS model for the weekly frequency. The parameter estimate of $\gamma$ is not significantly different from unity for the CKLS and KNSW models.

As the volatility of the short-term interest rate is one of the determinants for the pricing of interest rate contingent claims, we investigate the implications of the dynamics of shortterm interest rate volatility for the pricing of discount bond options. Our results suggest that the inclusion of a GARCH effect in addition to a level effect in the model specification is relevant for the pricing of short-term discount bond options. This result is related to the lower estimated value of $\gamma$ when volatility effects; are included. We show that at interest rate levels of $12 \%$ a change in the value of $\gamma$ results in a large change of the relative option value. 


\section{Appendix 7A: The Unconditional Distribution of the Spot Rate}

To compute the unconditional density we follow Geweke (1994). Let $f(x \mid y)$ denote the conditional density of $r_{t}$ given $r_{t-1}$. The unconditional density of the spot rate is the solution, if it exists, to the integral equation:

$$
g(x)=\int_{0}^{\infty} f(x \mid y) g(y) d y .
$$

Since the spot rates are highly correlated, a Monte Carlo simulation is highly inefficient for obtaining the unconditional density. The accuracy can be improved by drawing a sequence of conditional densities and averaging the densities. Define a grid of points $(i=1, \ldots, N)$ at which to estimate the density $g(y)$. Now draw a time series sample of spot rates $r_{t}$ $(t=1, \ldots, T)$, and for each $r_{t}$ evaluate the conditional density $f\left(y_{i} \mid r_{t}\right)$ at each of the grid points. The unconditional density at a point $y_{i}$ is finally estimated as:

$$
g\left(y_{i}\right)=\frac{1}{T} \sum_{t=1}^{T} f\left(y_{i} \mid r_{t}\right) . \quad(i=1, \ldots, N)
$$

Whenever a negative value of $r_{t}$ is drawn, the draw is rejected and the value of $r_{t}$ is set to zero, this way truncating the distribution to positive interest rates. The number of Monte Carlo draws was set to $1 \times 10^{6}$ and the number of negative interest rate drawings was zero for the weekly data. The starting value for the Monte Carlo runs was set to the sample mean. 


\section{Appendix 7B: Computation of Standard Errors}

The standard errors of the implied option values reflect the uncertainty about the parameter estimates but are conditional on an exogenously given initial term structure. Option standard errors are computed using the asymptotic formula:

$$
V(C(\hat{\theta}))=\left(\frac{\partial C(\hat{\theta})}{\partial \theta}\right)^{\prime} V(\hat{\theta})\left(\frac{\partial C(\hat{\theta})}{\partial \theta}\right)
$$

where $V(\hat{\theta})$ denotes the covariance matrix of the parameter estimates, and $\frac{\partial C(\hat{\theta})}{\partial \theta}$ denotes the partial derivatives of the option price with respect to the parameters of the volatility process evaluated at $\theta=\hat{\theta}$, where $\hat{\theta}$ are the parameters of the restricted volatility specification in Table 7.5.

We calculate derivatives numerically. Using the same sequence $\epsilon_{t}$ as for the estimation of the option value a new sample path $r_{t}(t=1, \cdots, m)$ is constructed with parameter vector $\overline{\theta_{j}}=\hat{\theta}+\ell_{j}$, where $\ell_{j}$ is a vector with zeros apart from a small number $\delta_{j}$ at position $j$ corresponding with the $j^{\text {th }}$ element of $\theta$. The new value for $\theta$ is used to compute a new option value at the expiration date. Using the same random numbers the procedure is repeated using $\underline{\theta_{j}}=\hat{\theta}-\ell_{j}$. The numerical central derivative of the option with respect to $\theta_{j}$ is then estimated as the average over $N$ simulations:

$$
\frac{\partial C(\hat{\theta})}{\partial \theta_{j}}=\frac{1}{N} \sum_{k=1}^{N} \frac{C\left(\overline{\theta_{j}}\right)_{k}-C\left(\underline{\theta_{j}}\right)_{k}}{2 \delta_{j}} .
$$




\section{Chapter 8}

\section{Summary and Suggestions for Further Research}

\subsection{Summary}

The present thesis describes an empirical study of the dynamics of exchange rates, interest rates and stock returns. The innovative character of the thesis resides not so much in the choice of the subjects but rather in the use of alternative techniques and data.

Many studies that deal with the concept of international integration compare prices of commodities and financial assets across countries. The basic idea is that in the absence of any barriers to trade, arbitrage ensures that identical tradable goods and assets in different countries have identical prices when denominated in the same currency.

When commodity prices as well as financial prices are examined across countries three fundamental parities play an important role, i.e. purchasing power parity (PPP), uncovered interest rate parity (UIP) and the Fisher parity. As the thesis deals with international financial market dynamics, PPP, UIP and the Fisher parity have been discussed in detail.

The first of the fundamental relations, PPP, occurs in the market of goods and services as a result of goods market arbitrage. According to PPP, the exchange rate between two countries is determined by the two countries' relative price levels. The two other parities occur in financial markets. The first, UIP, points out that as a result of uncovered arbitrage, the difference between interest rates on securities that are denominated in different 
currencies, equals the expected change in the exchange rate between the two countries. The Fisher parity, the second financial relationship, states that the nominal interest rate is equal to the real interest rate plus the markets' expected rate of inflation.

Chapter 2 establishes the theoretical foundation of the three parities. The parities are not new; they were already formulated at the beginning of this century. Subsequently, they were subjected to empirical tests by many researchers. The general conclusion that emerges from this research is that there are substantial short-run deviations from all three parities.

The traditional derivation of PPP is based on goods market arbitrage. Roll (1979) argues that alternatively an efficient markets version of PPP may be derived when combining UIP and the Fisher parity. It is not surprisingly, therefore, that explanations to deviations from these three fundamental parities share a common theoretical foundation.

The most commonly suggested explanation is that deviations from these parities are due to risk premiums. Furthermore, it is said that systematic (rational) forecast errors that may arise as a result of discrete changes in regimes that are expected but not realized in a particular period, may also cause these deviations. Third, the presence of transaction costs may lead to inactivity bands where no arbitrage takes place and price differences across countries are not equalized.

Chapters 3 to 5 empirically investigate each of these three parities.

Recently, the debate on PPP received a new stimulus through a theoretical contribution by Sercu, Uppal and Van Hulle (1995). Sercu and Uppal (1995), who generalize this study, show that in the presence of transaction costs the exchange rate change will be equal to the risk-aversion weighted differential of growth in nominal spending deflated with the totalconsumption weighted inflation rate plus a 'marginal' inflation differential. In chapter 3 we use panel techniques to test both absolute as well as relative versions of Sercu and Uppal's (1995) model for sixteen countries over the period 1973-1993. In the empirical tests we impose restrictions that make parameter estimates invariant to the choice of the numeraire currency. Surprisingly, our results show that PPP holds very strongly at horizons of approximately three years. We fail to find any evidence, however, for the theoretical effect of real expenditure on nominal exchange rate changes. We conclude that rejections of PPP parity in the seventies and eighties were not so much related to shortcomings of the underlying theoretical model, but much more to the empirical tests that were used.

Chapter 4 deals with the second parity, which is the so-called UIP. This parity implies that the forward rate is an unbiased prediction of the future spot rate. In this chapter 
we test the unbiasedness hypothesis using a panel approach for fifteen countries during the period 1979-1996. We distinguish time effects models and random effects models. Our results indicate that the rejection of UIP is not as severe as is commonly found. Traditional single-country times series tests of the unbiasedness hypothesis usually find negative slope coefficients in a regression of the forward premium on the future exchange rate. Our panel estimates, however, show a pooled slope coefficient that is equal to 0.5 . Moreover, we show that the slope coefficient is even very close to unity if only the largest five to ten percent of the observations are taken into account. These findings point to the potential importance of peso-problems and/or inactivity bands as explanation for the rcjection of UIP.

The last parity that we consider, the so-called Fisher parity, is addressed in chapter 5. This parity relates the nominal interest rate and the future expected inflation. The puzzle to be explained is why nominal interest rates do not move proportionally with the level of expected inflation. In this chapter, we try to explain this puzzle by the incorporation of macroeconomic risk in the Fisher equation. From an intertemporal consumption capital asset pricing model, we derive a generalized Fisher equation in which the nominal interest. rate is a function of inflation and the conditional second moments of money and production growth.

The conditional second moments of these macroeconomic variables are computed along two independent methods that both allow for stochastic volatility: a recursive Bayesian forecasting method - the multi state Kalman filter - and the so-called multivariate stochastic volatility model.

Since both the short-term interest rate and inflation are potentially nonstationary we use the Johansen (1988) test for cointegration and find that the nominal interest rate, the inflation and the conditional volatility of money growth are cointegrated. Our results suggest that the common rejection of the Fisher parity in the literature could at least partly be due to a misspecification bias. Incorporating macroeconomic risk by means of the conditional variance of money growth into the Fisher equation is important. Moreover, it is relevant that the econometric techniques used to estimate the conditional second moments allow for the possibility of permanent shocks to the risk premium and hence for a potential unit root.

Research on the price implication of financial integration is not only restricted to international bond markets, but also looks at international stock markets. To investigate stock returns in an integrated world, an international capital asset pricing model (ICAPM) is called for. Deviations from PPP play an important role in the ICAPM. 
Chapter 6 investigates an ICAPM that allows for deviations from PPP. One of the key assumptions of this model is that financial markets are integrated internationally. In other words, the model assumes that there are no barriers to international financial transactions. This assumption has important implications for the calculation of the cost of capital. In an integrated world the cost of capital should therefore be determined using the international capital asset pricing model (ICAPM) rather than the domestic capital asset pricing model (CAPM).

In this chapter we look at the domestic pricing error using an international asset pricing model that explicitly allows for deviations from PPP. The pricing error when using the CAPM rather than an ICAPM is zero if diversifiable domestic risk is orthogonal to the global market portfolio return and foreign currency changes. We use Hansen's (1982) generalized method of moments to test for orthogonality and implement this test for more than three thousand individual stocks from ten different countries. We cannot reject the hypothesis that the local market portfolio contains all the information relevant to price domestic assets. We find that the global market portfolio and the foreign currencies affect the cost of capital of an individual firm only through the effect of the global market on the risk premium of the local market and not through the global beta of the firm.

The final chapter has a somewhat isolated position within the framework of this thesis, as it does not examine an equilibrium model for financial prices but focuses on the volatility dynamics of the short-term interest rate.

Generally, a distinction between two types of volatility specifications is made. On the one hand, there are the econometric specifications of financial markets' volatility - like GARCH models - which concentrate on volatility persistence and clustering. Term structure models, on the other hand, relate volatility directly to the interest rate level. In this chapter both approaches are integrated as we present a model for the short-term interest rate volatility that encompasses both the level effect and the conditional heteroskedasticity effect of the GARCH class of models. The flexible specification of the conditional variance equation allows different effects to dominate as the level of the interest rate varies.

The different models are estimated for monthly as well as for weekly data. We find that both GARCH effects and level effect are important determinants of interest volatility. The empirical results show that under all volatility specifications, the interest rate innovations exhibit fatter tails than the normal distribution.

Ignoring GARCH effects creates an omitted variables problem for the estimate of the level effect in the volatility. The parameter that measures the sensitivity of the interest rate 
volatility with respect to the interest rate level turns out to be highly significant.

As the volatility of the short-term interest rate is one of the determinants for the pricing of interest rate contingent claims, we investigate the implications of the dynamics of shortterm interest rate volatility for the pricing of discount bond options. The main problem is that a closed-form solution for the term structure is not available for the KNSW-model. We propose, therefore, an efficient simulation algorithm to obtain an approximation of the term structure, which is a crucial input in the option price formula.

Our results suggest that the inclusion of a GARCH effect in addition to a level effect in the model specification is relevant for the pricing of short-term discount bond options.

\subsection{Suggestions for Further Research}

The motivation for the ICAPM of Adler and Dumas (1983) was the observation that PPP is violated instantaneously and could be expected to be violated for any forecast horizon. The empirical evidence in this thesis regarding PPP, UIP and the Fisher parity shows, however, that in some periods the parities do hold and in other periods they do not. These findings challenge the appropriateness of the specification of the ICAPM as the model does not take into account this feature of the data. Future research could be directed at ICAPMs that explicitly account for these empirical findings. A starting point may be the model of Dumas (1992) that assumes that international shipment is costly. One important implication is that PPP deviations are slowly mean-reverting.

Peso-problems, transaction costs and risk premiums can explain deviations from PPP, UIP and the Fisher parity. We subscribe the viewpoint of Lewis, who states that to obtain useful results in future research, the individual explanations of parity deviations should be integrated. It might be interesting to investigate the implications for ICAPMs that arise from the integration of risk premiums, transaction costs and peso-problems. The integra. tion of these three elements might possibly solve the home bias puzzle in international equity holdings.

A final suggestion for future research arises from chapter 7. In this chapter we propose an efficient simulation method to approximate a two factor term structure nodel. The reason that we use this simulation is that there is no closed form solution for the term structure available. It might be interesting to investigate the accuracy of the proposed simulation method. One way to get an idea about this is to compare the precision of this simulation 
method to a multifactor term structure model that has a closed form solution, like the Longstaff and Schwartz (1992) mode]. 


\section{Bibliography}

AbUaf, N. And P. Jorion (1990), Purchasing Power Parity in the Long Run, Journal of Finance, 45, 157-174.

Adler. M. and B. Dumas (1983), International Portfolio Choice and Corporation Finance: A Synthesis, Journal of Finance, 38, 925-984.

AdLfR, M. AND B. Lehman (1983), Deviations from PPP in the Long Run, Journal of Finance, 38, 1471-1487.

AïT-Sahalia, Y. (1996a), Nonparametric Pricing of Interest Rate Derivative Securities, Econometrica, 64, 527-560.

AÏT-Sahalia, Y. (1996b), Testing Continuous-Time Models of the Spot Interest Rate, Review of Financial Studies, 9, 385-426.

Andersen, T. And J. Lund (1996a), The Short Rate Diffusion Revisited: An Investigation Guided by the Efficient Method of Moments, Working Paper, Northwestern University.

Andersen, T. And J. Lund (1996b), Stochastic Volatility and Mean Drift in the Short Rate Diffusion: Sources of Steepness, Level and Curvature in the Yield Curve, Working, Paper, Northwestern University.

Andrews, D.W.K. (1991), Heteroskedasticity and Autocorrelation Consistent Covariance Matrix Estimation, Econometrica, 59, 817-858.

Balassa, B. (1964), The Purchasing Power Parity Doctrine: a Reappraisal, The Journal. of Political Economy, 72, 584-596.

Balduzzi, P., S.R. Das and S. Foresi (1995), The Central Tendency: A Second Factor in Bond Yields, Working Paper, New York University.

BALDWIN, R.E. (1990), Re-interpreting the Failure of Foreign Exchange Market Efficiency Tests: Small Transaction Costs, Big Hysteresis Bands, CEPR Discussion Paper no. 407.

Baltagi, B.H. (1995), Econometric Analysis of Panel Data, John Wiley and Sons, Chichester, England.

Barro, R.J. and X. Sala I Martin (1990), World Real Interest Rates, NBER Macroeconomics Annual 1990, 15-61.

Bayoumi, T. (1990), Saving-Investment Correlations: Immobile Capital, Government Policy, or Endogenous Behaviour?, International Monetary Fund. Staff Fapers, 37, 360-387. 
Bekaert, G. ANd R. Hodrick (1992), Characterizing Predictable Components in Excess Returns on Equity and Foreign Exchange Markets, Journal of Finance, 47, 467509.

Benninga, S. and A. Protopapadakis (1988), The Equilibrium Pricing of Exchange Rates and Assets when Trade Takes Time, Journal of International Money and Finance, 7, 129-149.

BILson, J.F.O. (1981), The Speculative Efficiency Hypothesis, Journal of Business, 54, 435-451.

BLACK, F. (1995), Interest Rates as Options, Journal of Finance, 50, 1371-1376.

Bodie, Z., A. Kane and R.L. MacDonald (1983), Why Are Real Interest Rates so High?, NBER Working Paper 1141.

Bollerslev, T. (1986), Generalized Autoregressive Conditional Heteroskedasticity, Journal of Econometrics, 31, 307-327.

Bollerslev, T. (1987), A Conditional Heteroskedastic Time Series Model for Speculative Prices and Rates of Return, Review of Economics and Statistics, 69, 542-547.

Bollerslev, T., R.Y. Chou and K.F. Kroner (1992), ARCH Modelling in Finance: Review of the Theory and the Empirical Evidence, Journal of Econometrics, 52, 5-59.

Bollerslev, T., R.F. Engle and D.B. Nelson (1994), ARCH models, in R.F. Engle and D.L. McFadden, (eds.), Handbook of Econometrics, volume 4, North-Holland, Amsterdam.

Bollerslev, T. AND J.M. Wooldridge (1992), Quasi Maximum Likelihood Estimation and Inference in Dynamic Models with Time Varying Covariances, Econometric Reviews, 11, 143-172.

Bomhoff, E.J. And P.C. Schotman (1988), The Term Structure in the United States, Japan and West Germany, Carnegie Rochester Conference Series on Public Policy, 28, 269-314.

Brenner, R.J., R.H. HarJes and K. Kroner (1995), Another Look at Alternative Models of the Short-Term Interest Rate, Journal of Financial and Quantitative Analysis, 1, 85-107.

Broze, L., O. Scaillet and J. Zakoian (1995), Testing for Contiuous-Time Models of the Short-Term Interest Rate, Journal of Emprical Finance, 2, 199-223.

Campbell, J.Y. and Y. Hamao (1992), Predictable Stock Returns in the United States and Japan: A Study of Long Term Capital Market Integration, Journal of Finance, 47, 43-69.

Chan, K.C., A. Foresi And L.H.P. Lang (1996), Does Money Explain Asset Returns? Theory and Empirical Evidence, Journal of Finance, 51, 345-361.

Chan, K.C., G.A. Karolyi, F.A. Longstaff and A.B. Sanders (1992), An Empirical Comparison of Alternative Models of the Short-Term Interest Rate, Journal of Finance, 52, 1209-1227.

CHEN, N. F. (1991), Financial Investment Opportunities and the Macroeconomy, Journal of Finance, 46, 529-554. 
Chen, N. F., R. Roll, AND S. Ross (1986), Economic Forces and the Stock Market, Journal of Business, 59, 383-403.

Cho, D.C., C.S. Eun And L.W. Senber (1986), International Arbitrage Pricing Theory: An Empirical Investigation, Journal of Finance, 41, 313-329.

Cochrane, J. (1994), Discrete-Time Empirical Finance, Unpublished Manuscript, University of Chicago.

Conley, T.G., L.P. Hansen, E.G.J. Luttmer and J.A. Scheinkman (1995), ShortTerm Interest Rates as Subordinated Diffusions, Working Paper.

Cooper, I.A. AND E. Kaplanis (1986), Costs to Crossborder Investment and International Equity Market Equilibrium, in Jeremy Edwards, (ed.), Recent Advances in Corporate Finance, Cambridge University Press, Cambridge.

COOPER, I.A. AND E. Kaplanis (1994), What explains the home bias in portfolio investment, Review of Financial Studies, 7, 165-176.

Cox, J.C., J.E. Ingersoll and S.A. Ross (1985), A Theory of the Term Structure of Interest Rates, Econometrica, 53, 385-408.

Cumby, R.E. (1988), Is it Risk? Explaining Deviations from Uncovered Interest Parity, Journal of Monetary Economics, 22, 279-300.

CumbY, R.E. (1990), Consumption Risk and International Equity Returns: Some Empirical Evidence, Journal of International Money and Finance, 9, 182-192.

DeMunnik, J.F.J. And P.C. Schotman (1994), Cross Sectional versus Time Series Estimation of Term Structure Models; Empirical Results for the Dutch Bond Market, Journal of Banking and Finance, 18, 997-1025.

Diebold, F.X. AND J.A. Nason (1990), Nonparametric Exchange Rate Prediction, Journal of International Economics, 28, 315-332.

Dooley, M. P., J.A. Frankel and D.J. Mathieson (1987), International Capital Mobility - What Do Saving-Investment Correlations Tell Us?, International Monetary Fund Staff Papers, 34, 503-530.

Drost, F.C. ANd T. E. Nijman (1993), Temporal Aggregation of GARCH Processes, Econometrica, 61, 909-927.

Dumas, B. (1992), Dynamic Equilibrium and the Real Exchange Rate in a Spatially Separated World, The Review of Financial Studies, 5, 153-180.

Dumas, B. (1994), Partial Equilibrium versus General Equilibrium of the International Capital Market, in F. van der Ploeg, (ed.), The Handbook of International Macroeconomics, Blackwell, Oxford, UK.

Dumas, B. And B. Solnik (1995), The World Price of Exchange Rate Risk, Journal of Finance, 50, 445-479.

Eldor, R., D. Pines and A. Schwartz (1988), Home Asset Preference and Productivity Shocks, Journal of International Economics, 25, 165-176.

Engle, C. (1996), The Forward Discount Anomaly and the Fisk Premium: A Survey of Recent Evidence, Journal of Emperical Finance, 3, 123-192. 
EnglE, R.F. (1982), Autoregressive Conditional Heteroskedasticity with Estimates of UK Inflation, Econometrica, 50, 987-1008.

ENGLE, R.F. (1984), Wald, Likelihood Ratio, and Lagrange Multpier Tests in Econometrics, in Z. Griliches and M.D. Intriligator, (eds.), Handbook of Econometrirs. volume 2, North-Holland, Amsterdam.

Engle, R.F. And T. Bollerslev (1986), Modelling the Persistence of Conditional Variances, Econometric Reviews, 5, 1-50, 81-87.

Engle, R.F. AND C. Mustafa (1992), Implied ARCH Models from Options Prices, Joumal of Econometrics, 52, 289-311.

ENGLE, R.F. AND V.K. NG (1993), Measuring and Testing the Impact of News on Volatility, Journal of Finance, 48, 1749-1778.

EVANs, M.D.D. AND K.K. Lewis (1994), Do Stationary Riskpremia Explain It All?, Journal of Monetary Economics, 33, 285-318.

Evans, M.D.D. AND K.K. Lewis (1995a), Do Long-Term Swings in the Dollar Affect Estimates of the Risk Premium?, Review of Financial Studies, 8, 709-742.

Evans, M.D.D. AND K.K. Lewis (1995b), Do Expected Shifts in Inflation Affect Estimates of the Long-Run Fisher Relation?, Journal of Finance, 50, 225-253.

Fama, E.F. (1984), The Information in the Term Structure, Journal of Financial Economics, 13, 509-528.

FAmA, E.F. (1990), Term Structure Forecasts of Interest Rates, Inflation and Real Returns, Journal of Monetary Economics, 25, 59-76.

FAmA, E.F. AND M.R. GibBons (1982), Inflation Real Returns and Capital Investment, Journal of Monetary Economics, 9, 297-323.

Feldotein, M. and C. Horioka (1980), Domestic Savings and International Capital Flows, Economic Journal, 90, 314-329.

Feldstein, M. and L. Summers (1978), Inflation, Taxe Rules and the Long-Term Interest Rate, Brookings Papers on Economic Activity, 1, 61-100.

FERson, W.E. (1990), Are the Latent Variables in Time-Varying Expected Returns Compensation for Inflation Risk?, Journal of Finance, 45, 397-429.

Ferson, W.E. and C.R. Harvey (1993), The Risk and Predictability of International Equity Returns, Working Paper, University of Washington.

FISHER, I. (1930), The Theory of Interest, Macmillan, New York.

FLOOD, R.P. AND A.K. Rose (1994), Fixes: of the Forward Discount Puzzle, NBER Working Paper no. 4928.

Flores, R.G., P. Preumont and A. Szafarz (199.1), Test Multivaries de Racines Unitaires, Working Paper, ULB.

Frankel, J.A. (1982), In Search of the Risk Premium: a Six Currency Test Assuming Mean-Variance Optimization, Journal of International Money and Finance, 1, 255274. 
Frankel, J.A. And K.A. Froot (1987), Using Survey Data to Test Standard Propositions Regarding Exchange Rate Expectations, American Economic Review, 77, 133153.

FrANKEL, J.A. AND A. ROSE (1995), An Empirical Characterization of the Nominal Exchange Rate, in K. Rogoff and G. Grossman, (eds.), Handbook of International Economics, North-Holland, Amsterdam.

Frankel, J.A. AND A.K. Rose (1995), A Panel Project on Purchasing Power Parity: Mean Reversion within and between Countries, NBER Working Paper 5006.

FrEnch, K. AND J. POTERBA (1991), International Diversification and International Equity Markets, American Economic Review, 81, 222-226.

Froot, K.A. And K. Rogoff (1995), Perspectives on PPP and Long-Run Real Exchange Rates, in G.M. Grossman and K. Rogoff, (eds.), Handbook of International Economics, volume 3, North-Holland, Amsterdam.

Geweke, J. (1994), Monte Carlo Simulation and Numerical Integration, Working Paper 562 , Federal Reserve Bank of Minneapolis.

Giovaninni, A. And P. Jorion (1987a), Interest Rates and Risk Premia in the Stock Market and in the Foreign Exchange Market, Journal of International Money and Finance, 6, 107-124.

Grovaninni, A. And P. Jorion (1987b), Foreign Exchange Risk Premia Volatility once again, Journal of International Money and Finance, 7, 111-114.

Goldstein, M., D. Folkerts-Landau, P. Garber, L. Rojas-Suárez and M. Spencer (1993), International Capital Markets, Part I, Exchange Rate Management and International Capital Flows, International Monetary Fund.

Grauer, F.L.A., R.H. Litzenberger and R. Stehle (1976), Sharing Rules and Equilibrium in an International Capital Market Under Uncertainty, Journal of Financial Economics, 3, 233-256.

Gultekin, M.N., B.G. Gultekin and A. Penati (1989), Capital Controls and International Capital Market Segmantation: The Evidence from the Japanese and American Stock Markets, Journal of Finance, 44, 849-869.

Hamilton, J.D. (1994), Time Series Analysis, Princeton University Press, Princeton, New Jersey.

Hansen, L.P (1982), Large Sample Properties of Generalized Method of Moments Estimators, Econometrica, 50, 1029-1054.

Hansen, L.P. And R.J. Hodrick (1983), Risk Averse Speculation in the Forward Foreign Exchange Market: An Econometric Analysis of Linear Models, in J.A. Frenkel, (ed.), Exchange Rates and International Macroeconomics, University of Chicago Press, Chicago IL.

Harvey, A., E. Ruiz and N. Shepard (1994), Multivariate Stochastic Variance Models, Review of Economic Studies, 61, 247-264.

Harvey, C.R. (1991), The World Price of Covariance Risk, Journal of Finance, 46, 111-157. 
HENDERSON, D.W. AND S. SAMpson (1984), Intervention in Foreign Exchange Markets: A Summary of Ten Staf Studies, Federal Reserve Bulletin, 830-836.

Heston, S.L., K.G. Rouwenhorst and R.E. Wessels (1995), The Structure of International Stock Returns and the Integration of Capital Markets, Journal of Empirical Finance, 2, 173-197.

HoDrick, R.J. (1987), The Empirical Evidence on the Efficiency of Forward and Future Foreign Exchange Markets, Harwood Academic Publishers, Chur, Switzerland.

Huizinga, J. And F.S. Mishkin (1986), Monetary Policy Regime Shifts and the Unusual Behaviour of the Real Interest Rate, Carnegie-Rochester Conference Series on Public Policy, 24, 231-274.

JACQuier, E., N.G. Polson AND P.E. Rossi (1994), Bayesian Analysis of Stochastic Volatility Models, Journal of Business Economics and Statistics, 12, $371+18$.

Jorion, P. (1990), The Exchange Exposure of U.S. Multinationals, Journal of Business, $63,331-345$.

Jorion, P. AND F. Mishinin (1991), A Multicountry Comparison of Term-Structure Forecasts at Long Horizons, Journal of Financial Economics, 29, 59-80.

Jorion, P. AND E. SChWARTZ (1986), Integration vs. Segmentation in the Canadian Stock Market, Journal of Finance, 31, 603-616.

KeYNes, J.M. (1923), A Tract on Monetay Reform, MacMillan, London.

KoediJK, K. AND P.C. Schotman (1990), How to Beat the Random Walk: An Empirical Model of Real Exchange Rates, Journal of International Economics, 29, 311-332.

KoEdIJK, K.G. AND C.J.M. Kool (1995), Future Inflation and Information in International Term Structures, Empirical Economics, 20, 217-242.

KoediJK, K.G., F.G.J.A. Nissen, P.C. Schotman and C.P. Wolff (1994), The Dynamics of the Short-Term Interest Rate Volatility Reconsidered, LIFE Working Paper 94-13.

Kocl, C.J.M. (1989), Recursive Bayesian Forecasting in Economics: The Multi State Kalman Filter Method, PhD thesis.

KorajCzYK, R.A. AND C.J. Viallet (1989), The Empirical Investigation of International Asset Pricing, Review of Financial Studies, 2, 553-585.

LABADIE, P. (1989), Stochastic Inflation and the Equity Premium, Journal of Monetary Economics, 24, 227-298.

LEE, S.S. (1995), Macroeconomic Sources of Time-Varying Risk Premia in the Term Structue of Interest Rates, Journal of Money, Credit and Banking, 27, 549-569.

LEWIS, K.K. (1996), What Can Explain the Apparent Lack of International Risk Sharing?, Journal of Political Economy, 104, 267-297.

LEWIS, K.K. (1995), Puzzles in International Financial Markets, in G.M. Grossman and K. Rogoff, (eds.), Handbook of International Economics, volume 3, North-Holland.

Lo, A.W. AND A.C. MacKinlay (1990), When are Contrarian Profits due to Stock Market Overreaction?, Review of Financial Studies, 3, 175-205. 
LongstafF, F.A. AND E.S. Schwartz (1992), Interest Rate Volatility and the Term Structure: A Two-factor General Equilibrium Model, Journal of Finance, 47, 12591282 .

Lothian, J.R. (1985), Equilibrium Relationships between Money and other Economic Variables, American Economic Review, 75, 828-835.

Lothian, J.R. AND Y. SimaAn (1995), International Financial Relations under the Current Float: Evidence from Panel Data, Working Paper Fordham University.

LUCAS, J.R. (1982), Interest Rates and Currency Prices in a Two-Country World, Journal of Monetary Economics, 10, 336-360.

LuCAS, J.R. (1990), Comment on World Real Interest Rate, NBER Macroeconomics Annual 1990, 69-74.

Mahieu, R. And P.C. Schotman (1994), Neglected Common Factors in Exchange Rate Volatility, Journal of Empirical Finance, 1, 279-311.

Marshall, D.A. (1992), Inflation and Asset Returns in a Monetary Economy, Journal of Finance, 47, 1315-1342.

MARSTON, R.C. (1995), International Financial Integration, Cambridige University Press, Cambridge.

Mascaro, A.R. AND A.H. Meltzer (1983), Long-and Short-Term Interest Rates in a Risky World, Journal of Monetary Economics, 12, 485-518.

MCCAllum, B.T. (1994), A Reconsideration of the Uncovered Interest Parity Relationship, Journal of Monetary Economics, 33, 105-132.

MCCUlloch, J. H. (1975), Operational Aspects of the Siegel Paradox, Journal of Economics, 89, 105-132.

Mehra, R. and E.C. Prescott (1985), The Equity Premium: A Puzzle, Journal of Monetary Economics, 15, 145-161.

Mishin , F.S. (1990a), What Does the Term Structure Tell Us about Future Inflation?, Journal of Monetary Economics, 25, 77-95.

MishKIN, F.S. (1990b), The Information in the Longer Maturity Term Structure about Future Inflation, Quarterly Journal of Economics, 55, 815-828.

Mundell, R. (1963), Inflation and Real Interest, Journal of Political Economy, 71, 280283.

Mussa, M. (1986), Nominal Exchange Rate Regimes and the Behaviour of Real Exchange Rates: Evidence and Implications, Carnegie Rochester Conference Series on Public Policy, 25, 117-214.

NeLson, D.B. (1989), Modelling Stock Market Volatility Changes, Proceedings from the American Statistical Association, Business and Economic Statistics Section, 93-98.

NELSON, D.B. (1990), ARCH Models as Diffusion Approximations, Journal of Econometrics, 45, 93-98.

Newey, W.K. AND K.D. West (1987), A Simple Positive Semi-Definite Heteroskedasticity and Autocorrelation Consistent Covariance Matrix, Econometrica, 55, 703-708. 
OBstreld, M. (1986), Capital Mobility in the World Economy: Theory and Measurement, Carnegie Rochester Conference Series on Public Policy, 25, 55-103.

Obstfeld, M. (1994), Risk Taking Global Diversification and Growth, American Economic Review, 84, 1310-1329.

Officer, L.H. (1976), The Purchasing Power Parity Theory of Exchange Rates: A Review Article, International Monetary Fund Staff Papers, 23, 1-60.

PAGAN, A. (1996), The Econometrics of Financial Markets, Journal of Empirical Finance, 3, 15-102.

Pagan, A. And A. Ullah (1988), The Econometric Analysis of Models with Risk Terms, Journal of Applied Econometrics, 3, 87-105.

PaGan, A.R., A.D. Hall and V. Martin (1994), Exploring the Relations between the Finance and Econometrics Literatures on the Term Structure, Working Paper, Australian National University.

Pfann, G.A., P.C. Schotman, and R. Tschernig (1996), Nonlinear Interest Rate Dynamics and Implications for the Term Structure, Journal of Econometrics, 74, 149-176.

PINDYck, R.S. (1984), Risk, Inflation and the Stock Market, American Economic Review, $70,183-190$.

Reilly, F.K. AND R.A. Akhtar (1995), The Benchmark Error Problem with Global Capital Markets, Journal of Portfolio Management, 33-52.

Rogoff, K. (1992), Traded Goods Consumption Smoothing and the Random Walk Behaviour of the Real Exchange Rate, NBER Working Paper 4119.

Rogoff, K. (1996), The Purchasing Power Parity Puzzle, Journal of Economic Literature, $34,647-668$.

Roll, R. (1979), Violations of PPP and their Implications for Efficient International Commodity Markets, in M. Sarnat and G.P. Szergo, (eds.), International Finance and Trade, volume 1, Cambridge, 133-179.

Roll, R. AND B. Solnik (1979), On Some Parity Conditions Encountered Frequently in International Economics, Journal of Macroeconomics, 1, 267-283.

Rose, A.K. (1994), Exchange Rate Volatility Monetary Policy and Capital Mobility: Empirical Evidence on the Holy Trinity, NBER Working Paper 4630.

Samuelson, P.A. (1964), Theoretical Notes on Trade Problems, Review of Economics and Statistics, 46, 145-154.

Samuelson, P.A. AND S. Swamy (1974), Invariant Economic Index Numbers and Canonical Duality: Survey and Synthesis, American Economic Review, 64, 566-593.

Schotman, P.C. AND H.K. VANDIJK (1991), A Bayesian Analysis of the Unit Root in Real Exchange Rates, Journal of Econometrics, 49, 195-238.

Sercu, P. (1980), A Generalization of the International Asset Pricing Model, Revue de l'Association Française de Finance, 1, 91-135.

SERCU, P. AND R. UPPAL (1995), The Microeconomic Foundations of Exchange Rate Determination, Working Paper. 
Sercu, P, R. Uppal, and C. Van Hulle (1995), The Exchange rate in the Presence of Transaction Costs: Implications for Tests of Relative Purchasing Power Parity, Journal of Finance, 50, 1308-1319.

ShePhard, N. (1994), Partial Non-Gaussian State Space, Biometrika, 81, 115-131.

Shome, D.K., S.D. Smith and J.M. Pinkerton (1988), The Purchasing Power of Money and Nominal Interest Rates: A Re-Examination, Journal of Finance, 43, 11131125 .

SiEgEL, J.J. (1972), Risk Interest and Foreign Exchange, Quarterly Journal of Economics, $86,303-309$.

Srlverman, B.W. (1986), Density Estimation for Statistics and Data Analysis, Chapmann and Hall, London.

SolNIK, B. (1974), An Equilibrium Model of the International Capital Market, Journal of Economic Theory, 8, 500-524.

Solnik, B. (1983), International Arbitrage Pricing Theory, Journal of Finance, 38, 449457.

Stanton, R. (1995), A Nonparametric Model of Term Structure Dynamics and the Market Price of Interest Rate Risk, Working Paper, U.C. Berkeley.

Stulz, R. (1981), A Model of International Asset Pricing, Journal of the Financial Economics, 9, 383-406.

Stulz, R. (1987), An Equilibrium model of Exchange Rate Determination and Asset Pricing with Nontraded Goods and Imperfect Information, Journal of Political Economy, 95, 1024-1040.

STUlZ, R. M. (1986), Interest Rates and Monetary Policy Uncertainty, Journal of Monetary Economics, 17, 331-347.

Stulz, R.M. (1995a), International Portfolio Choice and Asset Pricing, in R.A. Jarrow, V. Maksimovic, and W.T. Ziemba, (eds.), Finance, Handbook in Operations Research and Management Science, volume 9, North-Holland, Amsterdam.

STulz, R.M. (1995b), The Cost of Capital in Internationally Integrated Markets: The Case of Nestlé, European Financial Management, 1, 11-22.

Tauchen, G. (1996), New Mimimum Chi-Square Methods in Empirical Finance, Working Paper, Duke University.

TESAR, L.L. (1991), Saving, Investment and International Capital Flows, Journal of International Economics, 31, 55-78.

Tesar, L.L. And I.M. Werner (1992), Home Bias and Globalization of Equity Markets, NBER Working Paper 4218.

Tobin, J. (1965), Money and Economic Growth, Econometrica, 33, 671-684.

Torous, W. AND C.A. Ball (1995), Regime Shifts in the Short Term Riskless Interest Rates, IFA Working Paper 216.

Tzavalis, E. AND M.R. Wickens (1996), Forecasting Inflation form the Term Structure, Journal of Empirical Finance, 3. 
Uhlig, H. (1994), BVARTEC, Working Paper Princeton University.

Uppal, R. (1992), Deviations from Purchasing Power Parity and Capital Flows, Journal of International Money and Finance, 11, 126-144.

WeIL, P. (1989), The Equity Premium Puzzle and the Risk-Free Rate Puzzle, Journal of Monetary Economics, 24, 401-421.

Wheatley, S. (1988), Some Tests of International Equity Integration, Journal of Financial Economics, 21, 177-212.

White, H. (1980), A Heteroskedasticity-Consistent Covariance Matrix Estimator and a Direct Test for Heteroskedasticity, Econometrica, 48, 817-848.

WILcox, J.A. (1983), Why Real Interest Rates Were so Low in the 1970's, American Economic Review, 73, 44-53.

Wooldridge, J.M. (1994), Estimation and Inference for Dependent Processes, in R.F. Engle and D.L. McFadden, (eds.), Handbook of Econometrics, volume 4, North-Holland, Amsterdam. 


\section{Nederlandse Samenvatting}

De afgelopen tien jaar zijn beleggers zich bij de samenstelling van hun beleggingsportefeuille steeds meer op het buitenland gaan richten. Om een evenwichtige internationale beleggingsportefeuille te kunnen samenstellen, is een goed begrip van de dynamiek op internationale aandelenmarkten en markten voor vastrentende waarden van cruciaal belang. Bovendien dienen beleggers rekening te houden met het feit dat de rendementen op hun buitenlandse beleggingen door wisselkoersschommelingen worden beïnloed.

Dit proefschrift bevat een aantal empirische studies naar de dynamiek op internationale financiële markten. Het vernieuwende karakter van dit proefschrift is niet zo zeer gelegen in de gekozen onderwerpen maar meer in de keuze van de data en de gebruikte econometrische technieken. In tegenstelling tot eerdere studies, die de marktdynamiek van afzonderlijke landen tot onderwerp hebben, worden in dit proefschrift panels van landen onderzocht. $\mathrm{Bij}$ een dergelijke onderzoeksopzet zijn traditionele econometrische technieken niet langer bruikbaar en dient een beroep te worden gedaan op zogenaamde paneldatatechnieken.

Op internationale financièle markten spelen een drietal pariteiten een belangrijke rol: de koopkrachtpariteit, de ongedekte rentepariteit en de Fisher-pariteit.

De eerste pariteit, de koopkrachtpariteit, ontstaat door arbitrage in goederen- en dienstenmarkten en stelt dat de wisselkoers tussen twee landen wordt bepaald door het relatieve prijsniveau van deze landen. De andere twee pariteiten hebben betrekking op financiële markten. Volgens de rentepariteit zal als gevolg van ongedekte arbitrage het verschil tussen de korte rente op titels die zijn uitgedrukt in verschillende wisselkoersen, gelijk zijn aan de verwachte verandering van de wisselkoers tussen de landen. De laatste pariteit, de zogenaamde Fisher-pariteit, stelt dat de nominale korte rente gelijk is aan de reële korte rente plus de verwachte inflatie.

In hoofdstuk 2 komt de theoretische achtergrond van de drie pariteiten aan de orde. De pariteiten zijn niet nieuw maar werden reeds aan het begin van deze eeuw geformuleerd, 
waarna zij door veel onderzoekers aan empirische toetsen werden onderworpen. De algemene conclusie die uit dit eerdere onderzoek kan worden getrokken, is dat er zich op korte termijn substantiële afwijkingen van ieder van de pariteiten kunnen voordoen.

Verklaringen voor afwijkingen van de drie pariteiten zijn gebaseerd op dezelfde theoretische modellen. Dit impliceert dat de pariteiten een zekere samenhang moeten vertonen. Op het eerste gezicht lijkt dat misschien onlogisch omdat de rentepariteit en de Fisher-pariteit zijn gebaseerd op arbitrage op financiële markten, terwijl de koopkrachtpariteit voorvloeit uit arbitrage op goederenmarkten. Roll (1979) toont echter aan dat de koopkrachtpariteit tevens kan worden afgeleid door de twee pariteiten uit de financiële markt te combineren. De drie pariteiten hangen dan ook nauw met elkaar samen. Het zal niemand verbazen dat de verklaringen voor afwijkingen van de drie pariteiten gebaseerd zijn op dezelfde theoretische grondslagen.

Een belangrijke veronderstelling voor de onderbouwing van de drie pariteiten is dat beleggers geen extra vergoeding eisen voor het wisselkoersrisico dat zij lopen. Indien deze veronderstelling wordt losgelaten, kan worden aangetoond dat de pariteiten onder bepaalde onstandigheden niet langer houden. De afwijking van de pariteiten kan dan worden opgevat als een risicopremie die de beleggers eisen voor het risico dat zij lopen op hun internationale beleggingen. Een tweede belangrijke veronderstelling is dat beleggers geen systematische fouten maken als zij de omvang van toekomstige rendementen proberen te voorspellen. Indien beleggers echter wel systematische voorspelfouten maken - bijvoorbeeld als de verwachte veranderingen in het economisch klimaat zich niet blijken voor te doen gedurende de looptijd van hun beleggingen - kunnen afwijkingen van de pariteiten ontstaan. Ten slotte kunnen transactiekosten afwijkingen veroorzaken.

In de hoofdstukken 3 tot en met 5 worden de koopkrachtpariteit, de rentepariteit en de l'isher-pariteit empirisch getoetst.

De afgelopen tien jaar werd er relatief weinig empirisch onderzoek verricht naar de koopkrachtpariteit. Recentelijk is deze pariteit echter opnieuw in de belangstelling komen te staan, ondermeer door een theoretische bijdrage van Sercu, Uppal en Van Hulle (1995). In een vervolgstudie tonen Sercu en Uppal (1995) aan dat als gevolg van transactiekosten de wisselkoersveranderingen worden bepaald door een tweetal componenten. De eerste component is het gewogen verschil in de groeivoeten van nominale bestedingen tussen twee landen gedefleerd met het prijsindexcijfer voor consumptieve bestedingen. De gebruikte wegingsfactor weerspiegelt de risicohouding van investeerders in de twee landen. De tweede component is het zogenaamde marginale inflatieverschil. In hoofdstuk 3 worden paneldatatechnieken gebruikt om zowel een absolute als een relatieve versie van het 
'Sercu en Uppal'-model te testen voor een panel dat bestaat uit data voor zestien landen over de periode 1973-1993. In deze analyse leggen we restricties op die ervoor zorgen dat de schattingen van de modelparameters niet afhankelijk zijn van de keuze van de valuta waarin we de resultaten uitdrukken. In tegenstelling tot veel andere studies, die alleen afzonderlijke landen bestuderen, vinden we bij onze simultane bestudering van meerdere landen bewijs dat de koopkrachtpariteit houdt. Aan de andere kant kunnen we niet aantonen, zoals het 'Sercu en Uppal'-model voorspelt, dat wisselkoersen worden gestuurd door verschillen in bestedingen tussen landen. We concluderen dan ook dat de verwerping van de koopkrachtpariteit in studies uit de jaren zeventig en tachtig niet zozeer is gelegen in de tekortkomingen van het theoretische model maar meer in de empirische toetsen die werden gebruikt.

In hoofdstuk 4 komt de rentepariteit aan de orde. Deze pariteit impliceert dat een wisselkoers op de termijnmarkt een zuivere voorspeller is van de toekomstige wisselkoers in de spotmarkt. Dit betekent dat de coefficiënt van een regressie van de termijnpremie op de wisselkoersverandering gelijk is aan één. In dit hoofdstuk wordt deze hypothese getoetst voor een panel van vijftien landen voor de periode 1979-1996. Daarbij maken we gebruik van twee soorten modellen: modellen die tijdseffecten onderscheiden, en modellen die random-effecten meenemen. De resultaten van ons onderzoek geven aan dat de rentepariteit minder sterk wordt verworpen dan in traditionele toetsen die alleen een enkel land beschouwen. Deze traditionele toetsen vinden een negatieve regressiecoëfficiënt. Met behulp van het panelmodel vinden we daarentegen een coëfficiënt die significant positief is. Een verklaring hiervoor is het feit dat in een panelcontext tijdelijke verstoringen minder van invloed zijn op de uiteindelijke resultaten. Daarnaast tonen we aan dat indien we ons alleen beperken tot hoge termijnpremies, de regressiecoëfficiënt zelfs zeer dicht in de buurt van één ligt. Dit laatste resultaat wijst erop dat als gevolg van transactiekosten, arbitrage alleen lonend is indien de termijnpremie voldoende hoog is.

In hoofdstuk 5 gaan we uitgebreid in op de Fisher-pariteit. Bij deze pariteit wordt ervan uitgegaan dat de nominale korte rente proportioneel verandert met de verwachte inflatie. In dit hoofdstuk proberen we te achterhalen waarom deze relatie in de praktijk niet opgaat. Onze verklaring is gelegen in het feit dat economische agenten een premie eisen voor het inflatierisico dat zij lopen als zij obligaties aanhouden. In dit hoofdstuk leiden we een model af voor de risicopremie waarin de intertemporele consumptiebeslissingen van economische agenten in beschouwing worden genomen. In dit model is de risicopremie gerelateerd aan de conditionele volatiliteit van macro-economische variabelen zoals geldgroei en produktiegroei. Bovendien vergelijken we twee methoden om de conditionele volatiliteit te bepalen: het 'multi state Kalman filter'-model en een multivariaat stochastisch volatiliteitsmodel. Omdat zowel de nominale korte rente en inflatie mogelijker- 
wijs niet stationair zijn, maken we gebruik van de 'Johanssen (1988)'-test voor cointegratie. Deze analyse toont aan dat er een lange-termijnrelatie bestaat tussen de nominale korte rente, de inflatie en de conditionele volatiliteit van de geldgroei. Dit resultaat suggereert dat de Fisher-pariteit in traditionele toetsen wordt verworpen omdat in deze toetsen geen rekening wordt gehouden met macro-economisch risico.

In hoofdstuk 6 bestuderen we de dynamiek in internationale aandelenmarkten met behulp van een zogenaamd international capital asset pricing model (ICAPM). Dit model veronderstelt dat er geen restricties zijn op internationale beleggingen. Daarnaast zijn de beleggers in verschillende landen heterogeen orndat zijn hun reële beleggingsrendementen berekenen op basis van de inflatie in hun eigen land. Deze zal afwijken van die in andere landen als de koopkrachtpariteit niet houdt. Indien landen internationaal zijn geïntegreerd, dient de kapitaalvoet voor een investering te worden bepaald op basis van het ICAPM en niet met behulp van het traditionele capital asset pricing model (CAPM). We bestuderen de foul die wordt gemaakt als de kapitaalvoet in een geintegreerde wereld wordt berekend op basis van het CAPM in plaats van het ICAPM. Deze fout is gelijk aan nul indien het nationale diversifieerbare risico loodrecht staat op de wereldmarktportefeuille en alle wisselkoersveranderingen. We maken gebruik van een door Hansen (1982) ontwikkelde testmethode om voor meer dan drieduizend individuele aandelen uit tien verschillende landen expliciet te toetsen of de fout van het CAPM significant afwijkt van nul. De hypothese dat de lokale marktportefeuille alle informatie bevat waarmee de kapitaalvoet kan worden bepaald, kan niet worden verworpen. Dit impliceert dat de premie voor het mondiale marktrisico en het wisselkoersrisico al is verwerkt in het lokale marktrisico.

Het laatste hoofdstuk neemt een bijzondere positie in binnen dit proefschrift omdat we daarin niet het, verband tussen diverse financiële variabelen analyseren, maar ingaan op de tijdreekseigenschappen van de korte rente, en in het bijzonder op de volatiliteit daarvan. De korte rente is een cruciale variabele in de financiële modellen die in dit proefschrift aan de orde komen.

Er bestaan twee verschillende modellen voor de beschrijving van de volatiliteit van de korte rente. Allereerst de 'generalized autoregressive conditional heteroskedasticity (GARCH)'modellen waarbij persistentie en clustering van volatiliteit een belangrijke rol spelen. Daarnaast onderscheiden we termijnstructuurmodellen die de volatiliteit van de rente relateren aan de rentestand. In dit hoofdstuk trachten we deze twee benaderingswijzen in één model te integreren. Vervolgens worden de parameters van dit nieuwe model bepaald met maanddata en weekdata van de rente. Hierbij vinden we dat zowel de GARCH-effecten als de rentestand van invloed zijn op de volatiliteit van de rente. De parameter die de gevoeligheid van de volatiliteit voor renteveranderingen meet, is zeer significant. Dit betekent dat bij 
een hoge rente de volatiliteit van de rente ook hoog zal zijn. De volatiliteit van de korte rente speelt een belangrijke rol bij de prijsbepaling van derivaten zoals opties, omdat bij een hoge volatiliteit de kans groot is dat de optie bij expiratie 'in the money' is. Daarom bestuderen we de invloed die verschillende specificaties van de rentevolatiliteit hebben op de prijsbepaling van een optie op een obligatie. Een belangrijk probleem dat zich hierbij voordoet, is dat er voor het model dat zowel de GARCH-effecten als de rentevoet combineert, geen gesloten uitdrukking bestaat om de optieprijs direct te bepalen. Daarom maken we gebruik van een simulatiemethode. De resultaten tonen aan dat de specificatie van de conditionele volatiliteit van de rente uiterst belangrijk is bij het bepalen van optieprijzen. 


\section{Index}

Abuaf, 27, 29, 43, 92

Adler, 4, 6, 7, 10, 11, 17, 20, 25, 29, 56, $92,93,149$

Ait-Sahalia, 117, 120, 125, 128

Andersen, 117, 125

Andrews, 114

Athkar, 97

Balassa, 15

Balduzzi, 119

Baldwin, 21, 56, 67

Ball, 117

Baltagi, 34, 37, 38, 61

Barro, 71

Bayoumi, 3

Bekaert, 17, 52, 54, 91

Benninga, 14, 29

Bilson, 16, 21, 54, 56, 58, 64, 65

Bodie, 71

Bollerslev, 77, 118, 126, 128

Bomhoff, 119

Brenner, 117, 120

Broze, 119, 120

Campbell, 91

Chan, 7, 74, 117-121, 123, 125, 127, 128,

Chen, 74

$$
131,140,142
$$

Cho, 91

Chou, 77, 118

Cochrane, 72

Conley, 117, 120, 125

Cooper, 3

Cox, 119, 120, 123

Cumby, 17, 56, 91

Das, 119

DeMunnik, 123

Diebold, 29

Dooley, 3
Drost, 123

Dumas, $4,6,7,10-12,14,17,20,21,25$, $29,56,91 \cdots 93,106,149$

Eldor, 3

Engel, 4, 18, 20, 21

Engle, 25, 77, 98, 118, 126, 130

Eun, 91

Evans, 24, 56, 71, 72, 80, 84, 85

Fama, 22, 54, 71

Feldstein, 3, 22

Ferson, 74, 92

Fisher, 21

Flood, 58, 64, 67

Flores, 43

Foresi, 74, 119

Frankel, 3, 27, 56, 92

French, 3

Froot, 4, 10, 12, 15, 29, 56

Geweke, 143

Gibbons, 22

Giovanni, 56

Goldstein, 1, 2

Grauer, 93, 96

Gultekin B., 91

Gultekin M., 91

Hall, 73, 123

Hamao, 91

Hamilton, 113

Hansen, 20, 114, 115, 117, 120, 125, 148

Harjes, 117, 120

Harvey, 72, 78, 80, 81, 91, 92, 95

Henderson, 18

Heston, 91

Hodrick, 17, 20, 52, 54, 56, 91

Horioka, 3

Huizinga, 71,77 
Ingersoll, 119, 120, 123

Jacquier, 77

Johansen, 83, 86, 147

Jorion, 27, 29, 43, 56, 71, 91, 92, 98, 109

Kane, 71

Kaplanis, 3

Karolyi, $7,117-121,123,125,127,128$, $131,140,142$

Keynes, 16

Koedijk, 29, 35, 43, 63, 71, 118

Kool, 71, 72, 76, 78

Korajczyk, 91

Kroner, 77, 117, 118, 120

Labadie, 74

Lang, 74

Lee, $73,74,86$

Lehmann, 29

Lewis, $3,20,21,24,51,54,56,71,72,80$, $84,85,92$

Litzenberger, 93, 96

Lo, 98

Longstaff, $7,117-121,123,125,127,128$, $131,140,142,150$

Lothian, 36,58

Lucas, $18,24,71,84$

Lund, 117, 125

Luttmer, 117, 120, 125

MacDonald, 71

MacKinlay, 98

Mahieu, 34, 61

Mark, 29. 47

Marshall, 74

Marston, 4, 17

Martin, 73, 123

Mascaro, 74, 77, 84

Mathieson, 3

McCallum, 21, 56

McCulloch, 17

Mehra, 20

Meltzer, 74, 77, 84

Mishkin, 71, 77

Mundell, 22

Mussa. 95

Mustafa, 98
Nason, 29

Nelson, 121, 126, 127

Newey, 36, 114

$\mathrm{Ng}, 126,130$

Nijman, 123

Nissen, 118

Obstfeld, 3

Officer, 10,12

Pagan, 73, 77, 83, 1'3

Penati, 91

Pfann, 125

Pindyck, 77

Pines, 3

Pinkerton, 22

Polson, 77

Poterba, 3

Prescott, 20

Preumont, 43

Protopapadakis, 14, 29

Reilly, 97

Rogoff, 4, 10, 12, 15, 29

Roll, 16, 24, 29, 74, 146

Rose, 27, 29, 58, 64, 67, 92

Ross, $74,119,120,123$

Rossi, 77

Rouwenhorst, 91

Ruiz, 72, 78, 80, 81

Sala-I-Martin, 71

Sampson, 18

Samuelson, 11, 15, 16

Sanders, 7, 117-121, 123, 125, 127, 128, $131,140,142$

Scaillet, 119, 120

Scheinkman, 117, 120, 125

Schotman, 29, 34, 35, 43, 61, 63, 118, 119, 123,125

Schwartz, 3, 91, 119-121, 123, 127, 150

Senbet, 91

Sercu, 6, 12, 14, 15, 17, 21, 27, 29, 30, 33, $34,36,42,50,93,146$

Shephard, 72, 77, 78, 80, 81

Shome, 22

Siegel, 17

Silverman, 139 
Simaan, 58

Smith, 22

Solnik, 16, 91-93, 106

Stanton, 125

Stehle, 93, 96

Stulz, 7, 15, 30, 74, 92, 93, 95, 97, 106

Summers, 22

Swamy, 11

Szafarz, 43

Tauchen, 117

Tesar, 3

Tobin, 22

Torous, 117

Tschernig, 125

Tzavalis, 71,84

Uhlig, 77, 79

Ullah, 77

Uppal, 6, 12, 14, 15, 17, 21, 27, 29, 30, 33, $34,36,42,50,146$

Van Dijk, 29

Van Hulle, 6, 12, 14, 27, 29, 36, 50, 146

Viallet, 91

Weil, 73

Werner, 3

Wessels, 91

West, 36, 114

Wheatley, 91, 95

White, 114

Wickens, 71, 84

Wilcox, 71

Wolff, 118

Wooldridge, 123, 126

Zakoian, 119, 120 


\section{Curriculum Vitae}

François G.J.A. Nissen was born on January 6th 1969 in Tegelen (the Netherlands). In December 1992 he received a masters degree in Economics and Business Administration, with a specialization in monetary economics, from Maastricht University. He started his Ph.D. in January 1993 at the finance department of Maastricht University, where he has done research in various areas of finance and international economics. From 1994 to 1995 he was employed as a consultant at the Strategic Investment Policy group of the Algemeen Burgerlijk Pensioenfonds (ABP), in Heerlen, one of the world's largest pension funds. In December 1996 François Nissen completed his doctoral dissertation and he is currently employed at the ING bank in Amsterdam as a risk manager. His interests include squash and jazz music.

François G.J.A. Nissen werd geboren op 6 januari 1969 in Tegelen. In december 1992 studeerde hij af aan de Faculteit der Economische Wetenschappen van de Universiteit Maastricht, en wel in de specialisatie monetaire economie. Onmiddellijk daarna trad hij voor vier jaar in dienst als Assistent in Opleiding bij de sectie Financiering van dezelfde universiteit. Gedurende deze periode verrichtte hij onderzoek naar uiteenlopende vraagstukken op het gebied van internationale economie en financiering. In 1994 en 1995 was hij als adviseur verbonden aan de afdeling Algemeen Beleggingsbeleid van een van 's werelds grootste pensioenfondsen, het Algemeen Burgerlijk Pensioenfonds (ABP) in Heerlen. In december 1996 voltooide hij zijn proefschrift. Momenteel is hij werkzaam als risico manager bij de ING bank in Amsterdam. In zijn vrije tijd speelt hij graag squash en jazzmuziek. 
François G.J.A. Nissen was born on January 6 th 1969 in Tegelen (the Netherlands). In December 1992 he received a masters degree in Economics and Business Administration, with a specialization in monetary economics, from Maastricht University. He started his Ph.D. in January 1993 at the finance department of Maastricht University, where he has done research in various areas of finance and international economics. From 1994 to 1995 he was employed as a consultant at the Strategic Investment Policy group of the Algemeen Burgerlijk Pensioenfonds (ABP) in Heerlen, one of the world's largest pension funds. In December 1996 François Nissen completed his doctoral dissertation and he is currently employed at the ING bank in Amsterdam as a risk manager. His interests include squash and jazz music.

The present thesis describes an empirical study of the dynamics of exchange rates, interest rates and stock returns. When financial prices are examined across countries three fundamental parities play an important role, i.e. purchasing power parity (PPP), uncovered interest rate parity (UIP) and the Fisher parity. As the thesis deals with international financial market dynamics, PPP, UIP and the Fisher parity are discussed in detail. The thesis investigates international stock market dynamics by means of an international capital asset pricing model in which deviations from the three parity conditions play an important role. Finally, the dynamics of one of the key financial variables, the short-term interest rate, is analyzed. The innovative character of the thesis resides not so much in the choice of the subjects but rather in the use of alternative techniques and data. 